EDUARDO BARJUD BUGELLI

MODELOS DE FALHA EM ANÁLISE NUMÉRICA DE ESTRUTURA VEICULAR SUBMETIDA A IMPACTO DE BAIXA VELOCIDADE 
EDUARDO BARJUD BUGELLI

MODELOS DE FALHA EM ANÁLISE NUMÉRICA DE ESTRUTURA VEICULAR SUBMETIDA A IMPACTO DE BAIXA VELOCIDADE

Dissertação apresentada à Escola Politécnica da Universidade de São Paulo para Qualificação do Mestrado

São Paulo 
EDUARDO BARJUD BUGELLI

\section{MODELOS DE FALHA EM ANÁLISE NUMÉRICA DE ESTRUTURA VEICULAR SUBMETIDA A IMPACTO DE BAIXA VELOCIDADE}

Dissertação apresentada à Escola Politécnica da Universidade de São Paulo para obtenção do título de Mestre em Engenharia.

Área de Concentração:

Engenharia Mecânica de Projeto e Fabricação

Orientadora: Profa. Dra Larissa Driemeier

São Paulo

2010 


\section{FICHA CATALOGRÁFICA}

\section{Bugelli, Eduardo Barjud}

Modelos de falha em análise numérica de estrutura veicular submetida a impacto de baixa velocidade / E.B. Bugelli. -- São Paulo, 2010.

$130 \mathrm{p}$.

Dissertação (Mestrado) - Escola Politécnica da Universidade de São Paulo. Departamento de Engenharia Mecatrônica e de Sistemas Mecânicos.

1. Análise numérica 2. Segurança veicular 3. Estruturas ( Im pacto) 4. Ensaios de propriedades mecânicas 5. Estrutura veicular I. Universidade de São Paulo. Escola Politécnica. Departa mento de Engenharia Mecatrônica e de Sistemas Mecânicos II. t. 


\section{AGRADECIMENTOS}

Obrigado à amiga e orientadora Larissa pelo inestimável suporte, conselhos, dedicação, empenho e orientação demonstrados inúmeras vezes.

A amada Mo, pelo carinho, compreensão, ajuda e suporte despendidos desde o início da graduação, e recentemente, pela construção do nosso lar.

À minha família, pela paciência e suporte nos momentos difíceis, em especial ao meu irmão Rafael, pelo auxílio na preparação de malhas de elementos finitos utilizadas neste trabalho.

Aos colegas de trabalho da General Motors, que contribuíram de diversas formas, desde idéias para contornar dificuldades encontradas até o auxílio direto na execução de ensaios. 
"I hope I didn't brain my damage"

(Homer Simpson)

.... and this work is all about damage 


\section{RESUMO}

O presente trabalho visa o estudo e avaliação de diversos modelos de falha através de ensaios experimentais e análises numéricas. A caracterização do material foi feita por meio de ensaios de tração de espécimes com e sem entalhe e de cisalhamento, para prover dados em uma ampla faixa de triaxialidade. A calibração dos parâmetros necessários para cada modelo de falha ocorreu através da obtenção das componentes de tensões e de deformações na região de ruptura, obtidas por meio de análises numéricas destes ensaios. O critério da máxima deformação plástica equivalente, modelo de dano de Johnson-Cook e critério da máxima tensão cisalhante foram aplicados em um caso de impacto em pára-choque. Diversos ensaios de impacto foram realizados até a que se atingisse a ruptura satisfatória do componente. Os ensaios foram modelados em elementos finitos, através do programa comercial LS-Dyna ${ }^{\circledR}$, sendo que os modelos de falha calibrados foram aplicados para o ensaio onde se ocorreu ruptura. Houve boa concordância entre os resultados obtidos numericamente e experimentalmente, respeitadas as observações realizadas acerca da especificidade deste caso de impacto em baixa velocidade.

Palavras-chave: modelos de falha, pára-choque, impacto de baixa velocidade, ruptura dúctil. 


\section{ABSTRACT}

The aim of the present work is an assessment of several fracture models through experiments and numerical simulations. Tensile tests with notched and unnotched specimens were carried out to provide the material characterization in a wide range of stress triaxiality. The calibration of the parameters required by the fracture models was enabled by the parallel numerical simulation of the tensile tests, providing information on the stress and strain components at the failure locus. The constant equivalent strain criterion, the Johnson-Cook failure model and the maximum shear stress failure criterion were applied in a bumper beam impact case study. Several low speed impact tests were carried out in order to result in the component's rupture. Numerical simulation of the experiments was performed using commercial finite element code $L S-D y n a^{\circledast}$. Good correlation of experiments and numerical simulations was achieved when considering this particular low speed case study.

Keywords: fracture criterion, bumper beam, low speed crash, ductile fracture. 


\section{LISTA DE ILUSTRAÇÕES}

Figura 1. Comparativo entre casos de campo (superior) e crash-tests (inferior); (a) impacto frontal; (b) impacto lateral; (c) impacto contra poste.

Figura 2. Principais programas de avaliação de segurança veicular no mundo. .30

Figura 3. Impacto a $64 \mathrm{~km} / \mathrm{h}$ contra barreira deformável e $40 \%$ de sobreposição (3).

Figura 4. (a) e (b) resultado de um impacto lateral de uma barreira móvel de $1500 \mathrm{~kg}$ a $50 \mathrm{~km} / \mathrm{h}$; (c) padrão deformado da coluna $B$ em que o nível intrusão é classificado como "marginal" (4).

Figura 5. Caminhos de carga em estrutura (Mercedes Classe E) submetida a (a) impacto frontal; (b) impacto lateral.

Figura 6. Elementos estruturais veiculares, (a) barra de pára-choque; (b) conjunto da coluna B

Figura 7. (a) e (b) protótipo de pára-choque após impacto de alta velocidade; (c) impacto simulando atropelamento de um animal.

Figura 8. (a) barreira fixa em forma de pára-choque (7); (b) e (c) resultado pós teste.

Figura 9. Processo de transição entre Dano e Fratura (11). .38

Figura 10. Representação do critério da máxima deformação plástica equivalente..40

Figura 11. Relação empírica da deformação equivalente de ruptura com a triaxialidade para alumínio 2024-T351 (18).

Figura 12. Representação do critério simplificado de Bao-Wierzbicki (18). 42 
Figura 13. Representação da ocorrência de ruptura em função da triaxialidade e parâmetro de Lode (17)

Figura 14. Comparativo entre o ensaio físico e os modelos de Gurson e J-C (19). ..45

Figura 15. Simulação de impacto lateral utilizando algoritmo $\mathrm{CRACH}$ (8). .46

Figura 16. Modos de falha em elementos sólidos e de casca respectivamente (14).47

Figura 17. Deformação de ruptura em função do fator de triaxialidade considerando o critério de J-C (21). .52

Figura 18. Deformação de ruptura em função do fator de triaxialidade considerando o critério de Wilkins (17). .54

Figura 19. Geometria dos espécimes (medidas em $\mathrm{mm}$ ). (a)-(c) espécimes com entalhes de raio 1,25, 5 e $20 \mathrm{~mm}$, respectivamente; (d) espécime sem entalhe; (e) espécime de cisalhamento.

Figura 20. Espécimes para os ensaios de tração. 61

Figura 21. (a) Máquina de Tração INSTRON3369; (b) detalhe da fixação do extensômetro e mordentes convencionais; (c) detalhe da fixação do extensômetro e indicação dos pinos para ensaio de cisalhamento. .62

Figura 22. Espécime sem entalhe após a ruptura. 63

Figura 23. Espécimes com entalhe após a ruptura. 63

Figura 24. Espécime de cisalhamento após a ruptura. 63

Figura 25. Resultado experimental das curvas força-deslocamento para os espécimes com entalhe. 64

Figura 26. Início do surgimento da falha na região central do espécime T20_L_1 ..65 Figura 27. Malha dos corpos de prova, (a) entalhe de $1,25 \mathrm{~mm}$; (b) entalhe de 5 $\mathrm{mm}$;(c) entalhe de $20 \mathrm{~mm}$; (d) sem entalhe. .66

Figura 28. Malha do espécime de cisalhamento. 66 
Figura 29. Resultado numérico e experimental das curvas força-deslocamento para o espécime sem entalhe.

Figura 30. Deslocamento na direção da espessura do espécime de $20 \mathrm{~mm}$ de raio na região do entalhe (escala em $\mathrm{mm}$ ).

Figura 31. Triaxialidade em função do tempo para o elemento central de cada modelo de espécime. .69

Figura 32. Ajuste dos critérios de falha de J-C e Máxima Deformação Plástica Equivalente. .70

Figura 33. Resultado da simulação do espécime com entalhe de $20 \mathrm{~mm}$ e parâmetros de falha de J-C calibrados. 71

Figura 34. Barra de Hopkinson do GMSIE-USP 72

Figura 35. Resultados de ensaio de compressão dinâmica de um aço ABNT1047 (42). .73

Figura 36. Curvas de tensão x deformação em taxas de deformação médias (banco de dados da General Motors). .74

Figura 37. Tensão de escoamento em função da taxa de deformação segundo J-C e Cowper-Simonds. .75

Figura 38. Detalhe da geometria do pára-choque. 76

Figura 39. Pára-choque e seus suportes de fixação. .77

Figura 40. Detalhe da união do pára-choque com os suportes, (a) solda a ponto; (b) solda MIG.

Figura 41. (a) ensaio da barra de pára-choque visto de cima; (b) pêndulo; (c) sistema de iluminação e aquisição de imagens. .78

Figura 42. Detalhe das fixações do suporte do pára-choque na barreira. .79

Figura 43. Pára-choque depois do impacto (a) ainda no dispositivo; (b) fora do dispositivo. 
Figura 44. Imagens seqüenciais do impacto do Teste \#1 (massa de $950 \mathrm{~kg}$ a 1,39 $\mathrm{m} / \mathrm{s})$.

Figura 45. Detalhe das deformações no ponto de impacto do Teste \#1

Figura 46. (a) condição do Teste \#2 antes do ensaio; (b) depois do ensaio. .82

Figura 47. Detalhe das deformações no ponto de impacto do Teste \#2, (a) vista externa; (b) vista interna.

Figura 48. (a) Detalhe da ruptura dos suportes; (b) colapso dos suportes visto de topo; (c) vista lateral.

Figura 49. (a) condição do Teste \#3 antes do ensaio; (b) depois do ensaio e detalhe do suporte sem colapso.

Figura 50. Detalhe do suporte reforçado com uma alma metálica em seu interior....86

Figura 51. Imagens seqüenciais do impacto do Teste \#3 a cada 55 ms (massa de $1000 \mathrm{~kg}$ a $1,94 \mathrm{~m} / \mathrm{s}$ ) .86

Figura 52. Detalhe da ruptura do suporte no Teste \#4

Figura 53. Detalhe da condição de contorno dos suportes para o Teste \#5.

Figura 54. (a) preparação do Teste \#5; (b)-(c) detalhe da coluna adicionada a 480 $\mathrm{mm}$ da extremidade inferior .88

Figura 55. Imagens seqüenciais do Teste\#5 (massa de $1000 \mathrm{~kg}$ a 4,09 m/s). .89

Figura 56. Detalhe da ruptura na região de impacto com o pêndulo. .89

Figura 57. Ocorrência de ruptura próxima ao engaste inferior. .90

Figura 58. Ruptura iniciada na zona termicamente afetada pelo cordão de solda MIG. .90

Figura 59. Detalhe da região prensada entre o pêndulo e a barreira rígida. .91

Figura 60. llustração da união entre a coluna central e o pára-choque. 91 
Figura 61. (a) condição do Teste \#6 antes do ensaio; (b) depois do ensaio. .92

Figura 62. (a) condição do Teste \#6 depois do ensaio; (b) detalhe da ruptura. .92

Figura 63. Gráfico da força em função do tempo no Teste \#6. .93

Figura 64. Vista frontal da região da ruptura do pára-choque do Teste \#6. .94

Figura 65. Vista de topo da região da ruptura do pára-choque do Teste \#6. .94

Figura 66. Vista lateral da região da ruptura apoiada pela coluna central (Teste \#6).

Figura 67. (a) Malha do pára-choque; (b) vista frontal; (c) vista de topo. .97

Figura 68. (a) Malha de um dos suportes; (b) vista frontal; (c) vista de topo .97

Figura 69. (a) Malha do impactador; (b) vista frontal; (c) vista de topo. .98

Figura 70. Representação das condições de contorno e carregamento do modelo baseado no Teste \#1. 99

Figura 71. Comparativo da resposta numérica com o Teste\#1. .99

Figura 72. Malha do pára-choque (a) com elementos de $5 \times 5 \mathrm{~mm}$; (b) com elementos de $3 \times 3 \mathrm{~mm}$. 100

Figura 73. Representação das condições de contorno e carregamento do modelo baseado no Teste \#6.

Figura 74. Resultado do critério da máxima deformação plástica equivalente para a malha de $5 \times 5 \mathrm{~mm}$, elementos em vermelho indicam deformação plástica efetiva de $52 \%$. (a) vista geral; (b) elementos na deformação limite; (c) elementos eliminados da malha. 102

Figura 75. Seqüência de imagens do resultado do critério da máxima deformação plástica equivalente, escala aumentada na Figura 74. (a) malha com elementos de 5 $\mathrm{mm} \times 5 \mathrm{~mm}$; (b) malha com elementos de $3 \mathrm{~mm} \times 3 \mathrm{~mm}$ 102 
Figura 76. Comparativo da ruptura utilizando o critério da máxima deformação plástica equivalente, (a) malha com elementos de $3 \mathrm{~mm} \times 3 \mathrm{~mm}$; (b) resultado do Teste\#6.

Figura 77. Comparativo geral do resultado do critério da máxima deformação plástica equivalente, (a) malha com elementos de $3 \mathrm{~mm} \times 3 \mathrm{~mm}$; (b) resultado do Teste\#6. 103

Figura 78. Critério da máxima tensão cisalhante, elementos negros indicam tensão de cisalhamento acima do limite de $381 \mathrm{MPa}$, (a) vista geral com malha de $5 \mathrm{~mm} \times 5$ $\mathrm{mm}$; (b)-(c) detalhe das regiões com falha na malha de $3 \times 3 \mathrm{~mm}$ 104

Figura 79. Evolução da deformação plástica com o tempo dos elementos indicados pelas setas (escala da Figura 78a). 105

Figura 80. Resultado do modelo de dano de J-C com malha de $5 \mathrm{~mm}$, (a) modelo com parâmetros J-C Inferior; (b) J-C Superior. 106

Figura 81. Deformação plástica equivalente e triaxialidade do elemento indicado pela seta durante a simulação utilizando-se o modelo de J-C Superior e Inferior. 107

Figura 82. (a) região onde não houve ocorrência de falha no Teste\#6; (b) vista local. 108

Figura 83. Comparativo utilizando o modelo de dano de $\mathrm{J}-\mathrm{C}$ com malha de $5 \mathrm{~mm} \times 5$ mm (a) J-C Inferior; (b) J-C Superior; (c) resultado do Teste\#6. 108

Figura 84. Comparativo utilizando o modelo de dano de $\mathrm{J}-\mathrm{C}$ com malha de $3 \mathrm{~mm} \times 3$ mm (a) J-C Inferior; (b) J-C Superior; (c) resultado do Teste\#6. 108

Figura 85. Deformação plástica equivalente e triaxialidade do elemento indicado pela seta durante a simulação utilizando-se o modelo de J-C Superior e Inferior. 109

Figura 86. Comparativo da ruptura utilizando o modelo de dano de J-C Superior (a) resultado do Teste\#6; (b) malha com elementos de $3 \mathrm{~mm} \times 3 \mathrm{~mm}$ 109 
Figura 87. Comparativo da ruptura utilizando o modelo de dano de J-C Inferior com (a) malha com elementos de $5 \mathrm{~mm} \times 5 \mathrm{~mm}$; (b) malha com elementos de $3 \mathrm{~mm} \times 3$ $\mathrm{mm}$; (c) resultado do Teste\#6.

Figura A 88. Ensaio de impacto pendular, (a) desenho do pêndulo, (b) posições de impacto e (c) altura do pêndulo.

Figura B 89. Esquema de posicionamento de barreira no teste de reparabilidade $R C A R$ 123 


\section{LISTA DE TABELAS}

Tabela 1 - Lista de ensaios de caracterização do material 62

Tabela 2 - Resumo dos dados das malhas dos espécimes. .66

Tabela 3 - Parâmetros de J-C que melhor caracterizam o material. .67

Tabela 4 - Deformações de ruptura dos espécimes ensaiados .69

Tabela 5 - Triaxialidade e deformação plástica equivalente na ruptura de cada tipo de espécime.

Tabela 6 - Parâmetros do modelo de dano de J-C

Tabela 7 - Tensão máxima cisalhante dos espécimes. .72

Tabela 8 - Valores da deformação plástica equivalente na ruptura e máxima tensao cisalhante. .72

Tabela 9 - Parâmetros de Cowper-Simonds e J-C para casos dinâmicos. .75

Tabela 10 - Configuração dos ensaios de baixa severidade. 80

Tabela 11 - Configuração dos ensaios de alta severidade .84

Tabela 12 - Quantidades de nós e elementos das malhas dos componentes da análise numérica .98

Tabela 13 - Quantidades de nós e elementos das malhas de pára-choque para as análises com falha do material. 100

Tabela A 1 - ensaios de impacto que são realizados em laboratório seguindo diversos procedimentos internacionais 120 
Tabela A2 - Bateria de ensaios de impacto pendular frontal e traseiro conforme CMVSS 215

Tabela A3 - Bateria de ensaios de impacto pendular frontal e traseiro conforme CFR 49 Parte 581 122

Tabela A 4 - Bateria de ensaios de impacto pendular frontal e traseiro conforme $E C E$ R42 122

Tabela A 5 - Ensaios de impacto e baixa velocidade para análise de reparabilidade 124 


\section{LISTA DE ABREVIATURAS E SIGLAS}

\begin{tabular}{ll} 
ABNT & Associação Brasileira de Normas Técnicas \\
CESVI & Centro de Experimentação e Segurança Viária \\
CET & Cavity-Expansion Theory \\
CFR & Circular of the Federal Register \\
CONTRAN & Conselho Nacional de Trânsito \\
CMVSS & Canadian Motor Vehicle Safety Standard \\
DENATRAN & Departamento Nacional de Trânsito \\
ECE & Economic Comission for Europe \\
EEC & European Economic Community \\
FLD & Forming Limit Diagram \\
FMVSS & Federal Motor Vehicle Safety Standard \\
GMSIE & Grupo de Mecânica dos Sólidos e Impacto em Estruturas \\
IIHS & Insurance Institut for Highway Safety \\
J-C & Johnson-Cook \\
KMVSS & Korea Motor Vehicle Safety Standard \\
NCAP & New Car Assessment Program \\
NHTSA & Research Council for Automobile Repairs \\
RCAR & Sighway Traffic Saffety Administration \\
\hline
\end{tabular}




\section{LISTA DE SÍMBOLOS}

$A, B, n, c, m$ Parâmetros do modelo constitutivo de J-C

$C_{i=1: 4} \quad$ Constantes de calibração do modelo de X-W

$C_{c s} \quad$ Parâmetro da influência da taxa de deformação do modelo de CowperSymonds

D Dano acumulado

$D_{c r} \quad$ Valor de dano crítico

$\dot{D} \quad$ Taxa de danificação

$D_{i=1: 5} \quad$ Constantes de calibração do modelo de J-C

E Módulo de Elasticidade

v $\quad$ Coeficiente de Poisson

$\varepsilon_{N} \quad$ Deformação plástica média do modelo de Gurson

$\bar{\varepsilon} \quad$ Deformação plástica equivalente

$\dot{\varepsilon} \quad$ Taxa de deformação equivalente

$\varepsilon_{1}, \varepsilon_{2}, \varepsilon_{3} \quad$ Deformações principais

$\bar{\varepsilon}_{\text {rup }} \quad$ Deformação plástica equivalente na ruptura

$f_{N} \quad$ Fração de volume de vazios do modelo de Gurson

fo $\quad$ Fração de volume de vazios inicial do modelo de Gurson

$f_{c} \quad$ Fração de crítica de vazios no início de coalescência do modelo de Gurson 
$f_{F} \quad$ Fração de crítica de vazios no momento da falha do modelo de Gurson

$f^{*} \quad$ Função de instabilidade de Tvergaard e Needleman

$q_{1}, q_{2} \quad$ Constantes do material para o modelo de Gurson

$D_{1}, D_{2}$ e $D_{3} \quad$ Constantes de calibração do modelo de J-C

$I_{1}, I_{2}$ e $I_{3} \quad$ Primeiro, segundo e terceiro invariantes do tensor das tensões

$J_{1}, J_{2}$ e $J_{3} \quad$ Primeiro, segundo e terceiro invariantes do tensor de tensões desviador

$w_{1} \quad$ Primeiro termo do modelo de Wilkins, relacionado a pressão

$w_{2} \quad$ Segundo termo do modelo de Wilkins, relacionado a razão das tensões desviadoras

$\delta_{i j} \quad$ Delta de Kronecker

$\sigma_{1}, \sigma_{2}$ e $\sigma_{3} \quad$ Tensões principais máxima, média e mínima

$\sigma_{d} \quad$ Tensão de escoamento dinâmica do material

$\bar{S} \quad$ Constante do material para o modelo de Lemaitre

$S_{N} \quad$ Desvio padrão da distribuição Gaussiana de vazios para o modelo de Gurson

$\bar{\sigma} \quad$ Tensão equivalente de Von Mises

$\sigma_{m} \quad$ Tensão média ou hidrostática

$\sigma_{e q} \quad$ Tensão equivalente para o modelo de Gurson

$\tau_{m a ́ x} \quad$ Tensão cisalhante máxima

$\left(\tau_{m a ́ x}\right)_{f} \quad$ Tensão cisalhante máxima na ruptura

$\propto$

Razão de deformações 


$\begin{array}{ll}m & \text { Integrador ímpar para o modelo de X-W } \\ n & \text { Expoente de encruamento da função de escoamento } \\ \mathrm{p} & \text { Pressão média. } \\ q & \quad \text { Parâmetro da influência da taxa de deformação do modelo de Cowper- } \\ & \text { Symonds } \\ R_{c r} & \text { Volume crítico no modelo de Wilkins } \\ R_{v} & \text { Função triaxialidade } \\ T^{*} & \text { Temperatura adimensional para o modelo constitutivo de J-C } \\ u_{f} & \text { Deslocamento de ruptura nos ensaios de tração } \\ \alpha, \gamma \text { e } \beta & \text { Constantes do material no modelo de Wilkins } \\ s_{1}, s_{2} \text { e } s_{3} & \text { Tensões principais da parte desviadora } \\ \eta & \text { Triaxialidade das tensões } \\ \theta & \text { Ângulo de Lode } \\ \xi & \text { Parâmetro relacionado ao ângulo de Lode } \\ \sigma_{0} & \text { Tensão de escoamento estático do material } \\ \Phi_{e v p} & \text { Funão de escoamento do modelo de Gurson }\end{array}$




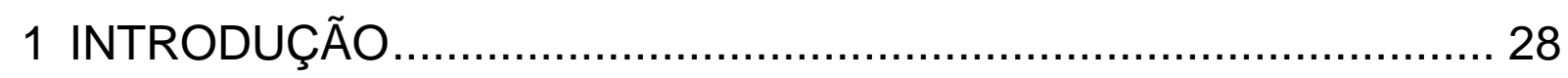

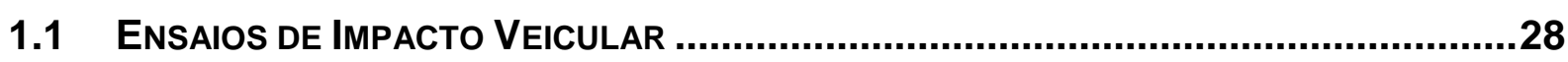

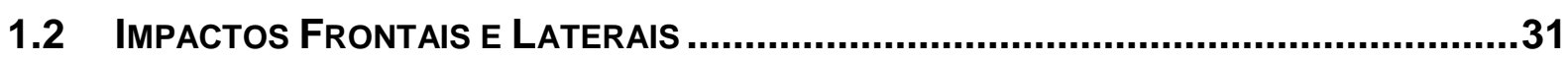

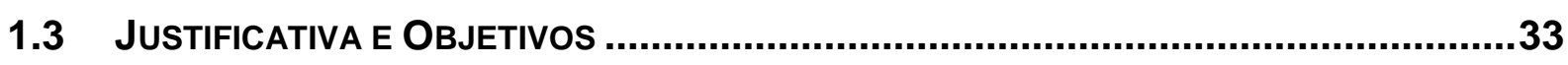

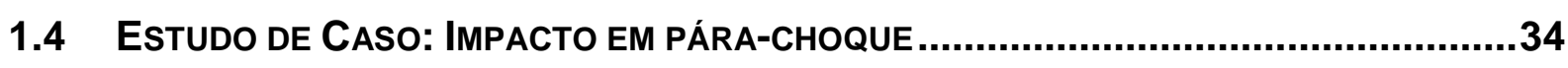

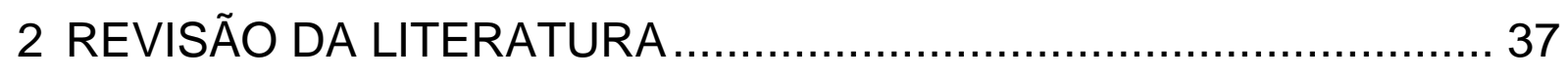

2.1 Aplicações Práticas de Modelos de Falha .................................................

3 CRITÉRIOS DE FALHA DA LITERATURA ................................ 49

3.1 Critério da Máxima Deformação Plástica Equivalente ..............................49

3.2 Critério da MÁxima Tensão Cisalmante....................................................50

3.3 MODELO DE DANO DE JOHNSON-COOK ..........................................................

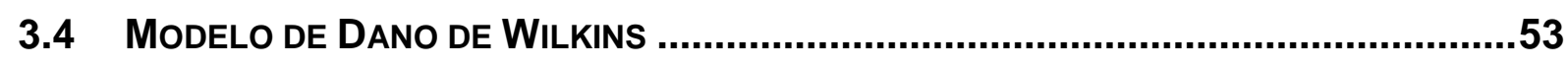

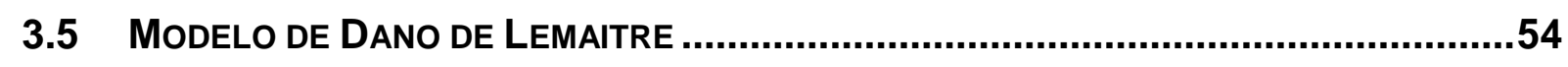

3.6 Modelo de Dano de Gurson / TVergaARd NeEdLeman ..................................55

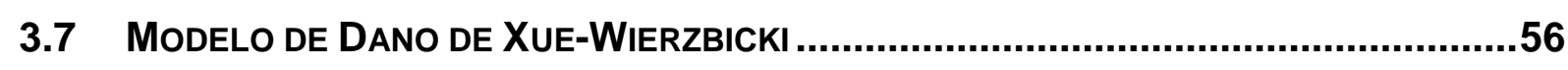

4 CARACTERIZAÇÃO DO MATERIAL ....................................... 59

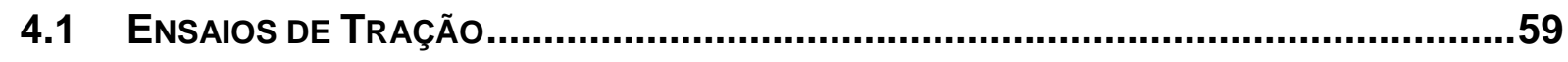

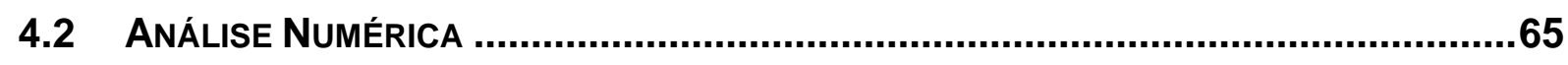




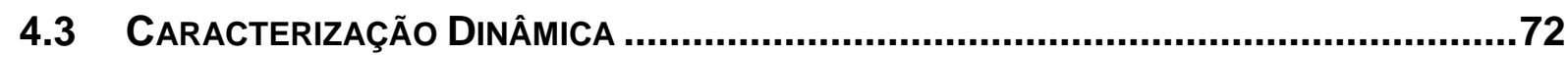

5 IMPACTO EM PÁRA-CHOQUE: EXPERIMENTOS ........................ 76

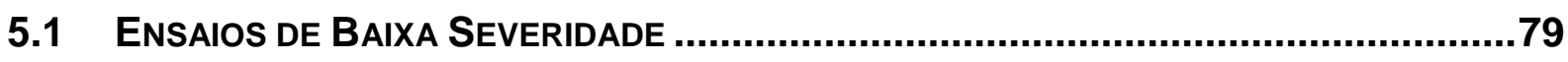

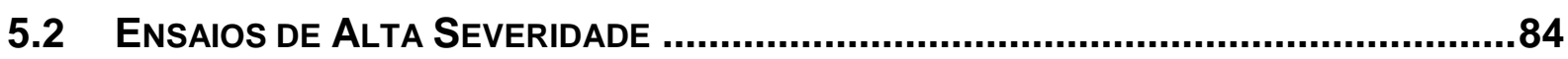

6 IMPACTO EM PÁRA-CHOQUE: ANÁLISE NUMÉRICA .................. 96

6.1 Análise Numérica de EnSaIOS de BaiXa SEVERIDADE ......................................96

6.2 Análise Numérica de EnSaios de Alta SeVteridade ....................................99

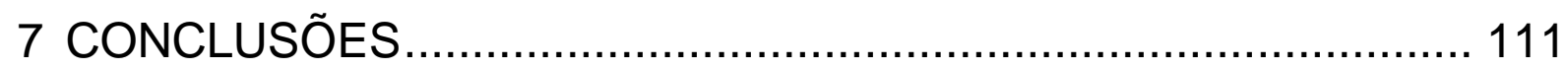

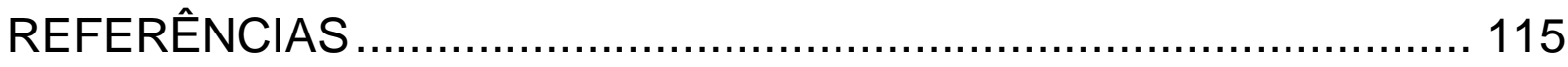

APÊNDICE A - PROCEDIMENTOS DE TESTE ............................. 120

APÊNDICE B - INVARIANTES DO TENSOR DAS TENSÕES .......... 125 


\section{INTRODUÇÃO}

A cada ano que passa o mercado global automotivo constitui cada vez mais um cenário de intensa concorrência entre as fabricantes de veículos. Nos mercados emergentes, onde o baixo custo de produção é essencial na disputa pelo alto volume de vendas de veículos de passeio, o projeto de carrocerias com baixa massa e com alto desempenho em absorção de energia quando submetidas a impactos é sinônimo de sucesso.

\subsection{Ensaios de Impacto Veicular}

Centenas de ensaios de impactos veiculares conhecidos como crash-tests são executados anualmente durante o desenvolvimento e validação de veículos conforme legislações nacionais e internacionais, além de requisitos de mercado dos programas de avaliação de veículos novos NCAP (New Car Assessment Program) presente em diversos países (Europa, Estados Unidos, China, Austrália e etc). $O$ principal objetivo dos ensaios de impacto é de avaliar o nível de proteção aos ocupantes baseados em acidentes reais. Em outras palavras, através de estudos estatísticos de casos de campo é possível criar procedimentos de laboratório que se assemelham em diversos aspectos. A Figura 1 ilustra a semelhança entre casos reais e resultados de testes em laboratório

São inúmeros os requisitos e procedimentos de testes, abrangendo proteção a pedestres, impactos de baixa velocidade para avaliação de custos de reparo, impactos de alta velocidade frontais, laterais e traseiros (1). Em geral, os fabricantes de veículos realizam ensaios de segurança veicular por três motivos:

- Pesquisa e desenvolvimento em engenharia do produto com o objetivo de projetar veículos mais seguros. 
- Atender a legislações vigentes, a fim de obter aprovação oficial e homologação para comercialização em diversos países.

- Atender a requisitos e avaliações de testes de mercado (NCAPs), presentes em diversos países conforme ilustrado pela Figura 2.
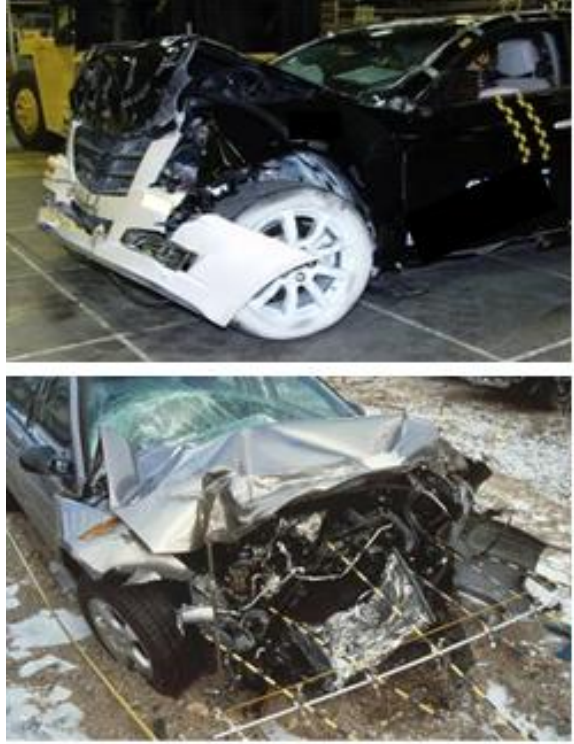

(a)
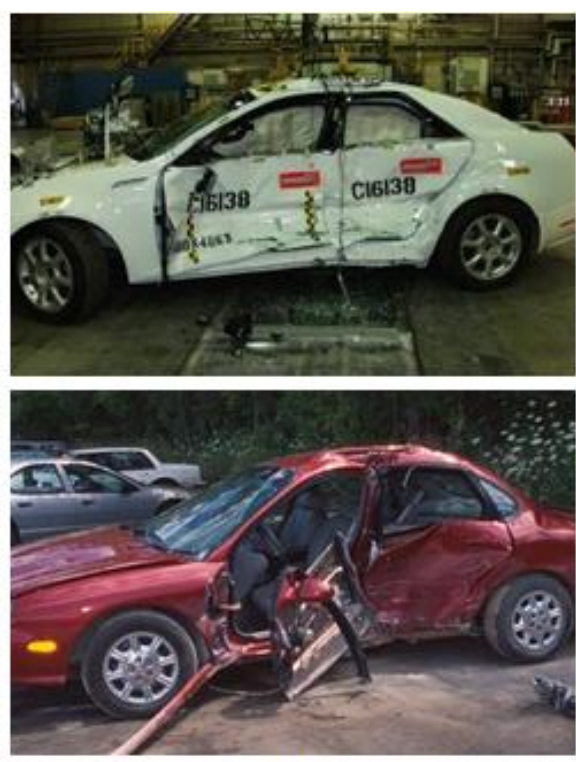

(b)
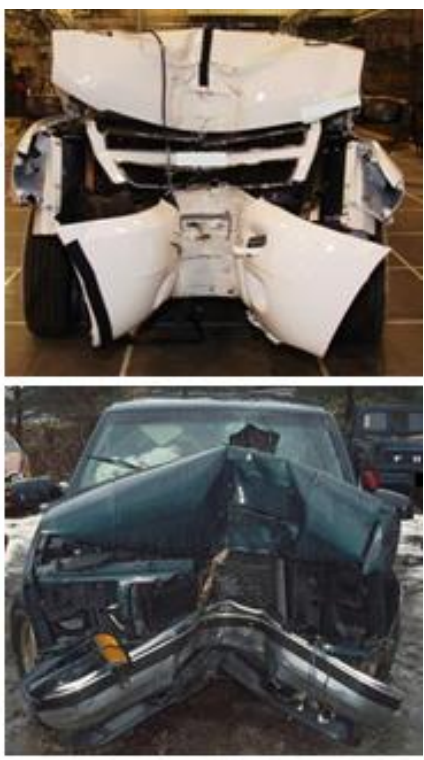

(c)

Figura 1. Comparativo entre casos de campo (superior) e crash-tests (inferior); (a) impacto frontal; (b) impacto lateral; (c) impacto contra poste'.

As normas americanas de segurança veicular FMVSS (Federal Motor Vehicle Standard) são emitidas pela NHTSA (National Highway Traffic Safety Administration) sob um mandato legislativo. Essas normas exigem um nível mínimo de desempenho em segurança de tal maneira que o público esteja protegido contra riscos de acidentes provocados por falha de projeto e construção, assim como proteção contra risco de morte em casos de colisões. As normas européias possuem o mesmo objetivo e são emitidas pela ECE (Economic Commission for Europe) e regulamentadas pela EEC (European Economic Community). No Brasil, a regulamentação é feita pelas resoluções do CONTRAN (Conselho Nacional de

\footnotetext{
${ }^{1}$ BAILEY, K. et. al. (University of Michigan Program for Injury Research and Education). Comparison of University of Michigan CIREN Cases to Existing Types of Crash Tests. Michigan, 2008.
} 
Trânsito) e portarias do DENATRAN (Departamento Nacional de Trânsito), que por sua vez, podem requisitar normas NBR publicadas pela ABNT (Associação Brasileira de Normas Técnicas) e NBR.

Apesar de não serem classificados como normas, os protocolos de testes da NCAP são extensivamente utilizados pelas montadoras durante o desenvolvimento e validação de veículos, pois seus resultados são parâmetros mundialmente reconhecidos em segurança veicular, classificando os carros em estrelas quanto ao seu nível de segurança. No Brasil, ainda não há uma NCAP vigente, porém há uma iniciativa do CESVI Brasil (Centro de Experimentação e Segurança Viária) em testar veículos em impactos de baixa velocidade para avaliação de custos de reparo, gerando um ranking disponível ao público (2). A Figura 2 ilustra a distribuição de iniciativas da NCAP e outras pelo mundo.

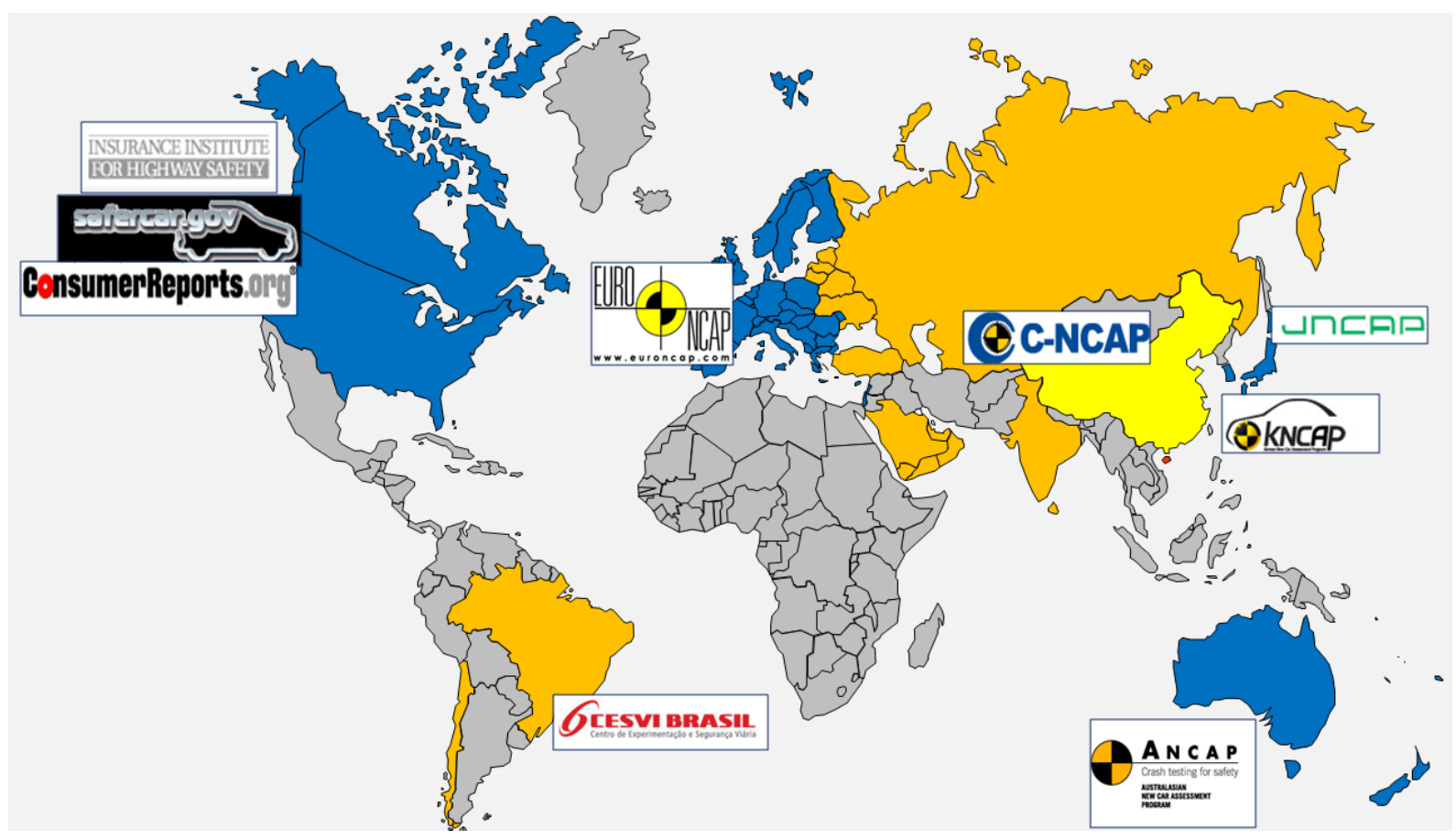

Figura 2. Principais programas de avaliação de segurança veicular no mundo.

Nos testes de impacto, geralmente são utilizados manequins antropométricos, conhecidos como dummies, instrumentados com acelerômetros, transdutores e células de carga para avaliação de índices biomecânicos (cabeça, pescoço, tórax e 
etc.), que representam níveis de lesão ao ocupante. Os manequins mais utilizados são o SID III (Side Impact Dummy) e o Hybrid III, de padrões ergonômicos de 5\%, $50 \%$ e $95 \%$. Existem ainda os manequins para ensaios de cadeira de criança, representando crianças de doze meses, três, seis e dez anos de idade. Além dos dummies, o veículo é instrumentado com dezenas de acelerômetros que capturam pulsos de aceleração importantes para avaliação do desempenho da estrutura durante do impacto, tal como comportamento das longarinas frontais, dinâmica do motor e integridade dos coxins, distribuição de carga pelos elementos primários da estrutura, captura de sinais para calibração do sistema de bolsas infláveis (conhecidos como airbag) e etc. Medições estáticas antes de depois do teste também são realizadas, pois trazem informações sobre os níveis de deformação da estrutura que podem afetar o habitáculo dos ocupantes. Dentre as medições mais importantes, podemos citar o deslocamento da coluna de direção, vão das portas dianteiras, intrusão na região dos pedais e do painel de instrumentos.

\subsection{Impactos Frontais e Laterais}

Em ensaios de impacto frontal, normalmente são avaliados o grau de deformação da estrutura através de medições estáticas, pulso de desaceleração (medida em diversas regiões da estrutura), integridade do sistema de combustível (ruptura das linhas de alimentação e tanque de combustível), integridade de painel de instrumentos e demais itens de acabamento interno (não podendo resultar em superfícies cortantes), integridade das ancoragens de bancos e cintos de segurança. Um dos procedimentos de impacto frontal mais conhecido é o da EuroNCAP, neste caso o veículo a $64 \mathrm{~km} / \mathrm{h}$ colide contra uma barreira deformável que atua sobre $40 \%$ da largura máxima do veículo (sem considerar os espelhos retrovisores), conforme ilustra a Figura 3.

Em impacto lateral, além dos itens mencionados acima, uma atenção especial é dada a coluna-B, uma vez que esse elemento estrutural é o maior responsável por proteger os ocupantes. Neste caso os níveis de intrusão no habitáculo devem ser 
reduzidos de modo a aumentar as chances de sobrevivência dos ocupantes (Figura 4). Para este ensaio acelerômetros são posicionados ao longo da coluna $B$, assim como na soleira, túnel central e na estrutura de ancoragem dos bancos.
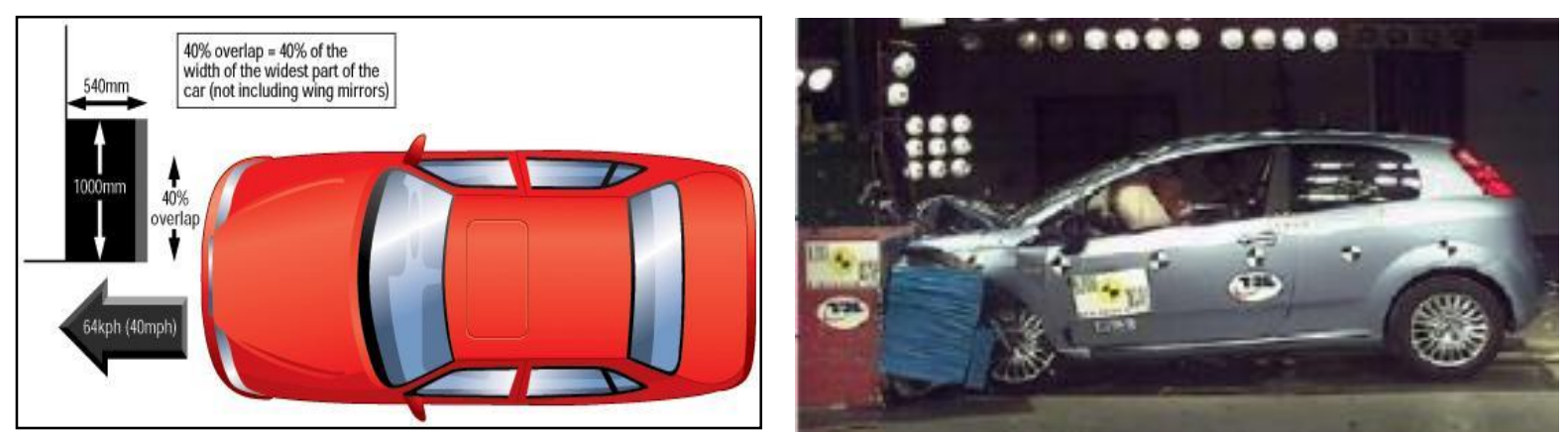

Figura 3. Impacto a $64 \mathrm{~km} / \mathrm{h}$ contra barreira deformável e 40\% de sobreposição (3).

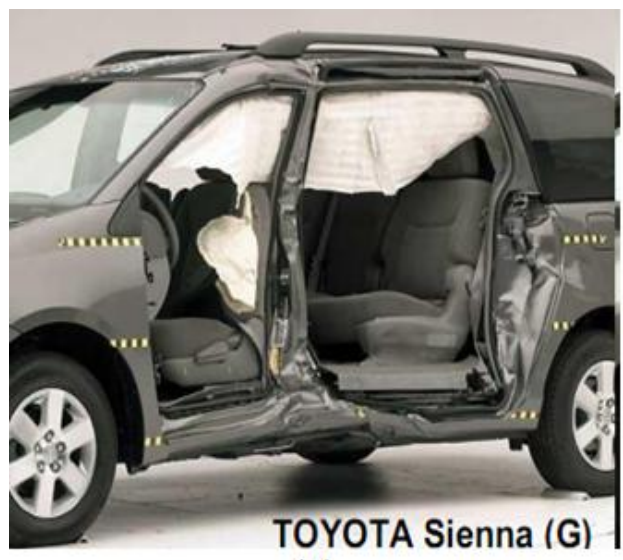

(a)

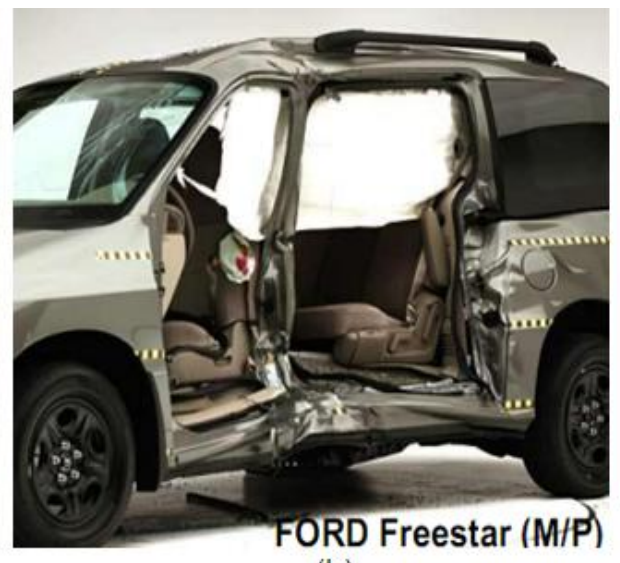

(b)

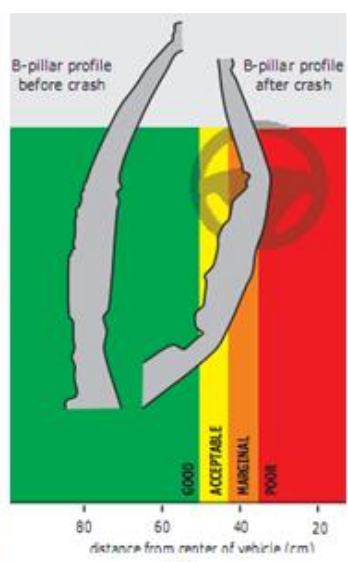

(c)

Figura 4. (a) e (b) resultado de um impacto lateral de uma barreira móvel de $1500 \mathrm{~kg}$ a $50 \mathrm{~km} / \mathrm{h}$; (c) padrão deformado da coluna B em que o nível intrusão é classificado como "marginal" (4).

Informações adicionais sobre os procedimentos de testes, assim como requisitos de legislações e avaliações de mercado são apresentados no Apêndice A. 


\subsection{Justificativa e Objetivos}

Estruturas de veículos de passeio são tradicionalmente construídas de chapas de aço de baixo custo soldadas a ponto. Com o objetivo de projetar estruturas mais leves, engenheiros de desenvolvimento buscam reduzir as espessuras até que a estrutura atinja o limite de atendimento aos requisitos de desempenho. Ao considerarmos os custos envolvidos nos ensaios de segurança veicular citados anteriormente, que podem atingir cifras da ordem de centenas de milhares de Reais por teste, fica ainda mais evidente a importância das ferramentas de simulação numérica na busca por redução de custos de desenvolvimento. Nesse sentido, a predição precisa de falha de estruturas metálicas submetidas a cargas de impacto se faz necessária. Nos últimos 15 anos, simulações numéricas utilizando-se de softwares de elementos finitos de método explícito, como o $P A M-C R A S H^{\circledR}$ e o LS$D y n a^{\circledR}$ têm demonstrado excelentes resultados na predição de deformações plásticas e absorção de energia, promovendo bons projetos de estrutura (Figura 5). Modelos constitutivos de comportamento dos materiais tem se tornado cada vez mais realistas com o avanço de técnicas experimentais para definição das propriedades mecânicas dos materiais, porém, prever a ocorrência ou não de falha no material ainda é um desafio (5).

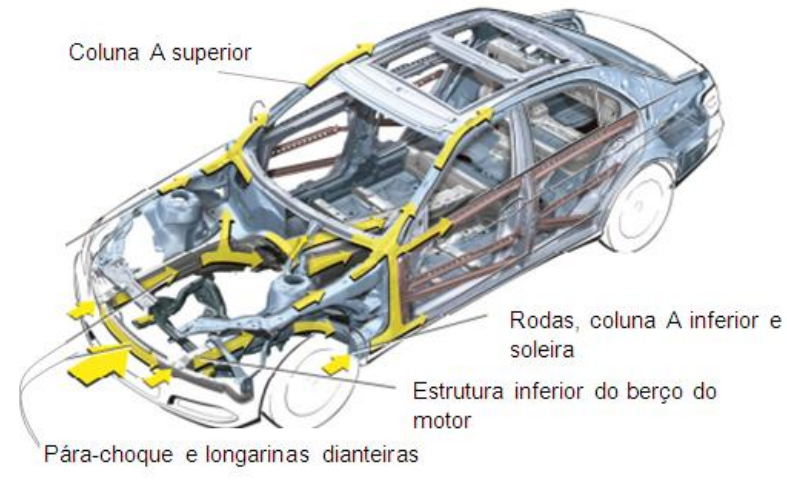

(a)

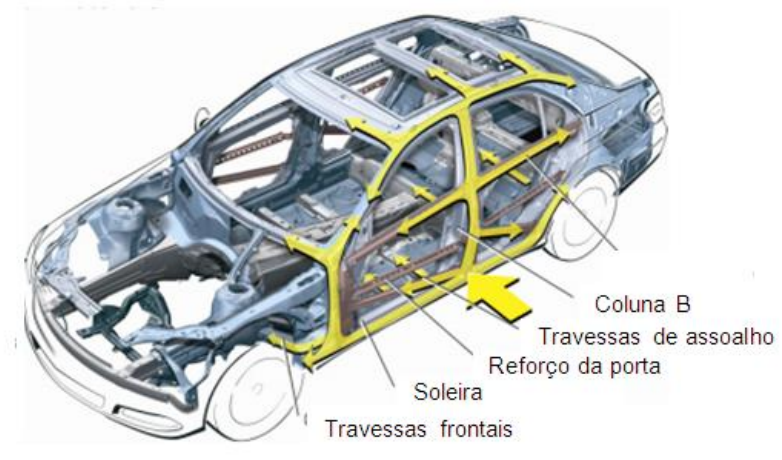

(b)

Figura 5. Caminhos de carga em estrutura (Mercedes Classe E) submetida a (a) impacto frontal; (b) impacto lateral ${ }^{2}$.

\footnotetext{
${ }^{2}$ KELLERMANN, H.; TRITSCHLER, S. Apresentacao do novo Classe E. EuroCar Body 2009. p. 11
} 
Este trabalho tem como objetivo estudar os diversos modelos de falha em materiais metálicos e realizar por meio de ensaios experimentais e simulações numéricas uma análise crítica das teorias apresentadas, assim como discutir eventuais desvios de resultados experimentais dos resultados numéricos e ainda avaliar sua aplicabilidade na indústria, mais precisamente em desenvolvimento de veículos.

É importante ressaltar que a análise numérica com falha deste estudo utiliza modelos de material baseados na teoria da mecânica do contínuo, e é capaz de descrever o surgimento e propagação de uma falha através da eliminação de elementos finitos que atinjam valores críticos relacionados com o critério de falha do material. É importante citar também que não deve se omitir a relevância do histórico de tensões desde o processo de fabricação da peça. De fato, tensões e deformações oriundas do processo de fabricação não são desprezíveis e constituem um tópico a ser abordado nos próximos anos (6).

Atualmente, portanto, projetos devem minimizar o número de ensaios experimentais, de modo a colher com eficiência dados que caracterizem o material nas condições necessárias de estudo. Esses dados, analisados, fornecem o input necessário para simulação numérica do problema. Dessa forma, podem-se racionalizar os investimentos, direcionando novos poucos testes experimentais, em situações reais, para validação da caracterização.

\subsection{Estudo de Caso: Impacto em pára-choque}

Conforme já discutido, a predição de falha de componentes através de simulações durante a fase de desenvolvimento de veículos é de grande importância quando se busca redução de massa e bom desempenho em absorção de energia em impactos. Para a barra de pára-choque e a coluna B (Figura 6), por exemplo, o conhecimento de seus limites de funcionalidade estrutural são críticos uma vez que constituem elementos de suma importância para a segurança dos ocupantes. 


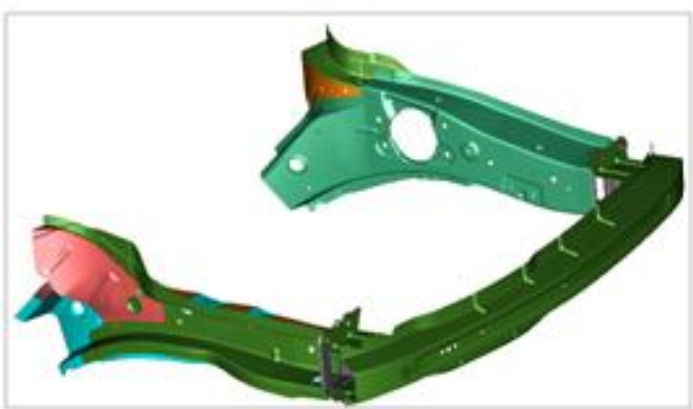

(a)

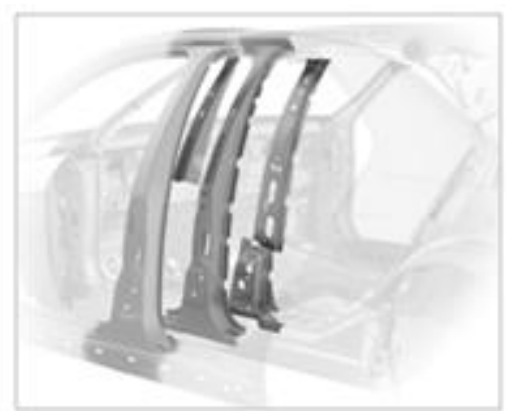

(b)

Figura 6. Elementos estruturais veiculares, (a) barra de pára-choque; (b) conjunto da coluna B.

A barra de pára-choque é responsável pela distribuição de carga em impacto frontal entre as longarinas dianteiras, estabilizando o carregamento das mesmas em casos de impactos angulares e com sobreposição. Dessa maneira tem-se o melhor aproveitamento da estrutura frontal para absorção de energia de impacto. Além disso, a barra de pára-choque também é responsável por transmitir os sinais de desaceleração para os sensores do sistema de airbag. A Figura 7a ilustra uma ocorrência de ruptura das bordas do pára-choque em um ensaio de alta velocidade (56 km/h com sobreposição), neste caso, não houve propagação da trinca devido a existência proposital de um reforço soldado na face interna do pára-choque. $\mathrm{Na}$ Figura 7c, o mesmo acontece em um ensaio de calibração do sistema de airbag no qual simula o atropelamento de um animal.

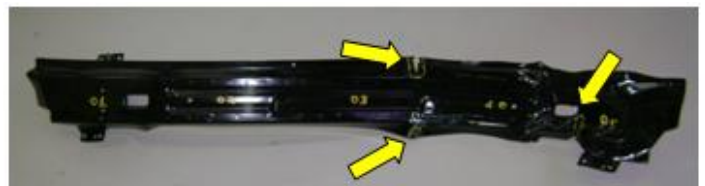

(a)

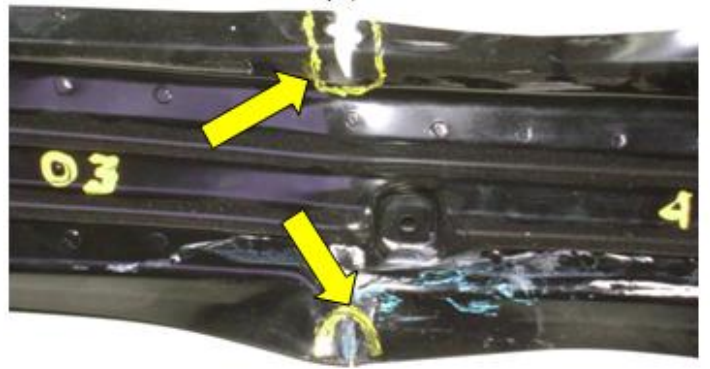

(b)

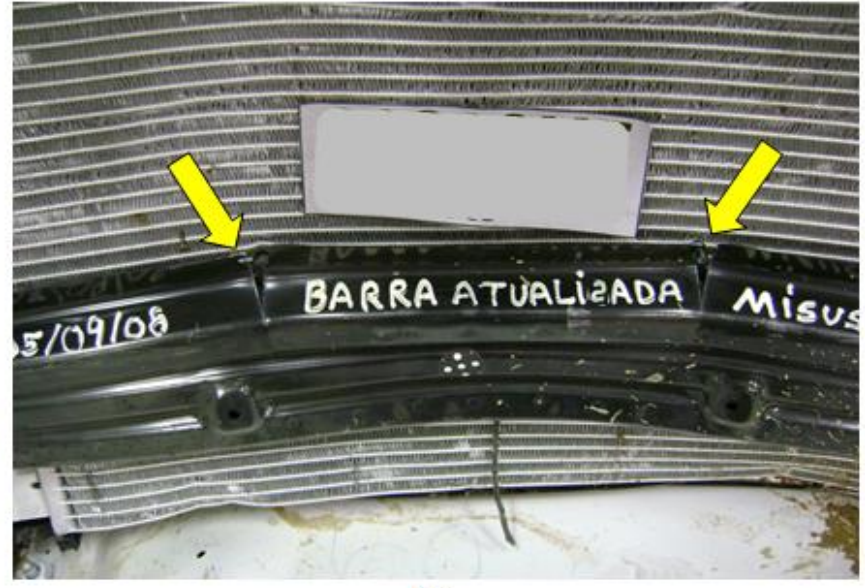

(c)

Figura 7. (a) e (b) protótipo de pára-choque após impacto de alta velocidade; (c) impacto simulando atropelamento de um animal. 
Em resumo, a falha da barra de pára-choque em casos de impacto frontal pode resultar em desempenho ruim do veículo como um todo, desde absorção de energia insuficiente até o não disparo das bolsas infláveis.

Além dos requisitos de desempenho em impactos a alta velocidade, os párachoques também devem ser efetivos na absorção de energia em impactos de baixa velocidade (de 2,4 km/h até $16 \mathrm{~km} / \mathrm{h}$ ). Legislações, normas e procedimentos de avaliações de mercado de diversos países estabelecem requisitos construtivos e de desempenho para o sistema de pára-choques, com foco em redução de danos. Estes procedimentos cobrem desde ensaios de impacto pendular com o veículo em repouso até ensaios de impacto do veículo contra uma barreira com um formato especificado. A barreira da Figura 8 simula um impacto em pára-choque mais alto, de modo a simular um impacto contra um veículo do tipo SUV.

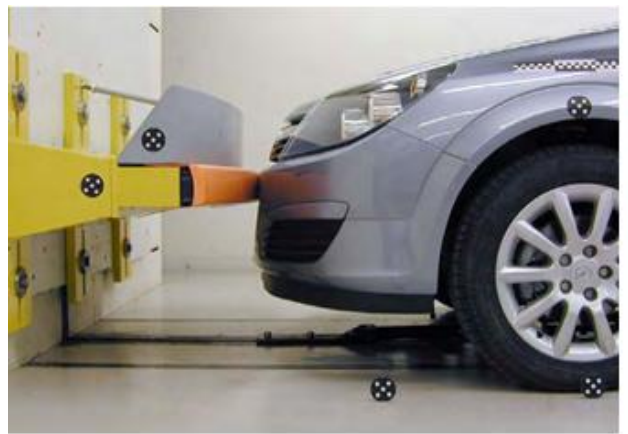

(a)

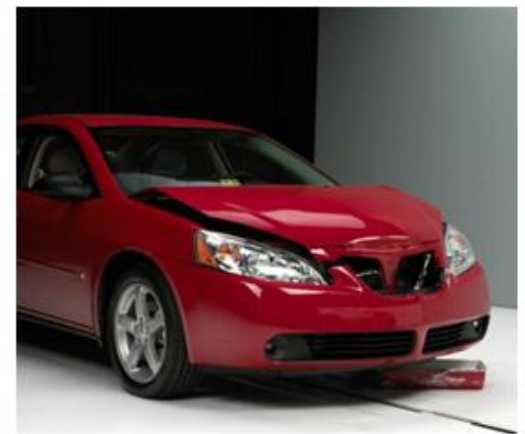

(b)

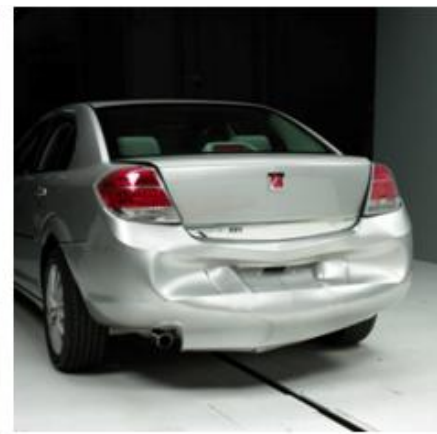

(c)

Figura 8. (a) barreira fixa em forma de pára-choque (7); (b) e (c) resultado pós teste.

Para fins de estudo e análise crítica dos modelos de falha, uma barra de párachoque será testada em um caso de impacto em baixa velocidade através do impacto de um pêndulo. Objetiva-se nesse trabalho a preparação e execução de ensaios deliberadamente severos, que possibilitem a ocorrência de ruptura da peça de modo que os modelos de falha apresentados possam ser avaliados através das simulações numéricas. 


\section{REVISÃO DA LITERATURA}

Diversos materiais aplicados na indústria automotiva e aeroespacial apresentam comportamento inelástico associado a grandes deformações. Na presença dessas grandes deformações, falhas localizadas devem surgir devido ao estiramento do material. Em adição a isso, a indústria em questão tem aplicado cada vez mais materiais leves, e conforme comentado em (8), esses materiais - compósitos alumínio e aços de alta resistência - apresentam baixa ductilidade. Nesses casos a probabilidade de ruptura é alta em eventos de impacto.

Portanto, a predição de falha constitui um grande desafio em diversas aplicações em engenharia. Durante os últimos trinta anos, o avanço da tecnologia, tanto no que se refere ao aparato para testes experimentais quanto à potência de computadores, tornou possível a formulação de modelos de material muito realistas, capazes de mimetizar seu comportamento, estático ou dinâmico, desde o regime elástico até a ruptura, que ocorre, geralmente, a grandes deformações e com mudanças significativas na temperatura, rigidez e resistência do material.

Basicamente, depois de atingido o limite elástico do material, ocorre sua plastificação e encruamento - fenômenos associados ao movimento de discordâncias na rede cristalina - seguido de danejamento - onde ocorre o rompimento de ligações atômicas. Como conseqüência do danejamento, o material perde resistência e rigidez; ocorre crescimento e coalescência de vazios, levando, finalmente, ao surgimento de uma macrotrinca que se propaga até a falha.

O termo "Mecânica do Dano Contínuo" surgiu em 1977 para designar modelos em Mecânica do Contínuo destinados ao estudo da resposta de materiais em regime de danejamento e conseqüente ruptura. Em 1985 as bases teóricas da mecânica do dano contínuo foram apresentadas em (9) em conformidade com os princípios da Termodinâmica dos Processos Irreversíveis. Por outro lado, o crescimento e propagação da trinca são estudados pela Mecânica da Fratura. 
Essencialmente, a diferença entre Mecânica do Dano e Mecânica da Fratura pode ser colocada, segundo (10) apud (11) nos seguintes termos:

- na Mecânica do Dano, a resistência de uma estrutura carregada é determinada em função da evolução de um campo de defeitos continuamente distribuídos;

- na Mecânica da Fratura, a resistência de uma estrutura carregada é determinada em função da evolução de um defeito em particular, como uma fissura pontiaguda pré-definida e o meio em volta da fissura é assumido como mecanicamente intacto.
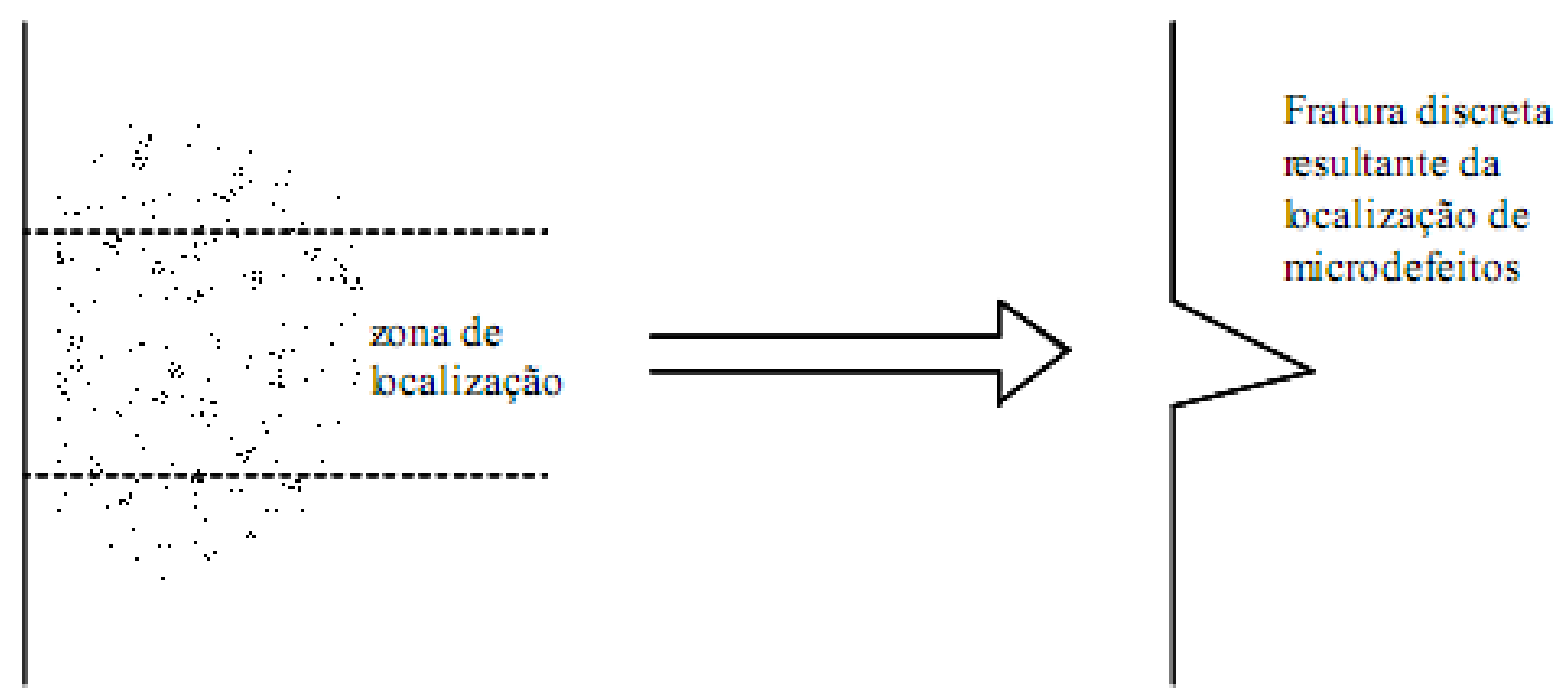

Figura 9. Processo de transição entre Dano e Fratura (11).

Apesar da importância do processo de danificação do material, muitos modelos ignoram esta etapa, e a falha ocorre sem perda de resistência e rigidez do material. Isso ocorre basicamente por dois motivos: primeiramente, alguns materiais se danejam muito pouco antes de falhar, tornando essa etapa desprezível e, por último, porque modelos de dano são muito sofisticados e requerem, em geral, maior número de parâmetros.

O modelo de falha mais simples e popular é o da máxima deformação plástica equivalente, segundo este critério, a falha ocorre quando a deformação plástica equivalente $\bar{\varepsilon}$, dada por 
$\bar{\varepsilon}=\sqrt{\frac{2}{3}} \sqrt{\varepsilon_{1}^{2}+\varepsilon_{2}^{2}+\varepsilon_{3}^{2}}$

atinge um valor crítico $\bar{\varepsilon}_{\text {rup }}$ independente do estado de tensões.

Porém, diversos autores consideram que a falha depende fortemente do estado triaxial de tensões no material. Trabalhos pioneiros de Rice e Tracey (12) demonstraram que a ruptura por coalescência é acelerada por um elevado fator de triaxialidade. $O$ fator de triaxialidade, importante na definição de relações constitutivas de dano, é dado por:

$\eta=\frac{\sigma_{m}}{\bar{\sigma}}$

Onde $\sigma_{m}$ é a tensão hidrostática e $\bar{\sigma}$ a tensão equivalente, ambos são funções das tensões principais $\sigma_{1}, \sigma_{2}$, e $\sigma_{3}$, dados por

$$
\sigma_{m}=\left(\sigma_{1}+\sigma_{2}+\sigma_{3}\right) / 3
$$

e

$\bar{\sigma}=\sqrt{1 / 2\left[\left(\sigma_{1}-\sigma_{2}\right)^{2}+\left(\sigma_{2}-\sigma_{3}\right)^{2}+\left(\sigma_{3}-\sigma_{1}\right)^{2}\right.}$

Ambas ainda podem ser escritas como função dos invariantes do tensor das tensões:

$\sigma_{m}=\frac{I_{1}}{3}$

e

$\bar{\sigma}=\sqrt{2 J_{2}}$

Onde $I_{1}$ é o primeiro invariante do tensor das tensões e $J_{2}$ o segundo invariante da parte desviadora (vide Apêndice B).

Trabalhos mais atuais [ (13), (14), (15), (16), (17), (18) e (19)] confirmam que a falha de materiais dúcteis é dependente não só dos níveis de deformação plástica, mas também do estado de triaxialidade. 
A Figura 10 ilustra a região de ocorrência de falha no plano composto pela deformação equivalente e pela triaxialidade de acordo com o critério da máxima deformação plástica equivalente. Porém, de acordo com os resultados experimentais de Bao e Wierzbicki (18) realizados em alumínio 2024-T351, a relação entre deformação equivalente e triaxialidade é mais complexa ao observar uma gama maior de triaxialidades.

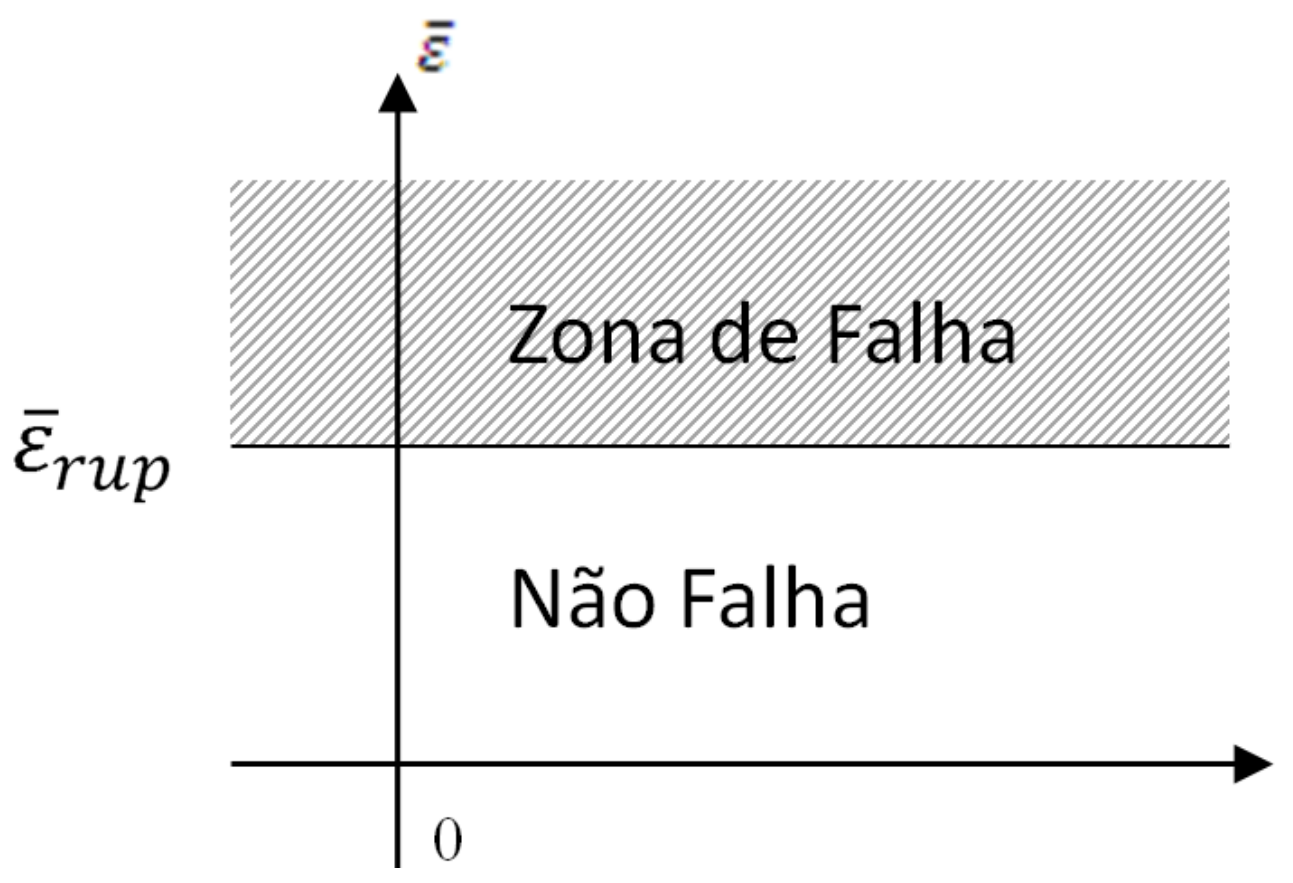

Figura 10. Representação do critério da máxima deformação plástica equivalente.

Resultados experimentais demonstram que ductilidade reduz com o aumento da triaxialidade, levando a conclusão que a tensão hidrostática acelera a nucleação e crescimento de vazios, reduzindo assim o nível de deformação na ruptura. Em adição a isso, temos que para triaxialidades negativas e positivas próximas de zero a falha ocorre tipicamente por cisalhamento. Para triaxialidades positivas elevadas, 0 modo de falha dominante passa a ser por meio de crescimento de vazios. Para triaxialidade negativa elevada $(-1 / 3)$, entretanto, foi observada a existência de um valor limite para o qual a falha não ocorre (20). A Figura 11 ilustra resultados experimentais em comparação o critério empírico de Bao-Wierzbick (18), sendo a 
relação da deformação equivalente de ruptura em função da triaxialidade para uma liga de alumínio.

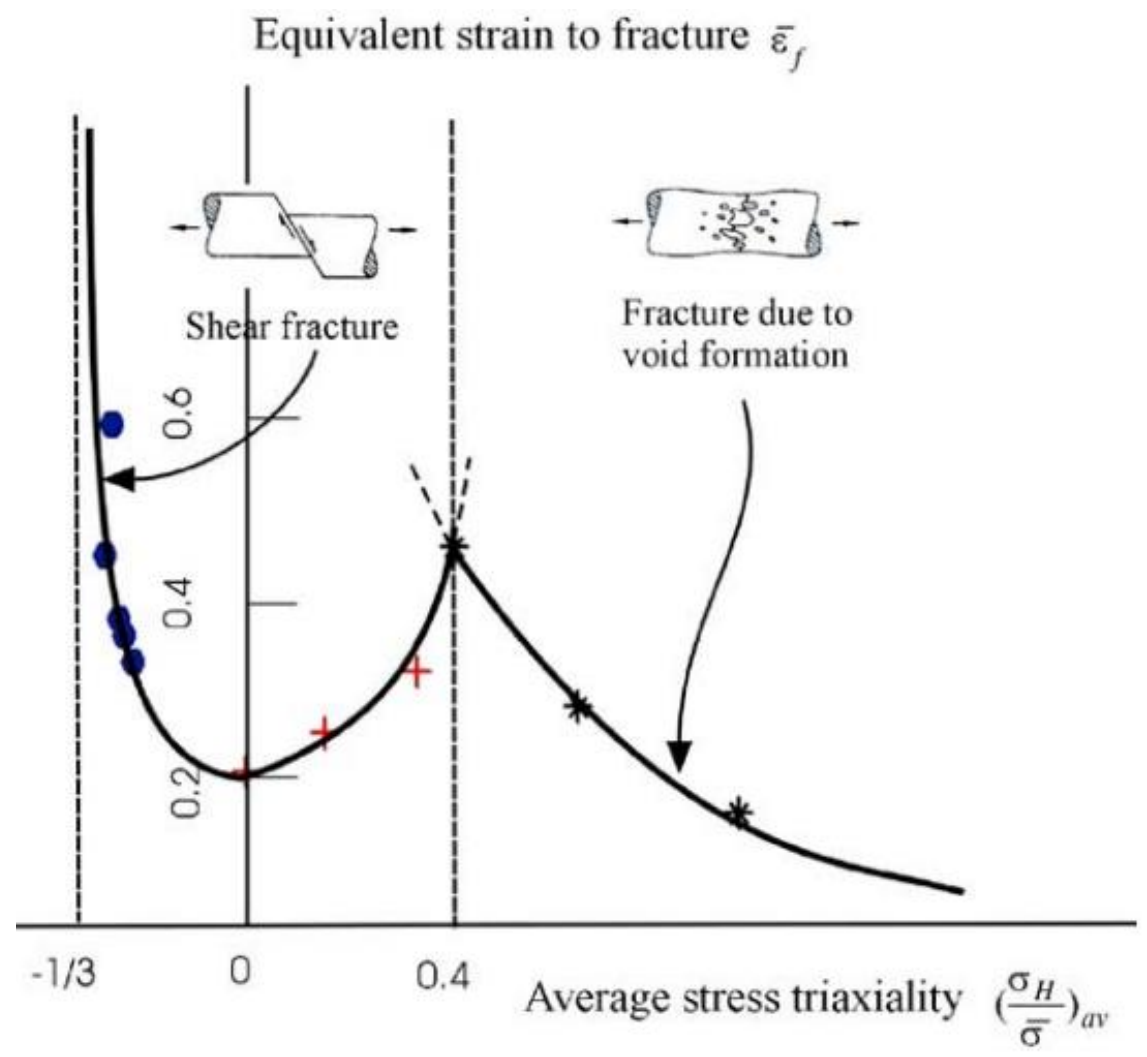

Figura 11. Relação empírica da deformação equivalente de ruptura com a triaxialidade para alumínio 2024-T351 (18).

Quando não se tem dados de ensaios suficientes para construir a curva empírica da Figura 11, Bao-Wierzbicki sugerem a adoção de um valor limite para baixas triaxialidades, conforme ilustrado pela Figura 12, levando a resultados melhores que o critério da máxima deformação plástica equivalente (21).

Além da máxima tensão equivalente, existe também o critério da máxima tensão cisalhante. Este critério considera que a ruptura ocorre no plano de máxima tensão cisalhante, seguindo o princípio de Tresca. No caso, a falha ocorre quando a máxima tensão de cisalhamento atinge um valor crítico. Este critério é usado para materiais frágeis, quando a falha ocorre com pouca deformação plástica, e tem sido aplicado com resultados satisfatórios em estudos de mecânica dos solos (22). Em 
(17), este é considerado o melhor método também para materiais dúcteis como alumínio quando boa previsão e número de experimentos são considerados, uma vez que traz informações do segundo e terceiro invariantes do tensor das tensões.

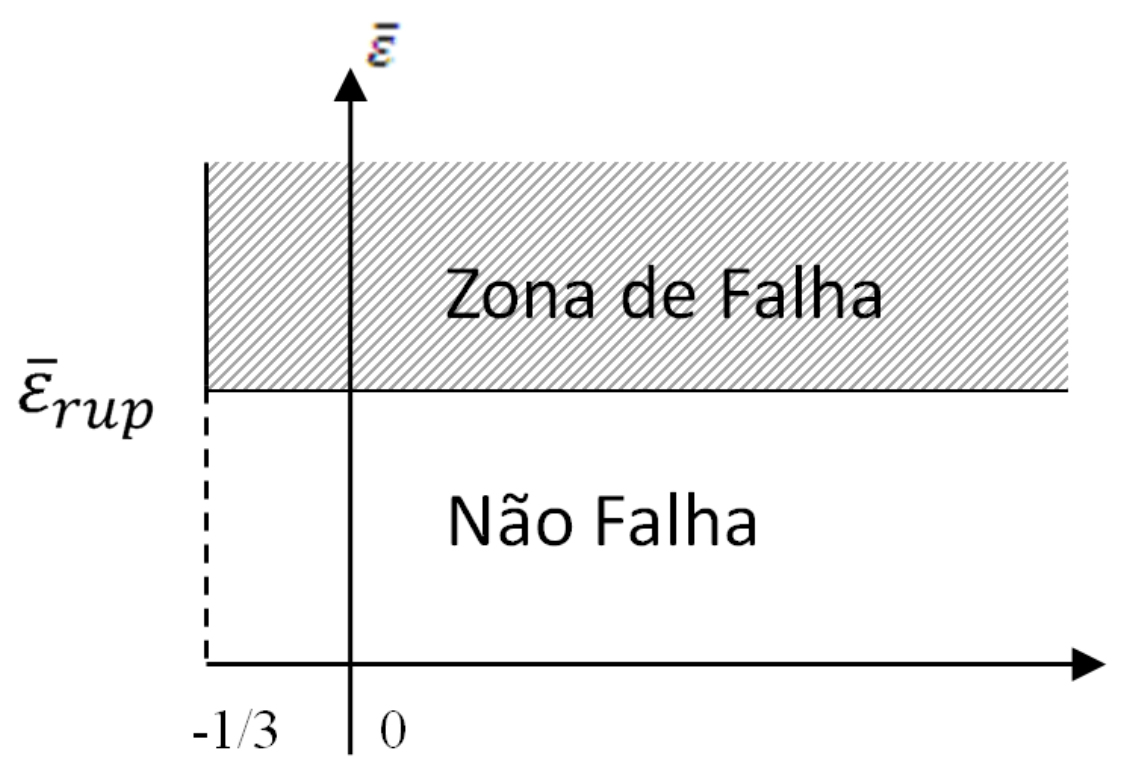

Figura 12. Representação do critério simplificado de Bao-Wierzbicki (18).

Em ordem crescente de complexidade após o critério de máxima deformação plástica equivalente, podemos citar os modelos que incluem um dano permanente do material devido à micro-fissuração, sendo esta cumulativa linearmente até a formação da falha, como Johnson \& Cook (23) e Wilkins et.al. (24).

Desenvolvimento posterior de modelos com variável de dano leva à Mecânica do Dano Contínuo, já comentado no início deste capítulo. Neste caso a variável de dano é inserida na lei constitutiva, representando a deterioração do material desde o início do escoamento. O dano resulta na perda de rigidez, possibilitando que a falha se inicie nessa região danificada. Em geral, esses modelos consideram a triaxialidade na evolução do dano e, como exemplo, podemos citar Lemaitre (9), Mirone (25), Brunig (26)- (27) e X-W (17).

Recentemente, diversos trabalhos de Wierzbicki et. al. (18) e (17) observaram experimentalmente e numericamente a importância do estado de triaxialidade para a 
formação da ruptura, e neste sentido, propondo novos critérios, como o empírico de Bao-Wierzbicki comentado anteriormente. Porém, somente a triaxialidade não é suficiente para representar todos os modos de falha. O modelo de Xue-Wierzbicki, apresentado em (28) e resumido em (17) considera ainda o ângulo de Lode, mais conhecido como terceiro invariante do tensor das tensões. Neste caso, todos os estados de tensão possíveis podem ser descritos, ao contrário dos modelos anteriores onde a triaxialidade corresponde apenas aos dois primeiros invariantes do tensor das tensões (vide Apêndice B). Para este modelo, temos que o dano não linear e calculado através da chamada "decomposição cilíndrica" (28). A Figura 13 ilustra o plano de ruptura, agora representado por três eixos, adicionando-se o parâmetro relacionado ao terceiro invariante $\xi$.

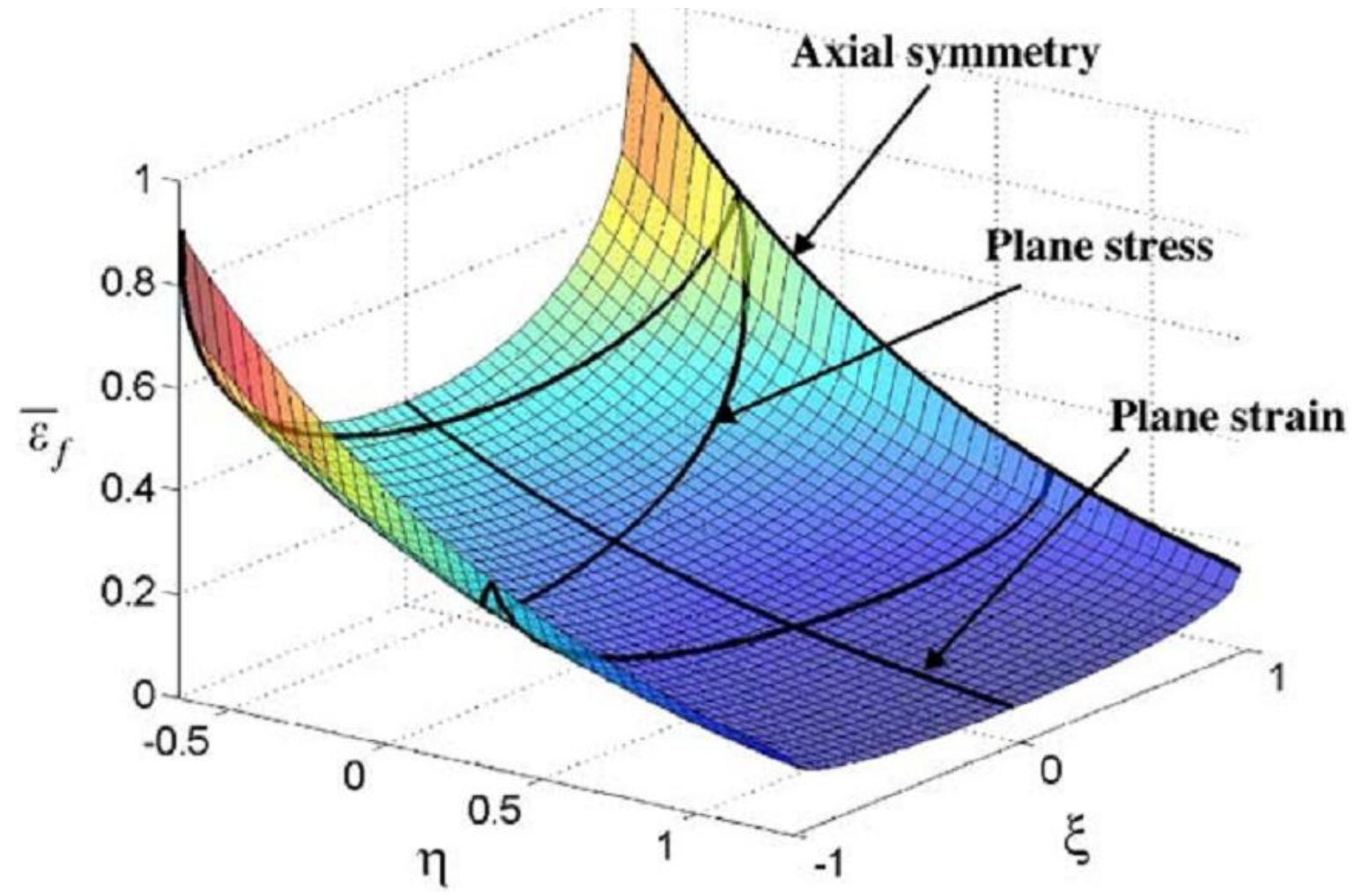

Figura 13. Representação da ocorrência de ruptura em função da triaxialidade e parâmetro de Lode (17).

O modelo de Xue-Wierzbicki é recente e pouco explorado em estudos na área. Mirone e Corallo (29) exploraram este modelo em ensaios experimentais e análises numéricas em barras circulares e placas com entalhe com o intuito de verificar a 
influência do parâmetro de Lode no processo de danejamento do material. Foi verificado que o parâmetro de Lode influencia consideravelmente a evolução do encruamento do material no regime plástico, porém pouca influência no processo de danejamento na faixa de triaxialidade estudada.

Além de pouco explorado, a implementação do modelo de Xue-Wierzbicki em software de elementos finitos ainda é um trabalho em andamento. Dessa forma, este modelo ainda é indisponível para uso industrial.

Outro tipo de modelo de falha é o micro-mecânico, nestes modelos o comportamento macroscópico da estrutura é resultado do crescimento de vazios no material. Nestes modelos, os parâmetros necessários para calibração do material independem da geometria do espécime. Como exemplo de modelos micromecânicos, podemos citar Gurson (29), posteriormente modificado por Needleman e Tvegaard (30). A limitação desse modelo reside no fato de não representar falha por cisalhamento, essa limitação foi posteriormente reduzida por Gologanu (31) ao considerar a evolução do formato e orientação de vazios.

Dada a complexidade e insuficiência de resultados experimentais, assim como 0 modelo de Xue-Wierzbicki, os modelos de Gurson e Wilkins não serão abordados neste trabalho, uma vez que o objetivo é de avaliar a praticidade e aplicabilidade dos modelos de falha disponíveis em softwares comerciais utilizados na indústria.

\subsection{Aplicações Práticas de Modelos de Falha}

Diversos estudos têm sido realizados pela indústria em conjunto com universidades objetivando a aplicabilidade e eficácia dos modelos de falha em casos específicos, assim como tentando diminuir as dificuldades práticas de obtenção das constantes e propriedades do material requeridas por cada modelo. Atualmente, a aplicação dos modelos de falha em simulações tem se mostrado útil em casos de balística, projetos de componentes automotivos sujeitos a falha em impactos como párachoques, coluna $B$, barra de impacto lateral das portas, simulações em processos de 
fabricação como estampagem de chapas metálicas e outras aplicações para colisões em baixa velocidade.

O critério da máxima deformação plástica equivalente é amplamente empregado durante as fases iniciais de desenvolvimento de veículos dada sua praticidade (32). Em (33), diferentes seções de barras de proteção lateral de porta em aço de alta resistência foram ensaiados até a ocorrência de falha em um teste de flexão em três pontos, o mesmo carregamento foi simulado em LS-Dyna ${ }^{\circledR}$ considerando dois modelos de materiais distintos, porém com mesmo limite de deformação. As discrepâncias observadas entre resultados experimentais e simulações foram de $0 \%$ a 50\%, além disso, a deformação de ruptura também se mostrou sensível ao tamanho do elemento utilizado ( $2 \mathrm{~mm}, 4 \mathrm{~mm}$ e $8 \mathrm{~mm}$ ).

Componentes automotivos foram ensaiados e simulados em (19) explorando os modelos de falha de Gurson e Johnson-Cook. No estudo em questão, lâminas de pára-choque estampadas e outro componente em metal fundido, ambos em alumínio, foram submetidos a ensaios de flexão até a formação e propagação da falha. Foi observado que o modelo micro-mecânico de Gurson foi capaz de representar a falha em triaxialidades da ordem de 1,5 com parâmetros do material obtidos somente de ensaios de tração, enquanto que o modelo de $\mathrm{J}-\mathrm{C}$ necessitou de ensaios adicionais para caracterizar a falha na mesma faixa de triaxialidade, conforme ilustrado na Figura 14. Neste caso, o fator de triaxialidade observado na região da falha foi de cerca de 1,5 e os parâmetros de J-C não foram calibrados em ensaios nesse nível de triaxialidade.
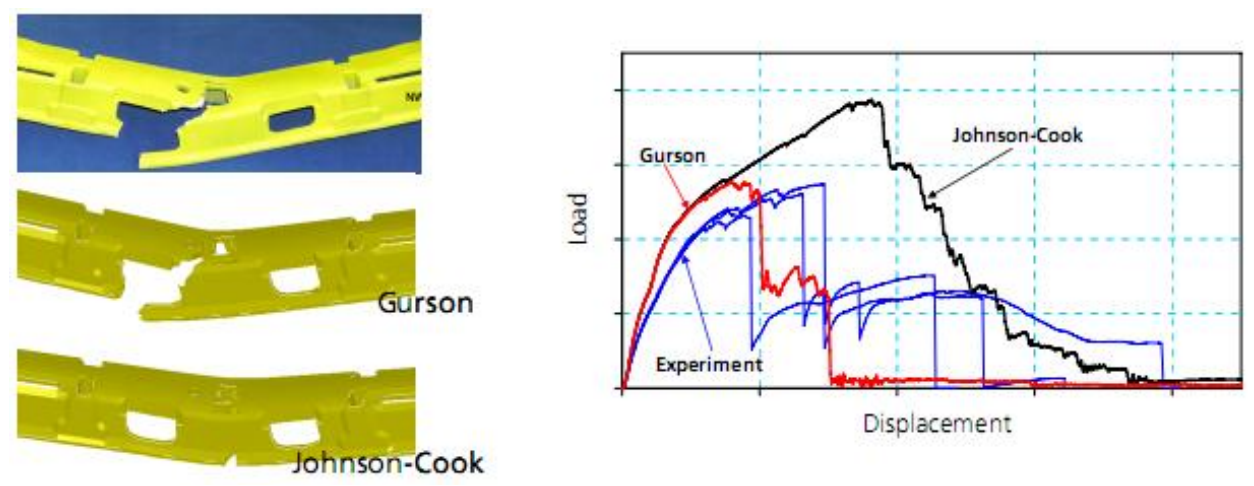

Figura 14. Comparativo entre o ensaio físico e os modelos de Gurson e J-C (19). 
A predição de falha também foi extensivamente analisada utilizando-se de diversos modelos e critérios em (8), aplicando-os em casos comumente vistos em projetos de veículos (Figura 15). Neste trabalho, além de Gurson, Gologanu, Wilkins e Lemaitre entre outros critérios foram abordados, como o chamado $\mathrm{CRACH}$, baseado no modelo de instabilidade de Marciniak (34). Novamente, para o modelo de Gurson foi observado que a falha ocorre apenas por tensão hidrostática, isto é, cisalhamento não é considerado.
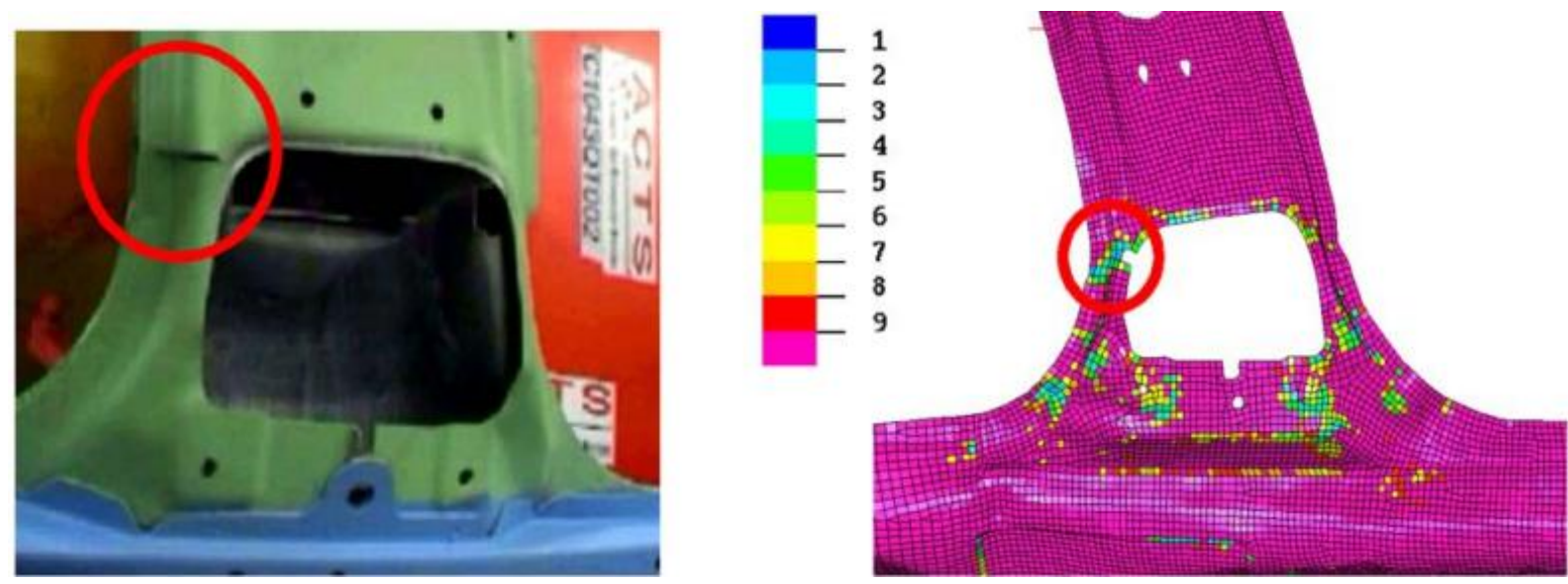

Figura 15. Simulação de impacto lateral utilizando algoritmo CRACH (8).

Aplicações em construção civil off-shore de estruturas em alumínio motivou estudo de perfuração quase-estática de chapas. Em seu trabalho, Grytten et. al. (14) realizou diversos ensaios de perfuração quase-estática, comparando com resultados de simulação utilizando-se de elementos sólidos e de casca, ambos com o modelo de J-C (Figura 16). Qualitativamente foi observada boa correlação entre os ensaios e as simulações, porém, para dados quantitativos as discrepâncias foram mais significativas. A curva força $x$ deslocamento, por exemplo, foi sistematicamente mais elevada nas simulações do que nos testes, indicando que o modelo de $\mathrm{J}-\mathrm{C}$ superestima a ductilidade para a liga de alumínio em estudo. 

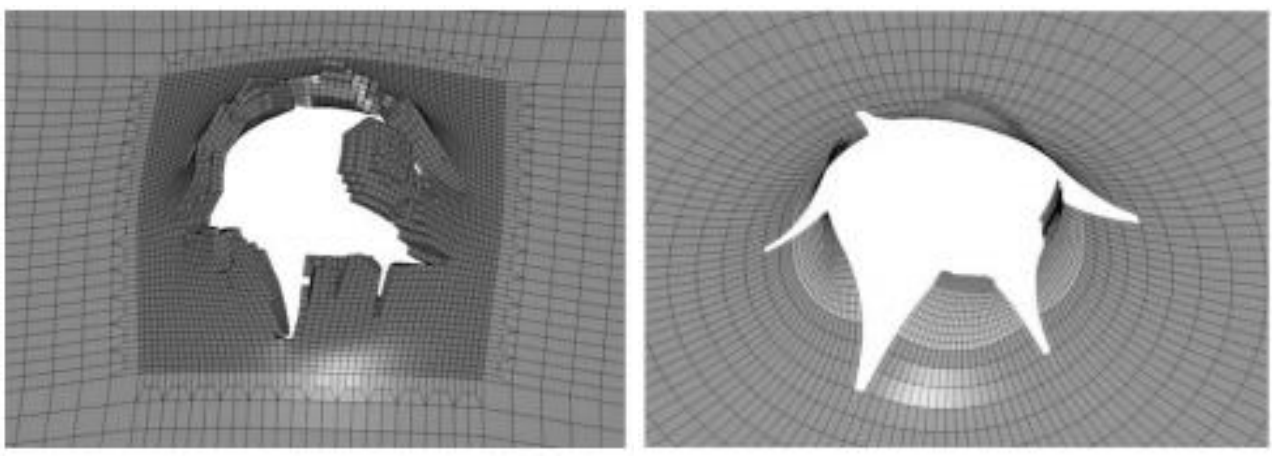

Figura 16. Modos de falha em elementos sólidos e de casca respectivamente (14).

Comportamento de estruturas sob impacto balístico, por sua vez, é de grande interesse na indústria da defesa. Em (16), casos de balística ensaiados em (15) foram simulados com elementos $2 \mathrm{D}$ axissimetricos com relação constitutiva de $\mathrm{J}-\mathrm{C}$, neste caso, um furo foi adicionado no ponto de impacto de modo a permitir o crescimento dúctil da perfuração sem a necessidade de um critério de falha. Os resultados foram comparados também com modelo analítico conhecido como CET (Cavity-Expansion Theory). Ambos os resultados, tanto numérico quanto analítico, foram não conservativos, isto é, previram um limite balístico superior ao verificado nos ensaios físicos. A modelagem axissimetrica foi apontada como um dos fatores para o desvio, uma vez que esse tipo de elemento não pode representar falhas radiais.

Kurtaran et. al. (35) simularam o comportamento balístico da porta em aço 4340 de um veículo militar, disparando um projétil a até $1500 \mathrm{~m} / \mathrm{s}$ contra uma chapa metálica. Modelos de material com modelo de falha de $\mathrm{J}-\mathrm{C}$ e plástico cinemático (plastic kinematic hardening) foram confrontados. Foi observado que os padrões de deformação tanto da bala quanto da chapa variam de acordo com o modelo de material utilizado. O modelo plástico cinemático não é tão sofisticado quanto o de JC uma vez que este último considera a evolução do dano durante a ruptura e efeitos de temperatura na dureza do material, provando que os efeitos da temperatura influenciam na configuração deformada do material.

Modelos de falha também têm sido aplicados em simulações de estampagem de chapas metálicas, principalmente para a indústria automotiva. Para essas aplicações, gráficos como o FLD (Forming Limit Diagram) são utilizados. Neukamm 
et.al (36) comparou modelos de falha utilizados em simulações de estampagem com modelos aplicados em simulações de impacto veicular. Em adição, ensaios de Nakazima utilizados para compilar o FLD de um dado material foram simulados. Nesses casos as triaxialidades vão de um estado de tensão de tração uniaxial para chapas de espessuras finas a tração equi-biaxial para espessuras maiores. Foram realizadas simulações com elementos de casca e elementos sólidos com o objetivo de verificar a aplicabilidade da hipótese de tensões planas para os ensaios de Nakazima. Por meio de gráficos de triaxialidade ao longo do tempo durante o ensaio, foi possível verificar no modelo em elementos sólidos que a triaxialidade não é constante ao logo do teste.

Além das aplicações citadas acima, critérios de falha também têm sido avaliados em casos de biomecânica. Em (37), por exemplo, o critério da máxima deformação equivalente foi confrontado com critérios de falha baseados em tensão de Von Mises e da máxima tensão principal. Para este caso, espécimes de ossos de fêmur foram avaliados através de ensaios físicos de compressão e simulações em elementos finitos. O estudo identificou que o critério da máxima deformação equivalente apresentou resultados melhores que os critérios baseados em tensão, indicando mais precisamente o local da falha. 


\section{CRITÉRIOS DE FALHA DA LITERATURA}

Neste capítulo os critérios de falha e modelos de dano de maior relevância da literatura serão abordados. Alguns são critérios de falha já consolidados e amplamente utilizados na indústria, como o Critério da Máxima Deformação Plástica Equivalente, Máxima Tensão Cisalhante, outros são mais comuns no meio acadêmico, como o modelo de Wilkins, Johnson-Cook e os recentes modelos de Xue-Wierzbicki. Modelos que incluem dano na lei constitutiva do material como o modelo de Lemaitre e Gurson também serão abordados, porém, com caráter informativo.

\subsection{Critério da Máxima Deformação Plástica Equivalente}

Trata-se de um dos modelos mais populares e utilizados atualmente para prever falha de estruturas. Segundo este modelo, a falha ocorre quando a deformação equivalente $\bar{\varepsilon}$ de um dado elemento atinge um valor critico $\bar{\varepsilon}_{\text {rup }}$. Para um material incompressível, $\bar{\varepsilon}$ é dado pela eq.(1), reescrita aqui por conveniência:

$$
\bar{\varepsilon}_{\text {rup }}=\sqrt{\frac{2}{3}} \sqrt{\varepsilon_{1}^{2}+\varepsilon_{2}^{2}+\varepsilon_{3}^{2}}
$$

Tipicamente, o valor de $\bar{\varepsilon}_{\text {rup }}$ é obtido através de um ensaio de tração uniaxial. Este critério é muito usado na prática, pois, além de sua simplicidade, permite a identificação das potenciais zonas de falha no material. 


\subsection{Critério da Máxima Tensão Cisalhante}

O critério da máxima tensão cisalhante é derivado do critério de escoamento de Tresca, que define que o escoamento inicia no plano onde ocorre a máxima tensão de cisalhamento. Assim sendo, assume-se que a falha ocorre quando a tensão cisalhante atinge um valor crítico $\left(\tau_{m a ́ x}\right)_{f}$.

A máxima tensão cisalhante é calculada a partir das tensões principais conforme se segue:

$\left(\tau_{m a ́ x}\right)_{f}=\tau_{m a ́ x}=\operatorname{máx}\left\{\frac{\sigma_{1}-\sigma_{2}}{2}, \frac{\sigma_{2}-\sigma_{3}}{2}, \frac{\sigma_{3}-\sigma_{1}}{2}\right\}$

O único parâmetro do modelo é $\left(\boldsymbol{\tau}_{m a ́ x}\right)_{f}$, que pode ser obtido, preferencialmente, com ensaios de cisalhamento puro.

Em (21), o critério da máxima tensão cisalhante foi aplicado a casos de perfuração de chapas em alta velocidade. Neste caso, a calibração foi realizada através de engenharia reversa, estimando o valor de $\left(\tau_{m a ́ x}\right)_{f}$ através da velocidade residual do projétil, sendo que a calibração encontrada não foi validada por meio de outro ensaio. O mesmo trabalho conclui ainda que este critério de falha é insuficiente para casos de falha em impacto de alta velocidade, uma vez que esse tipo de carregamento o material sofre perda de rigidez por aquecimento, como resultado, a tensão máxima cisalhante observada cresce até atingir um valor máximo e depois decresce em função da deformação plástica equivalente. Porém, há autores (17) que afirmam a eficácia deste critério para casos de tensão ou deformação planas, indicando ainda que este critério considera informações do segundo e terceiro invariante do tensor das tensões. 


\subsection{Modelo de Dano de Johnson-Cook}

O modelo de falha de Johnson-Cook (23) estabelece que a deformação limite $\overline{\varepsilon_{f}}$ é uma função exponencial da triaxialidade,

$\bar{\varepsilon}_{\text {rup }}=\left[D_{1}+D_{2} \cdot e^{\left(D_{3} \eta\right)}\right] \cdot\left(1+D_{4} \cdot \ln \dot{\varepsilon}\right) \cdot\left(1+D_{5} \cdot T^{*}\right)$,

onde $D_{1}, D_{2}, D_{3}, D_{4}$ e $D_{5}$ são constantes do material. O modelo assume ainda que o dano é acumulado linearmente, sendo a razão entre a deformação plástica atual e a deformação plástica na ruptura, e a falha ocorre quando o dano $D$ atinge $o$ valor critico $D_{c r}=1,0$.

$D=\int_{0}^{\bar{\varepsilon}} \frac{1}{\bar{\varepsilon}_{\text {rup }}} d \varepsilon$

Devido à grande disponibilidade de constantes para diversos metais (38), o critério de Johnson-Cook tem sido largamente utilizado em diversos trabalhos.

São necessários ao menos três ensaios de tração a diferentes triaxialidades para calcular as constantes, sendo por sua vez necessário conhecer o estado de tensões do espécime na região de ocorrência de falha, no momento de ocorrência da mesma. Figura 17 ilustra o plano de ruptura obtido por (21) através de ensaios de tração em barras circulares de aço com diferentes entalhes.

Uma maneira de se conhecer o estado de tensões é através da execução de simulações numéricas dos testes de tração. Geralmente considera-se que a triaxialidade calculada numericamente representa o estado triaxial real do espécime quando os resultados numéricos e experimentais são semelhantes. O problema que reside nesse tipo de abordagem é que a simulação dificilmente apresentará boa coincidência com os resultados experimentais depois que a tensão máxima foi atingida. Isso porque ocorre dano no material à medida que o espécime começa a apresentar empescoçamento. Em um teste de tração, o dano pode ser verificado pela redução da tensão de engenharia após o início do empescoçamento. Além disso, para definir um modelo de dano é necessário caracterizar os parâmetros do 
material. Isso acarreta em problemas iterativos ou ensaios especiais de tração com descarregamento, que não são os objetivos deste trabalho.

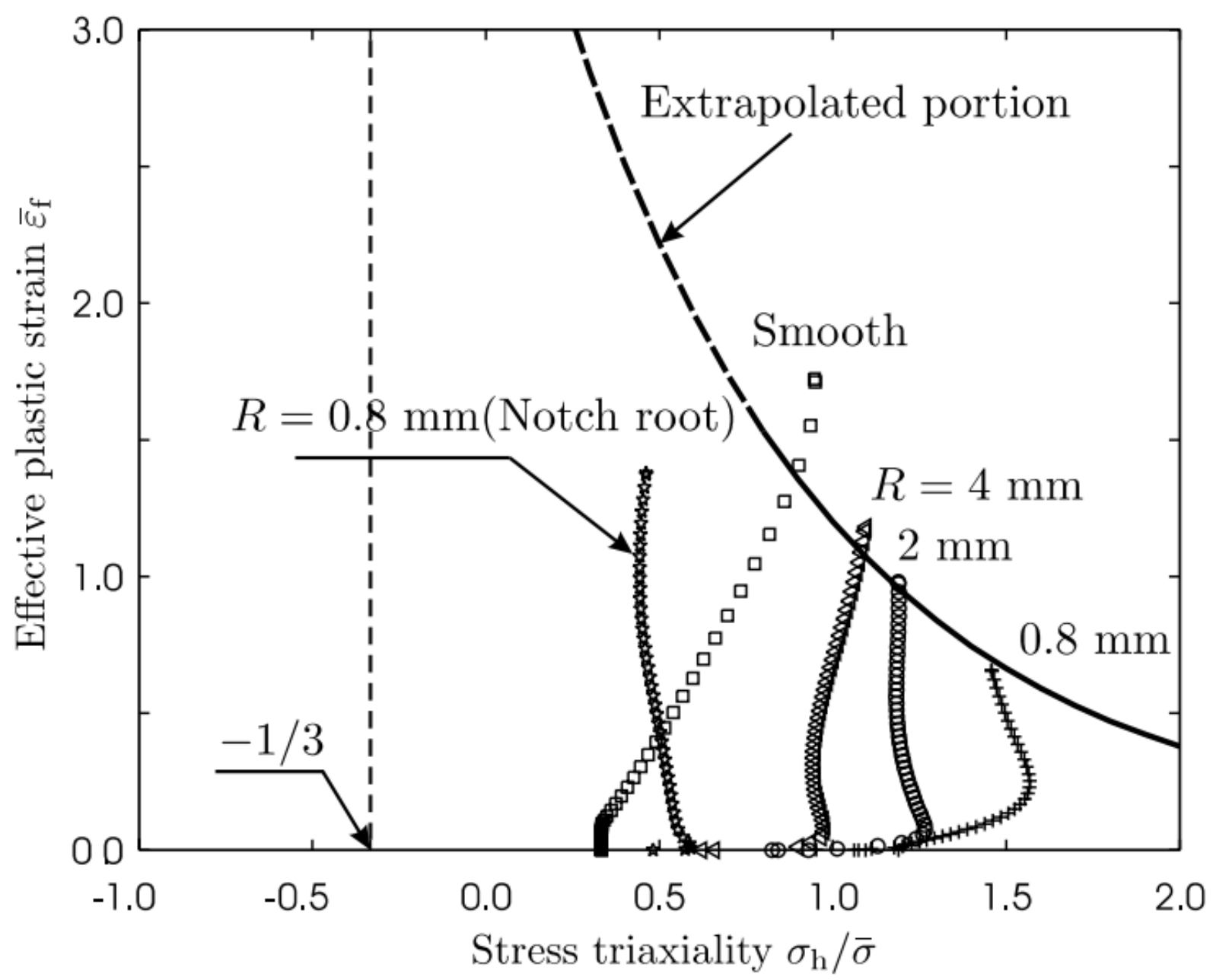

Figura 17. Deformação de ruptura em função do fator de triaxialidade considerando o critério de J-C (21).

Além disso, a calibração do modelo pode ser dificultada, uma vez que a triaxialidade varia durante o carregamento. Esse fenômeno também é ilustrado pela Figura 17 pela evolução da triaxialidade durante a aplicação da carga, para cada espécime. Temos ainda que aplicabilidade da eq.(8) em faixas de triaxialidade baixas e até mesmo negativas é arriscada uma vez que dados desses níveis de triaxialidade foram pouco abordados na literatura (17). 


\subsection{Modelo de Dano de Wilkins}

O modelo de falha de Wilkins et. al (24) consiste em uma integral da deformação plástica com dois pesos $w_{1}$ e $w_{2}$, relacionados com a pressão hidrostática e a tensão desviadora respectivamente.

$D=\int_{0}^{\bar{\varepsilon}} w_{1} \cdot w_{2} \cdot d \varepsilon, \quad$ em $R_{c r}$

$w_{1}=\left(\frac{1}{1-\alpha \sigma_{m}}\right)^{\gamma}$

e

$w_{2}=(2-A)^{\beta}$

Onde $D$ é a variável de dano, $\alpha, \gamma$ e $\beta$ são constantes do material e $A$ é a máxima razão entre as tensões principais desviadoras. $R_{c r}$ corresponde à dimensão crítica da zona de ruptura, em aplicações em elementos finitos, essa dimensão é associada ao tamanho do elemento.

$A=\max \left(\frac{s_{2}}{s_{3}}, \frac{s_{2}}{s_{1}}\right), \quad s_{3} \leq s_{2} \leq s_{1}$

A falha ocorre quando $D$ atinge um valor crítico $D_{c r}$, relacionado às características do material e independente das condições do carregamento, geometria ou tamanho do corpo.

As constantes detalhadas acima devem ser determinadas através de no mínimo quatro ensaios (17) também a diferentes triaxialidades, de modo a termos um sistema de quatro equações e quatro incógnitas $\left(D_{c r}, \alpha, \gamma\right.$ e $\left.\beta\right)$. A Figura 18 ilustra o plano de ruptura para uma liga de alumínio (2024-T351) através das equações e resultados experimentais. 


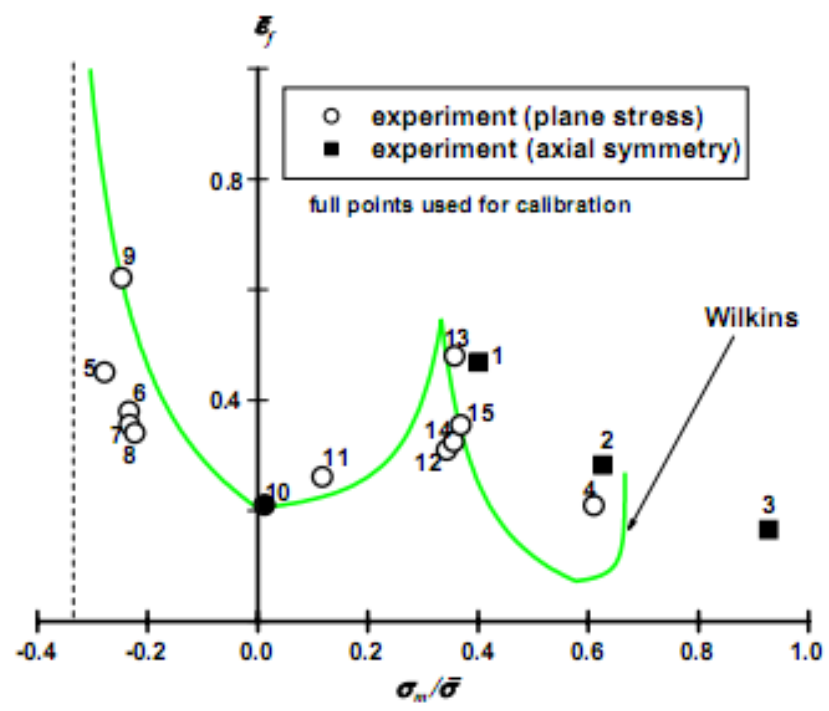

Figura 18. Deformação de ruptura em função do fator de triaxialidade considerando o critério de Wilkins (17).

\subsection{Modelo de Dano de Lemaitre}

O modelo de Lemaitre está inserido no contexto da mecânica do contínuo. A variável de dano contribui para perda de rigidez do material. No caso unidimensional, a lei constitutiva é escrita na forma,

$\sigma=(1-D) \varepsilon$

significando que, para valores de $D$ igual a 0 , o material é íntegro, e para valores de dano $D$ igual $D_{c r}$, ocorreu falha. No caso bidimensional, o modelo original foi proposto considerando hipótese de dano isotrópico, e, portanto, $D$ continua sendo uma variável unidimensional. Posteriormente, o modelo foi estendido para problemas anisotrópicos (8), de modo que o dano passa a ser representado por um tensor.

Por estar inserido na lei constitutiva do material, diferente dos modelos de dano de Wilkins e J-C, o modelo de dano de Lemaitre é chamado de modelo acoplado.

A teoria é dada em (9), e resumida a seguir. O início do dano ocorre quando $\bar{\varepsilon}>\varepsilon_{D}$ conforme 
$\dot{D}=\frac{\bar{\sigma}^{2} \cdot R_{v}}{2 E \bar{S}} \cdot \dot{\bar{\varepsilon}}$

Onde $\bar{\sigma}$ e $\bar{\varepsilon}$ são as tensões e deformações equivalentes, $E$ é o módulo de elasticidade e $\bar{S}$ é uma constante do material. Além disso,

$R_{v}=\frac{2}{3} \cdot(1+v)+3 \cdot(1-2 v) \cdot \eta^{2}$

Onde $v$ é o coeficiente de Poisson. Os parâmetros do modelo de Lemaitre são determinados por meio de ensaios de tração com monitoramento da degradação do módulo de elasticidade, conforme detalhado em (6) e (39).

\subsection{Modelo de Dano de Gurson / Tvergaard Needleman}

No modelo de Gurson a taxa de nucleação de vazios é dada por uma distribuição Gaussiana sobre as deformações plásticas. A deformação plástica média $\varepsilon_{N}$, a fração de volume de vazios $f_{N}$ e o desvio padrão da distribuição Gaussiana $S_{N}$, são os três parâmetros a serem encontrados. O aumento dos vazios é controlado pela deformação plástica e o estado hidrostático de tensões. Com relação aos vazios, alguns parâmetros ainda são necessários, como o estado inicial de vazios $f_{0}$, a fração de volume crítico de vazios no início da coalescência $f_{C}$ e a fração crítica de vazios no momento em que a falha ocorre $f_{F}$. De acordo com (8), técnicas de engenharia reversa são utilizadas para determinar esses parâmetros, correlacionando testes físicos com simulação. O modelo de Gurson é uma formulação quadrática do potencial plástico, que também pode ser usado como função de escoamento, na qual $\sigma_{e q}$ é a tensão equivalente, $\sigma_{M}$ é a tensão elastoviscoplástica e $\sigma_{m}$ é a tensão média, $q_{1}$ e $q_{2}$ são constantes do material e $f^{*}$ a função adicionada por Tvergaard e Needleman (30) para prever a instabilidade causada pela coalescência de micro vazios.

$\Phi_{e v p}=\frac{\sigma_{e q}^{2}}{\sigma_{m}^{2}}-\varphi=0$ 
onde

$\varphi=1+\left(q_{1} \cdot f^{*}\right)^{2}-2 \cdot q_{1} \cdot f^{*} \cosh \left(\frac{3}{2} \cdot \frac{q_{2} \cdot \sigma_{m}}{\sigma_{M}}\right)$

$f^{*}=\left\{\begin{array}{r}f, f_{C} \leq f \\ f_{C}+\frac{\left(1 / q_{1}-f_{C}\right)}{f_{F}-f_{C}} \cdot\left(f-f_{C}\right), f>f_{C}\end{array}\right.$

A taxa de fração volumétrica é dada por

$\dot{f}=\dot{f}$ cres $+\dot{f}$ nucleação

Onde o crescimento de vazios existentes é dado por

$\dot{f}$ cres $=(1-f) \cdot \dot{\varepsilon_{k k}}$

e a nucleação de vazios, que é controlada pela deformação plástica é dada por

$\dot{f}$ nucleação $=\frac{f_{N}}{S_{N} \sqrt{2 . \pi}} \exp \left[-\frac{1}{2} \cdot\left(\frac{\varepsilon_{M}-\varepsilon_{N}}{S_{N}}\right)^{2}\right] \dot{\varepsilon}_{M}$

Uma das desvantagens do modelo de Gurson é a numerosa quantidade de parâmetros a serem determinados $\left(\varepsilon_{N}, S_{N}, q_{1}, q_{2}, f_{N}, f_{0}, f_{F}\right)$, além do mais, conhecidamente este modelo não representa falhas por cisalhamento conforme adiantado no Capítulo 0. Dada essas limitações e baixa praticidade quando se objetiva sua aplicação direta, o modelo de Gurson não será abordado neste trabalho.

\subsection{Modelo de Dano de Xue-Wierzbicki}

O modelo de falha de X-W é recente, e ainda não disponível em softwares comerciais. Segundo Wierzbicki et al (17), a falha ocorre quando a deformação plástica equivalente, alterada por uma função da triaxialidade $\eta$ e de um parâmetro desviador $\xi$, atinge um valor limite. 
$\bar{\varepsilon}=\int_{0}^{\overline{\varepsilon_{f}}} \frac{d \bar{\varepsilon}}{F(\eta, \xi)}=1$

O parâmetro そ refere-se ao ângulo de Lode, e é definido por:

$\xi=\frac{27 \cdot J_{3}}{2 \bar{\sigma}^{3}}$

onde $J_{3}$ é o terceiro invariante do tensor das tensões. Os valores de $\eta$ e $\xi$ utilizados são médios, uma vez que estes variam ao longo do carregamento.

Para o cálculo da função $F(\eta, \xi)$, uma série de hipóteses são tomadas por Wierzbicki et al. A deformação de ruptura ocorre sempre dentro de um limite superior, sendo este o estado de tensão axissimétrico $(\xi=1)$ e um limite inferior, sendo o estado plano de deformação $(\xi=0)$. Sendo assim, é possível definir a deformação em estados distintos de $\xi$ como sendo:

$\bar{\varepsilon}_{\text {rup }}{ }^{\text {axi }}=C_{1} e^{-C_{2} \eta}, \xi=1$

e

$\bar{\varepsilon}_{\text {rup }}^{p s}=C_{3} e^{-C_{4} \eta}, \xi=0$

onde $C_{i}$ são parâmetros do material e $\bar{\varepsilon}_{\text {rup }}{ }^{a x i}$ e $\bar{\varepsilon}_{\text {rup }}{ }^{p s}$ são os valores de deformação equivalente na ruptura, nos estados limites, para diferentes triaxialidades $\eta$.

Para obter os valores intermediários das curvas de deformação para outras combinações de $(\eta, \xi)$ deve-se considerar um plano $\eta$ igual a uma constante. A variação da deformação $\Delta \bar{\varepsilon}_{r u p}$ devido a $\xi$ é descrito pela função elíptica abaixo:

$\left(\frac{\Delta \bar{\varepsilon}_{r u p}}{\bar{\varepsilon}_{r u p}{ }^{a x i}-\bar{\varepsilon}_{r u p}{ }^{p s}}\right)^{1 / \mathrm{m}}+\xi^{1 / \mathrm{m}}=1$

Sendo

$\bar{\varepsilon}_{\text {rup }}=\bar{\varepsilon}_{\text {rup }}{ }^{\text {axi }}-\Delta \bar{\varepsilon}_{\text {rup }}$

Onde $m$ é o integrador ímpar mais próximo de $1 / n$, onde $n$ é o expoente de encruamento da função de escoamento. Temos então que a função $F(\eta, \xi)$ vale:

$F(\eta, \xi)=C_{1} e^{-C_{2} \eta}-\left(C_{1} e^{-C_{2} \eta}-C_{3} e^{-C_{4} \eta}\right)\left(1-\xi^{1 / n}\right)^{n}$ 
Sendo $C_{1}, C_{2}, C_{3}$ e $C_{4}$ os quatro parâmetros a serem calibrados. A superfície de ruptura para o alumínio 2024-T351 é ilustrada pela Figura 13, apresentada no Capítulo 2. 


\section{CARACTERIZAÇÃO DO MATERIAL}

Para determinar os parâmetros do material, um procedimento baseado em ensaios experimentais de caracterização e análise numérica detalhada desses ensaios foi realizado, conforme descrito abaixo.

(1) Realizar uma série de ensaios em espécimes e obter a curva força $x$ deslocamento;

(2) Realizar análises numéricas que reproduzem os ensaios, ajustando-se os parâmetros do modelo constitutivo do material;

(3) Determinar o deslocamento de ruptura para cada um dos casos ensaiados;

(4) Obter dados de deformação plástica equivalente, pressão hidrostática, tensão equivalente de Von Mises e tensão máxima de cisalhamento;

(5) Calcular a triaxialidade média observada na resposta numérica até 0 deslocamento de ruptura verificado no ensaio e obter o valor da deformação plástica equivalente na ruptura.

\subsection{Ensaios de Tração}

Os ensaios de caracterização do material foram planejados para prover dados em uma ampla faixa de triaxialidade, uma vez que este parâmetro contribui para evolução do dano e iniciação da falha. Para tal, são testados espécimes de tração com e sem entalhe e de cisalhamento. Os espécimes com entalhe resultam em diferentes triaxialidades. Já os estados de triaxialidade próximos de zero são obtidos através de espécimes de cisalhamento, sugeridos por (40). Em adição, espécimes de tração sem entalhe também são utilizados para se extrair as propriedades do 
modelo constitutivo elasto-plástico, assim como avaliar o grau de anisotropia existente. A Figura 19 ilustra as geometrias e dimensões dos espécimes.

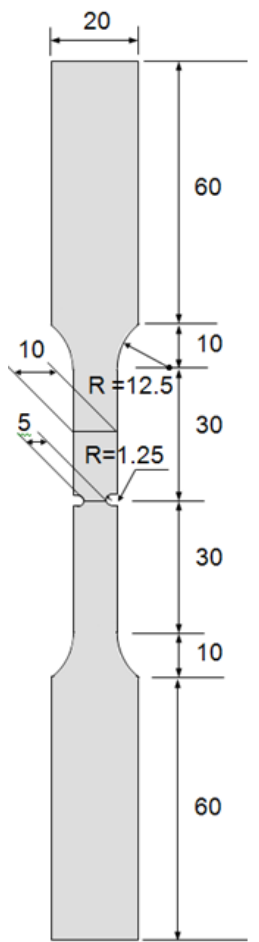

(a)

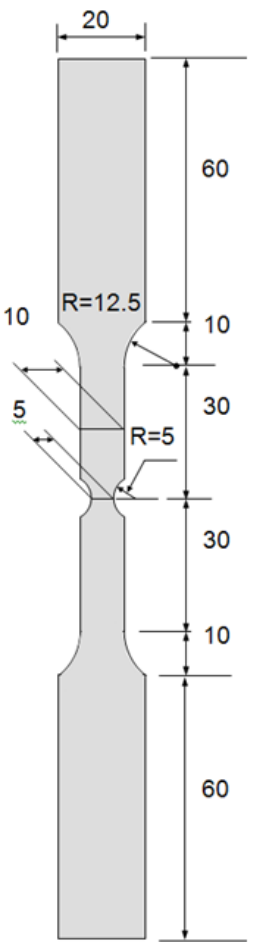

(b)

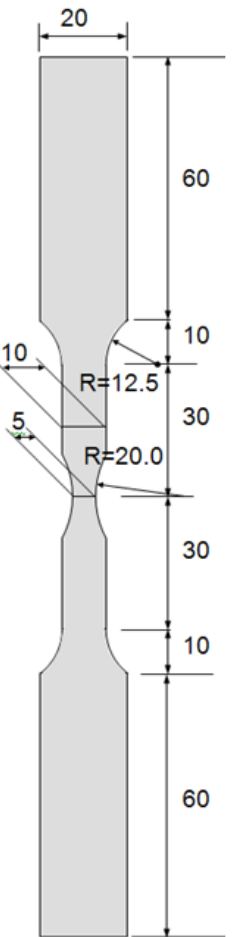

(c)

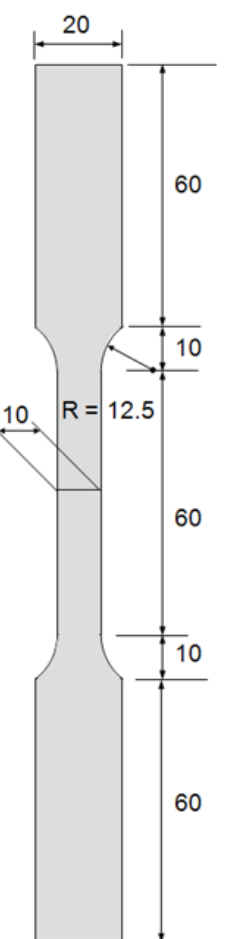

(d)

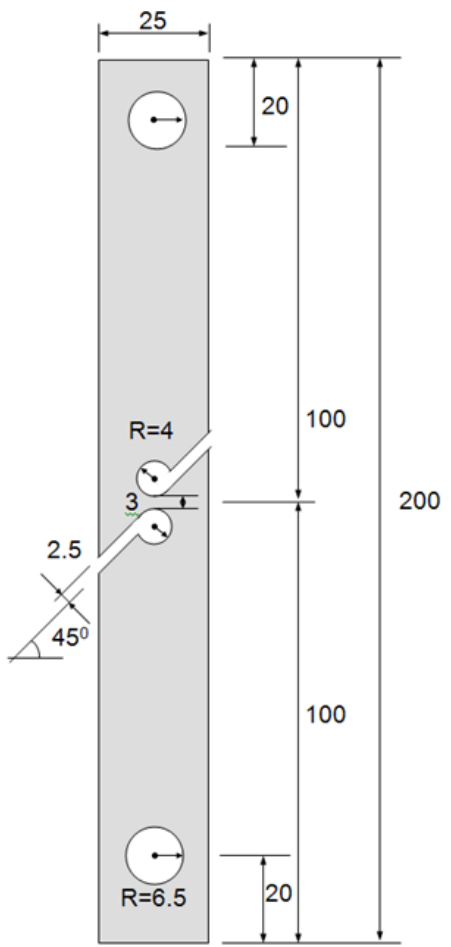

(e)

Figura 19. Geometria dos espécimes (medidas em mm). (a)-(c) espécimes com entalhes de raio 1,25, 5 e $20 \mathrm{~mm}$, respectivamente; (d) espécime sem entalhe; (e) espécime de cisalhamento.

O material ensaiado é um aço comum na indústria automotiva, de nomenclatura e propriedades desconhecidas para o presente estudo. Os espécimes foram retirados por meio de corte a laser de uma chapa plana de $1,5 \mathrm{~mm}$ de espessura. Ao todo quatro espécimes de cada geometria foram preparados, dos quais dois foram retirados no sentido da laminação da chapa e outros dois no sentido transversal a laminação. A Figura 20 mostra os espécimes utilizados nos ensaios.

Os ensaios de tração foram realizados na máquina INSTRON3369 do Laboratório de Impacto do GMSIE-USP (Figura 21a). Para que o teste seja considerado quaseestático, os espécimes são tracionados a uma velocidade de $1 \mathrm{~mm} / \mathrm{min}$ a $2 \mathrm{~mm} / \mathrm{min}$, força e deslocamento são gravados com taxa de aquisição a cada décimo de segundo pela placa de aquisição National Instruments ${ }^{\circledR}$. O deslocamento é adquirido 
através de um extensômetro $\left(L_{0}=50 \mathrm{~mm}\right.$ e $\left.L_{0}=25 \mathrm{~mm}\right)$ firmemente fixo ao espécime de modo que abranja a região do entalhe e do possível surgimento da falha. A força é medida por uma célula de carga com capacidade de até $50 \mathrm{kN}$.

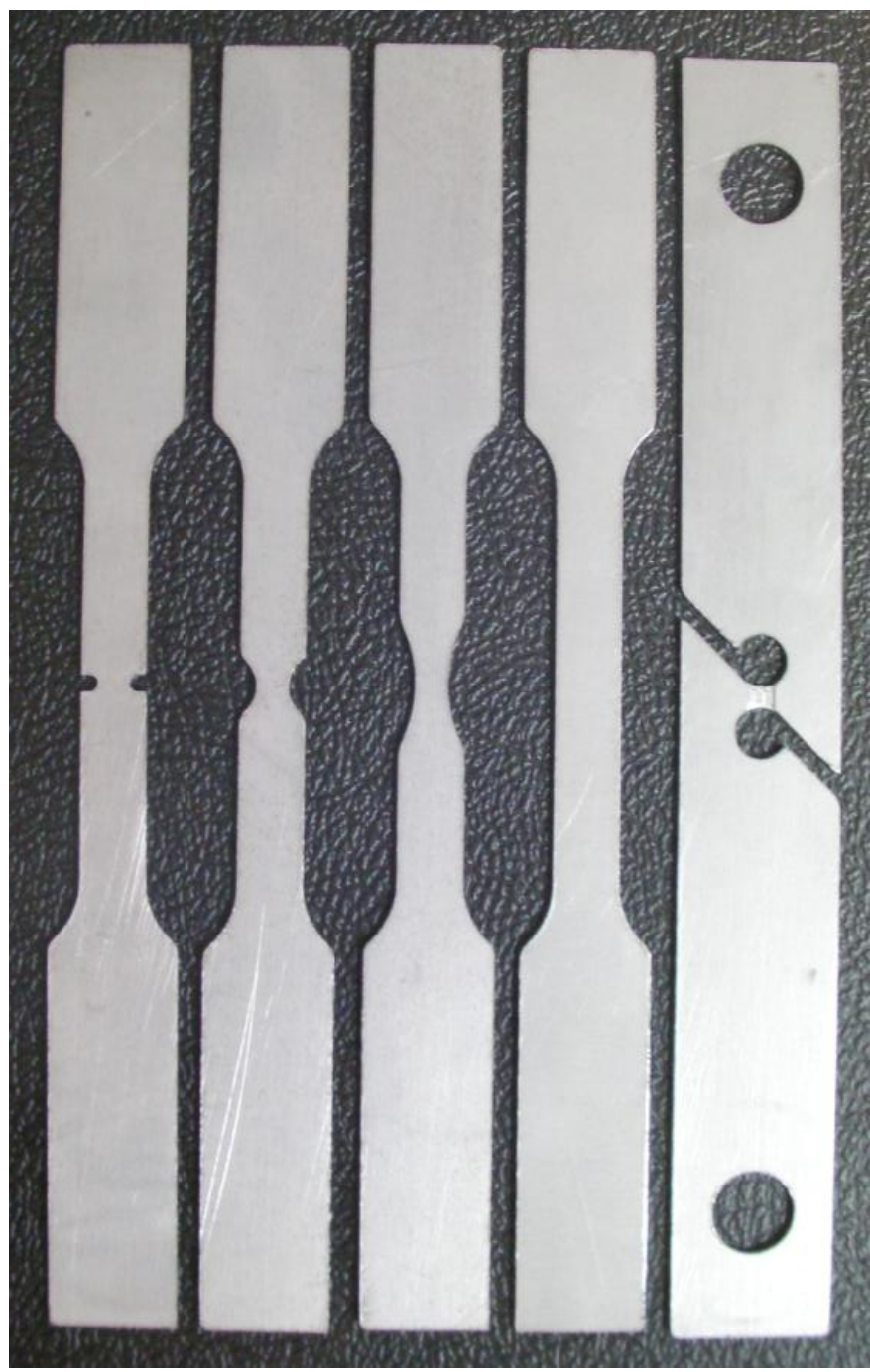

Figura 20. Espécimes para os ensaios de tração.

Para os ensaios dos espécimes com e sem entalhe, a fixação das extremidades foi realizada por meio de mordentes convencionais, conforme indicado na Figura $21 \mathrm{~b}$. Já os espécimes de cisalhamento, suas extremidades foram fixadas por meio de pinos conforme a Figura $21 \mathrm{c}$, de modo a permitir rotação do espécime durante o teste. 


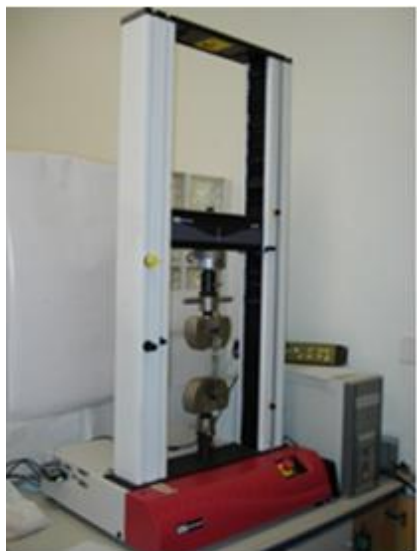

(a)

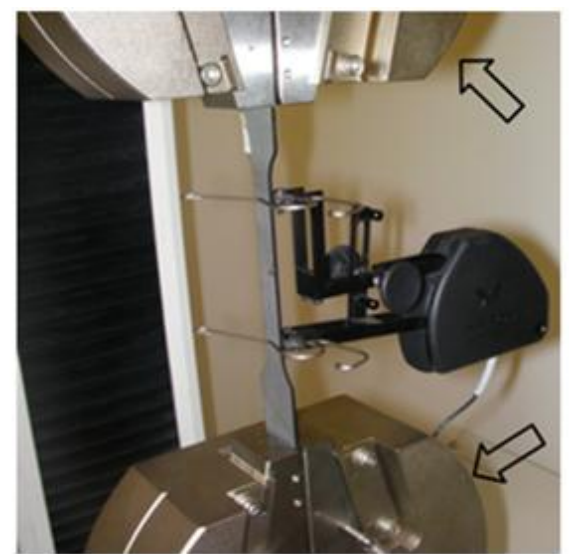

(b)

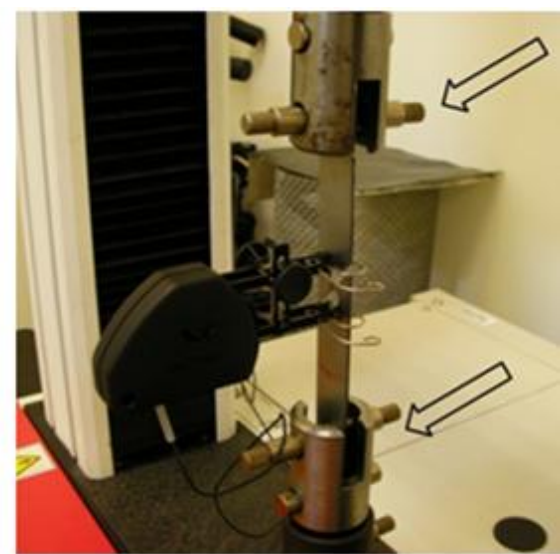

(c)

Figura 21. (a) Máquina de Tração INSTRON3369; (b) detalhe da fixação do extensômetro e mordentes convencionais; (c) detalhe da fixação do extensômetro e indicação dos pinos para ensaio de cisalhamento.

Ao todo 12 ensaios foram realizados conforme descrito na Tabela 1. Os corpos de prova retirados na direção longitudinal TSE_L_1 e TSE_L_2 e transversal TSE_T_1 apresentaram pequena variação nos níveis de força, sendo da ordem de 3,5\% na força de pico. Pode-se dizer, portanto, que não houve anisotropia considerável e que a hipótese de material isotrópico é válida.

Tabela 1 - Lista de ensaios de caracterização do material.

\begin{tabular}{lll}
\hline $\begin{array}{l}\text { \# do } \\
\text { Ensaio }\end{array}$ & Espécime & Descrição \\
\hline 1 & T0125_L_1 & Entalhe com raio de $1,25 \mathrm{~mm}$, retirado no sentido da laminação \\
2 & T0125_L_2 & Entalhe com raio de $1,25 \mathrm{~mm}$, retirado no sentido da laminação \\
3 & T05_L_1 & Entalhe com raio de $5,0 \mathrm{~mm}$, retirado no sentido da laminação \\
4 & T05_L_2 & Entalhe com raio de $5,0 \mathrm{~mm}$, retirado no sentido da laminação \\
5 & T20_L_1 & Entalhe com raio de $20,0 \mathrm{~mm}$, retirado no sentido da laminação \\
6 & T20_L_2 & Entalhe com raio de $20,0 \mathrm{~mm}$, retirado no sentido da laminação \\
7 & TSE_L_1 & Espécime sem entalhe, retirado no sentido da laminação \\
8 & TSE_T_1 & Espécime sem entalhe, transversal a laminação \\
9 & TSE_L_2 & Espécime sem entalhe, retirado no sentido da laminação \\
10 & Cis_L_1 & Espécime de cisalhamento, retirado no sentido da laminação \\
11 & Cis_L_2 & Espécime de cisalhamento, retirado no sentido da laminação \\
12 & Cis_T_1 & Espécime de cisalhamento, transversal a laminação \\
\hline
\end{tabular}

As Figuras 22-24 ilustram os espécimes após a ocorrência da ruptura. Os resultados dos ensaios dos espécimes com entalhe são ilustrados na Figura 25. O resultado do 
ensaio com o espécime sem entalhe é apresentado em conjunto com o resultado numérico (Figura 29), a serem descritos no item 1.14 deste capítulo.

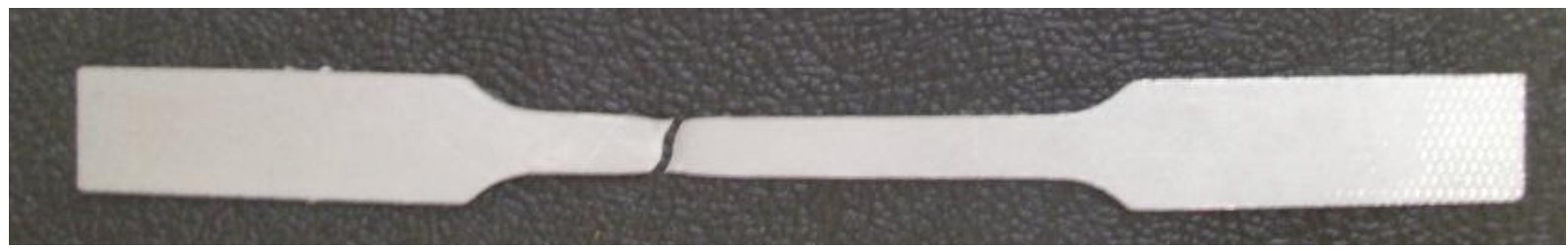

Figura 22. Espécime sem entalhe após a ruptura.

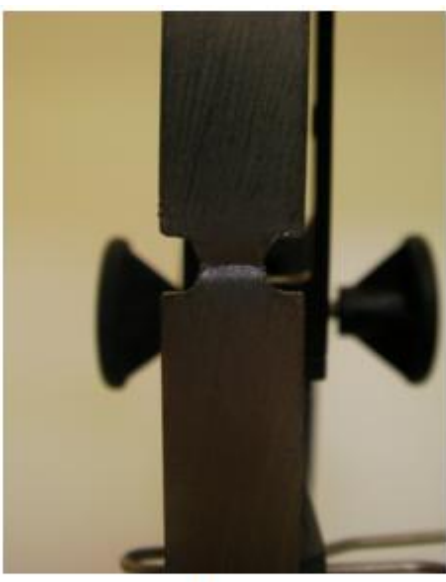

(a)

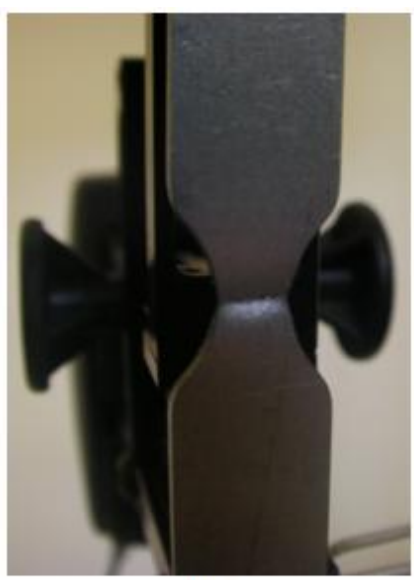

(b)

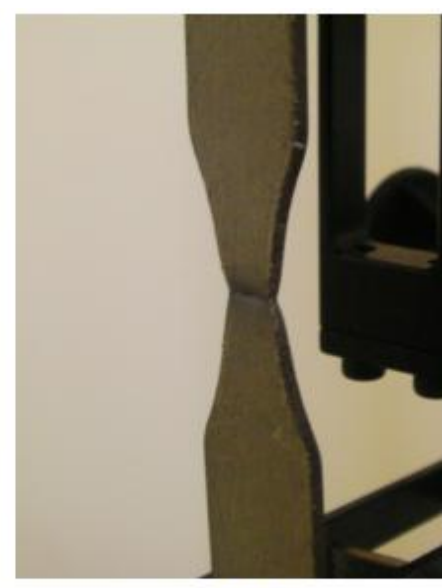

(c)

Figura 23. Espécimes com entalhe após a ruptura.

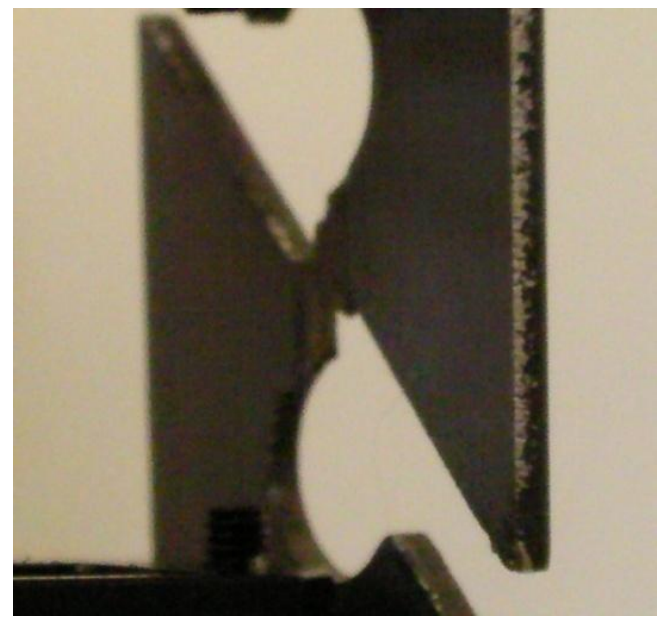

Figura 24. Espécime de cisalhamento após a ruptura. 


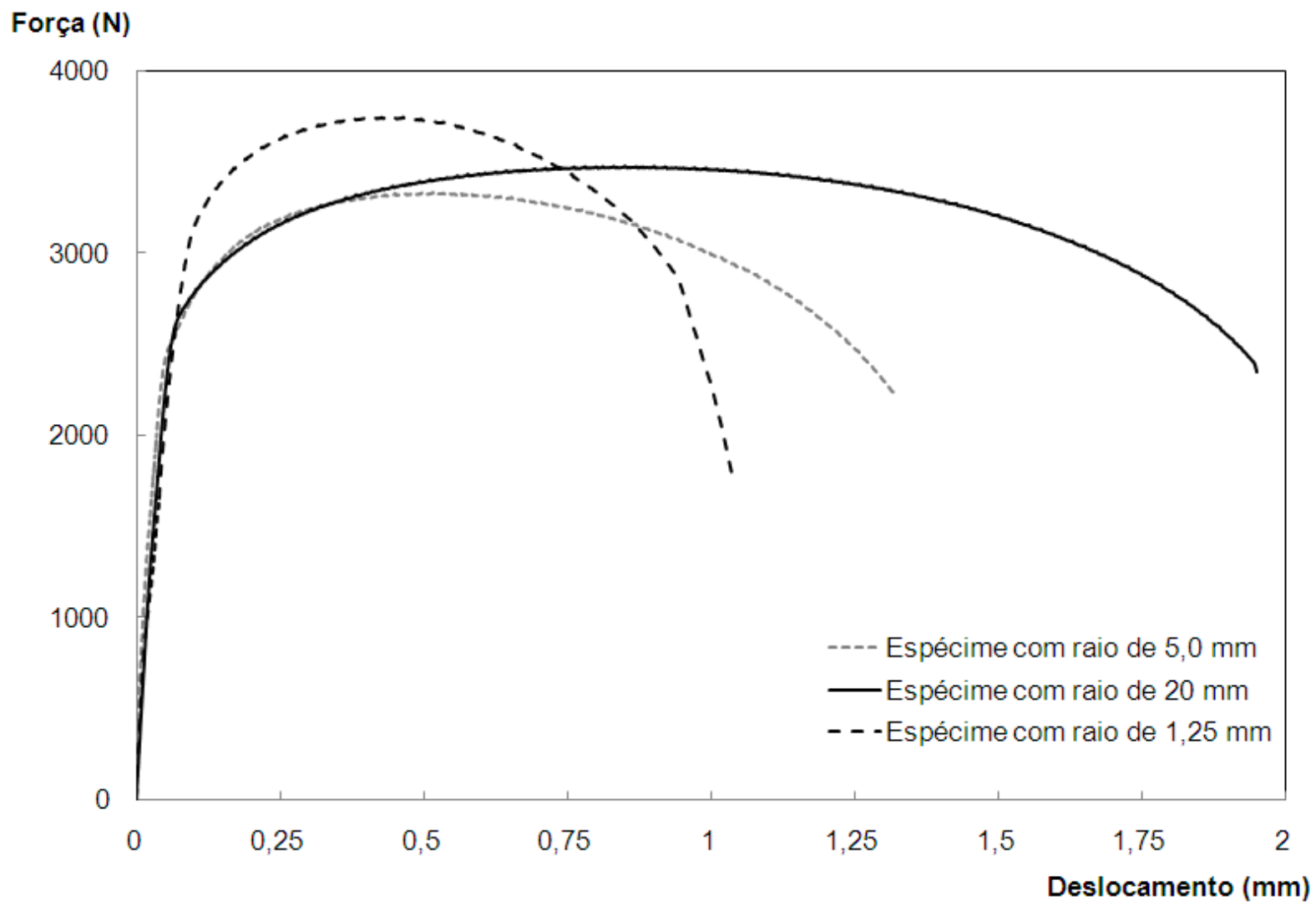

Figura 25. Resultado experimental das curvas força-deslocamento para os espécimes com entalhe.

Foi verificado, após os ensaios de tração que, em alguns espécimes, a falha se inicia bem no centro do espécime. A explicação reside no fato de essa região ser a que apresenta maior triaxialidade, portanto, é de se esperar que o início do crescimento de vazios e posterior ruptura possa ocorrer nessa região. Esse fenômeno pode ser visto com clareza no espécime T20_L_1 ilustrado na Figura 26, uma vez que o mesmo não foi completamente separado em duas partes após o teste. 


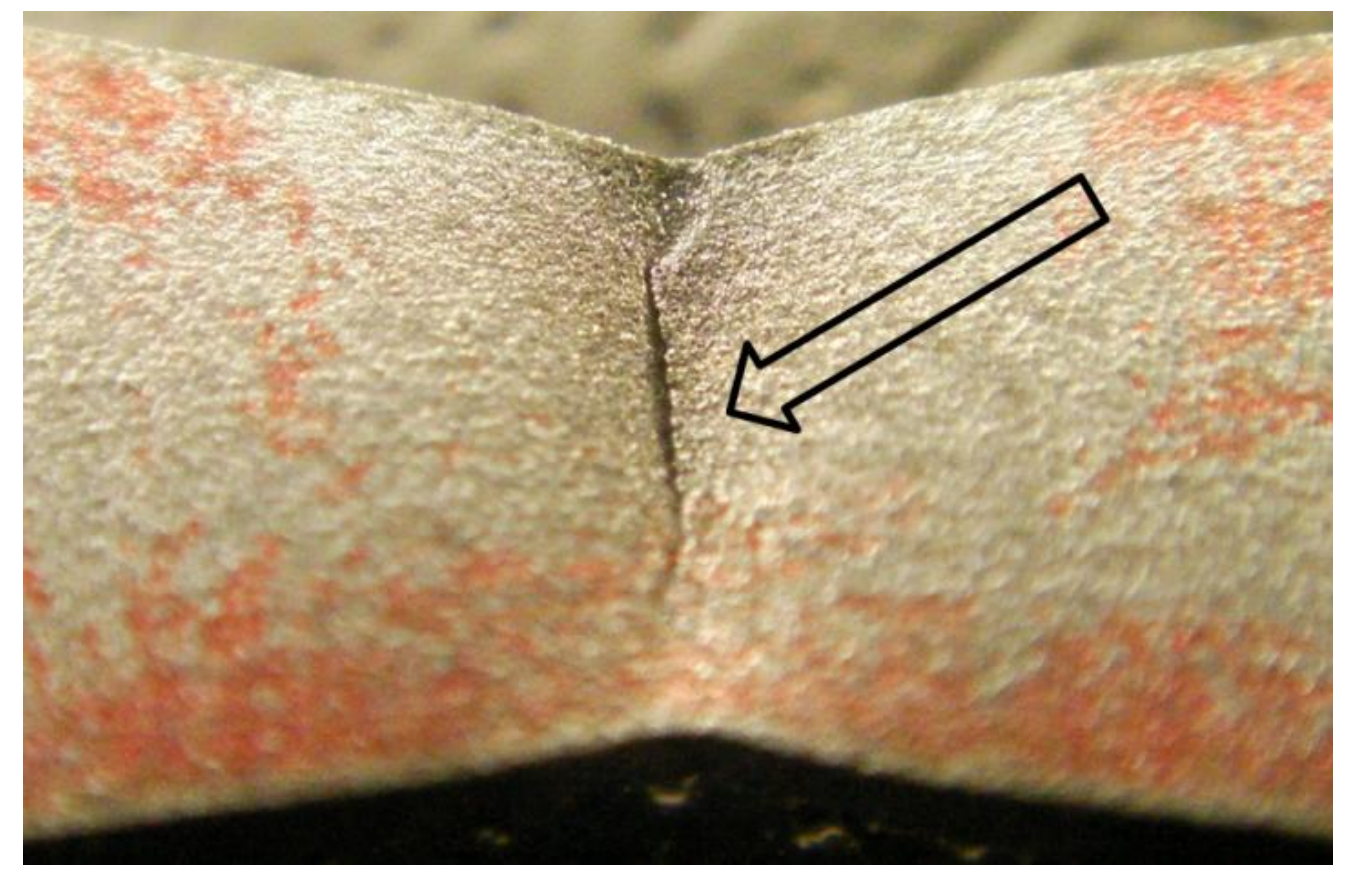

Figura 26. Início do surgimento da falha na região central do espécime T20_L_1.

\subsection{Análise Numérica}

Além dos ensaios experimentais, análises numéricas foram realizadas em paralelo com o software de elementos finitos $L S-D y n a^{\circledR}(41)$. O pré processamento pelo HyperMesh $^{\circledast}$ e o pós processamento pelo HyperView ${ }^{\circledR}$ e HyperGraph ${ }^{\circledast}$. O objetivo da análise numérica, além do ajuste de parâmetros do modelo constitutivo, é de fornecer componentes de tensões e de deformações na região de ruptura.

Elementos sólidos de oito nós foram utilizados para discretizar os corpos de prova de $1,5 \mathrm{~mm}$ de espessura. Para os espécimes com e sem entalhe, foi considerado simetria de um oitavo de espécime, permitindo maior refinamento da malha na região de interesse. As malhas dos espécimes com e sem entalhe estão ilustradas pela Figura 27.

O espécime de cisalhamento foi modelado por completo, sem o uso de simetria, dada a complexidade da geometria. A Figura 28 ilustra a malha modelada em elementos sólidos de oito nós. 


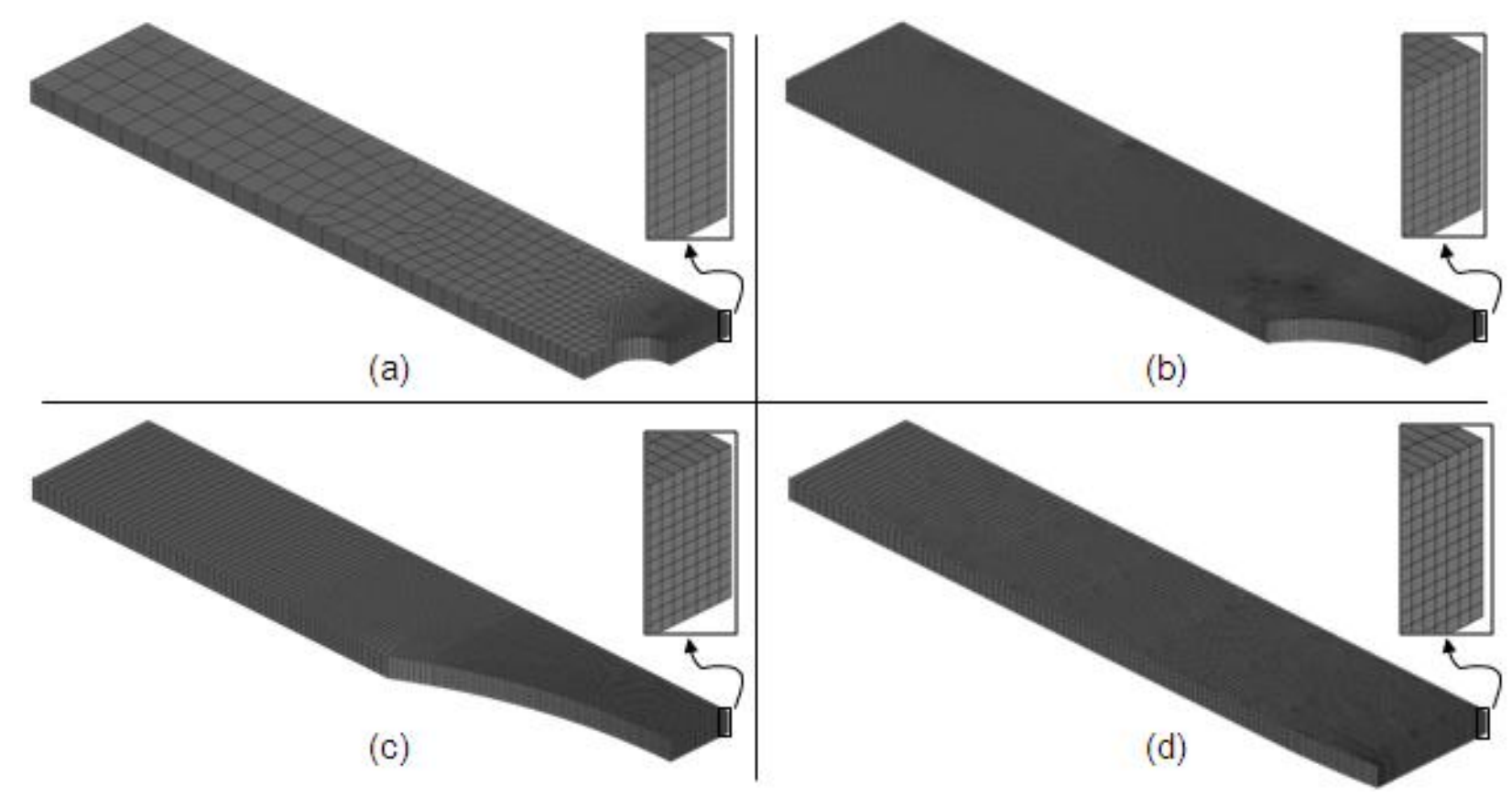

Figura 27. Malha dos corpos de prova, (a) entalhe de 1,25 mm; (b) entalhe de $5 \mathrm{~mm}$;(c) entalhe de 20 $\mathrm{mm} ;$ (d) sem entalhe.

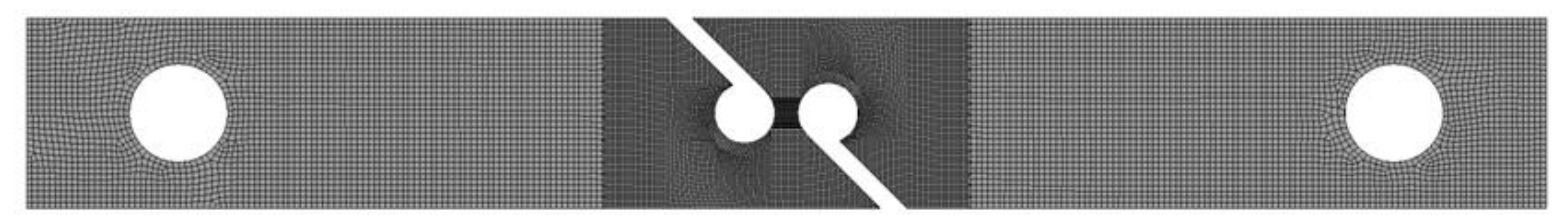

Figura 28. Malha do espécime de cisalhamento.

Malhas bastante refinadas foram consideradas nas análises, principalmente nas regiões de ocorrência de plasticidade e ruptura. A Tabela 2 resume as informações das malhas analisadas.

Tabela 2 - Resumo dos dados das malhas dos espécimes.

\begin{tabular}{lllll}
\hline Modelo de espécime & \# de elementos & \# de nós & $\begin{array}{c}\text { Dimensões do elemento central: } \\
\text { larg. } \times \text { comp. } \times \text { altura }(\mathrm{mm})\end{array}$ & Simetria \\
\hline R $0,125 \mathrm{~mm}$ & 10462 & 12194 & $0,0961 \times 0,1061 \times 0,0625$ & um oitavo \\
R $5,0 \mathrm{~mm}$ & 89616 & 99983 & $0,0824 \times 0,0833 \times 0,0625$ & um oitavo \\
R $20,0 \mathrm{~mm}$ & 60480 & 67821 & $0,0699 \times 0,1277 \times 0,0625$ & um oitavo \\
Sem entalhe & 76512 & 85150 & $0,0625 \times 0,0119 \times 0,0625$ & um oitavo \\
Cisalhamento & 42122 & 57814 & $0,1783 \times 0,2737 \times 0,1268$ & completo \\
\hline
\end{tabular}


O modelo constitutivo do material usado nas análises numéricas dos ensaios de tração foi o de J-C, já disponível no LS-Dyna ${ }^{\circledR}$, dado por

$$
\sigma=\left(A+B \cdot \bar{\varepsilon}^{n}\right) \cdot(1+c \cdot \ln \dot{\varepsilon}) \cdot\left(1-T^{* m}\right),
$$

Onde $A, B, n, c$ e $m$ são as constantes do material. Ao considerarmos o caso estático e sem a influência da temperatura, restam as constantes $A, B$ e $n$ para serem calibradas a partir da correlação das curvas de força e deslocamento dos ensaios físicos e análises numéricas.

Ensaios com os espécimes sem entalhe foram considerados para a determinação dos parâmetros elasto-plásticos do material. A inclinação inicial da curva tensãodeformação de engenharia indica o módulo de Young de 196839,0 MPa e o coeficiente de Poisson foi considerado 0,3. Após dezenas de ciclos de simulações numéricas para cada espécime, foi possível determinar um conjunto de parâmetros (listados na Tabela 3) que descrevesse com boa precisão a resposta forçadeslocamento observada nos ensaios, conforme ilustra a Figura 29.

Tabela 3 - Parâmetros de J-C que melhor caracterizam o material.

\begin{tabular}{ccccc}
\hline $\mathrm{E}(\mathrm{MPa})$ & $\mathrm{A}(\mathrm{MPa})$ & $\mathrm{B}(\mathrm{MPa})$ & $\mathrm{n}$ & $v$ \\
\hline 196839.0 & 335,4 & 451,5 & 0,502 & 0,29 \\
\hline
\end{tabular}

O fenômeno do empescoçamento também foi detectado nas análises numéricas. A Figura 30 ilustra o deslocamento absoluto na direção da espessura para o modelo com entalhe de raio de $20 \mathrm{~mm}$.

Uma vez que foi encontrada boa correlação das relações de força-deslocamento dos resultados experimentais e numérico, é possível analisar a ductilidade do material por meio das informações de tensões e deformações dos elementos da malha referentes aos locais de início de ruptura.

Para traçar as relações de deformação de ruptura $\bar{\varepsilon}_{\text {rup }}$ e triaxialidade $\eta$ são necessárias as informações de tensão e deformação do elemento da malha que representa a região do espécime onde se inicia a ocorrência de falha. A deformação plástica equivalente de ruptura foi considerada como sendo a deformação plástica 
equivalente do elemento em questão no instante em que ocorre o deslocamento de ruptura $u_{f}$ verificado nos ensaios experimentais (Tabela 4 ).

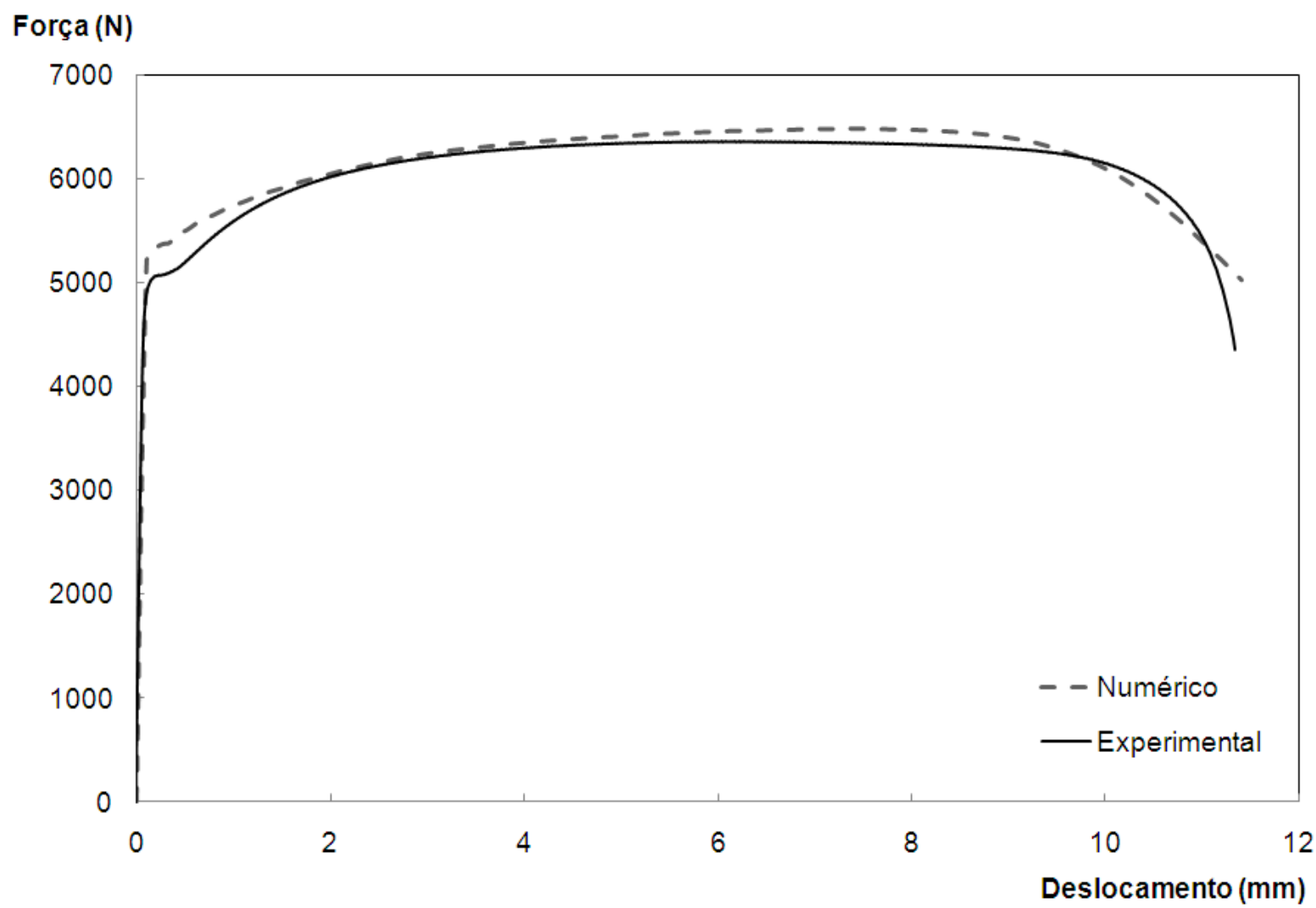

Figura 29. Resultado numérico e experimental das curvas força-deslocamento para o espécime sem entalhe.

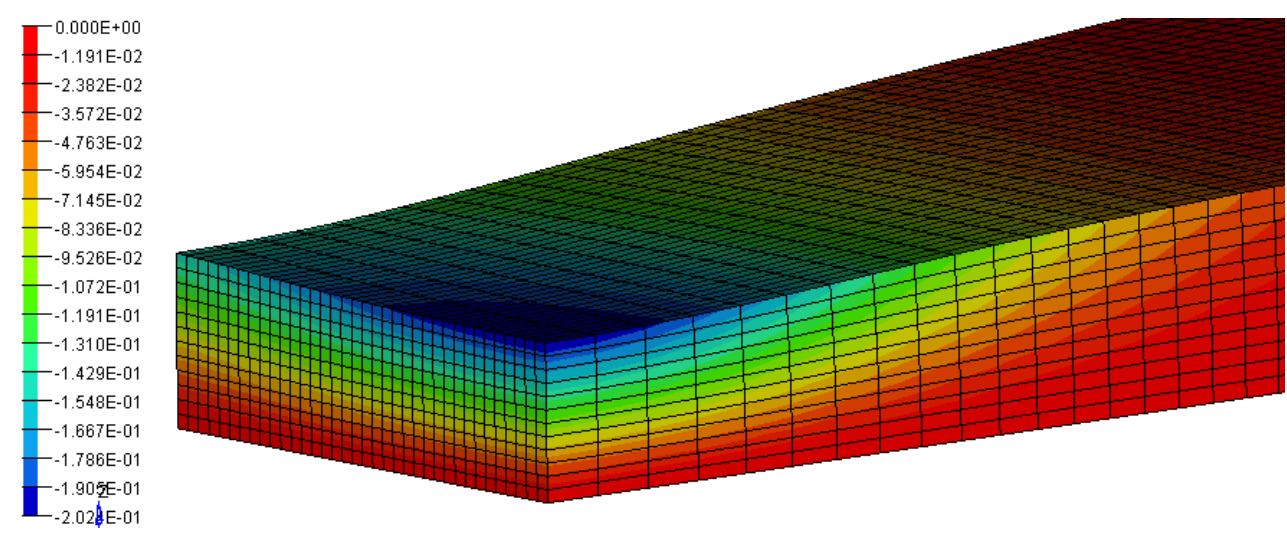

Figura 30. Deslocamento na direção da espessura do espécime de $20 \mathrm{~mm}$ de raio na região do entalhe (escala em $\mathrm{mm}$ ). 
Tabela 4 - Deformações de ruptura dos espécimes ensaiados.

\begin{tabular}{cc}
\hline Espécime & $u_{f}(\mathrm{~mm})$ \\
\hline T0125_L_2 & 1,04 \\
T05_L_2 & 1,32 \\
T20_L_2 & 1,95 \\
TSE_L_2 & 1,13 \\
\hline
\end{tabular}

Já a triaxialidade é calculada a partir da razão entre a tensão hidrostática e a tensão efetiva atuantes no elemento, que podem ser deduzidas a partir do conhecimento das tensões principais e de Von Mises.

Calculada a triaxialidade ao longo da simulação, pode-se verificar que a mesma não se mantém constante, conforme ilustrado pela Figura 31. Sendo assim, apenas o valor médio da triaxialidade deve ser considerado para a caracterização do modelo de falha. Os valores médios de triaxialidade, assim como as deformações plásticas equivalentes na ruptura para cada tipo de espécime estão listados na Tabela 5.

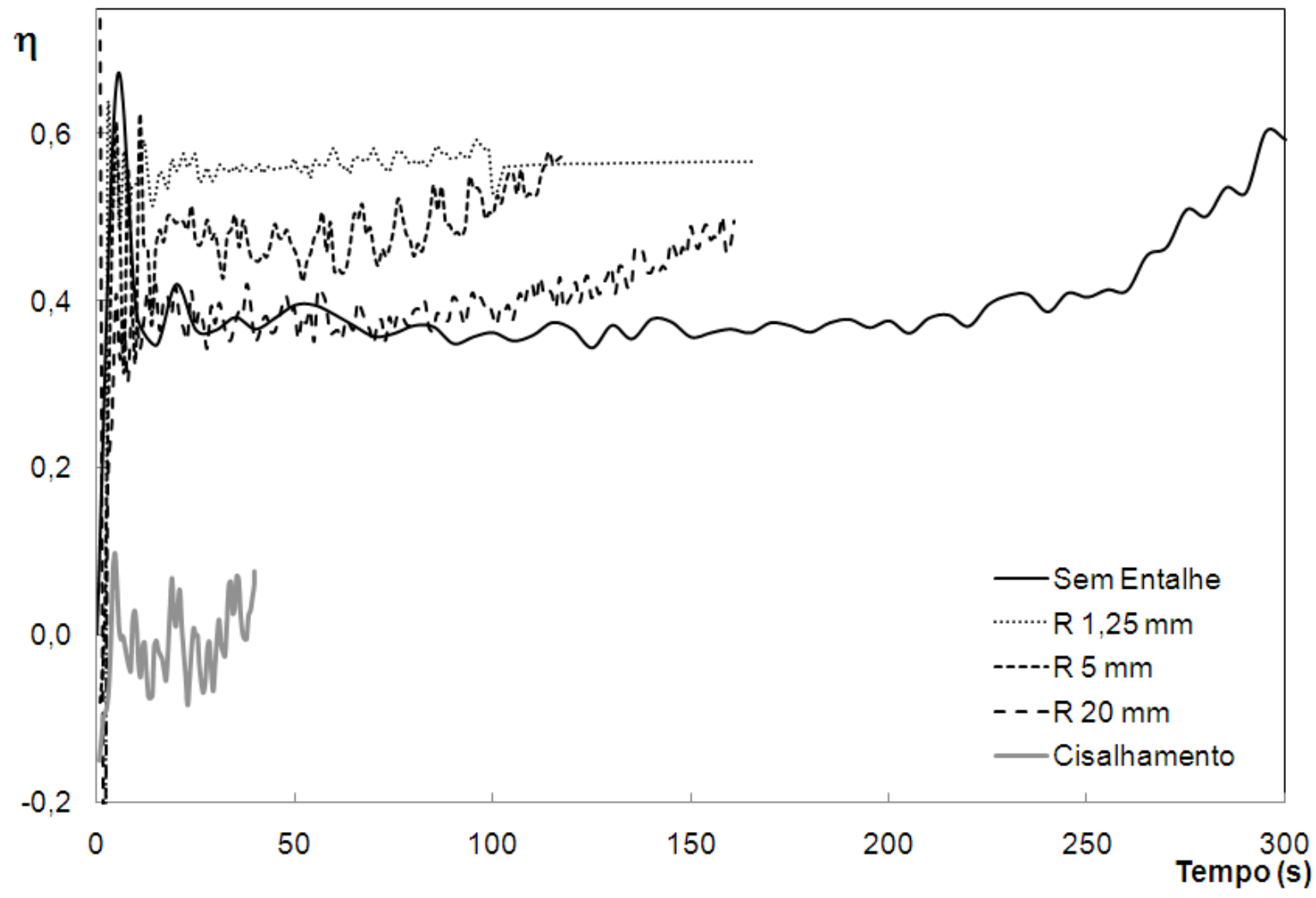

Figura 31. Triaxialidade em função do tempo para o elemento central de cada modelo de espécime. 
Tabela 5 - Triaxialidade e deformação plástica equivalente na ruptura de cada tipo de espécime.

\begin{tabular}{lccccc} 
Espécime $\rightarrow$ & $\mathrm{R} 1,25 \mathrm{~mm}$ & $\mathrm{R} 5 \mathrm{~mm}$ & $\mathrm{R} 20 \mathrm{~mm}$ & Sem entalhe & Cisalhamento \\
\hline$\eta$ & 0,5622 & 0,4866 & 0,3957 & 0,3952 & 0,0090 \\
\hline $\bar{\varepsilon}_{\text {rup }}$ & 0,5157 & 0,5347 & 0,5423 & 1,0405 & 0,7132 \\
\hline
\end{tabular}

A caracterização do critério de falha é feita ajustando-se os pontos da Tabela 5 a um critério estabelecido. Para o critério de J-C explorado no item 1.8, os parâmetros $D_{4}$ e $D_{5}$ da eq.(30) são desconsiderados para esta aplicação. $D_{1}$ é fixado como sendo a deformação de ruptura do espécime de maior triaxialidade e $D_{2}$ e $D_{3}$ ajustados pelo método dos mínimos quadrados.

De modo a termos um ajuste do modelo de falha de J-C satisfatório, foi necessário separar em dois conjuntos de parâmetros, sendo um mais conservador. A Figura 32 e a Tabela 6 ilustra os resultados experimentais e os ajustes do critério de J-C e Máxima Deformação Plástica Equivalente.

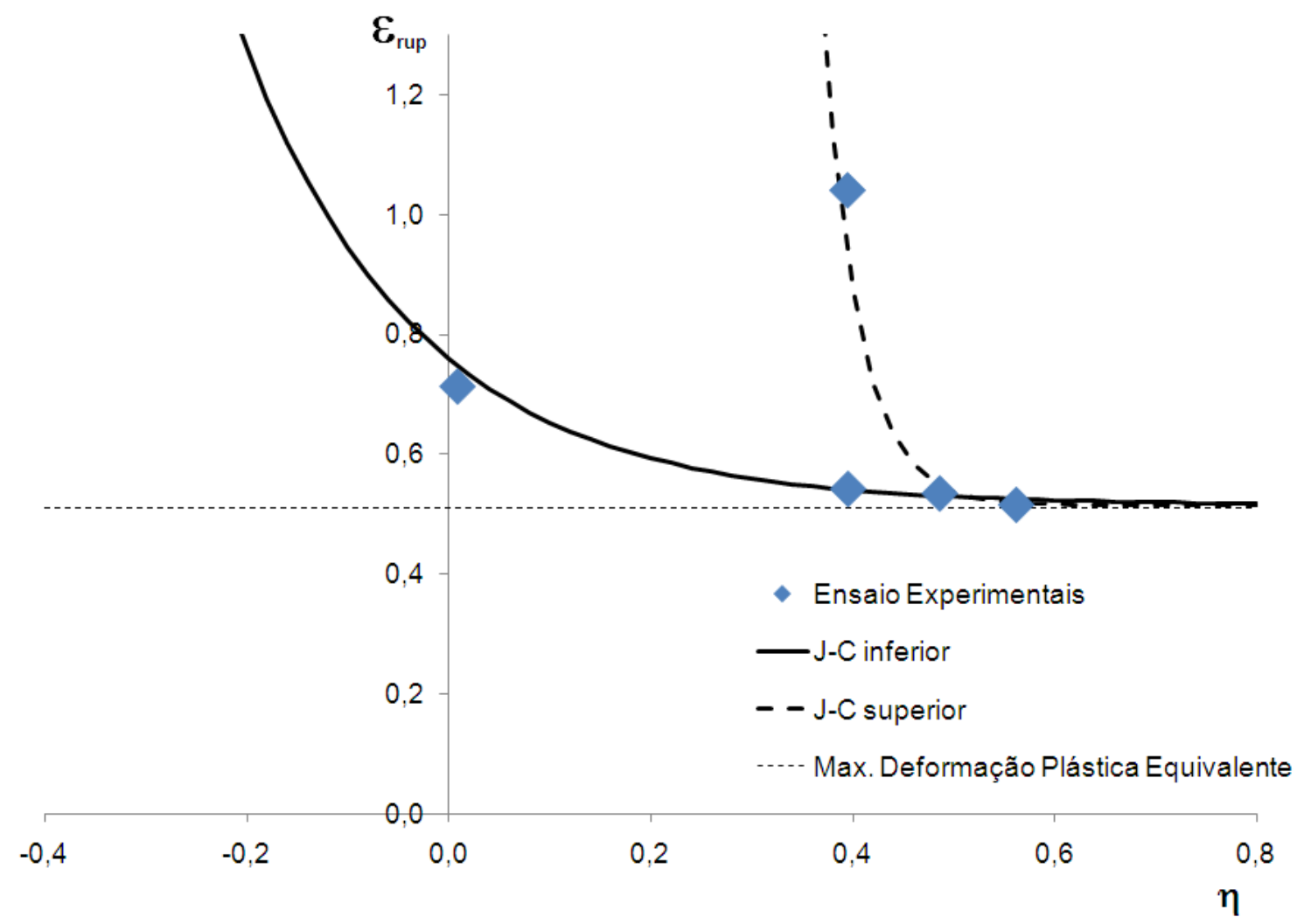

Figura 32. Ajuste dos critérios de falha de J-C e Máxima Deformação Plástica Equivalente. 
A curva de J-C "Inferior" foi ajustada desconsiderando-se o ponto referente ao ensaio do espécime sem entalhe, sendo mais conservadora que a curva J-C "Superior", que por sua vez desconsidera o ponto referente ao ensaio de cisalhamento.

Tabela 6 - Parâmetros do modelo de dano de J-C.

\begin{tabular}{lccc}
\hline Parâmetros de J-C & $D_{1}$ & $D_{2}$ & $D_{3}$ \\
\hline J-C Inferior & 0,52 & 0,24 & $-5,68$ \\
\hline J-C Superior & 0,52 & 20527,0 & $-27,4$ \\
\hline
\end{tabular}

A partir dos parâmetros de J-C calibrados, novas simulações dos espécimes de tração foram realizadas. As simulações apresentaram boa concordância com os ensaios físicos. A Figura 33 ilustra o início de ruptura no centro do modelo numérico de um oitavo de espécime em comparação com a Figura 26, recolocada aqui por conveniência.
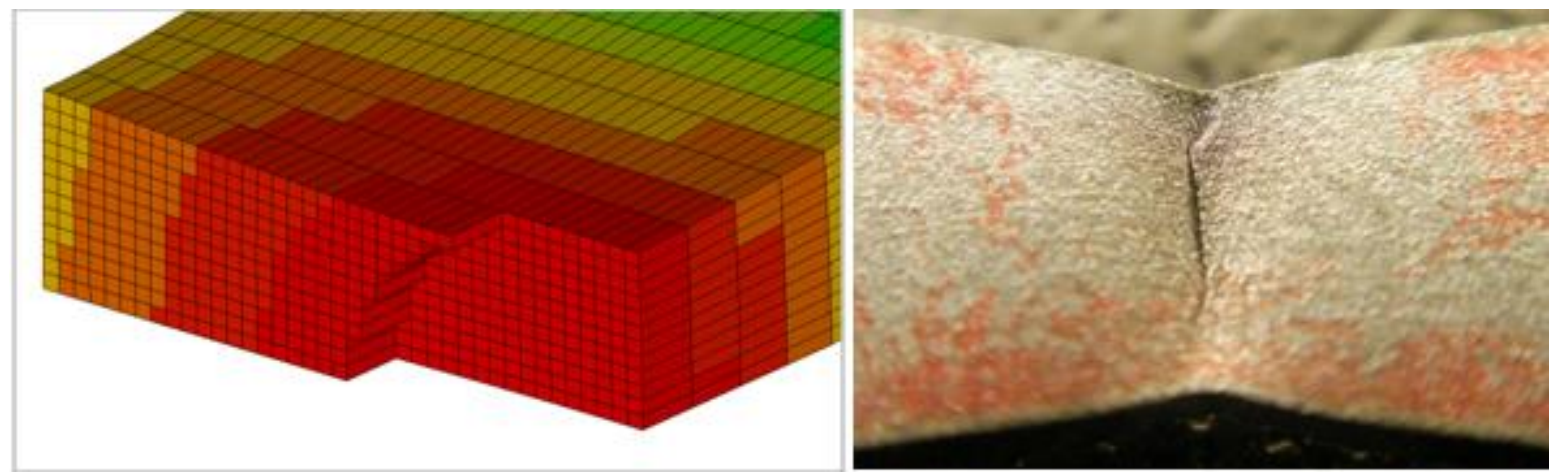

Figura 33. Resultado da simulação do espécime com entalhe de $20 \mathrm{~mm}$ e parâmetros de falha de J-C calibrados.

Além dos parâmetros de falha de $\mathrm{J}-\mathrm{C}$, a máxima tensão cisalhante também pode ser calculada através das tensões principais segundo a eq.(7). Para o critério de falha baseado da máxima tensão cisalhante, foi considerado um valor médio a partir das tensões indicadas na Tabela 7 . Já a deformação plástica utilizada no critério de falha 
baseado na máxima deformação plástica equivalente $\bar{\varepsilon}_{\text {rup }}$, foi considerado o menor valor da Figura 32. A Tabela 8 resume os parâmetros em questão.

Tabela 7 - Tensão máxima cisalhante dos espécimes.

\begin{tabular}{lcccc}
\hline Espécime $\rightarrow$ & $\mathrm{R} 1,25 \mathrm{~mm}$ & $\mathrm{R} 5 \mathrm{~mm}$ & $\mathrm{R} 20 \mathrm{~mm}$ & Sem entalhe \\
\hline$\tau_{\text {máx }}(\mathrm{MPa})$ & 384,5 & 372,5 & 368,4 & 398,4 \\
\hline
\end{tabular}

Tabela 8 - Valores da deformação plástica equivalente na ruptura e máxima tensao cisalhante.

\begin{tabular}{ll}
\hline Modelo & Parâmetros \\
\hline Deformação Plástica Equivalente & $\bar{\varepsilon}_{\text {rup }}=0,52$ \\
Máxima Tensão Cisalhante (MPa) & $\left(\tau_{\text {máx }}\right)_{f}=381$ \\
\hline
\end{tabular}

\subsection{Caracterização Dinâmica}

Em adição à caracterização quase-estática descrita no item anterior, informações sobre o comportamento do material a diferentes taxas de deformação são importantes para obter resultados numéricos mais precisos.

Para a caracterização dinâmica a altas taxas de deformação $\left(10^{2}\right.$ a $\left.10^{4} \mathrm{~s}^{-1}\right)$, ensaios podem ser realizados com a Barra de Hopkinson (Figura 34).

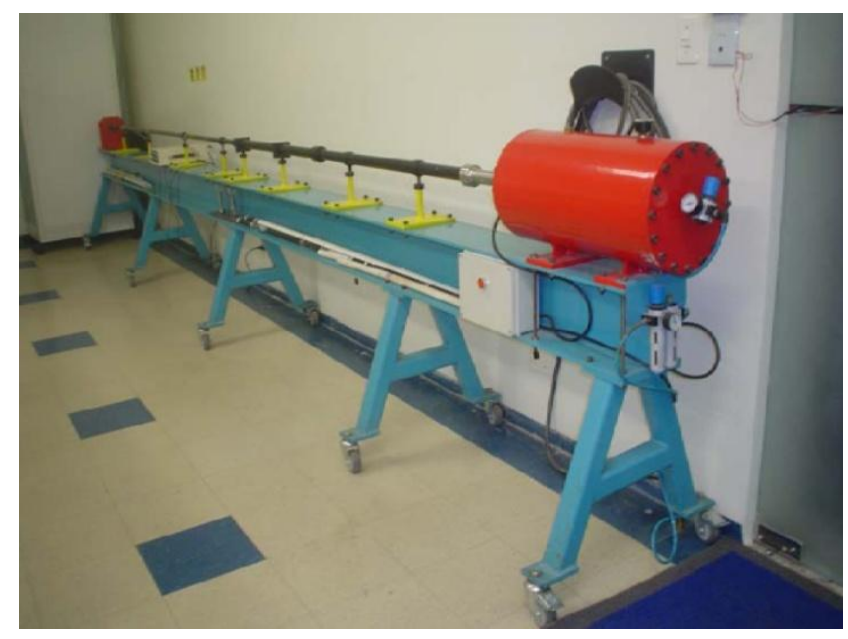

Figura 34. Barra de Hopkinson do GMSIE-USP. 
Neste ensaio, espécimes em forma de disco ou anel são comprimidos dinamicamente por duas barras instrumentadas, fornecendo a curva tensão $x$ deformação para várias taxas de deformação, conforme ilustrado pela Figura 35.

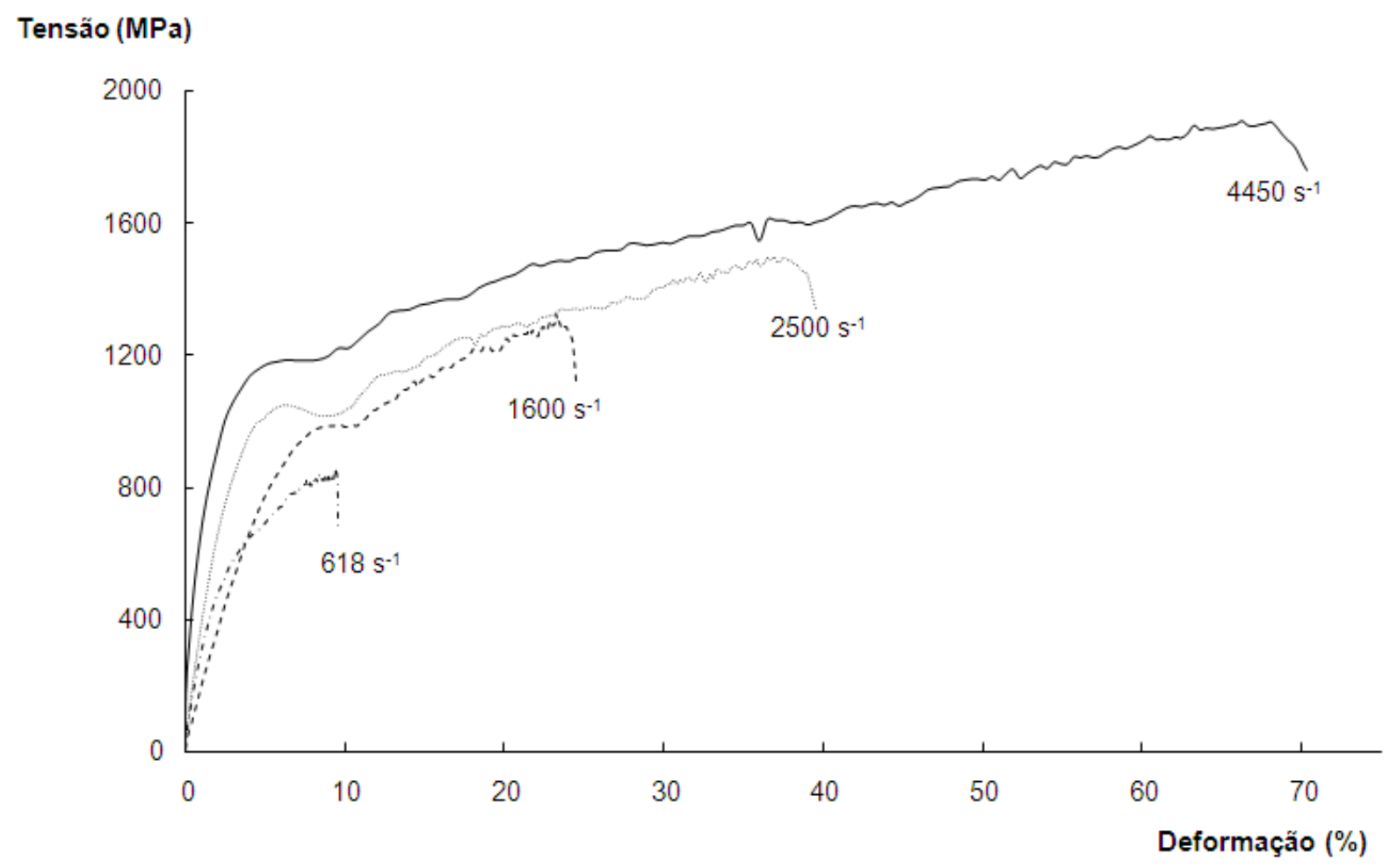

Figura 35. Resultados de ensaio de compressão dinâmica de um aço ABNT1047 (42).

A partir dos resultados experimentais, o comportamento visco-plástico do material pode ser descrito pela equação de Cowper-Symonds

$\sigma_{d}=\sigma_{0}\left[1+\left(\dot{\varepsilon} / C_{c s}\right)^{\frac{1}{q}}\right]$,

onde $C_{c s}$ e $q$ são constantes do material, $\dot{\varepsilon}$ é a taxa de deformação e $\sigma_{d}$ a tensão dinâmica correspondente à tensão estática $\sigma_{0}$. Assim, o material apresenta uma tensão de escoamento dinâmica que aumenta com a taxa de deformação, que por sua vez está diretamente relacionada com a velocidade de aplicação da carga. 
Observa-se, porém, que as menores taxas de deformação que a Barra de Hopkinson do GMSIE-USP pode fornecer são da ordem de $600 \mathrm{~s}^{-1}$. Tendo em vista que as taxas de deformação verificadas nos estudos de caso de impacto em párachoque são da ordem de $100 \mathrm{~s}^{-1}$, temos que a caracterização dinâmica através da Barra de Hopkinson do GMSIE-USP não resultaria em valores na faixa de taxa de deformação de interesse. Decidiu-se então calcular os parâmetros a partir das curvas tensão e deformação para taxas de deformação médias obtidas do banco de dados de material da General Motors, ilustrados na Figura 36.

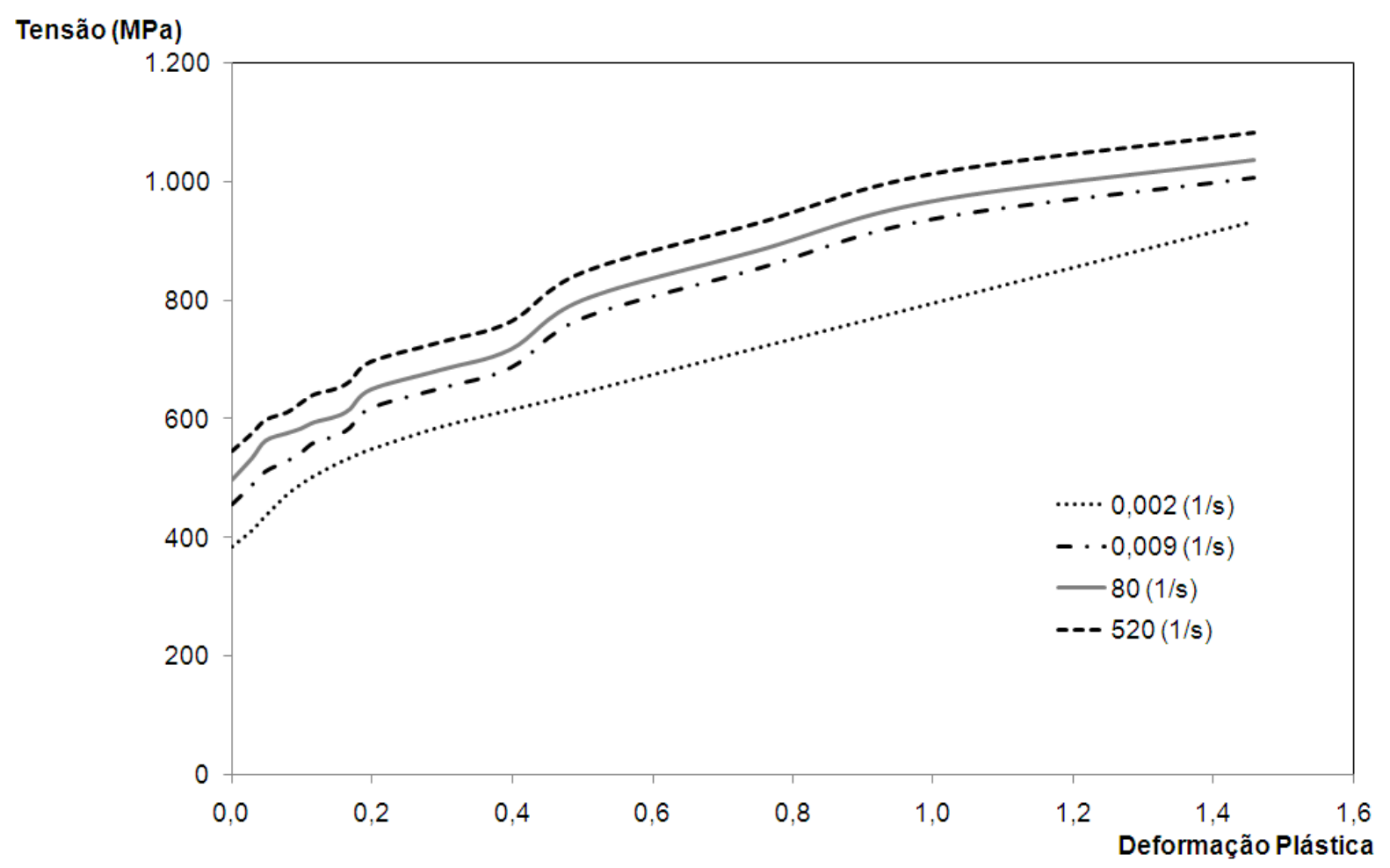

Figura 36. Curvas de tensão $\mathrm{x}$ deformação em taxas de deformação médias (banco de dados da General Motors).

Após o ajuste dos pontos da através da linearização das equações eq.(30) e eq.(31), os parâmetros de Cowper-Simonds e J-C são obtidos e listados na Tabela 9.

O gráfico da Figura 37 ilustra o acréscimo na tensão de escoamento do aço em questão em função da taxa de deformação segundo as equações de J-C e CowperSimonds. 
Tabela 9 - Parâmetros de Cowper-Simonds e J-C para casos dinâmicos.

\begin{tabular}{ll}
\hline Modelo & Parâmetros \\
\hline J-C & $c=0,0335$ \\
Cowper-Simonds & $C_{c s}=19957,2$ \\
Cowper-Simonds & $q=7,0117$ \\
\hline
\end{tabular}

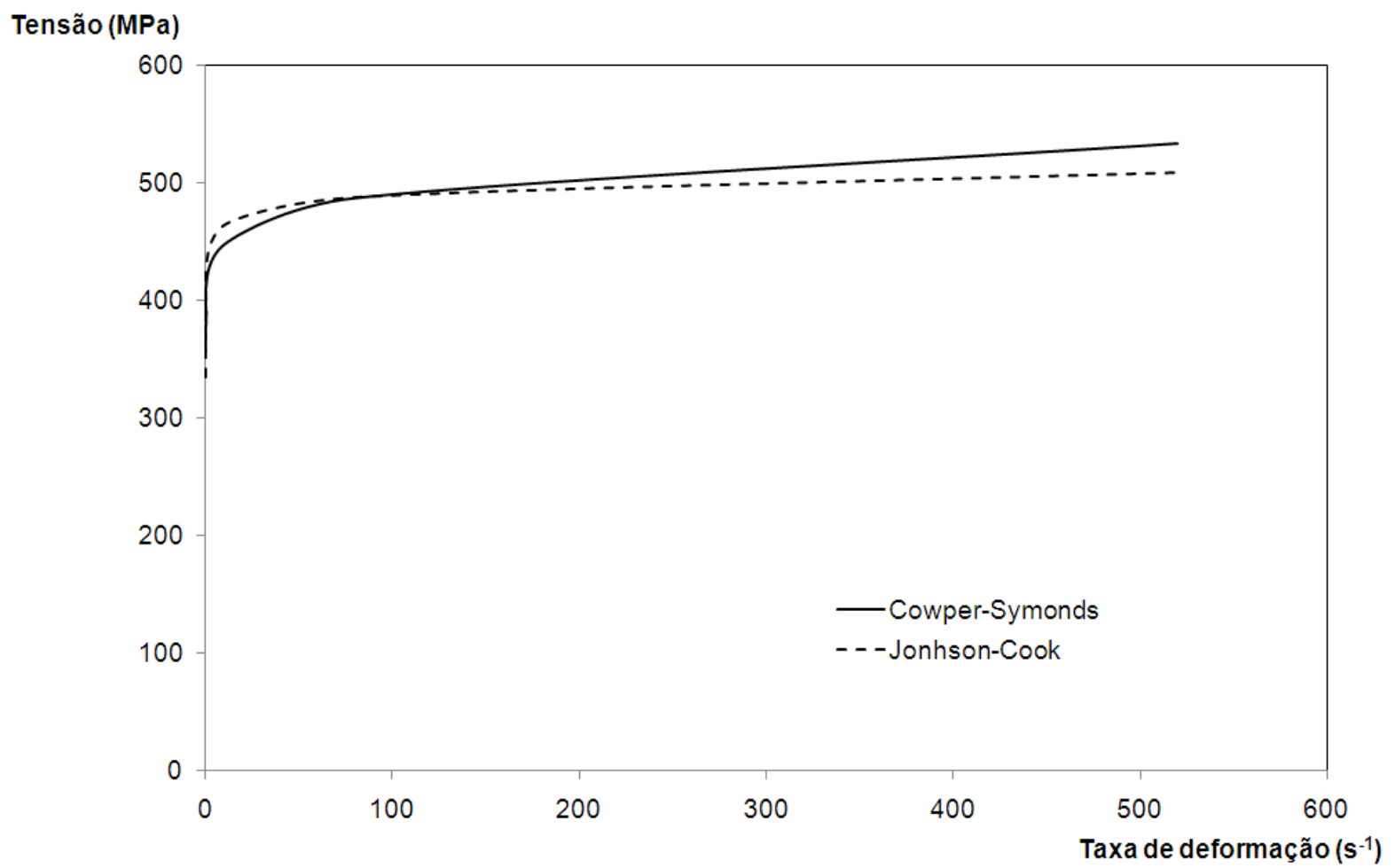

Figura 37. Tensão de escoamento em função da taxa de deformação segundo J-C e CowperSimonds. 


\section{IMPACTO EM PÁRA-CHOQUE: EXPERIMENTOS}

Com o objetivo de validar os modelos de falha calibrados, foram feitos ensaios experimentais em barras de pára-choque. O pára-choque em questão tem $1153 \mathrm{~mm}$ de comprimento e as principais dimensões da seção transversal conforme a Figura 38. O material da barra é um aço considerado comum na indústria automotiva e de propriedades mecânicas conforme descritas no Capítulo 0 , com 1,3 mm de espessura.
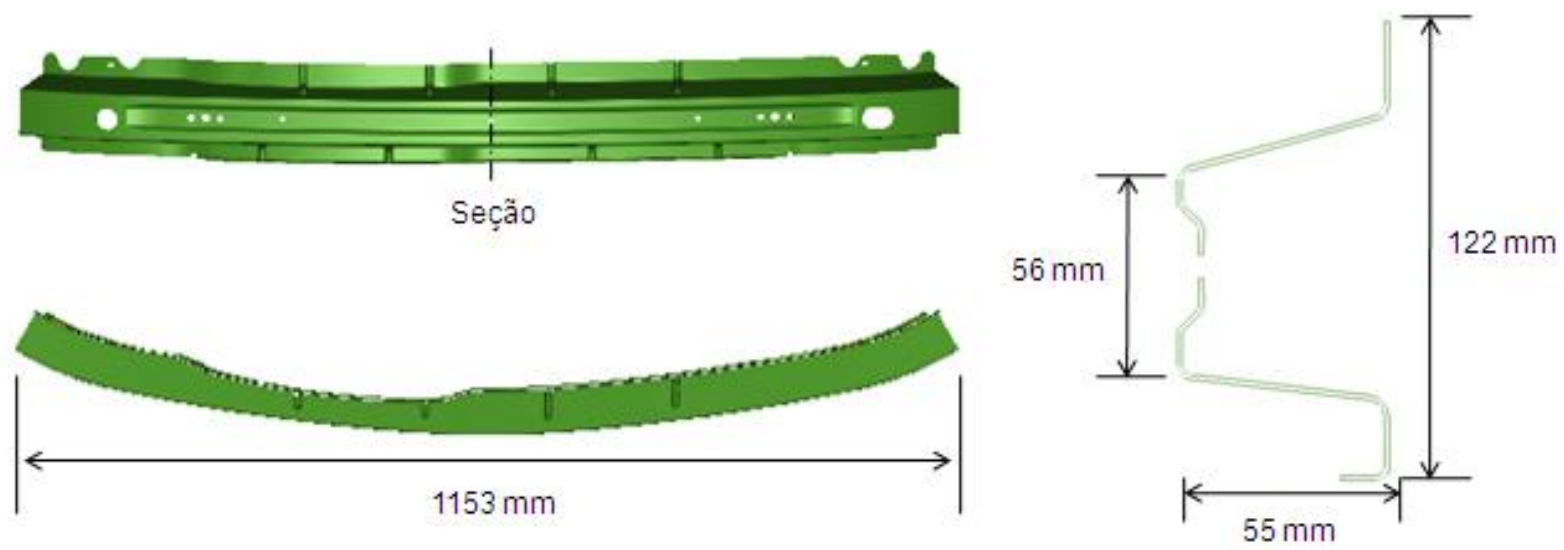

Figura 38. Detalhe da geometria do pára-choque.

O pára-choque é fornecido com dois suportes soldados nas extremidades conforme ilustrado na Figura 39. Os suportes são soldados a ponto internamente à barra (quatro pontos em cada uma das quatro superfícies de contato, ilustrado na Figura 40a e por dois pequenos cordões de solda MIG em cada uma das arestas, ilustrado na Figura 40b. A espessura dos suportes é de $2,0 \mathrm{~mm}$ e o material o mesmo da barra. O conjunto é então posicionado na linha de ação de um pêndulo, que por gravidade acelera um impactador (Figura 41a) de encontro à barra. O pêndulo pode ser carregado com uma massa máxima de $3500 \mathrm{~kg}$ e a velocidade máxima é de aproximadamente $4 \mathrm{~m} / \mathrm{s}$ (medida através de um sensor ótico). A Figura $41 \mathrm{~b}$ ilustra o pêndulo a ser utilizado. O aparato de teste ainda conta com uma câmera de alta 
velocidade e iluminação de alta potência ilustrada na Figura 41c para garantir a aquisição das imagens. Além das imagens, importantes para definir o instante da falha, o teste ainda pode fornecer o histórico de força ao longo do tempo através de uma célula de carga no interior do impactador.

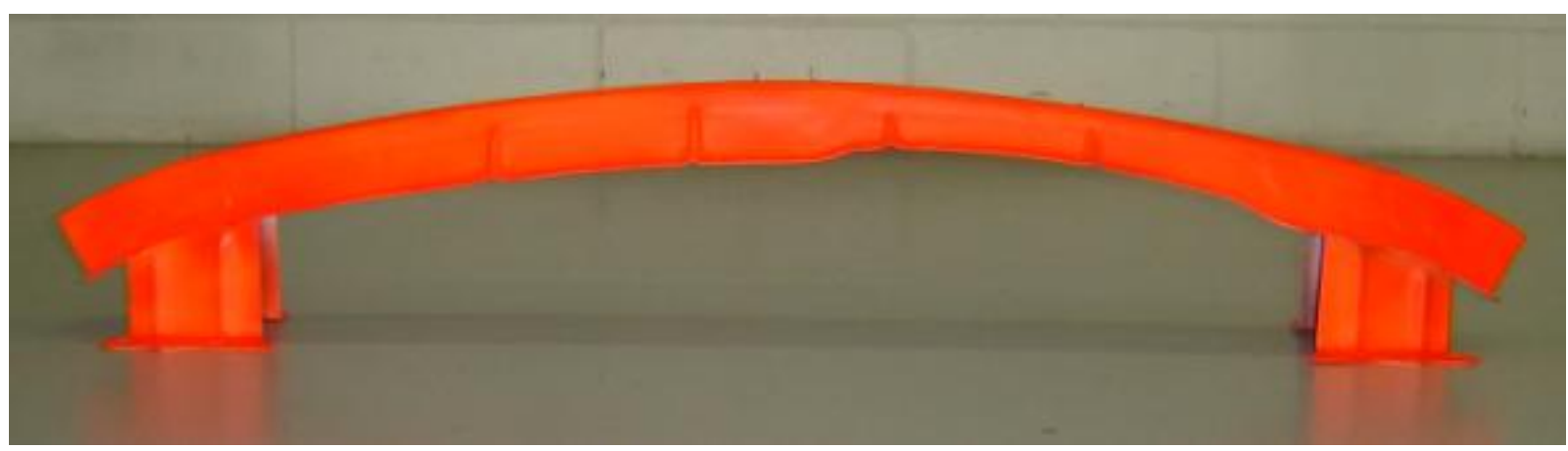

Figura 39. Pára-choque e seus suportes de fixação.

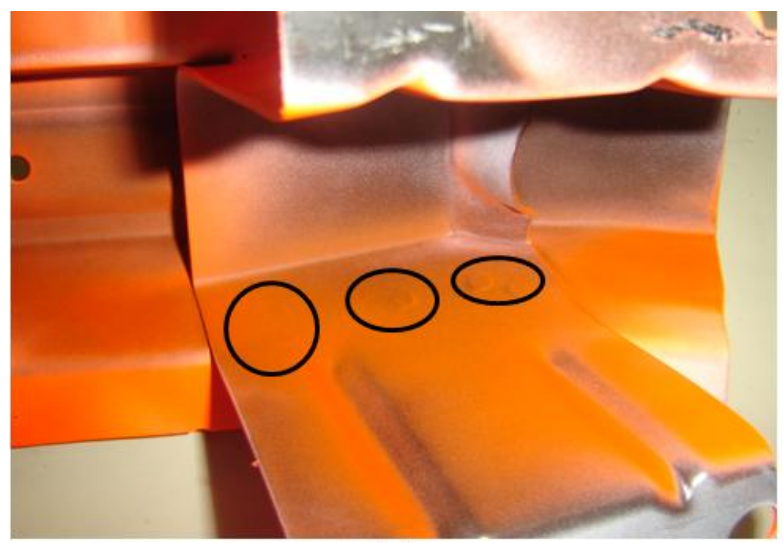

(a)

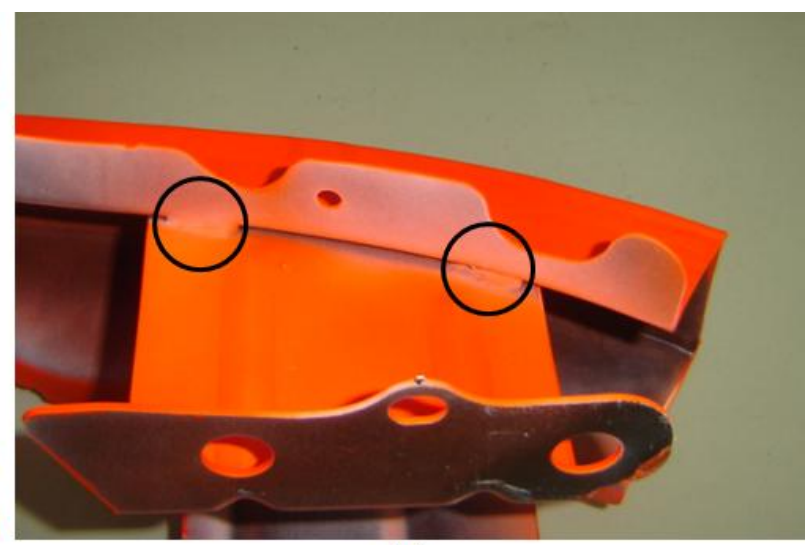

(b)

Figura 40. Detalhe da união do pára-choque com os suportes, (a) solda a ponto; (b) solda MIG.

Os ensaios experimentais estão divididos em duas etapas:

a) Ensaios de baixa severidade: esta etapa busca a correlação de parâmetros importantes do modelo de elementos finitos, como tipo de elemento e quantidade de pontos de integração na espessura, qualidade da malha, propriedades de contato, condições de contorno, modelo de material entre outros. Busca-se, portanto, conhecer a resposta estrutural da barra sem que haja falha da mesma. 
b) Ensaios de alta severidade: nesta etapa busca-se a ocorrência da falha. Os ensaios nesta fase servirão para o comparativo com as análises numéricas considerando ocorrência de falha, utilizando modelos distintos (calibrados através dos ensaios de tração) de modo estudar a eficiência desses modelos na previsão de falha.

É importante ressaltar que o objetivo dos ensaios é de permitir uma análise crítica aos critérios de falha estudados. O trabalho não tem como objetivo analisar ou sugerir mudanças à estrutura do pára-choque utilizado.

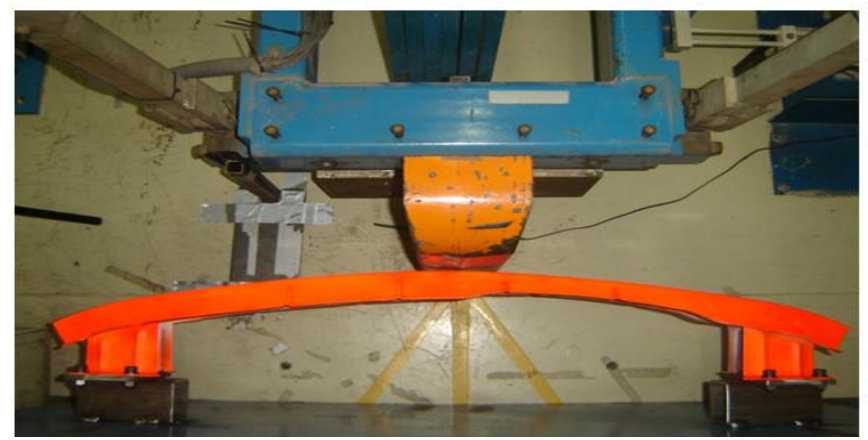

(a)

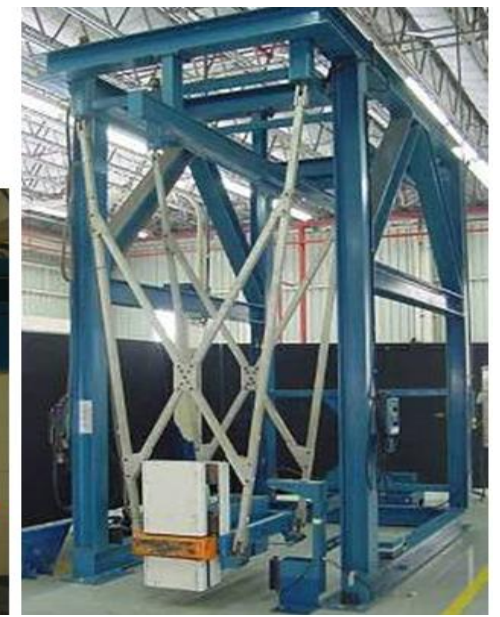

(b)

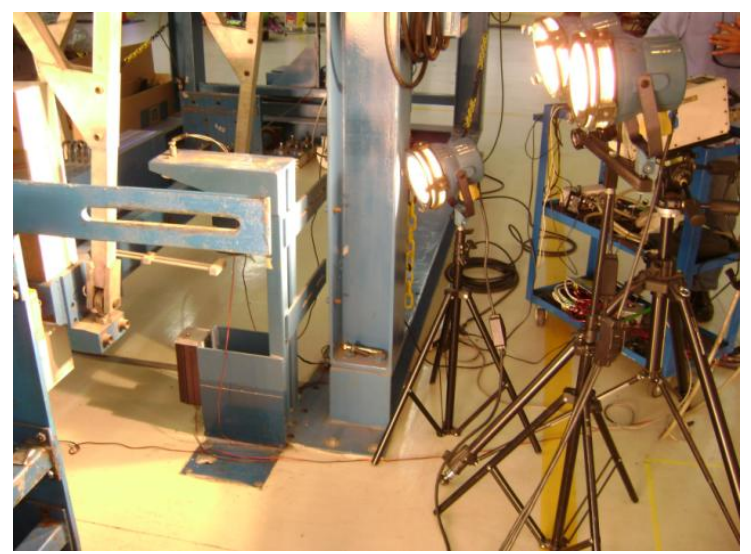

(c)

Figura 41. (a) ensaio da barra de pára-choque visto de cima; (b) pêndulo; (c) sistema de iluminação e aquisição de imagens. 


\subsection{Ensaios de Baixa Severidade}

Ao todo dois ensaios de baixa severidade foram realizados. Nestes ensaios os suportes da Figura 40 foram aparafusados em um espaçador, que por sua vez está soldado a uma barreira imóvel e indeformável, conforme Figura 42. O espaçador foi adicionado a fim de se evitar o contato do pára-choque com a barreira durante a sua deformação. O pára-choque foi pintado para facilitar a visualização nas filmagens.

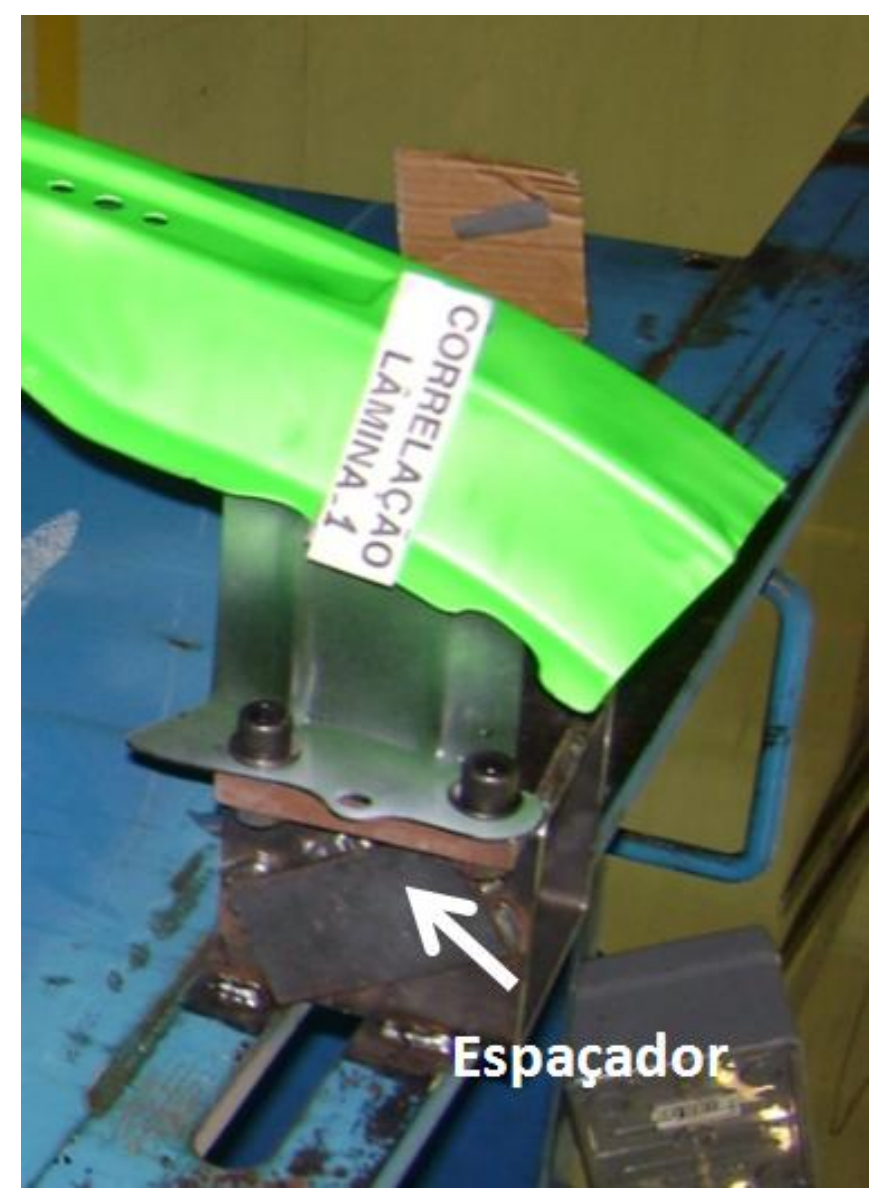

Figura 42. Detalhe das fixações do suporte do pára-choque na barreira.

Ambos os testes foram executados impactando-se o pára-choque no centro, o primeiro a $1,39 \mathrm{~m} / \mathrm{s}$ e $980 \mathrm{~kg}$ e o segundo, mais severo, a $1,94 \mathrm{~m} / \mathrm{s}$ e $1000 \mathrm{~kg}$, conforme resumido na Tabela 10. 
Tabela 10 - Configuração dos ensaios de baixa severidade.

\begin{tabular}{lcccc}
\hline \# Teste & Velocidade $(\mathrm{m} / \mathrm{s})$ & Massa $(\mathrm{kg})$ & $\begin{array}{c}\text { Ponto de } \\
\text { impacto }\end{array}$ & Condição de contorno \\
\hline 1 & 1,39 & 950 & Centro & Suporte aparafusado \\
2 & 1,94 & 1000 & Centro & Suporte aparafusado \\
\hline
\end{tabular}

A Figura 43 ilustra a condição depois do impacto e a Figura 44 a seqüência de imagens capturadas pela câmera de alta velocidade.

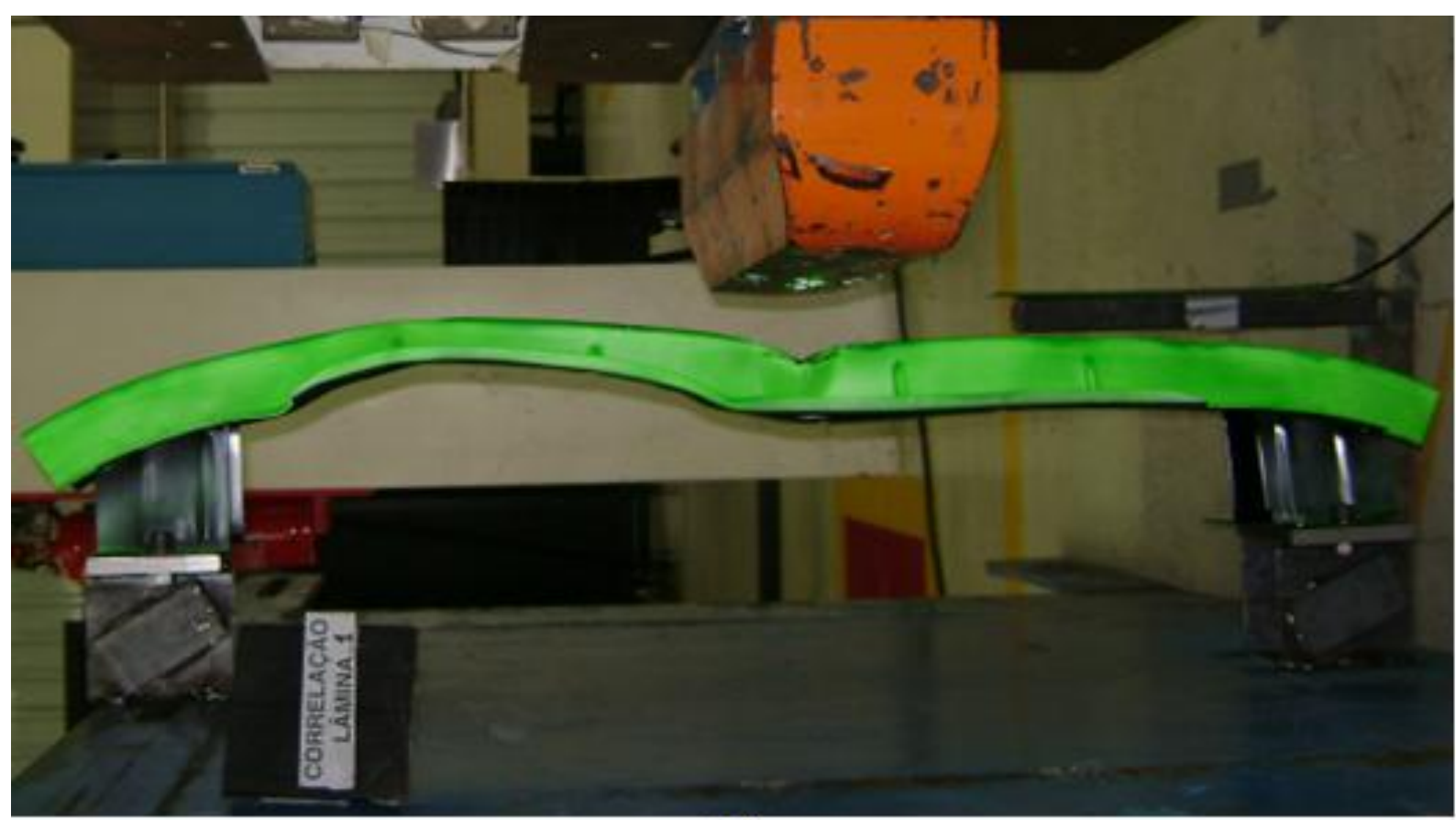

(a)

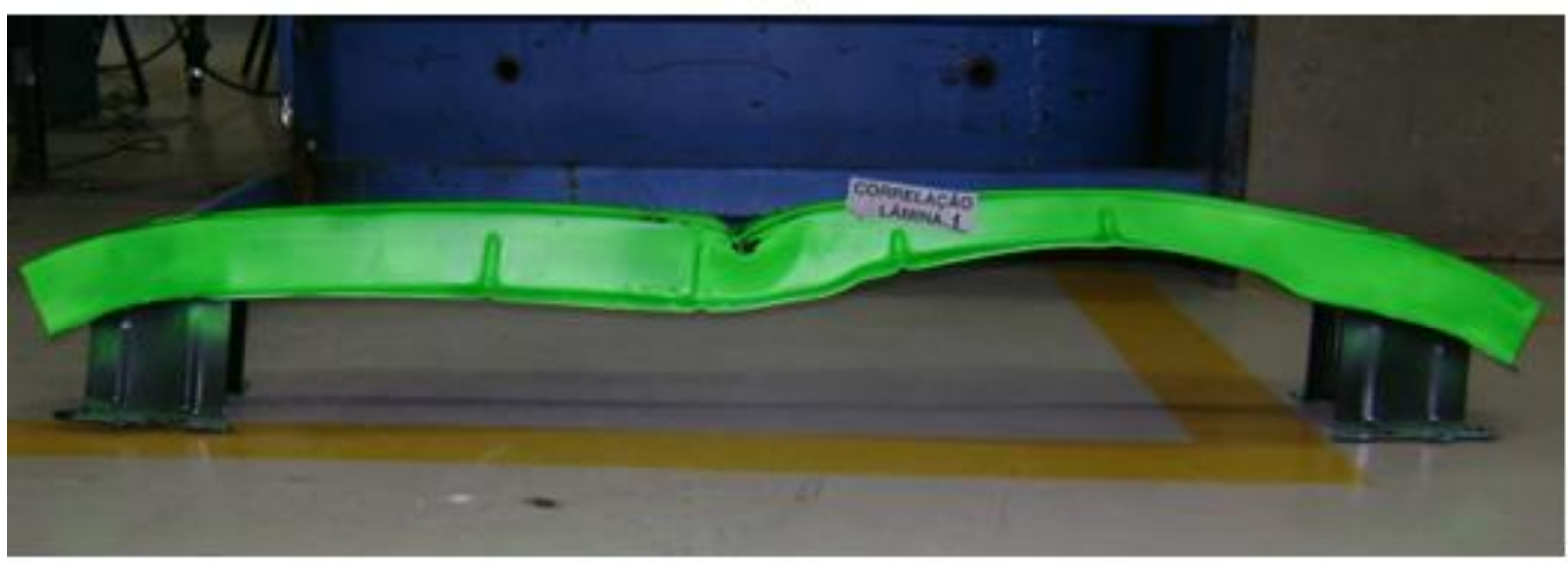

(b)

Figura 43. Pára-choque depois do impacto (a) ainda no dispositivo; (b) fora do dispositivo. 


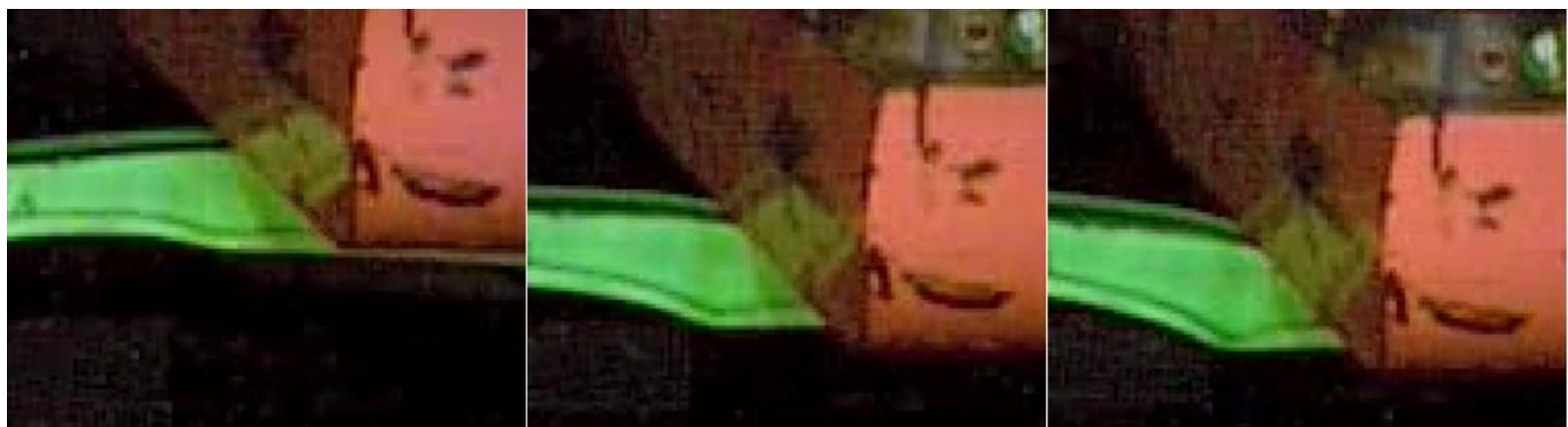

Figura 44. Imagens seqüenciais do impacto do Teste \#1 (massa de $950 \mathrm{~kg}$ a 1,39 m/s).

Como se pode observar pela Figura 45, não houve ocorrência de falha do material na região de impacto, sendo que as regiões escuras correspondem aos pontos onde a tinta foi destacada devido ao atrito com o impactador.

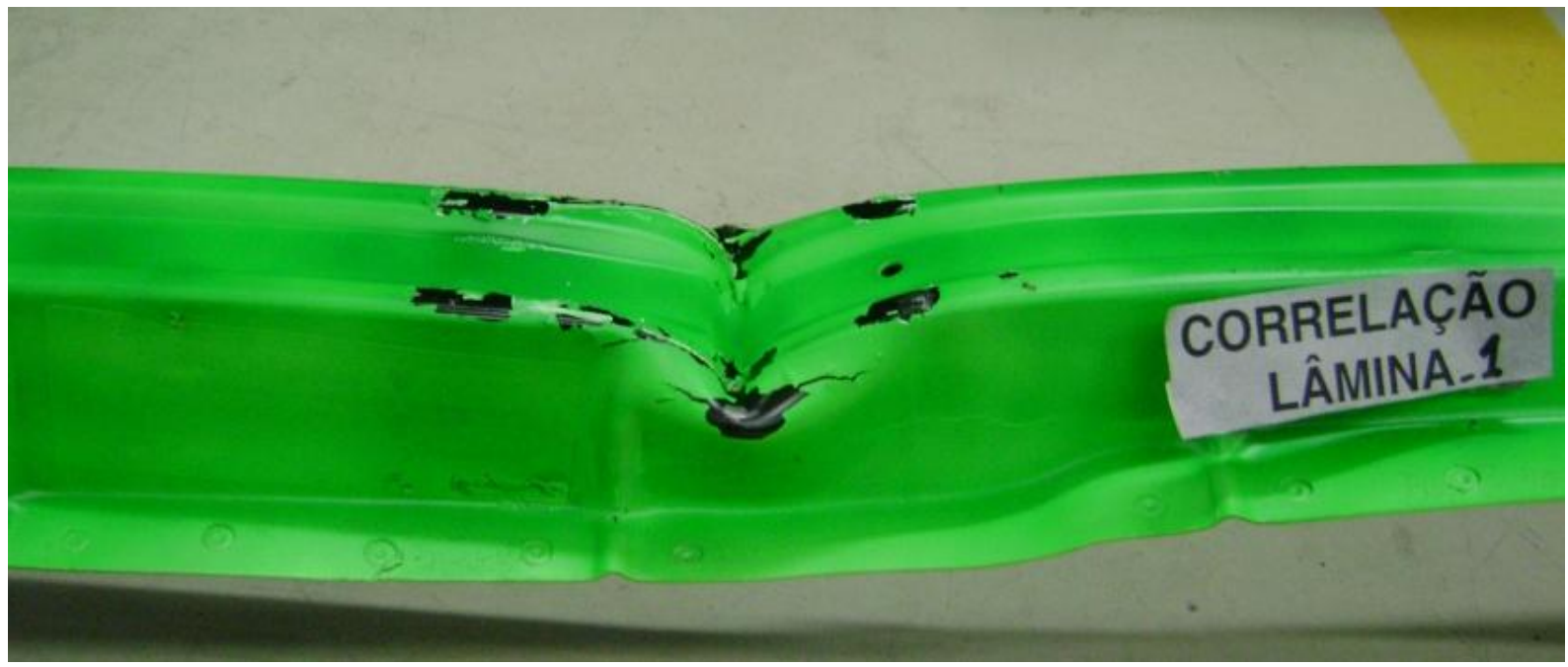

Figura 45. Detalhe das deformações no ponto de impacto do Teste \#1.

Conforme esperado, no Teste \#2 as deformações do pára-choque foram maiores devido à maior massa e velocidade de impacto. A Figura 46 ilustra o nível de deformação do pára-choque após o ensaio. 


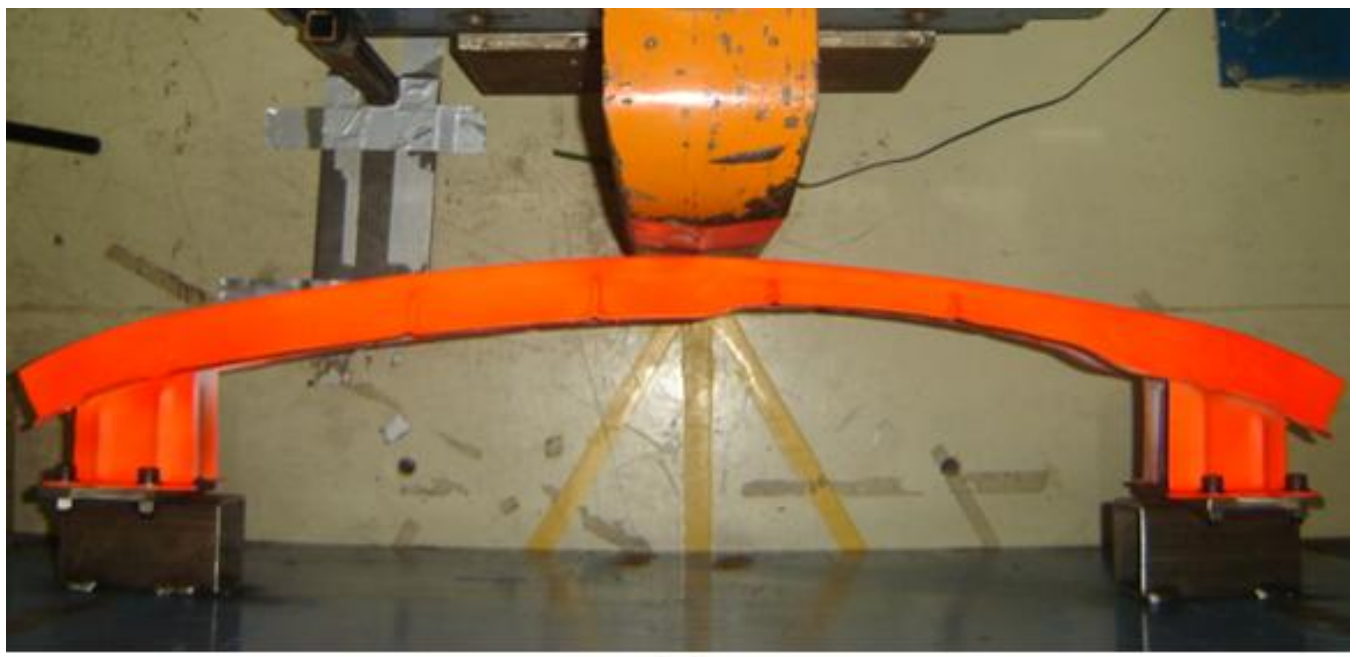

(a)

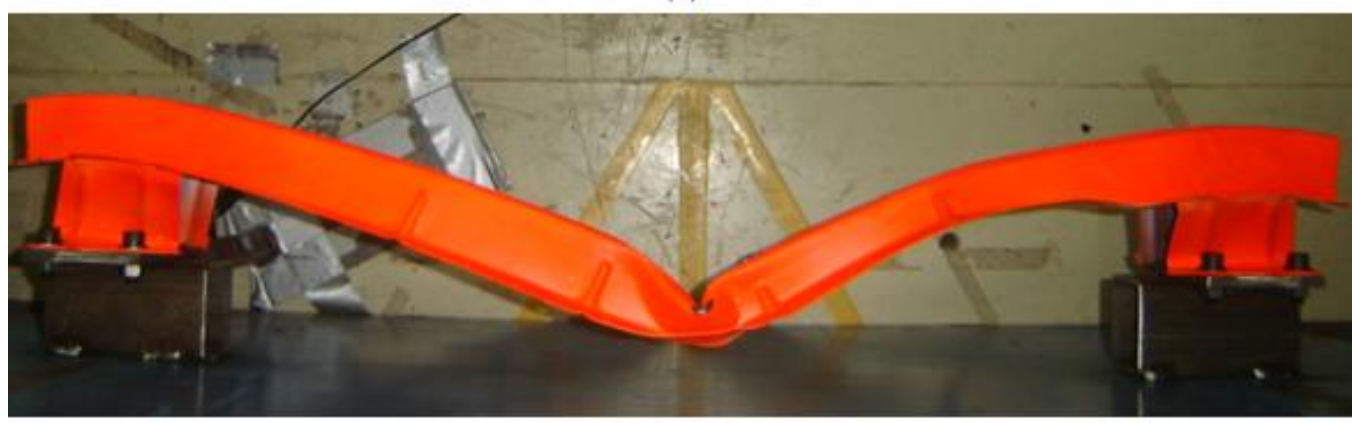

(b)

Figura 46. (a) condição do Teste \#2 antes do ensaio; (b) depois do ensaio.

Assim como no Teste \#1, não foi observada ruptura do material na região de impacto, conforme ilustrado na Figura 47. No entanto, foi verificado o colapso dos suportes seguido de ruptura das regiões aparafusadas (Figura 48).

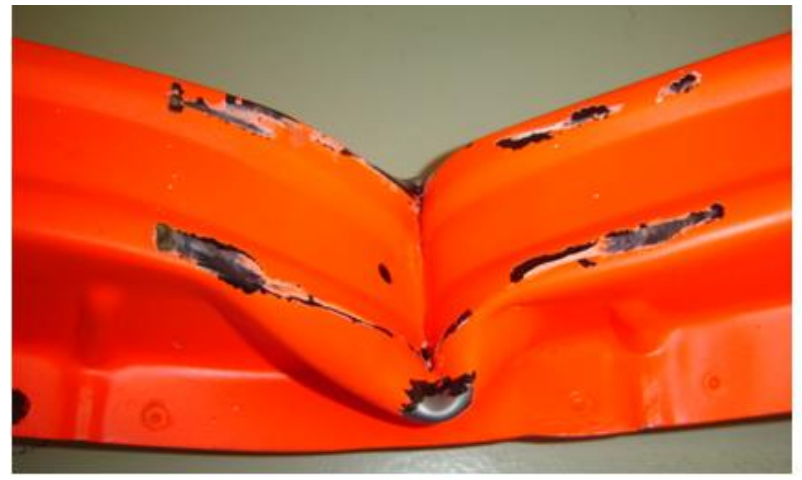

(a)

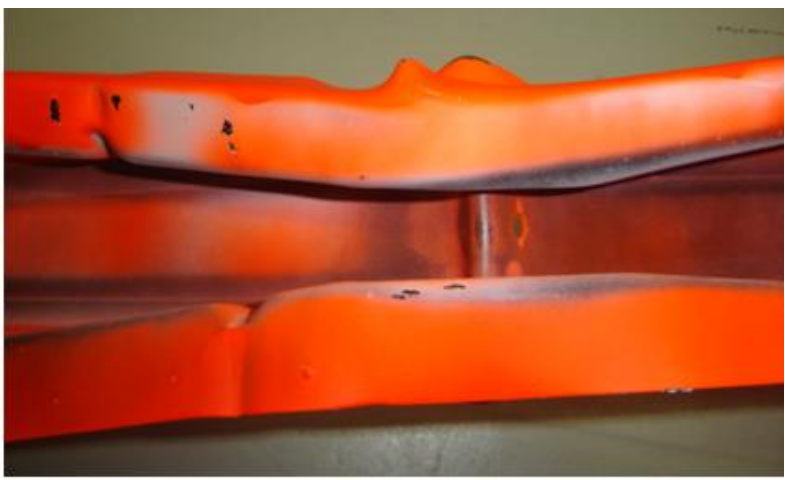

(b)

Figura 47. Detalhe das deformações no ponto de impacto do Teste \#2, (a) vista externa; (b) vista interna. 


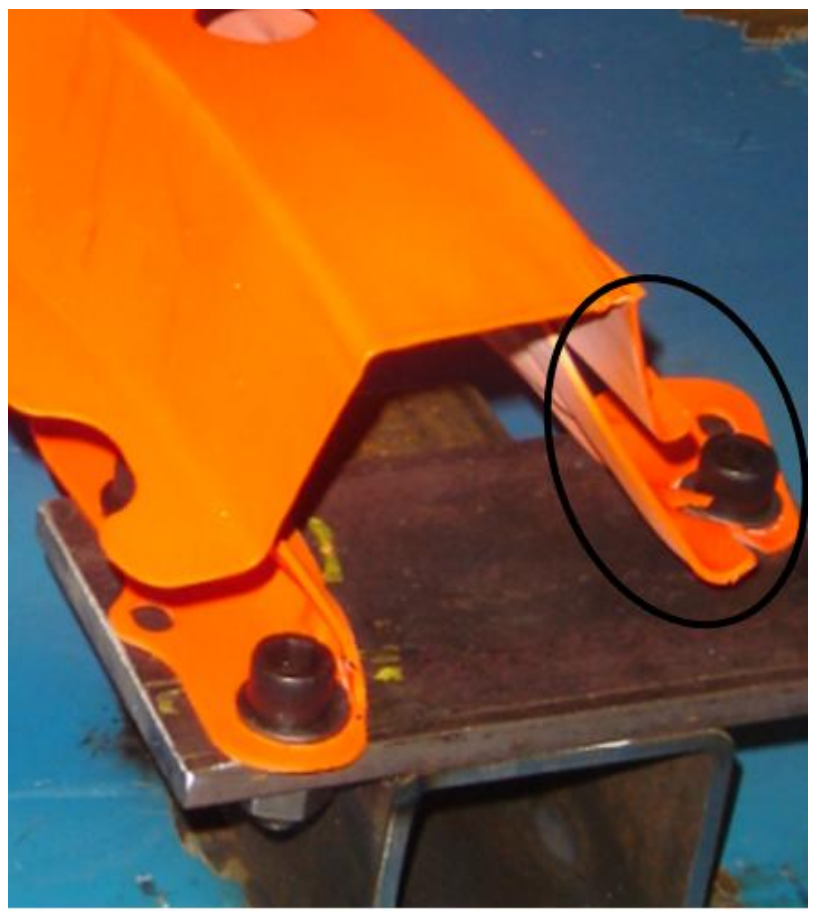

(a)

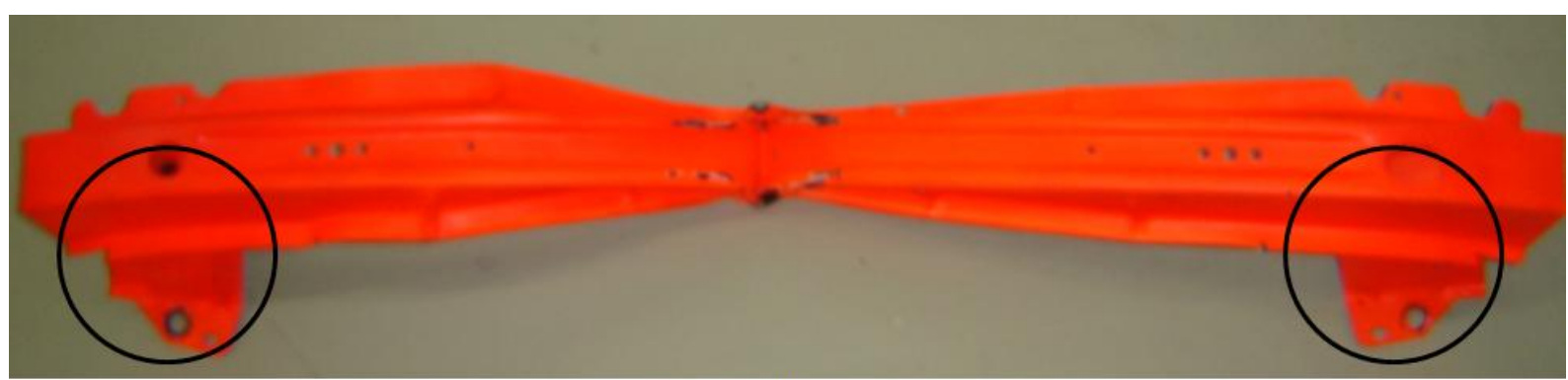

(b)

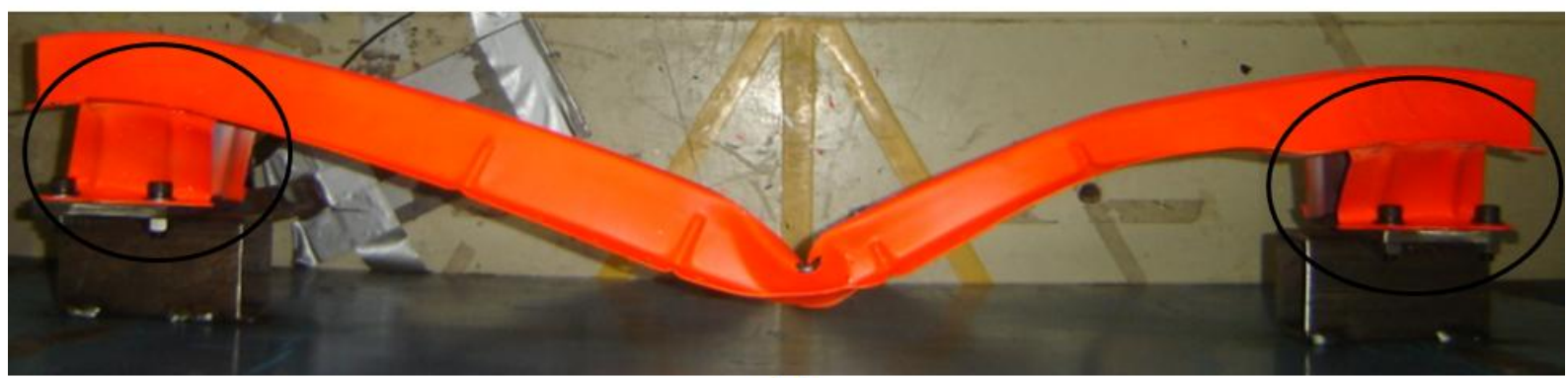

(c)

Figura 48. (a) Detalhe da ruptura dos suportes; (b) colapso dos suportes visto de topo; (c) vista lateral.

Pode-se concluir, portanto, que para ensaios mais severos objetivando-se a ruptura do material do pára-choque, a união dos suportes deve ser reforçada a fim de se caracterizar um engaste rígido. 


\subsection{Ensaios de Alta Severidade}

Os ensaios de alta severidade aqui descritos são meramente didáticos e visam deliberadamente o surgimento de uma falha no componente, não representando nenhum tipo de teste de desenvolvimento e nem fazendo parte da validação do veículo ou componente.

Foram necessários quatro ensaios de severidade alta para se atingir a ruptura do material do pára-choque de maneira satisfatória. A Tabela 11 resume as condições de teste, sendo que o aprendizado do teste anterior foi aplicado ao posterior.

Tabela 11 - Configuração dos ensaios de alta severidade.

\begin{tabular}{lcccc}
\hline \# Teste & $\begin{array}{c}\text { Velocidade } \\
(\mathrm{m} / \mathrm{s})\end{array}$ & $\begin{array}{c}\text { Massa } \\
(\mathrm{kg})\end{array}$ & $\begin{array}{c}\text { Ponto de } \\
\text { impacto }\end{array}$ & Condição de contorno \\
\hline 3 & 1,94 & 1000 & Extremidade & $\begin{array}{c}\text { Suporte aparafusado com reforço } \\
4\end{array}$ \\
3,88 & 1000 & Extremidade & $\begin{array}{c}\text { Suporte aparafusado com reforço } \\
\text { Suporte soldado com reforço }\end{array}$ \\
5 & 4,08 & 1000 & Extremidade & Suporto \\
6 & 4,09 & 800 & Extremidade & Suporte soldado com reforço \\
\hline
\end{tabular}

Para viabilizar ensaios de impacto de maior severidade objetivando-se a ruptura do material do pára-choque, foi necessário reforçar a região do suporte, uma vez que este colapsou no Teste \#2. Para atingir tal condição, foi adicionada dentro do suporte uma alma metálica de perfil quadrado (25 mm x $25 \mathrm{~mm}$ ) considerada rígida, de modo a transmitir toda a carga axial proveniente do impacto para a barreira. Além disso, o ponto de impacto no pára-choque foi deslocado do centro, para $350 \mathrm{~mm}$ da extremidade.

O Teste \#3 foi então executado com a mesma massa e velocidade do Teste \#2. A Figura 49 ilustra a condição do ensaio \#3 e a Figura 50 detalha o comportamento do suporte, reforçado por meio de uma alma metálica em seu interior. 


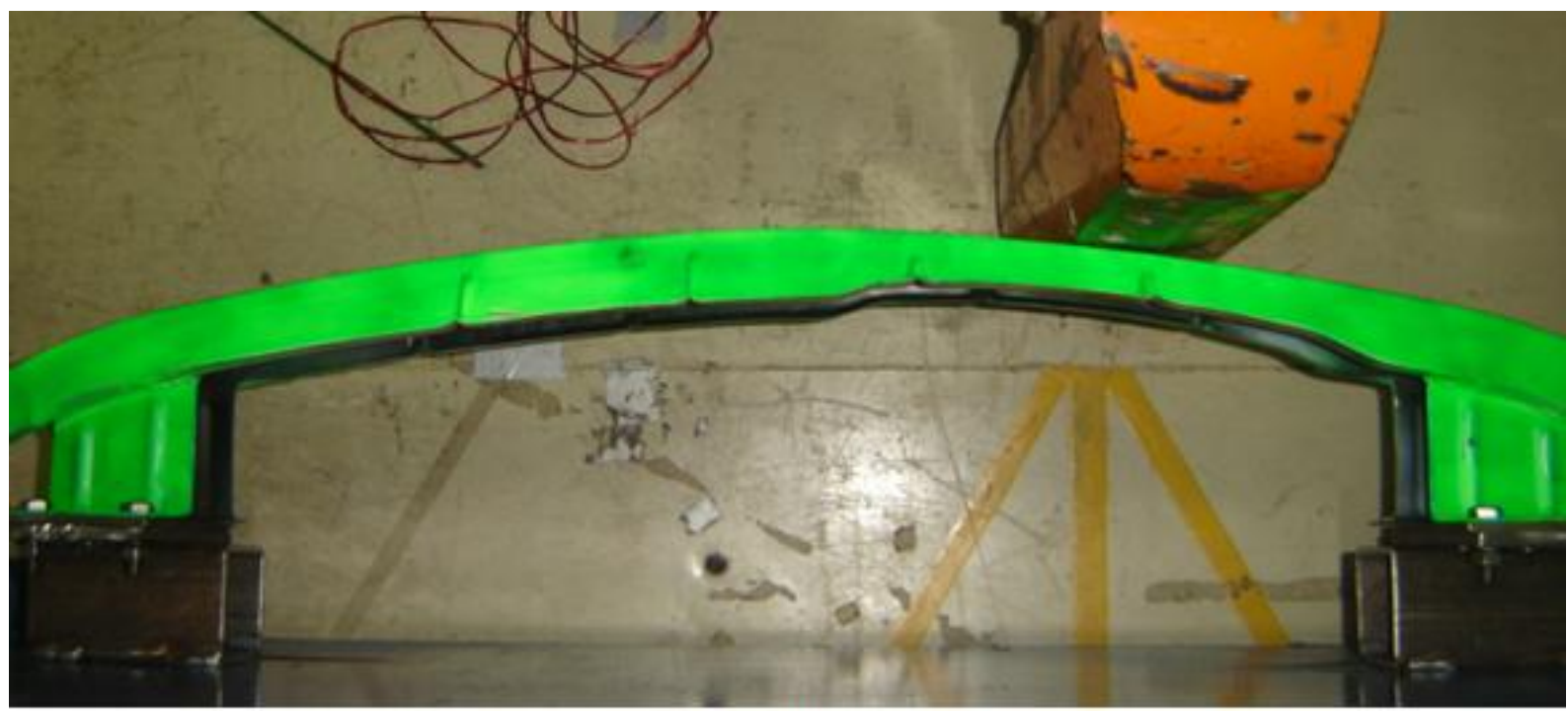

(a)

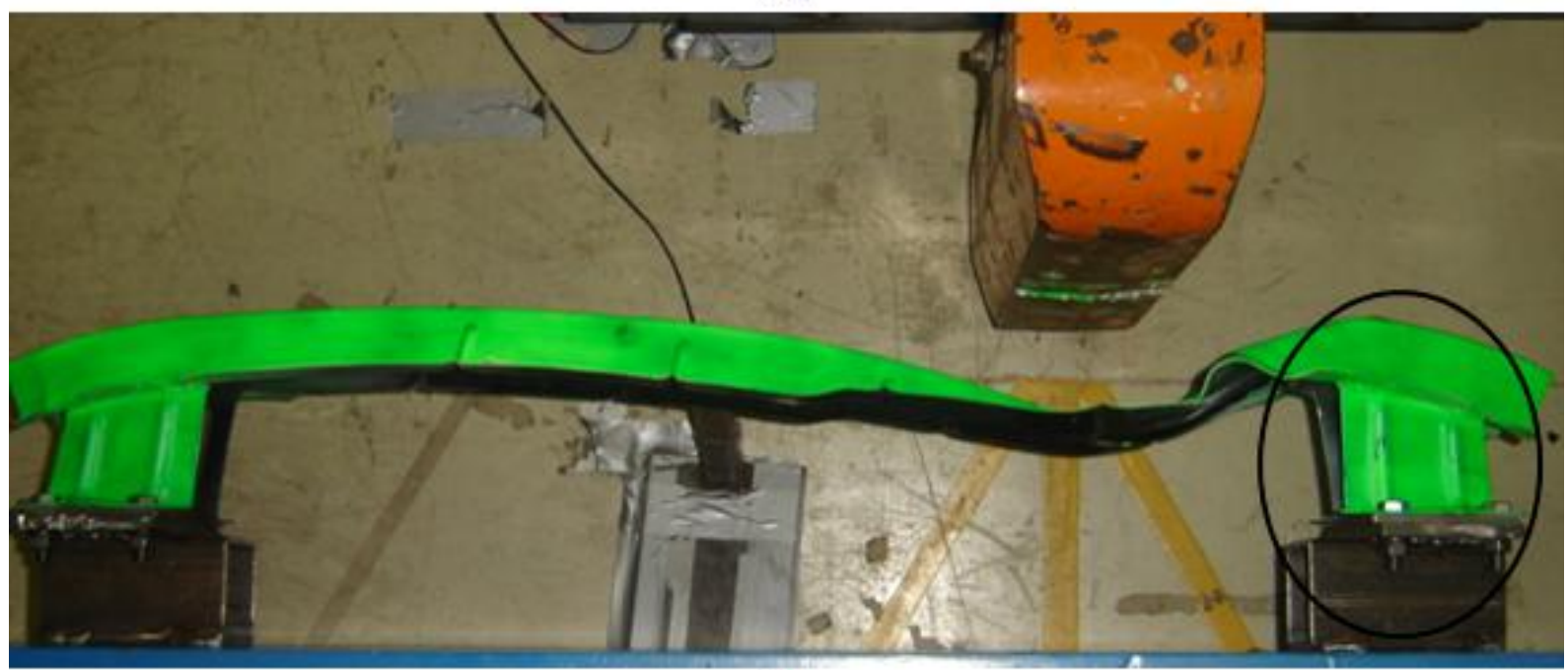

(b)

Figura 49. (a) condição do Teste \#3 antes do ensaio; (b) depois do ensaio e detalhe do suporte sem colapso.

Apesar das alterações de ponto de impacto e rigidez dos suportes, não foi observada ruptura do pára-choque. Sendo assim, para o Teste \#4, a velocidade foi aumentada para $3,88 \mathrm{~m} / \mathrm{s}$, mantendo-se os demais parâmetros iguais ao do Teste \#3. Como resultado, obteve-se deformações elevadas não só no pára-choque, mas também no suporte mais próximo do ponto de impacto. 0 mesmo não suportou o momento aplicado pelo impacto pendular e sofreu ruptura na região aparafusada. Além disso, os espaçadores (Figura 42) não foram suficientes para evitar o contato do pára-choque com a barreira rígida durante 0 impacto, resultando no esmagamento do pára-choque. A Figura 52 ilustra as ocorrências supracitadas. 


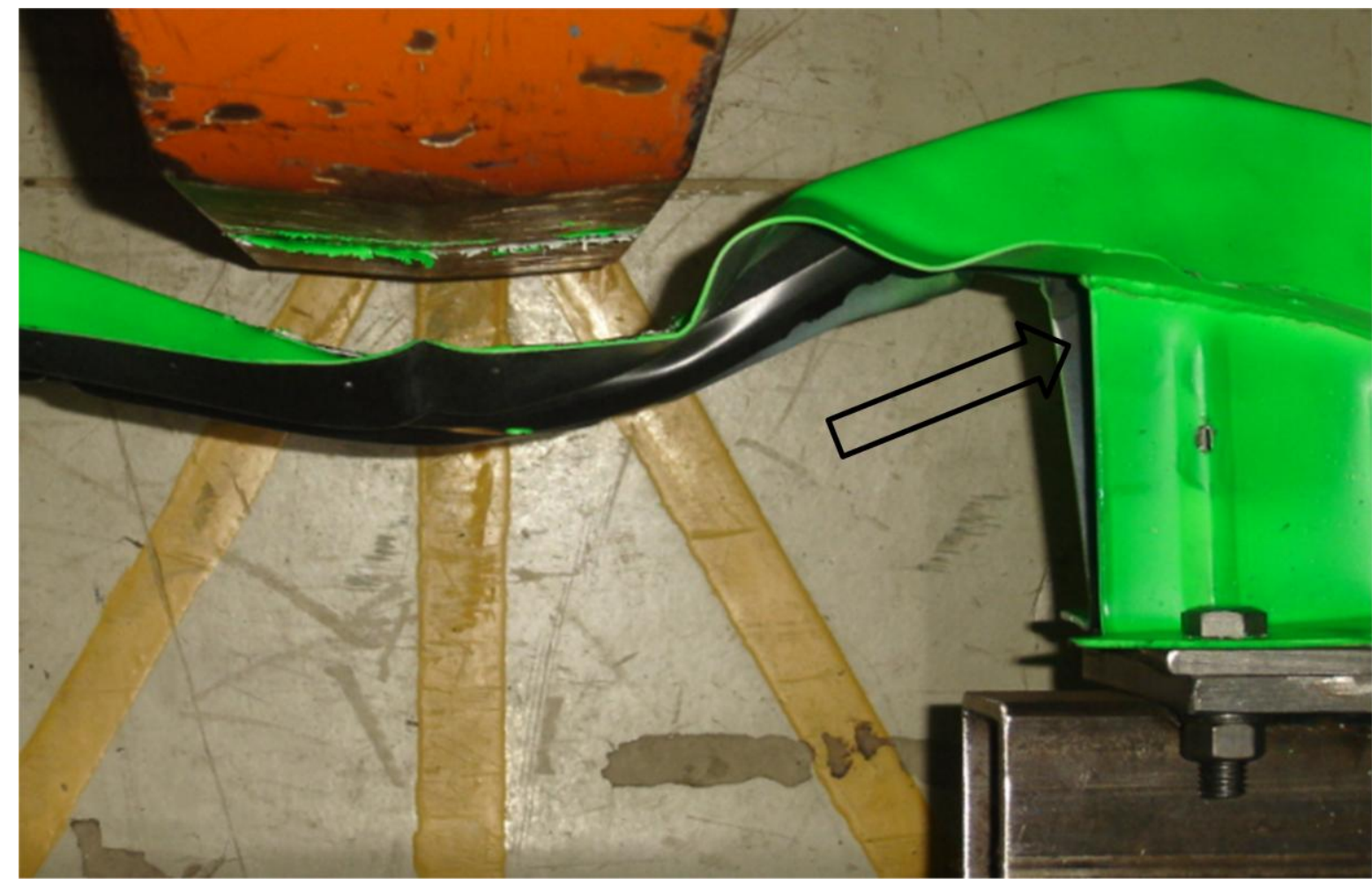

Figura 50. Detalhe do suporte reforçado com uma alma metálica em seu interior.

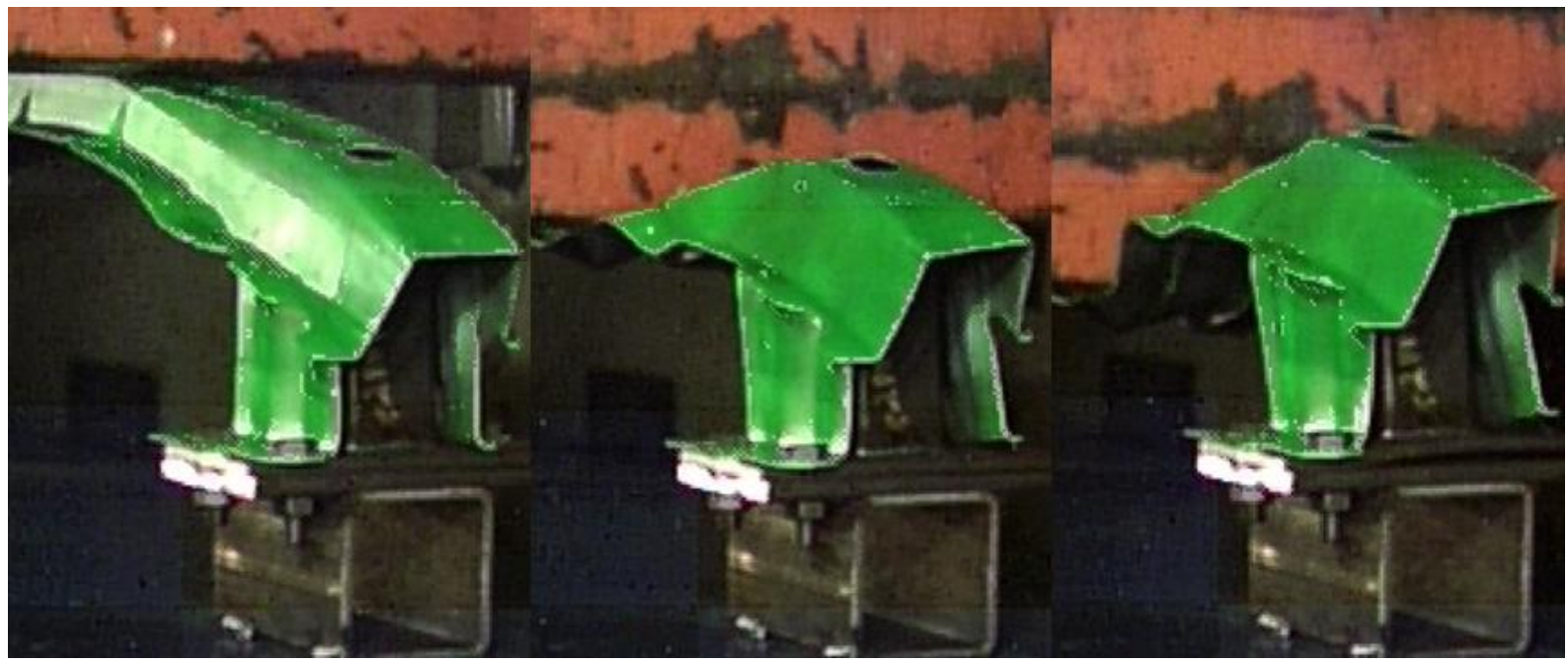

Figura 51. Imagens seqüenciais do impacto do Teste \#3 a cada $55 \mathrm{~ms}$ (massa de $1000 \mathrm{~kg}$ a 1,94 $\mathrm{m} / \mathrm{s})$. 


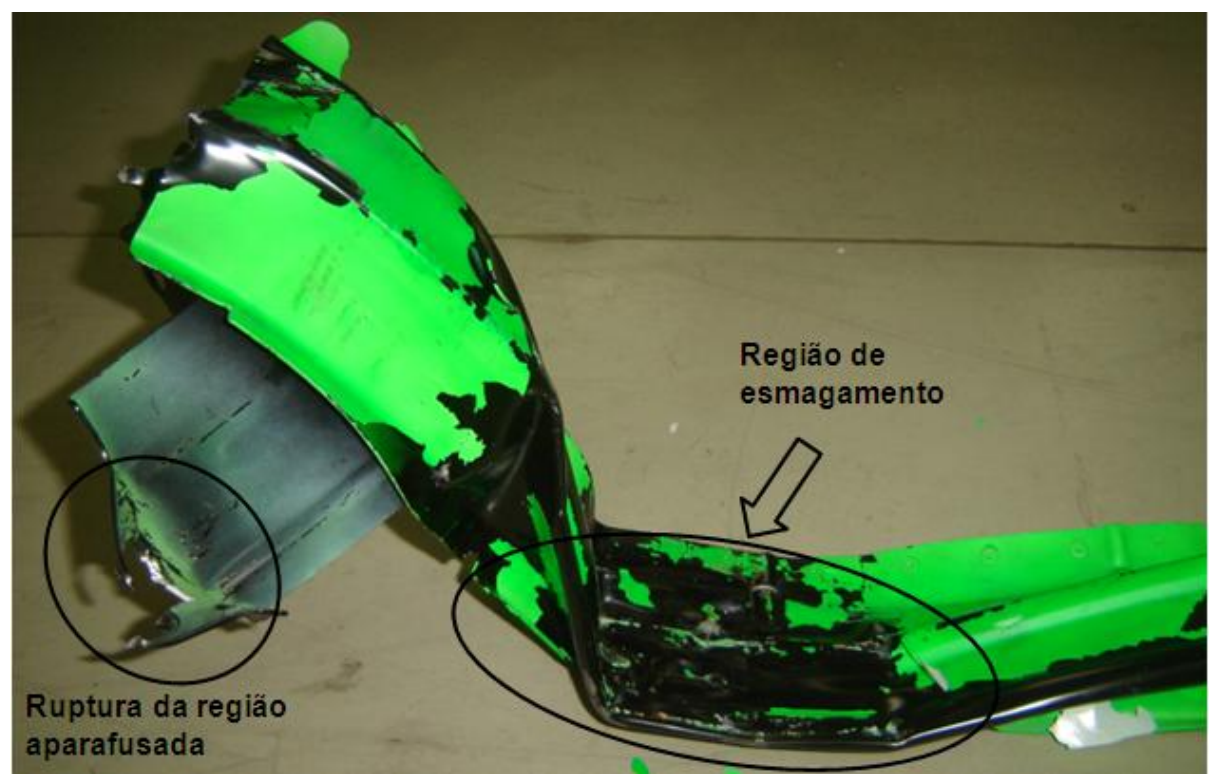

Figura 52. Detalhe da ruptura do suporte no Teste \#4.

A fim de se evitar novamente o colapso dos suportes, os mesmos foram fixados ao espaçador por solda MIG ao invés de parafusos, de modo a termos uma situação de engaste quase ideal e, para evitar o esmagamento do pára-choque, o espaçador foi duplicado. A Figura 53 ilustra essas alterações nas condições de contorno.

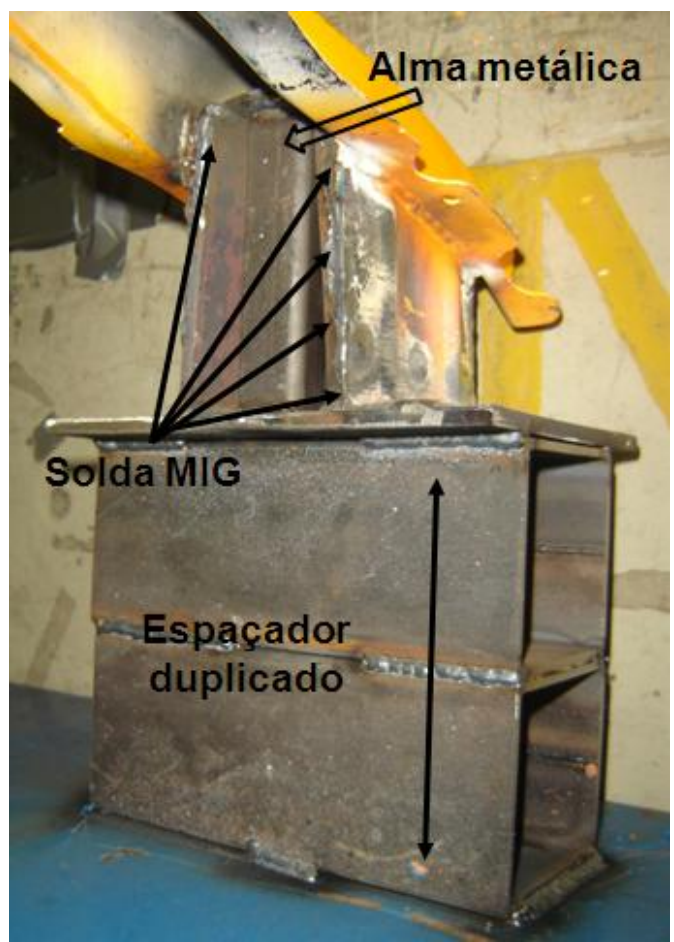

Figura 53. Detalhe da condição de contorno dos suportes para o Teste \#5. 
Além das alterações acima, foi adicionada uma coluna, ilustrada na Figura 54, a 480 $\mathrm{mm}$ da extremidade esquerda do pára-choque com o objetivo de reduzir o vão e aumentar a solicitação imposta ao pára-choque durante o ensaio.

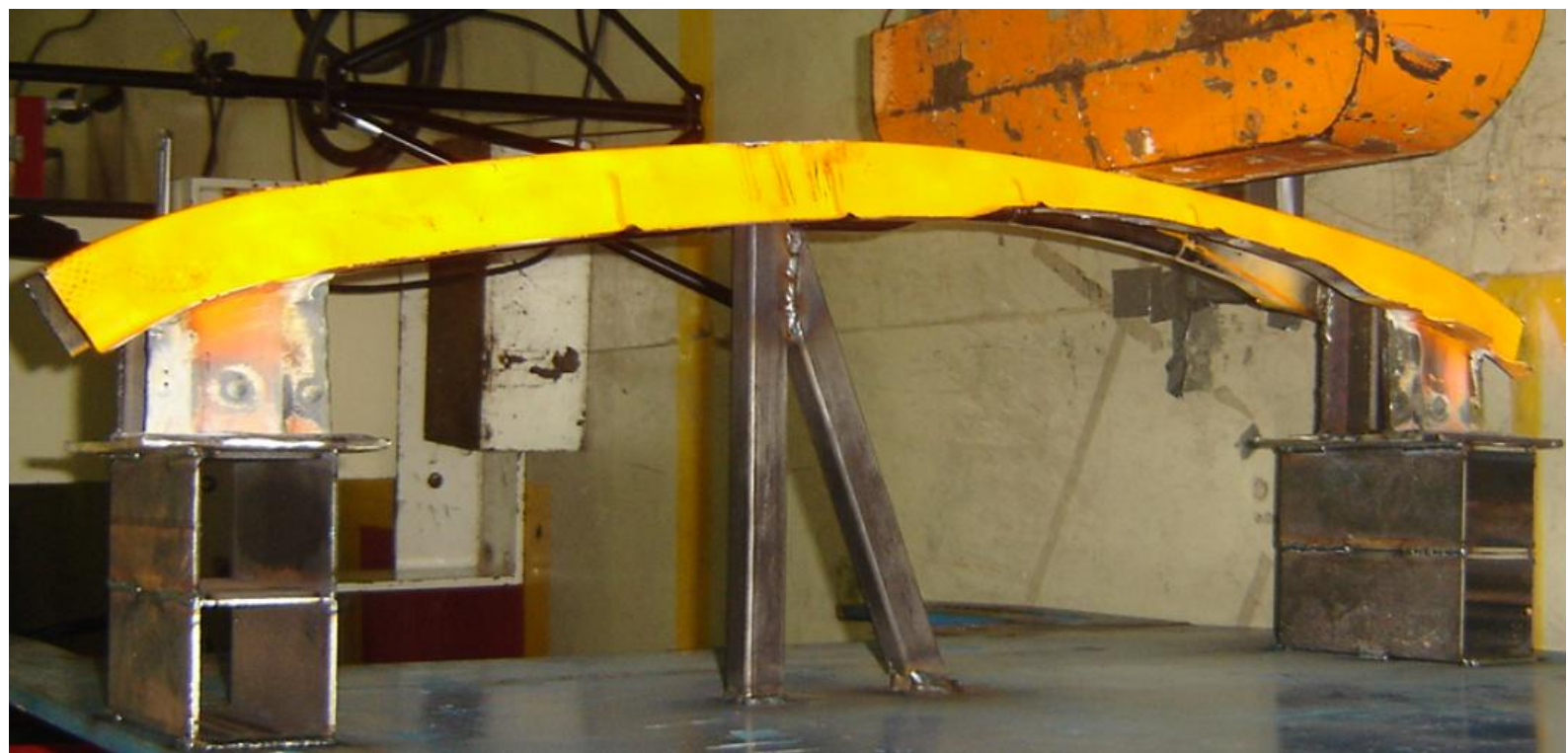

(a)

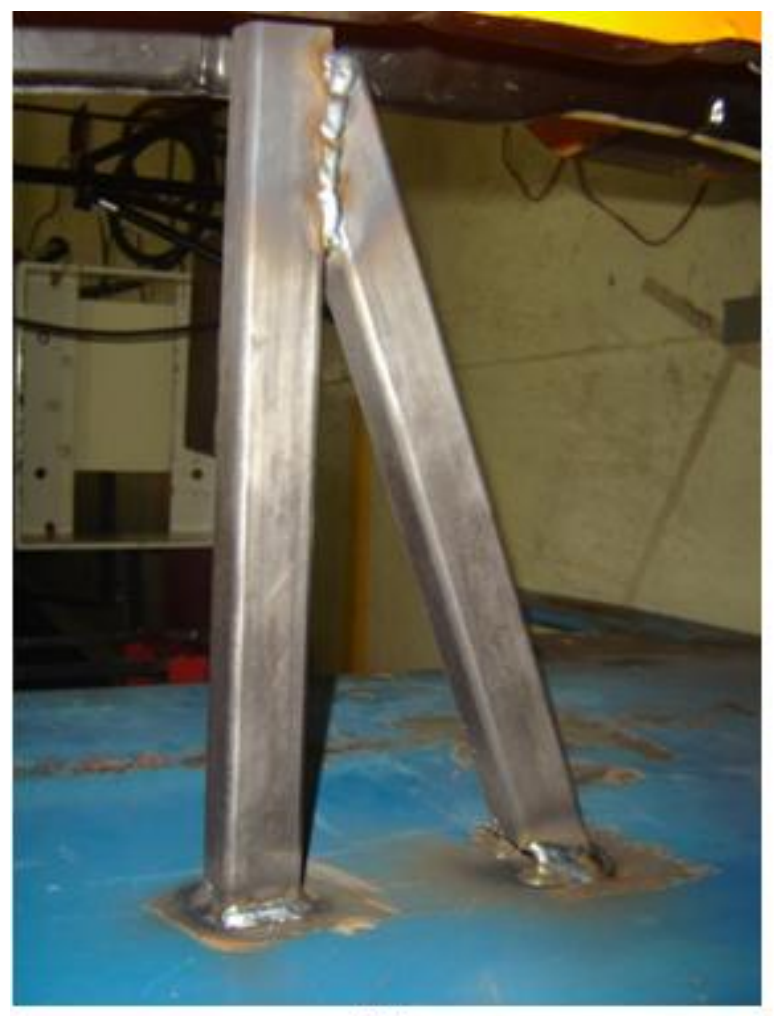

(b)

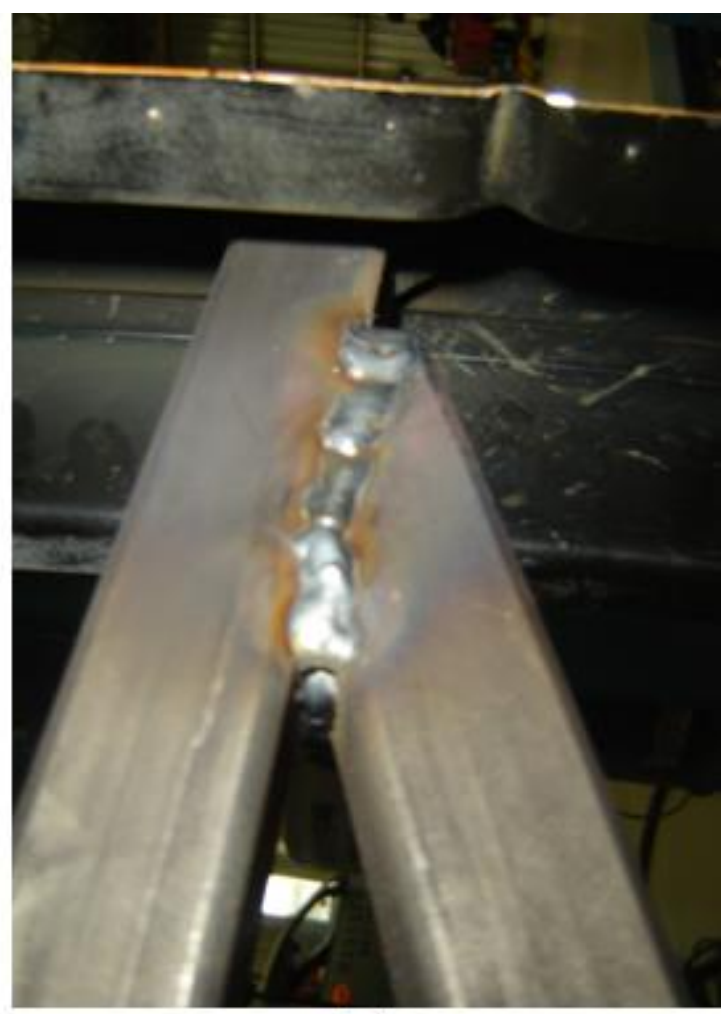

(c)

Figura 54. (a) preparação do Teste \#5; (b)-(c) detalhe da coluna adicionada a $480 \mathrm{~mm}$ da extremidade inferior. 
Como resultado do impacto, o pára-choque sofreu ruptura em três regiões. Com o auxilio da filmagem em alta velocidade da Figura 55, pode-se observar que a primeira ruptura surge na porção de união com a coluna central, a segunda surge depois na região de impacto com o pêndulo, detalhada na Figura 56. A terceira região de falha ocorreu próxima do engaste inferior, conforme Figura 57.

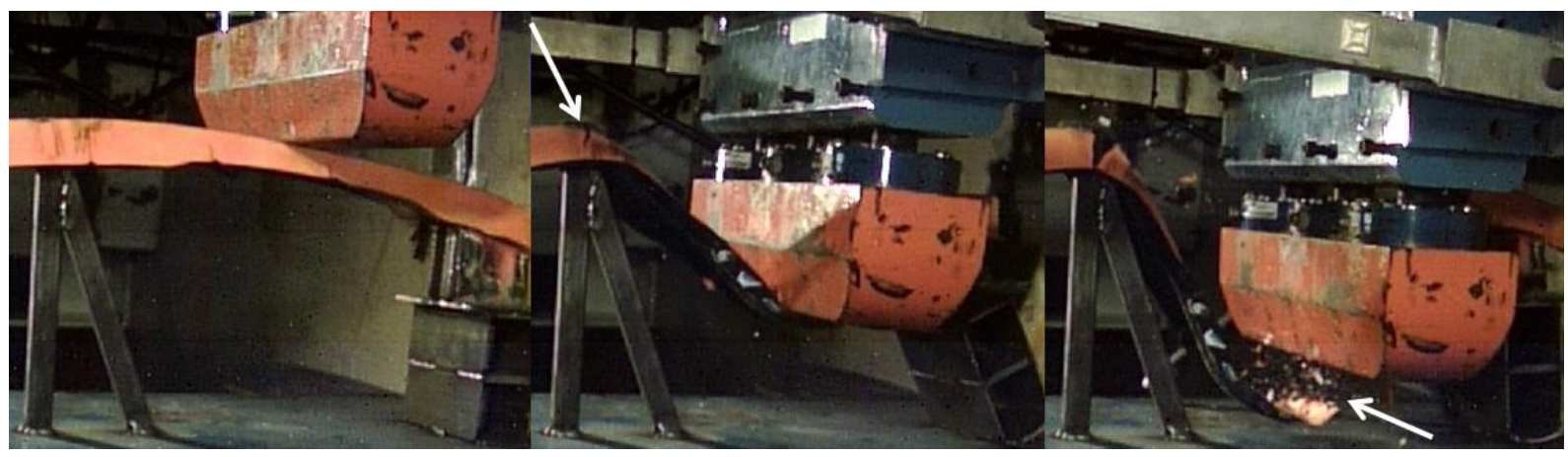

Figura 55. Imagens seqüenciais do Teste\#5 (massa de $1000 \mathrm{~kg} \mathrm{a} \mathrm{4,09} \mathrm{m/s).}$
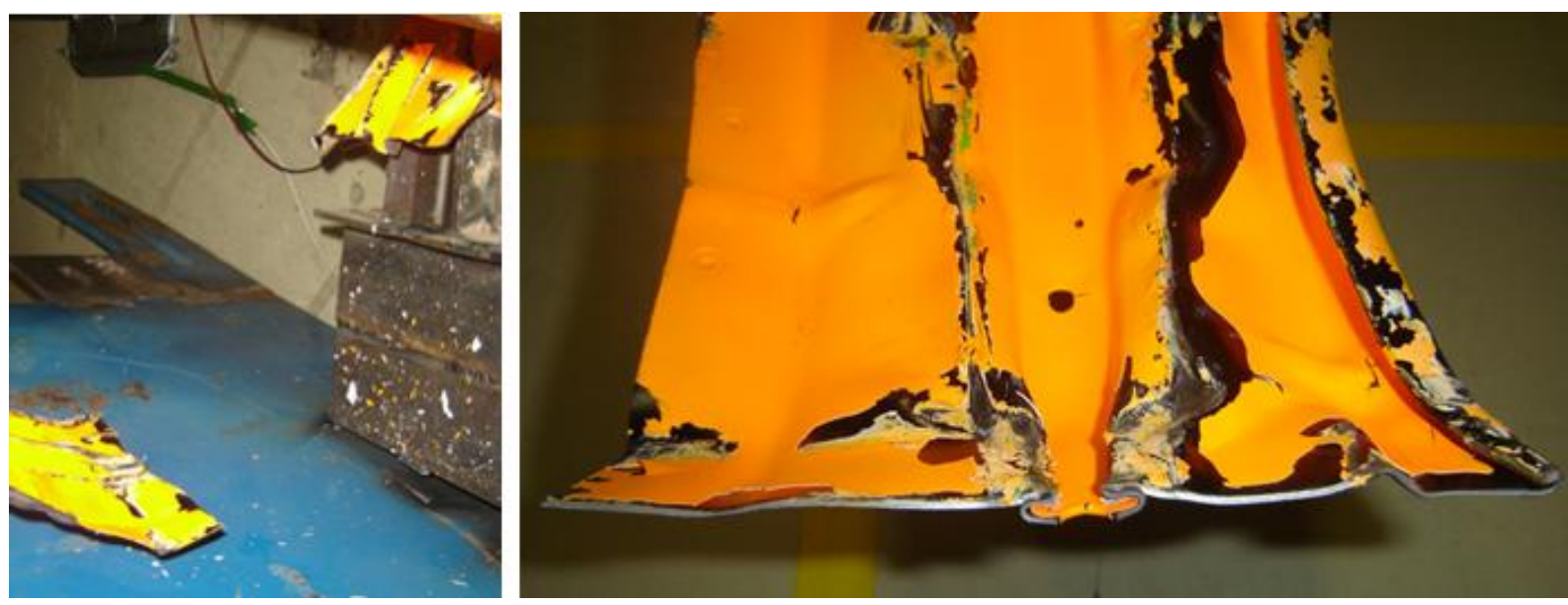

Figura 56. Detalhe da ruptura na região de impacto com o pêndulo.

Após o teste, foi verificado que a ruptura ocorrida na junção do pára-choque com a coluna central iniciou-se a partir da zona termicamente afetada pela solda MIG, conforme evidenciado na Figura 58. Além disso, a imagem de alta velocidade indica que houve novamente o esmagamento do pára-choque, evidenciada também na Figura 59. 


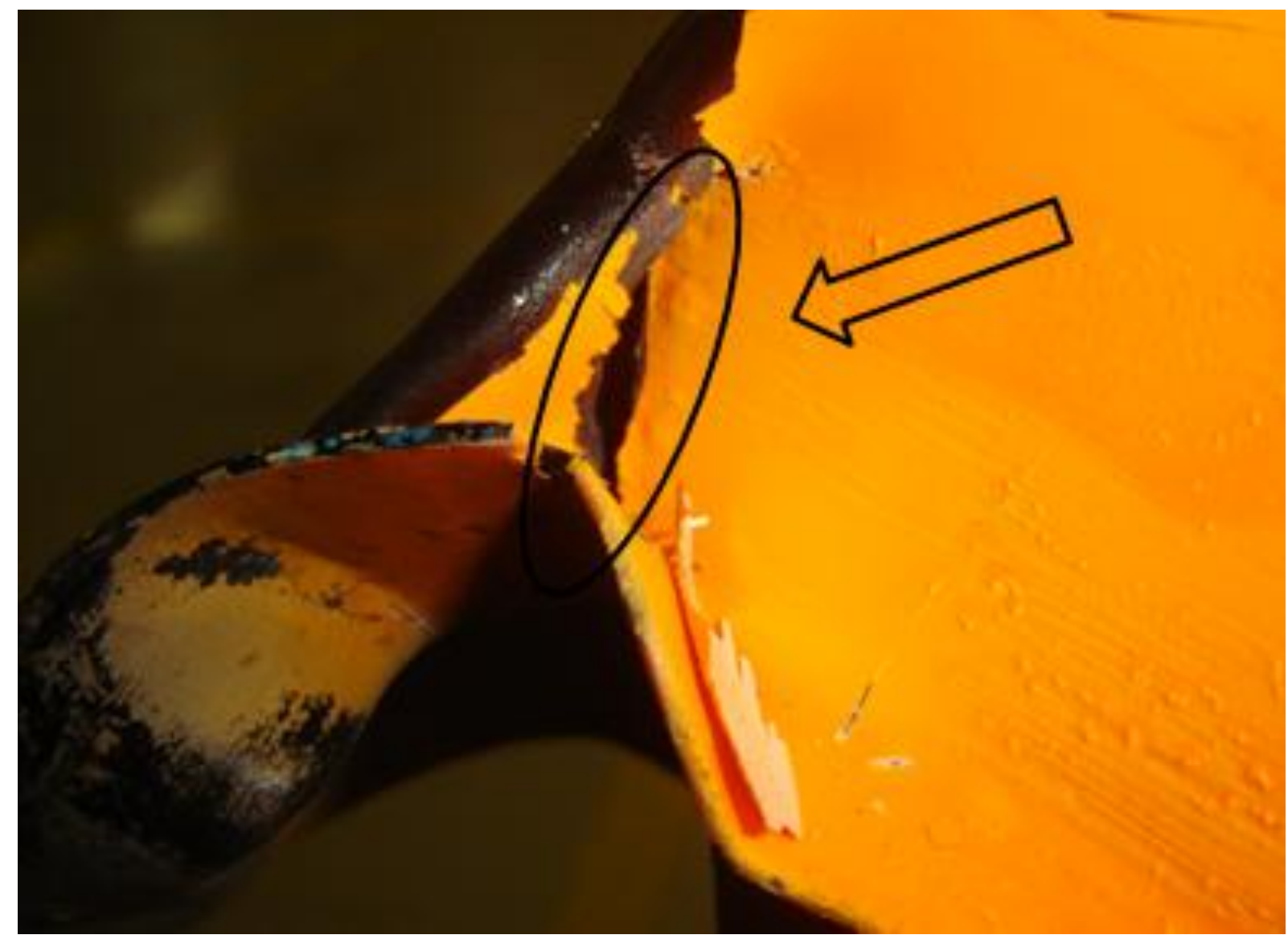

Figura 57. Ocorrência de ruptura próxima ao engaste inferior.
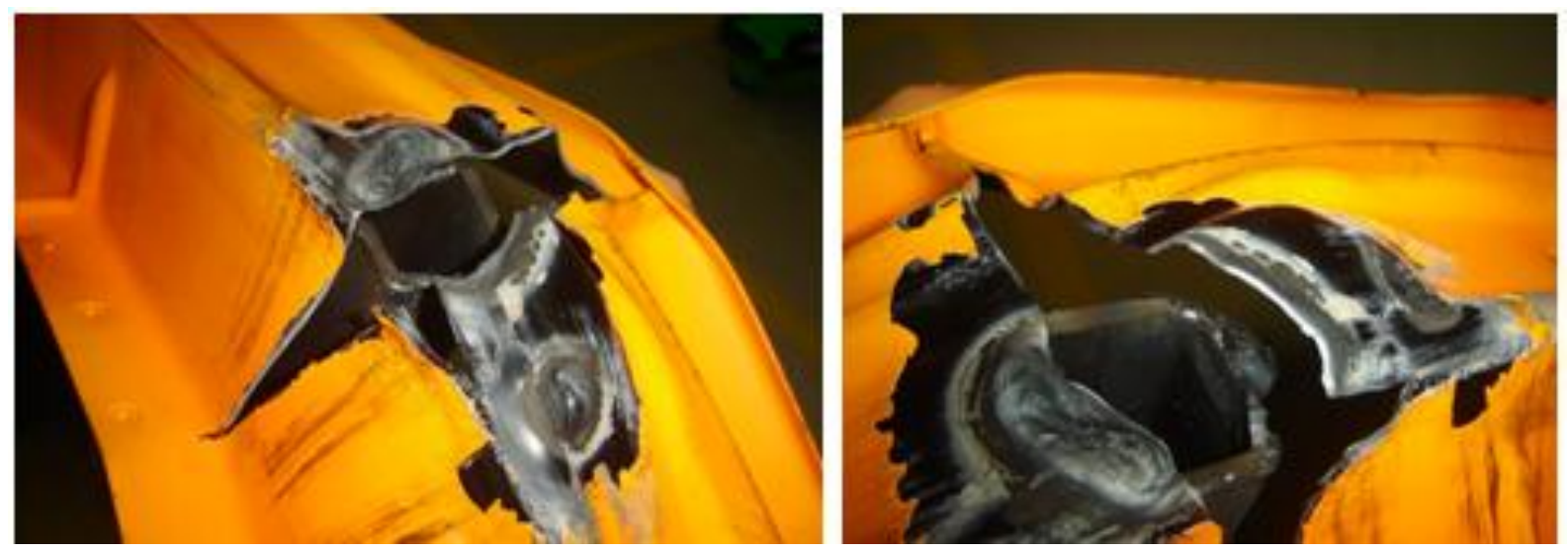

Figura 58. Ruptura iniciada na zona termicamente afetada pelo cordão de solda MIG. 


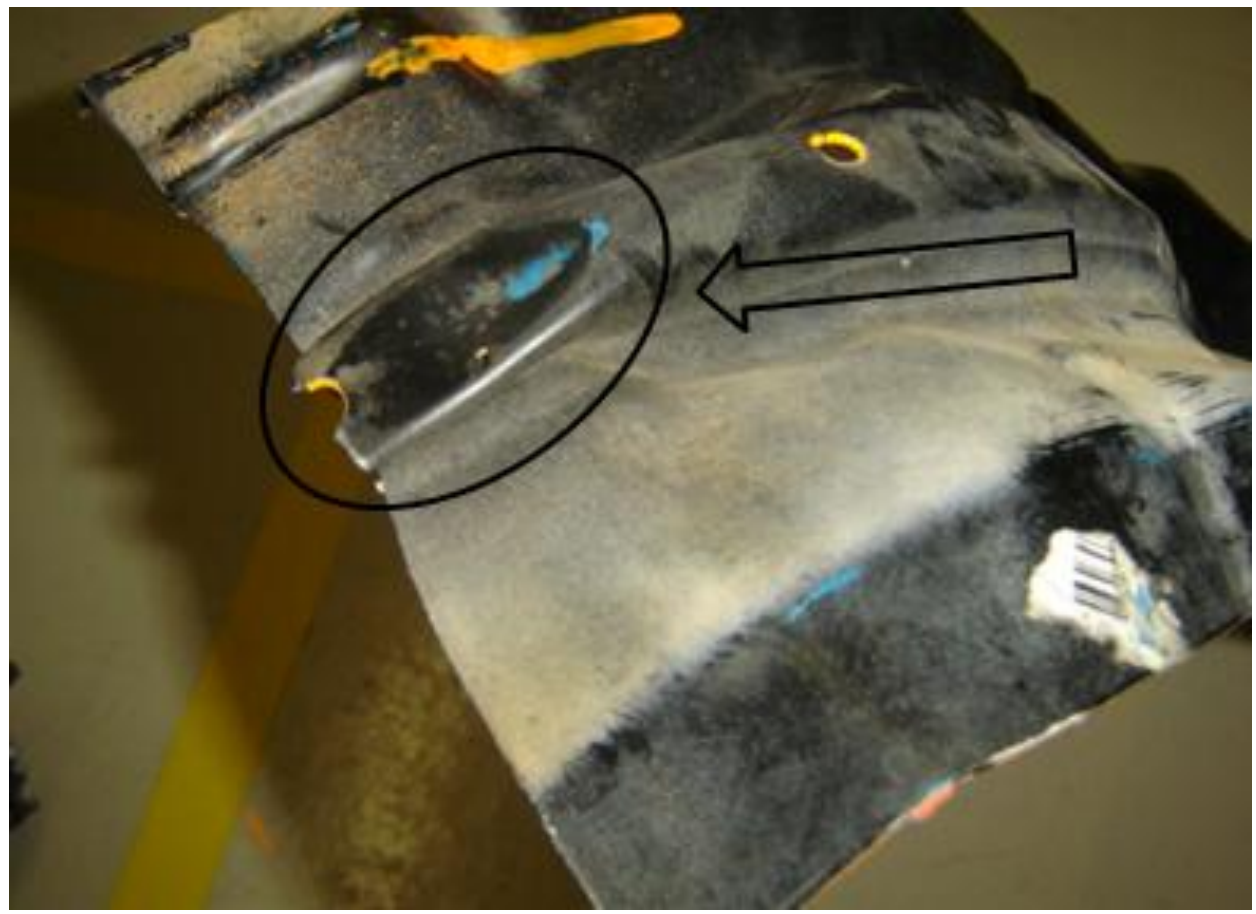

Figura 59. Detalhe da região prensada entre o pêndulo e a barreira rígida.

Com o intuito de obter um ensaio mais controlado sem esmagamento do párachoque, decidiu-se reduzir a energia de impacto. Sendo assim, o Teste \#6 foi executado com uma massa de $800 \mathrm{~kg}$ e mesma velocidade do Teste \#5. Além disso, para evitar a ocorrência de ruptura do pára-choque na zona termicamente afetada pela solda (Figura 58), optou-se por adicionar uma chapa metálica entre a coluna da Figura 54b e o pára-choque e soldá-los através de apenas um cordão de solda, sendo este distanciado da aresta de ruptura verificado no Teste \#5 (Figura 60).

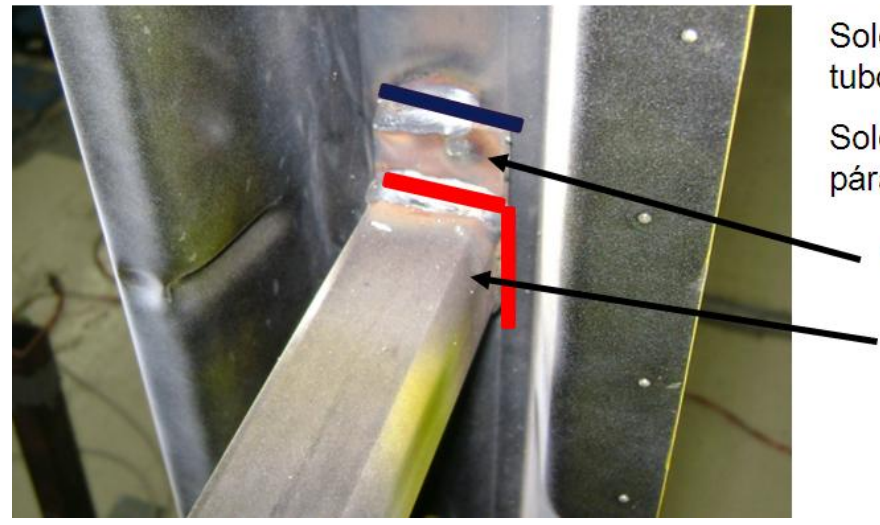

Solda entre chapa e tubo quadrado

Solda entre chapa e pára-choque

Figura 60. Ilustração da união entre a coluna central e o pára-choque. 
Os resultados das modificações para o Teste \#6 (Figura 61) foram satisfatórios, isto é, a energia do ensaio foi suficiente para que o pára-choque sofresse ruptura sem ser prensado contra a barreira e não houve influencia do cordão de solda na região de ruptura, conforme evidenciado pela Figura 62.

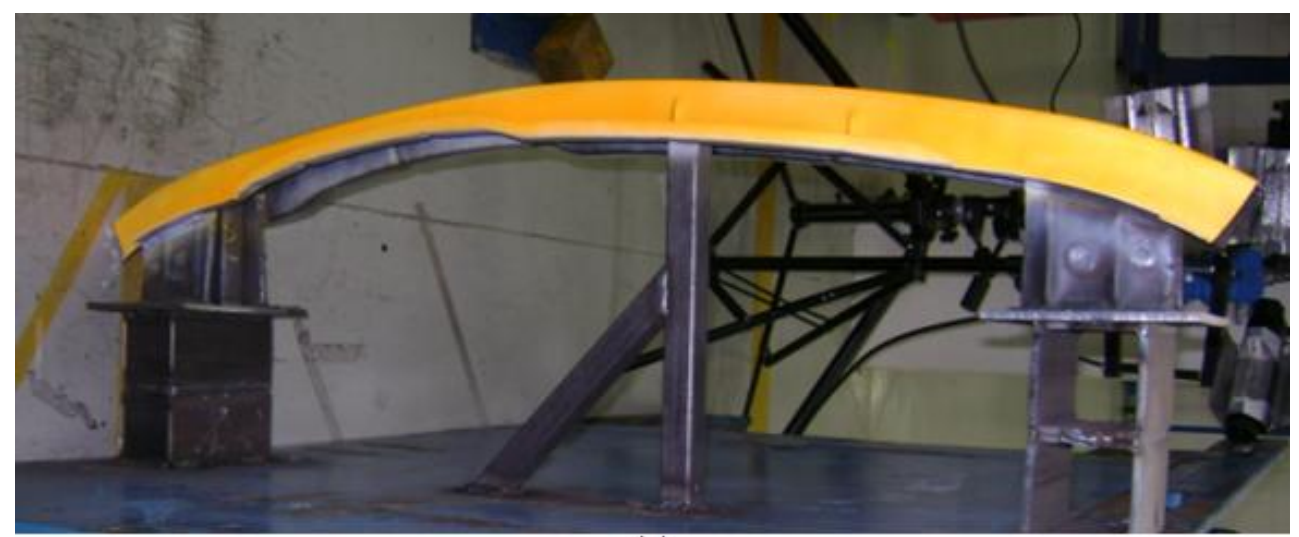

(a)

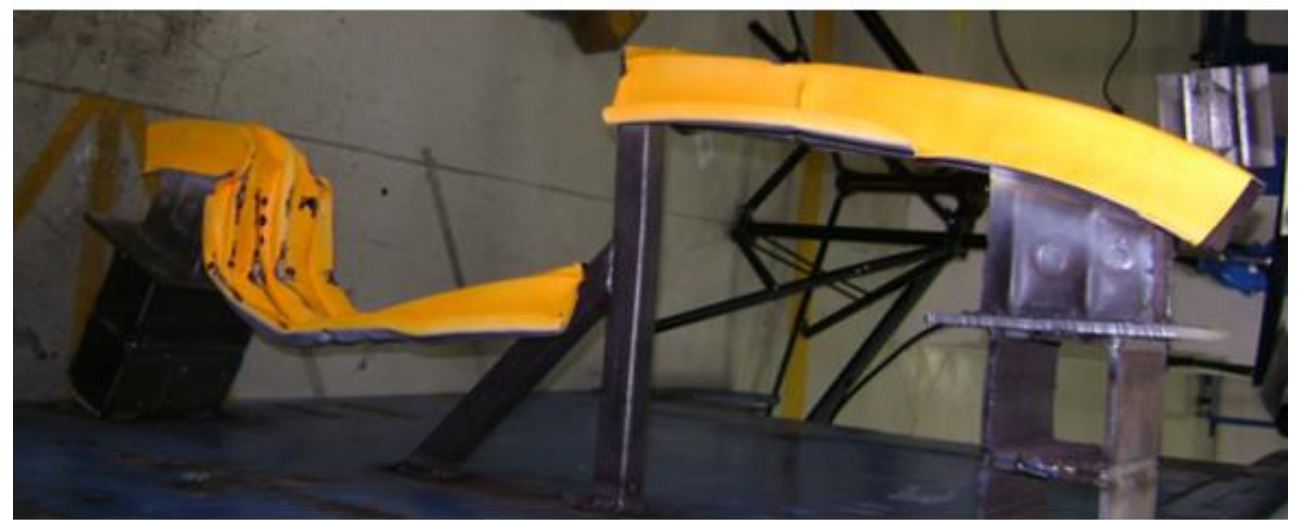

(b)

Figura 61. (a) condição do Teste \#6 antes do ensaio; (b) depois do ensaio.

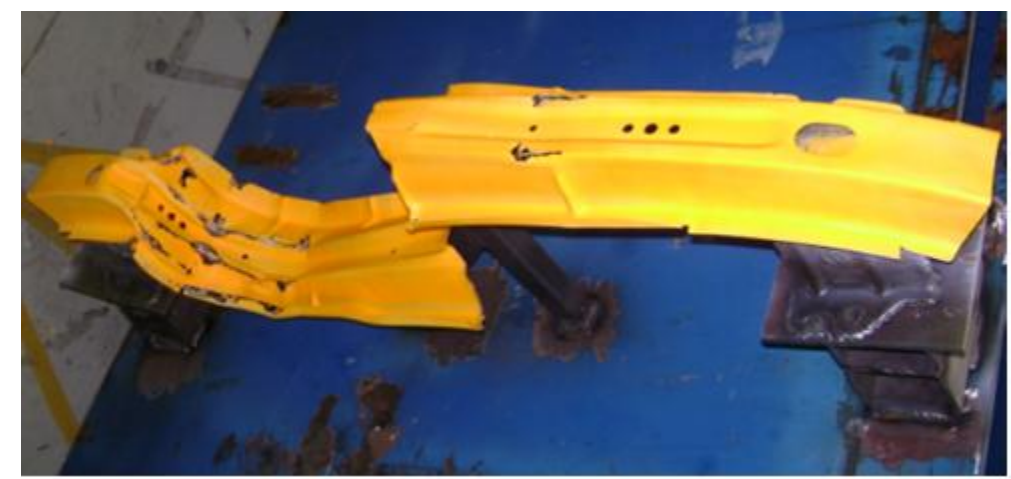

(a)

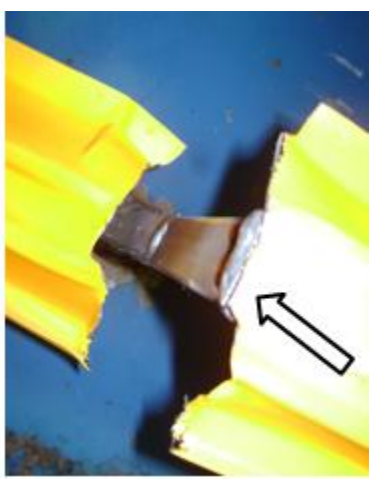

(b)

Figura 62. (a) condição do Teste \#6 depois do ensaio; (b) detalhe da ruptura. 
A ruptura iniciou-se logo abaixo da coluna central, propagando-se para as laterais do pára-choque até que ocorresse a separação completa das duas metades do párachoque. O gráfico de força em relação ao tempo da Figura 63 ilustra das fases do impacto. O primeiro pico de força acontece em (a), quando o perfil do pára-choque é deformado e achatado. Os demais picos de força referem-se aos sucessivos rebatimentos do impactador no pára-choque. Em (b) a ruptura se inicia e propaga-se até (e), quando finalmente o pára-choque é separado em duas partes.

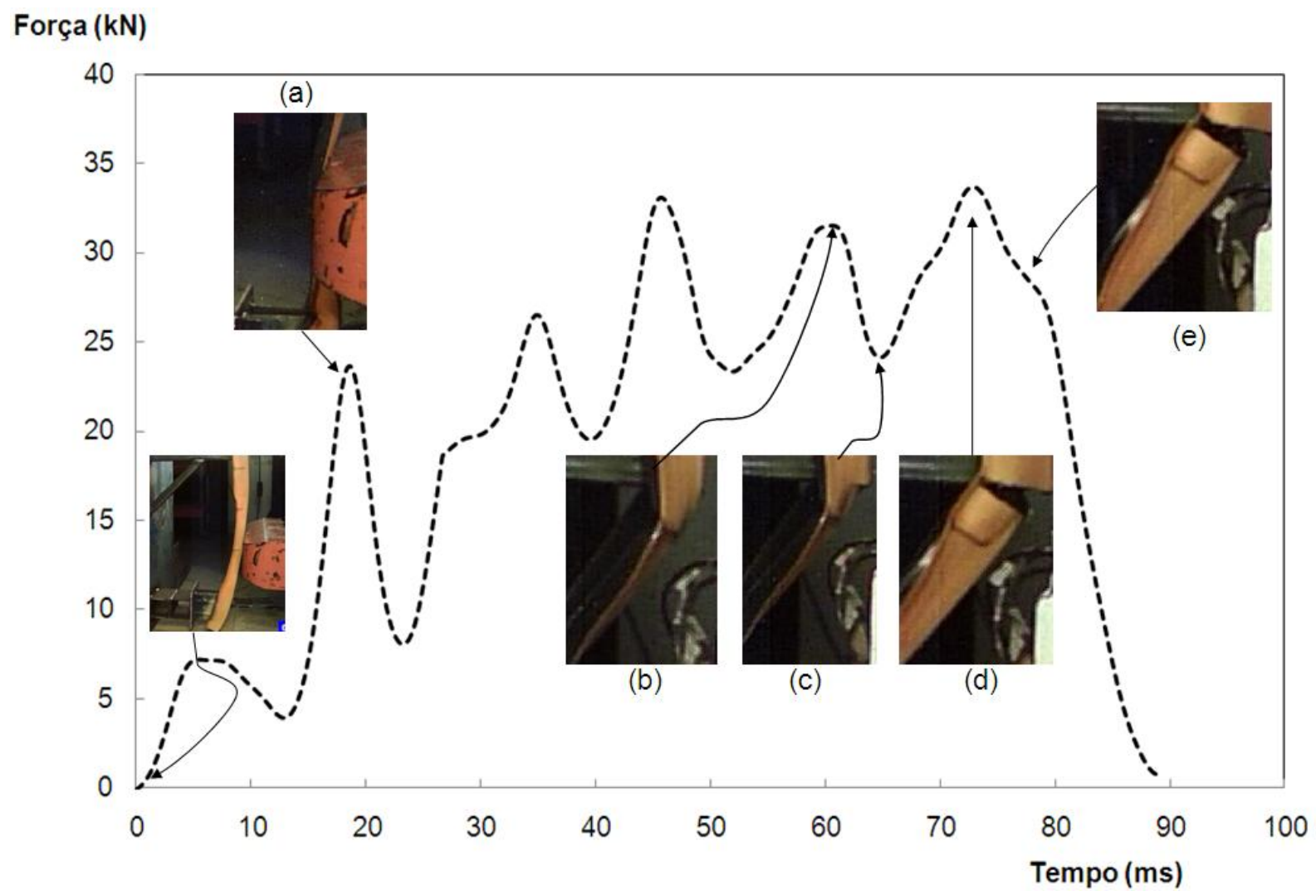

Figura 63. Gráfico da força em função do tempo no Teste \#6.

A região onde ocorreu a ruptura esta ilustrada nas Figuras 64-66, onde foi observada deformação plástica em toda sua extensão.

Conforme comentado no item 1.4, o pára-choque deve ser um componente desenvolvido para absorver energia, portanto, obter falha através de um ensaio de impacto pendular não é uma tarefa trivial. Os ensaios aqui descritos tiveram sua 
severidade aumentada apenas para viabilizar o objetivo deste trabalho de analisar os critérios de falha através de uma ruptura obtida de experimentos.

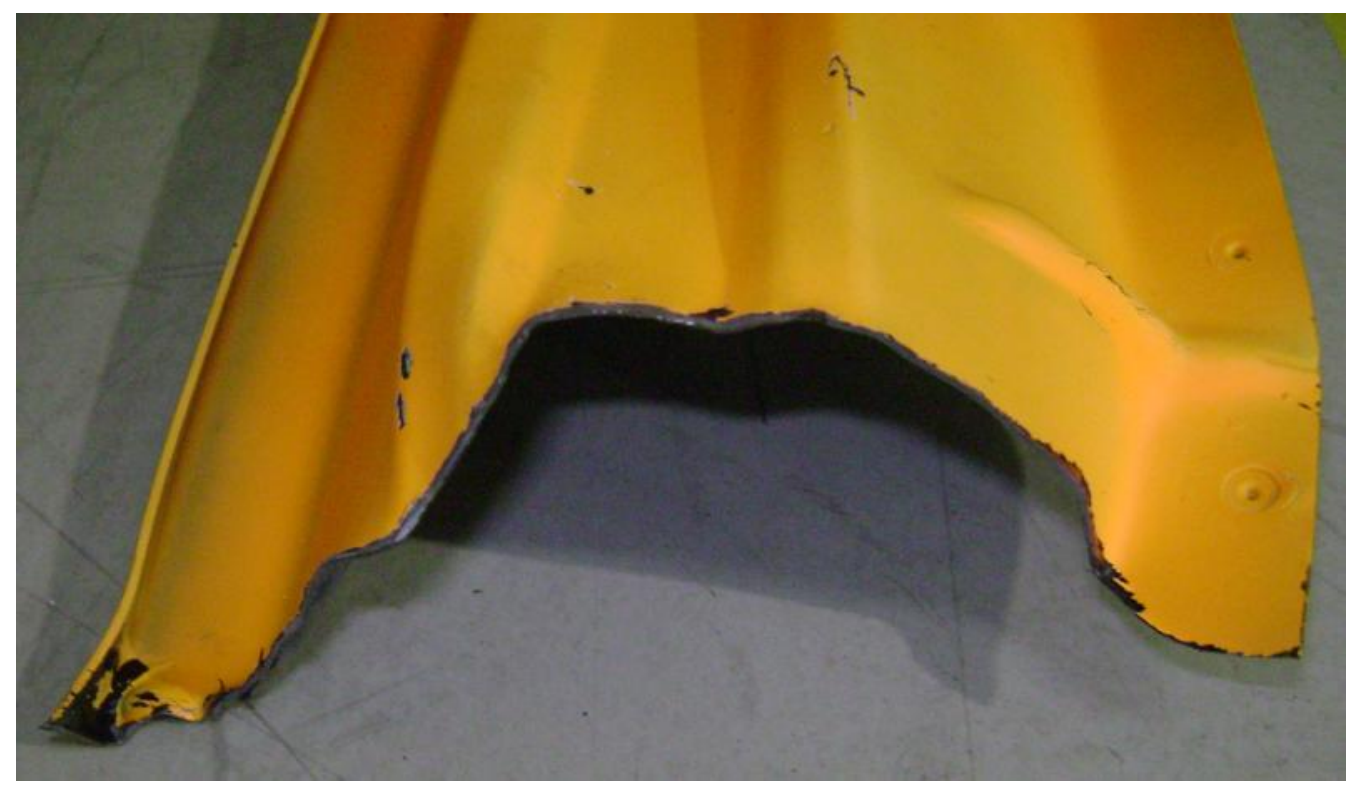

Figura 64. Vista frontal da região da ruptura do pára-choque do Teste \#6.

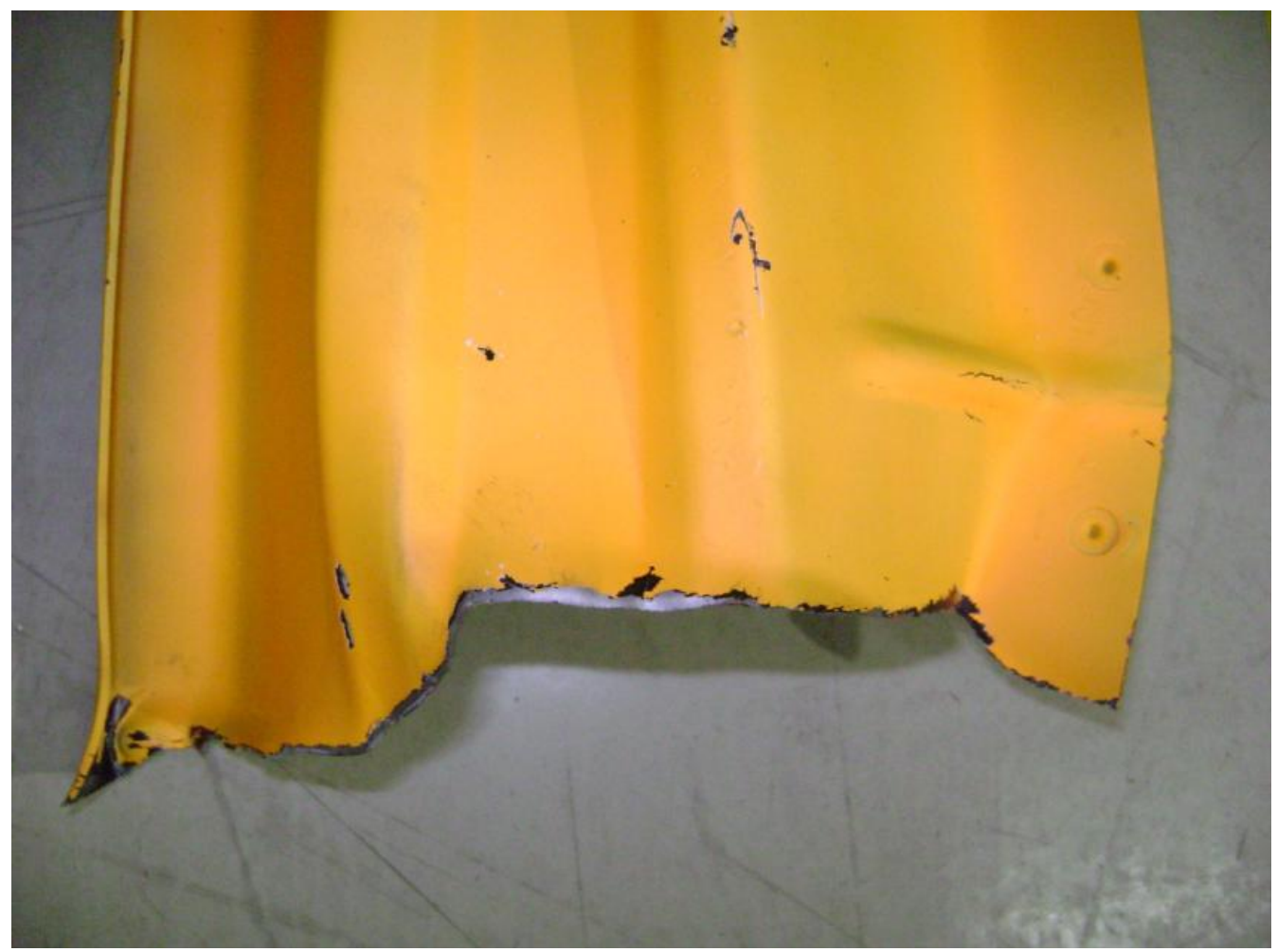

Figura 65. Vista de topo da região da ruptura do pára-choque do Teste \#6. 


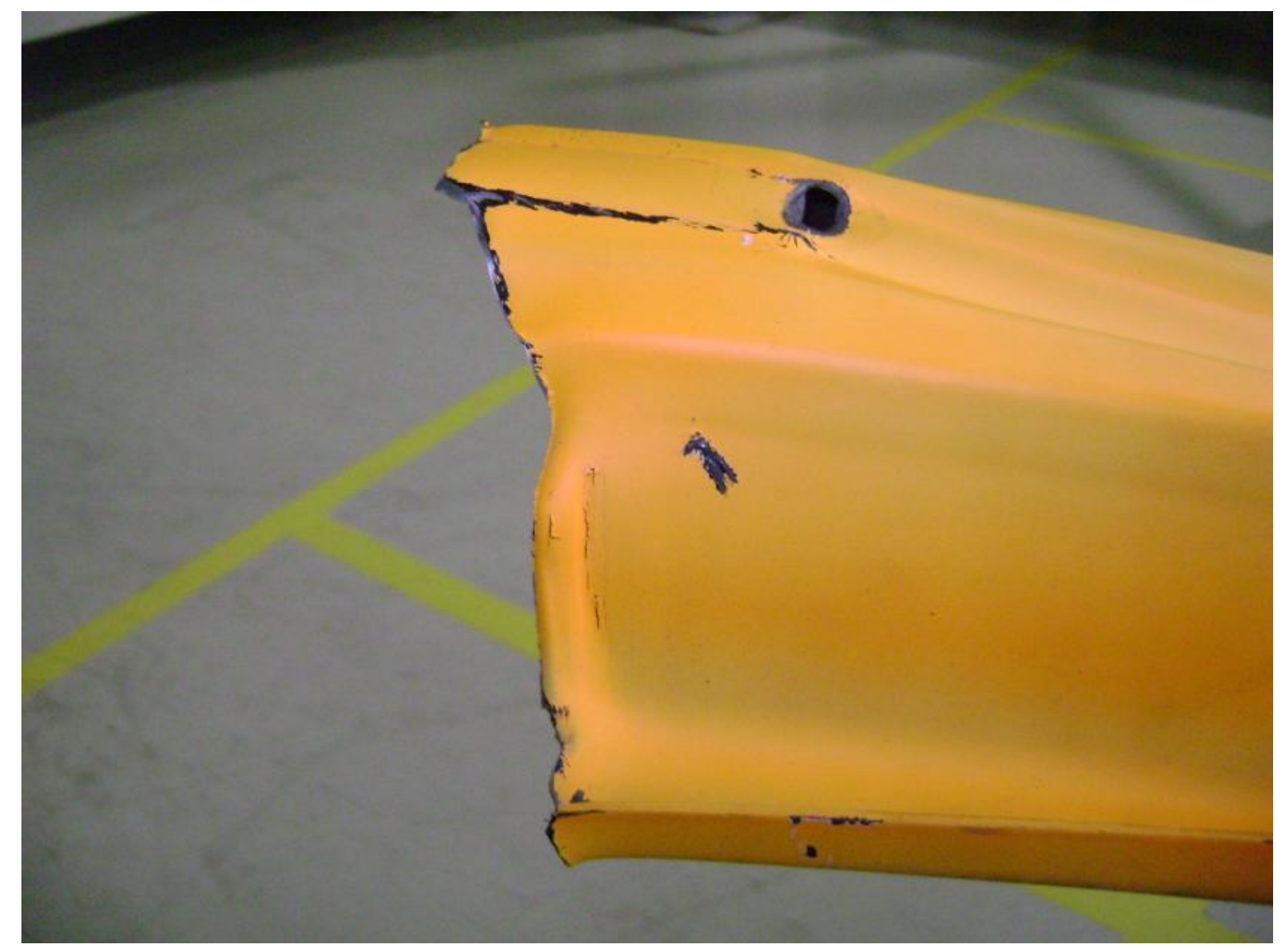

Figura 66. Vista lateral da região da ruptura apoiada pela coluna central (Teste \#6). 


\section{IMPACTO EM PÁRA-CHOQUE: ANÁLISE NUMÉRICA}

A fim de se estudar os critérios de falha calibrados no Capítulo 0, análises numéricas de alguns dos casos apresentados no Capítulo 0 foram realizadas. Assim como nas análises dos ensaios de tração, os softwares LS-Dyna ${ }^{\circledR}$ (41), HyperMesh ${ }^{\circledR}$, HyperView $^{\circledR}$ e LS-Prepost $2.1^{\circledR}$ foram utilizados para o cálculo, pré e pós processamento respectivamente. A modelagem dos experimentos de impacto em pára-choques também foi dividida em duas etapas:

a) Correlação com um ensaio de baixa severidade em que não ocorreu falha local a fim de se determinar parâmetros importantes, como modelo elasto-plástico do material, tipo de elemento, quantidade de pontos de integração na espessura, qualidade da malha, propriedades de contato e condições de contorno.

b) Análise numérica de um ensaio com ocorrência de falha utilizando os critérios de falha calibrados através dos ensaios de caracterização do material, de modo estudar a eficiência dos modelos na previsão de falha. Nesta fase o refinamento da malha foi alterado a fim de se avaliar a influência do tamanho do elemento na resposta numérica.

\subsection{Análise Numérica de Ensaios de Baixa Severidade}

As análises numéricas com foco na correlação de parâmetros básicos e ajuste da malha foram realizadas com base no ensaio de baixa severidade. Apenas a configuração do Teste \#1 foi explorada, uma vez que no Teste \#2 ocorreu o colapso dos suportes e essa não é condição desejada. Ao todo cerca de trinta simulações foram realizadas.

Nesta fase a malha do pára-choque é constituída de elementos de casca, com integração completa. São 3685 elementos, cujas dimensões variam de $7 \mathrm{~mm}$, em regiões mais refinadas, a $10 \mathrm{~mm}$ para as demais áreas (Figura 67). São utilizados 
cinco pontos de integração na espessura, de modo que as respostas dos elementos à flexão e torção são satisfatórias quando comparados com os ensaios experimentais.

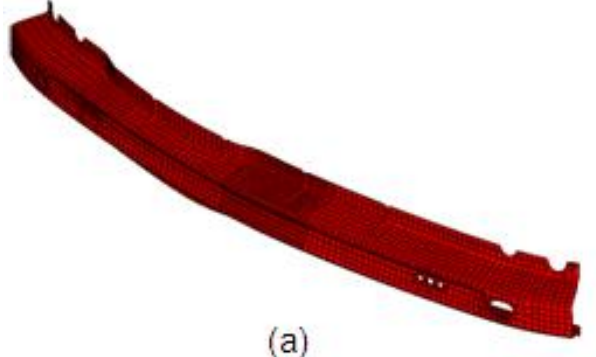

(a)

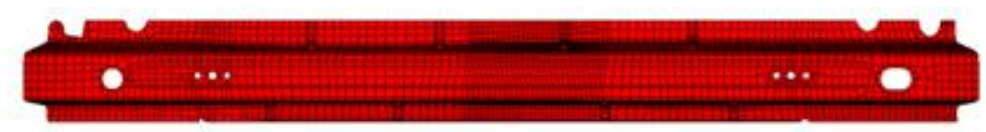

(b)

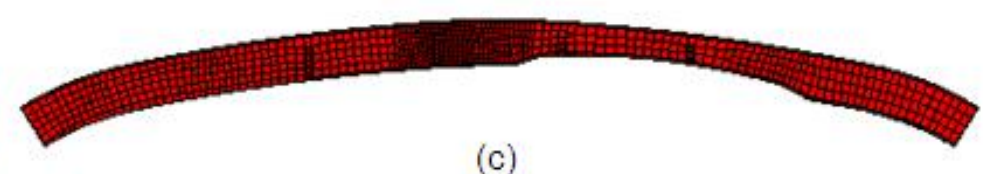

(c)

Figura 67. (a) Malha do pára-choque; (b) vista frontal; (c) vista de topo..

Os suportes do pára-choque também são modelados por elementos de casca (Figura 68), porém, com formulação de material rígido e indeformável uma vez que não é de interesse deste trabalho avaliar o colapso dos mesmos. O impactador é modelado com 9343 elementos de casca e material de corpo rígido e indeformável (Figura 69). O tamanho dos elementos foi mantido em $5 \mathrm{~mm} \times 5 \mathrm{~mm}$ para evitar a ocorrência de instabilidades no contato com o pára-choque. A Tabela 12 resume as características de geometria dos elementos em análise.

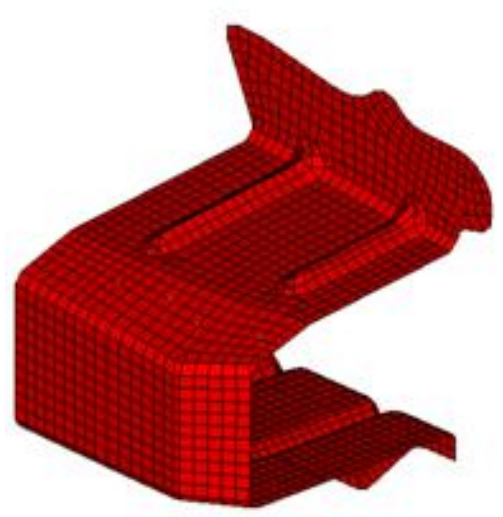

(a)

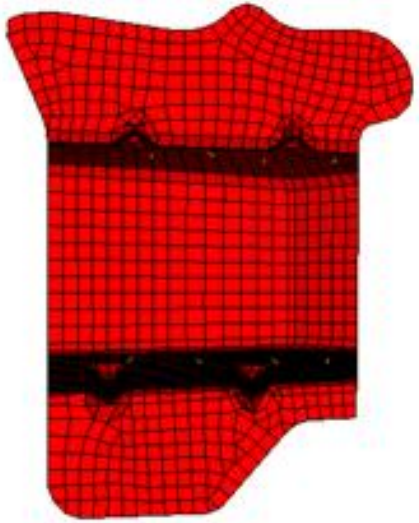

(b)

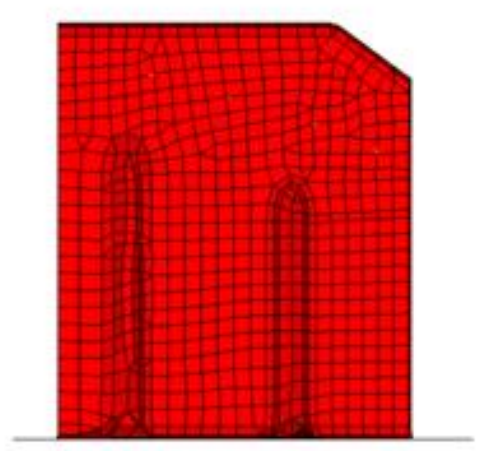

(c)

Figura 68. (a) Malha de um dos suportes; (b) vista frontal; (c) vista de topo 


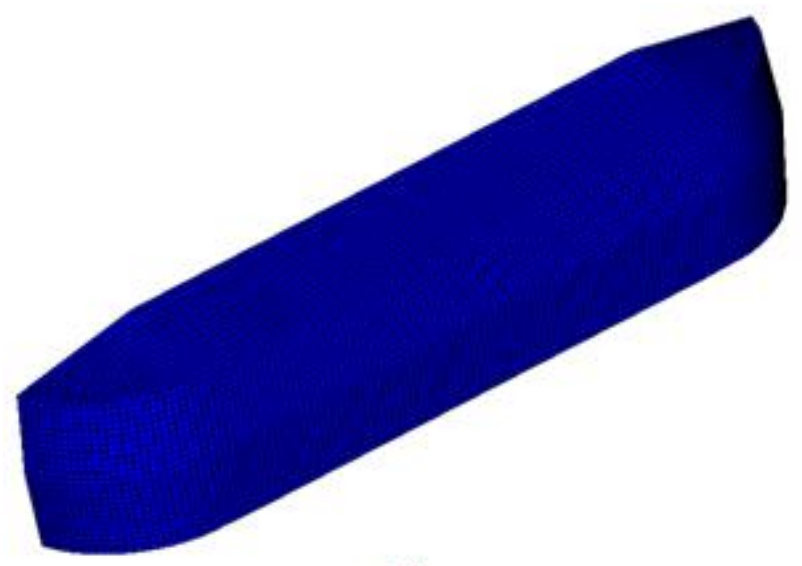

(a)

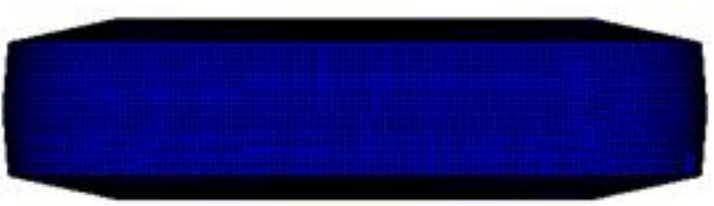

(b)

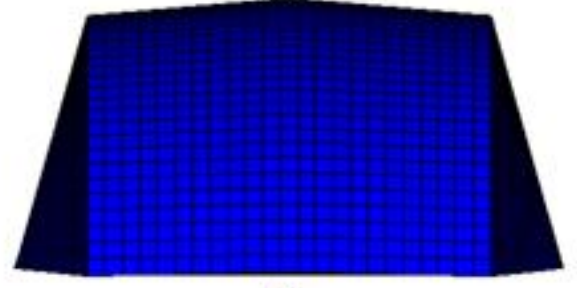

(c)

Figura 69. (a) Malha do impactador; (b) vista frontal; (c) vista de topo.

Tabela 12 - Quantidades de nós e elementos das malhas dos componentes da análise numérica

\begin{tabular}{llcc}
\hline Componente & \# de elementos & \# de nós & Espessura $(\mathrm{mm})$ \\
\hline Pára-choque & $3685(10 \times 10 \mathrm{~mm})$ & 3818 & 1,3 \\
Suporte (lado direito) & $1853(5 \times 5 \mathrm{~mm})$ & 1900 & 2,0 \\
Suporte (lado esquerdo) & $1890(5 \times 5 \mathrm{~mm})$ & 1955 & 2,0 \\
Impactador & $9343(5 \times 5 \mathrm{~mm})$ & 9297 & 8,0 \\
\hline
\end{tabular}

As condições de contorno dos suportes da barra foram modeladas com restrição aos seis graus de liberdade dos nós, que representam a região aparafusada dos suportes na barreira rígida, conforme detalhe na Figura 42. Ao impactador foi dada uma velocidade inicial, que corresponde ao valor medido experimentalmente, no instante que este impacta o pára-choque. A Figura 70 ilustra as condições de contorno e carregamento do modelo.

O modelo de material elasto-plástico do pára-choque segue o modelo de von Mises, de propriedades mecânicas apresentadas no Capítulo 0.

A simulação numérica e o experimento mostram uma boa relação qualitativa, focando-se em níveis de deformação conforme ilustra a Figura 71. 


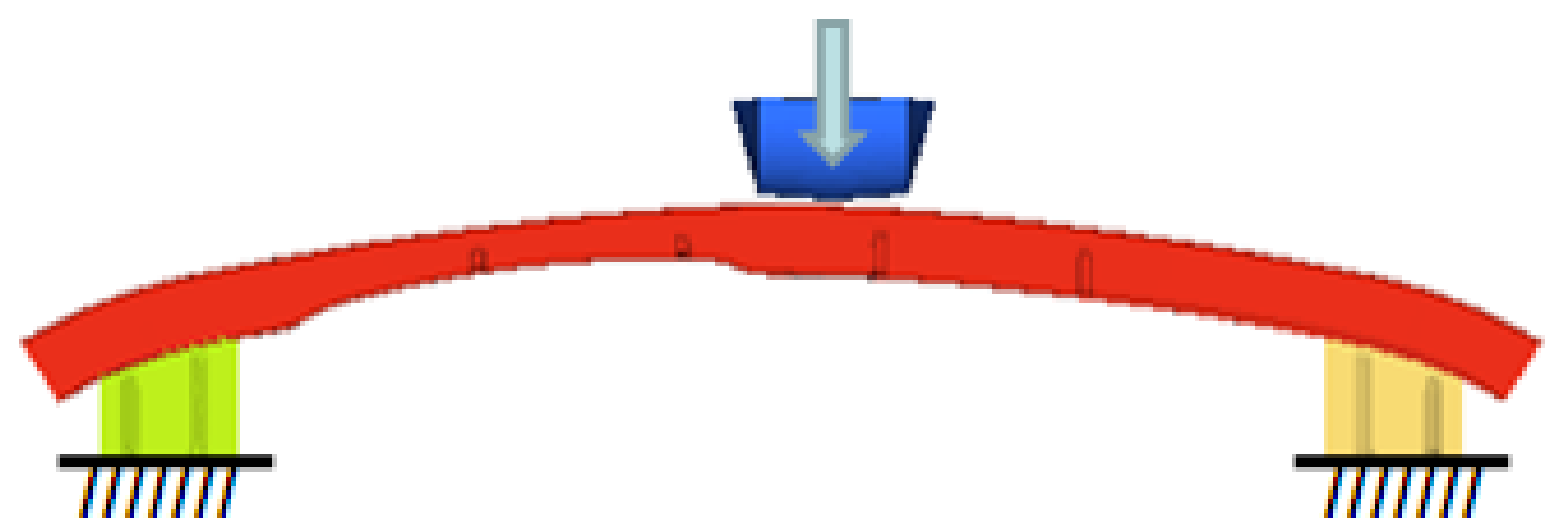

Figura 70. Representação das condições de contorno e carregamento do modelo baseado no Teste $\# 1$.
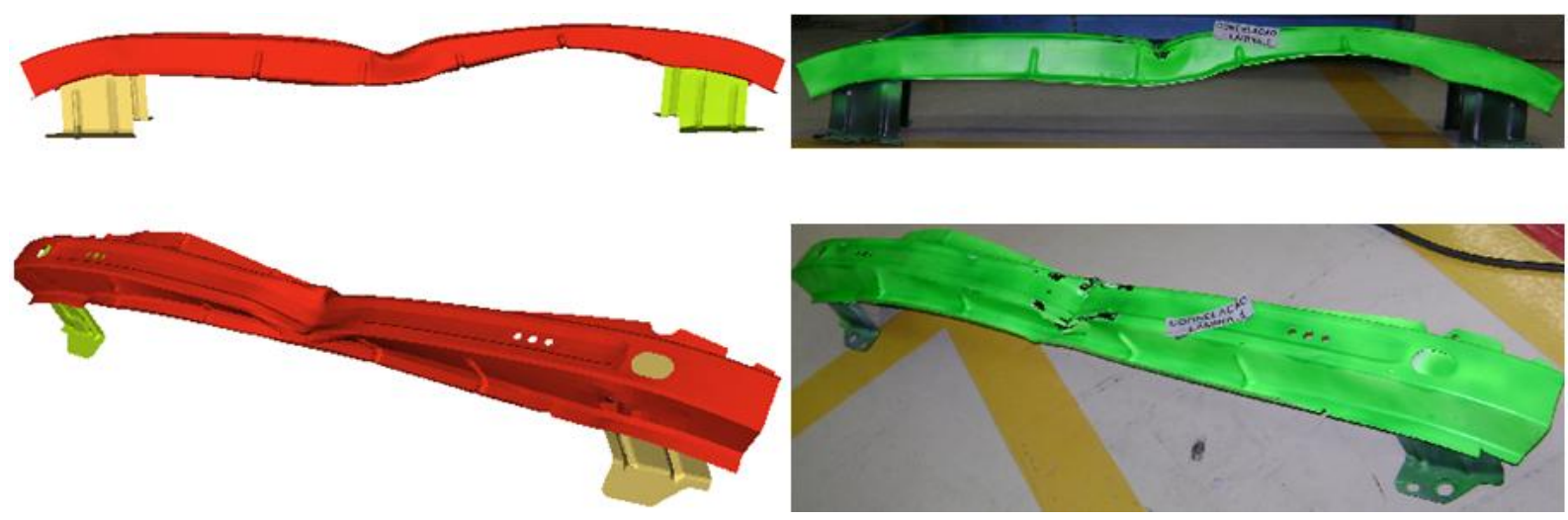

Figura 71. Comparativo da resposta numérica com o Teste\#1.

\subsection{Análise Numérica de Ensaios de Alta Severidade}

Com o objetivo de estudar os modelos de falha calibrados no Capítulo 0, optou-se por simular apenas as condições do Teste \#6 por ter resultado em ruptura sem a influência da zona termicamente afetada pela solda. Para representar mais precisamente os detalhes da geometria do pára-choque, a malha do mesmo foi refinada. De um modo geral, simulações de impacto veicular são realizadas com malhas de componentes com elementos de cerca de $5 \mathrm{~mm}$. Para este caso, decidiuse utilizar dois níveis de refinamento na malha, o primeiro considerando elementos de $5 \mathrm{~mm} \times 5 \mathrm{~mm}$ e outro com elementos de $3 \mathrm{~mm} \times 3 \mathrm{~mm}$, conforme ilustrado na 
Figura 72. As quantidades de elementos assim como número de nós constam na Tabela 13.

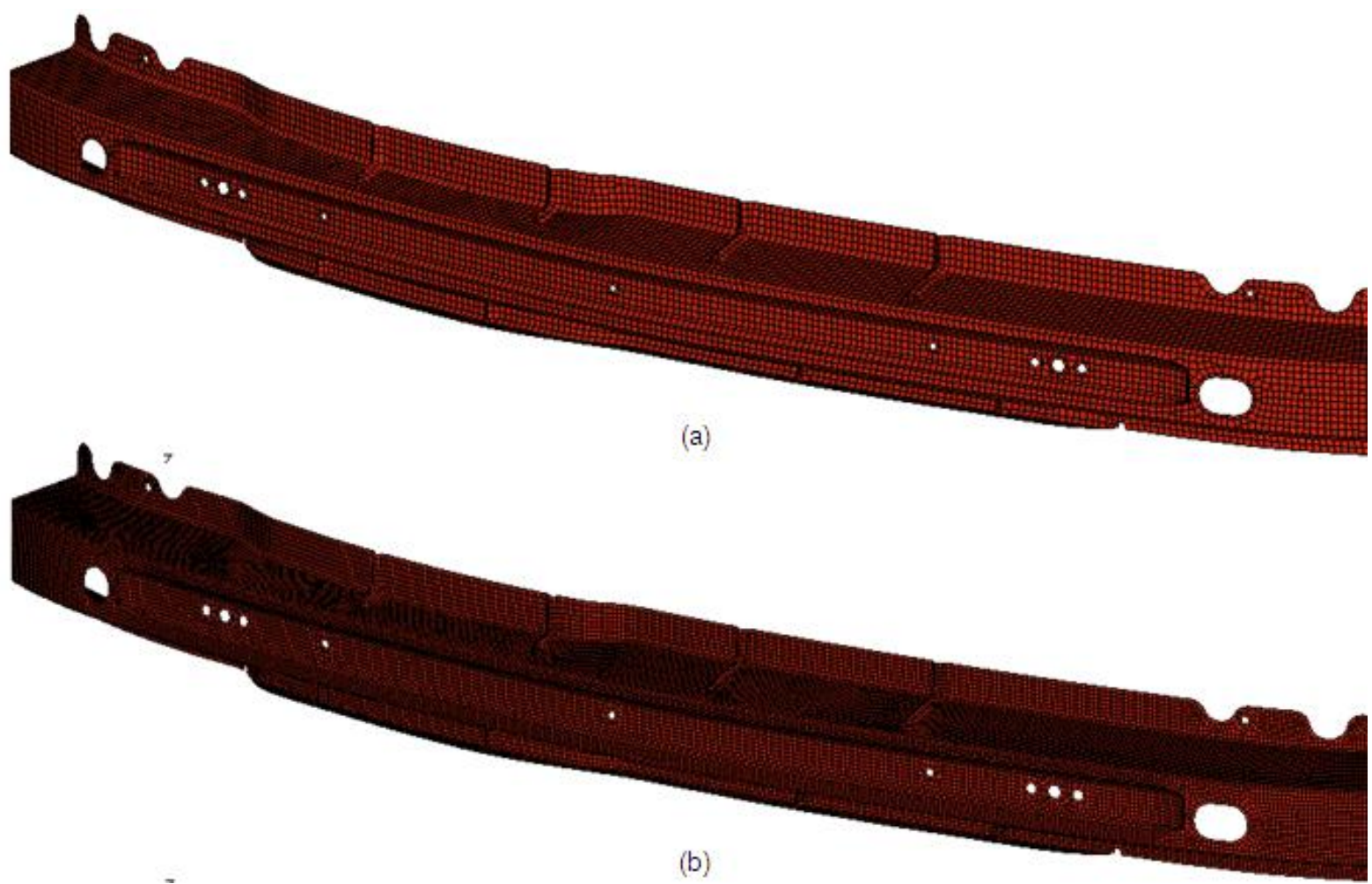

Figura 72. Malha do pára-choque (a) com elementos de $5 \times 5 \mathrm{~mm}$; (b) com elementos de $3 \times 3 \mathrm{~mm}$.

Tabela 13 - Quantidades de nós e elementos das malhas de pára-choque para as análises com falha do material.

\begin{tabular}{ccc}
\hline Pára-choque & \# de elementos & \# de nós \\
\hline $3 \times 3 \mathrm{~mm}$ & 28169 & 28676 \\
$5 \times 5 \mathrm{~mm}$ & 10586 & 10746 \\
\hline
\end{tabular}

Além da malha do pára-choque, foram alteradas também as condições de contorno e carregamento (Figura 73), de modo que representassem as mesmas condições do Teste \#6, onde resultou em ocorrência controlada de ruptura. Os demais parâmetros de simulação e malhas do impactador e suportes permaneceram os mesmos dos utilizados nas análises do item 1.18. 


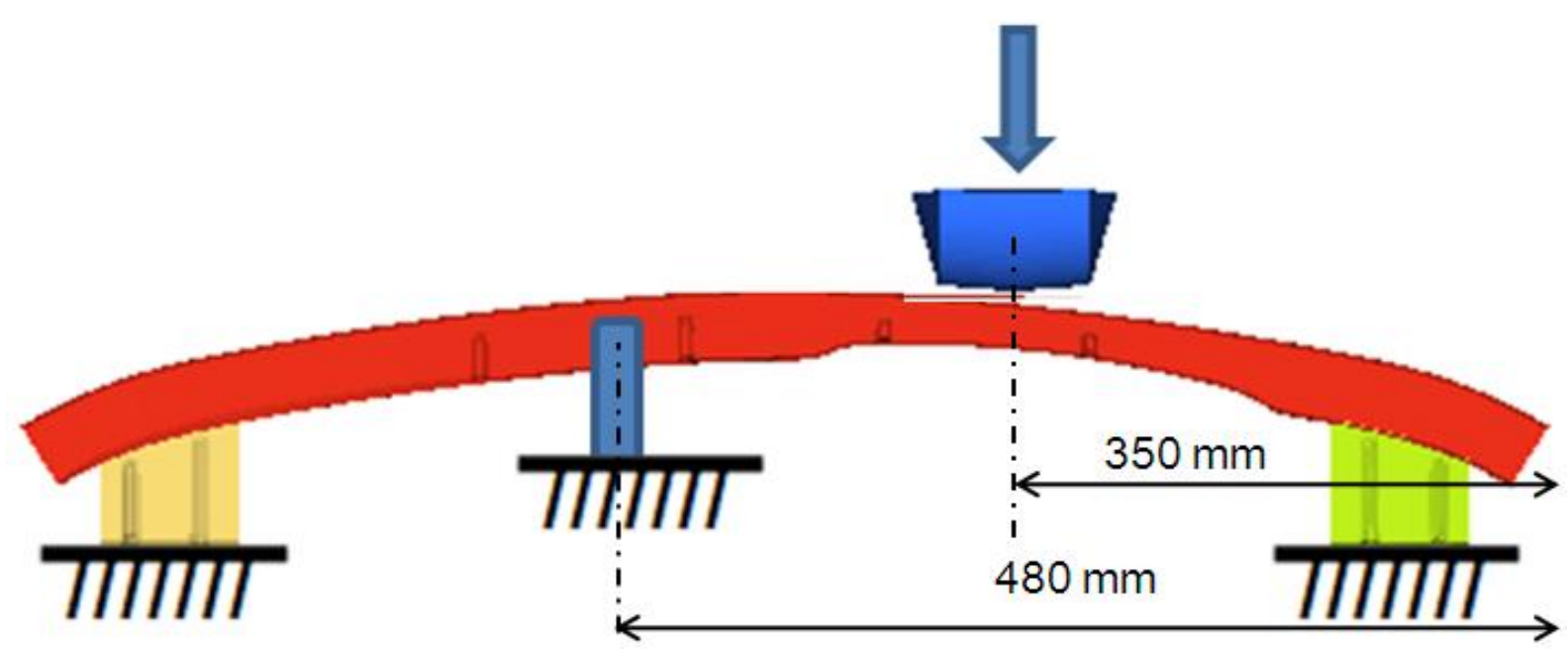

Figura 73. Representação das condições de contorno e carregamento do modelo baseado no Teste \#6.

O primeiro critério de falha analisado foi o da máxima deformação plástica equivalente. O modelo de material disponível no software simula a ruptura do material permitindo que o elemento que atingir a deformação limite seja eliminado da malha, isto é, passa a ser desconsiderado nos cálculos subseqüentes. Isso faz com que os elementos na vizinhança recebam a carga que o elemento eliminado deixou de suportar. Este critério indicou corretamente a localização do início de ruptura do material, conforme ilustra a Figura 74. Porém, a malha com elementos de $5 \mathrm{~mm}$ não resultou em boa resposta no que diz respeito a propagação da ruptura quando comparado ao resultado experimental. A malha com elementos de $3 \mathrm{~mm}$, por sua vez, resultou em uma evolução da ruptura diferenciada (Figura 75), com resultados muito próximos ao experimental, conforme ilustrado nas Figura 76 e Figura 77. Isso indica que a geometria do componente é um fator importante na caracterização e evolução da ruptura quando o critério da máxima deformação plástica equivalente é utilizado. 


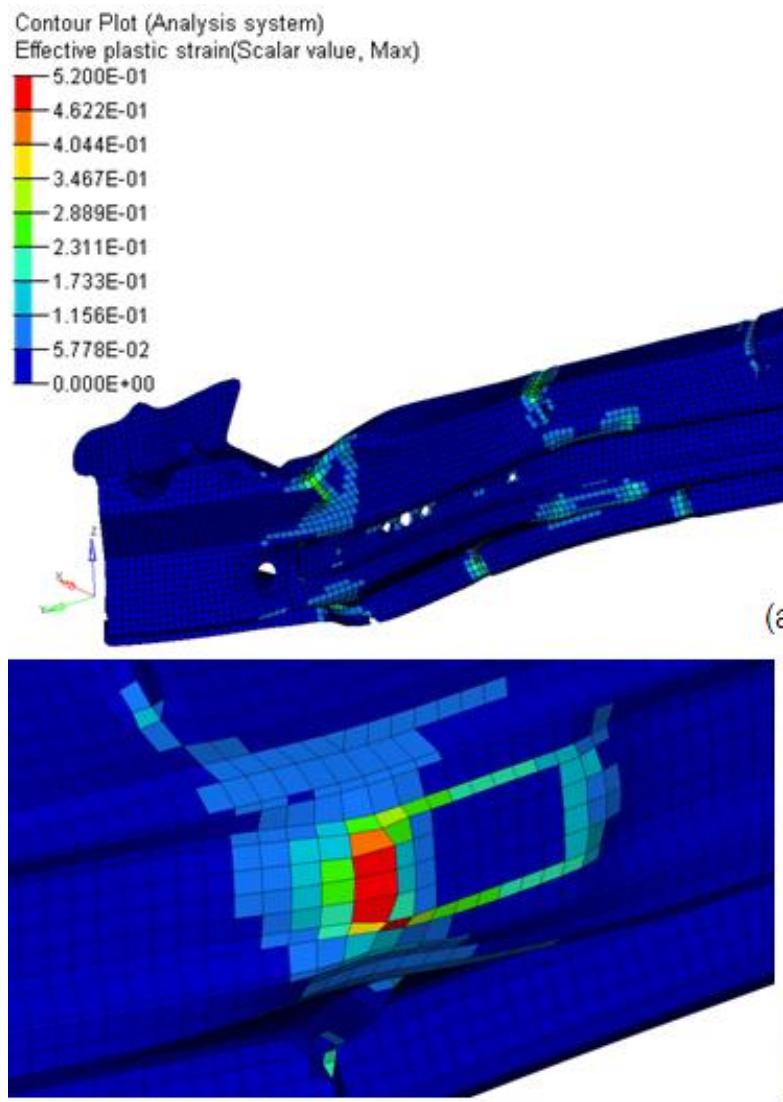

(b) (a)

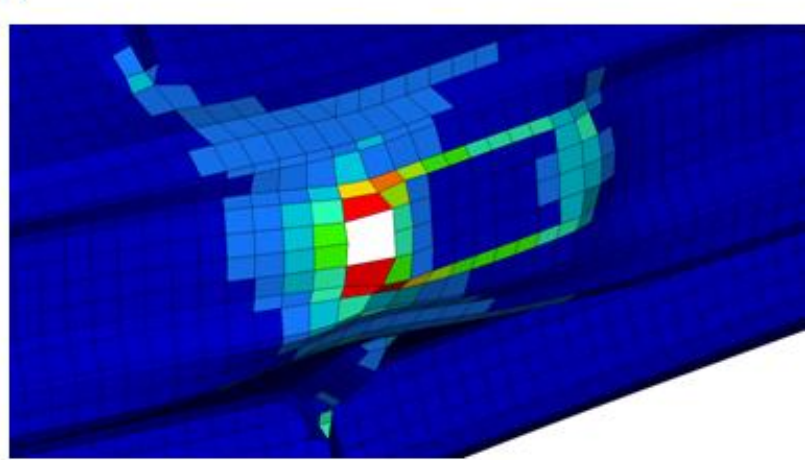

(c)

Figura 74. Resultado do critério da máxima deformação plástica equivalente para a malha de $5 \times 5$ $\mathrm{mm}$, elementos em vermelho indicam deformação plástica efetiva de $52 \%$. (a) vista geral; (b) elementos na deformação limite; (c) elementos eliminados da malha.

(a)

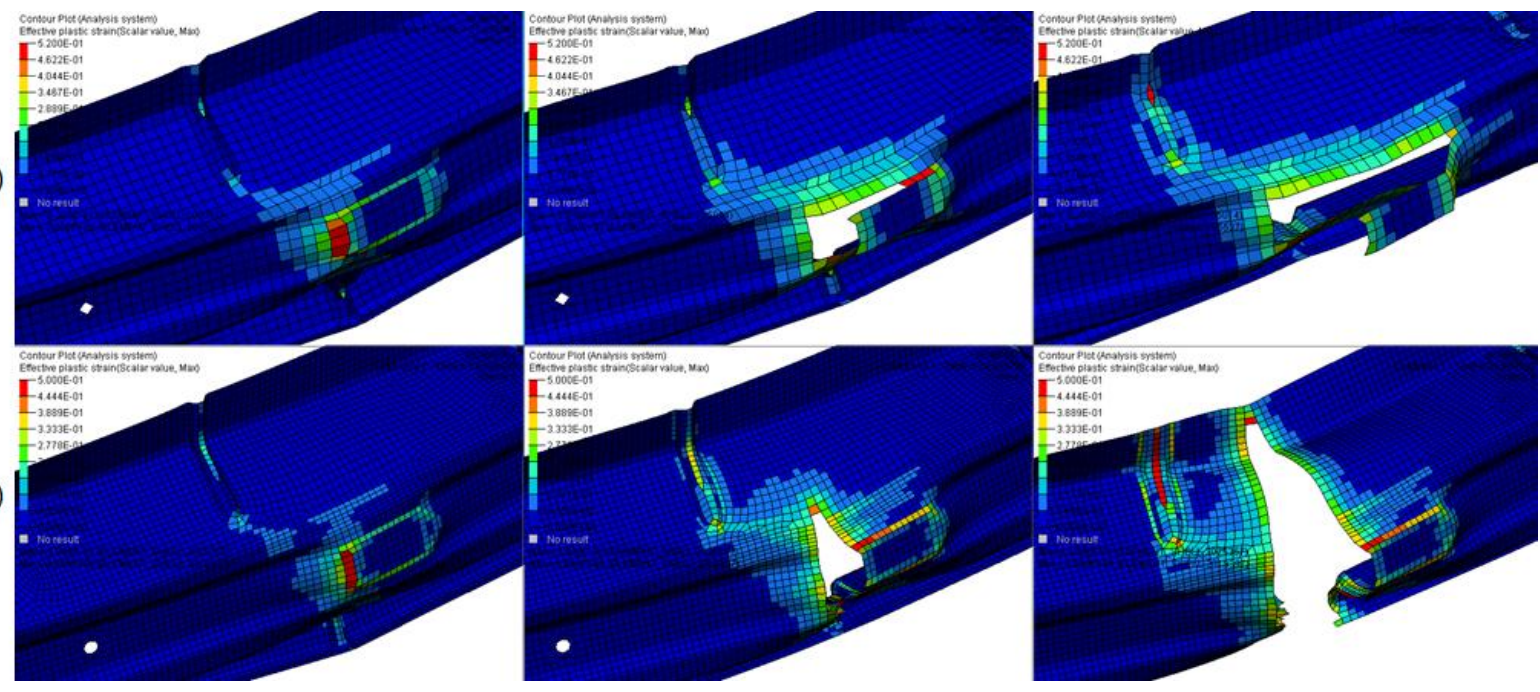

Figura 75. Seqüência de imagens do resultado do critério da máxima deformação plástica equivalente, escala aumentada na Figura 74. (a) malha com elementos de $5 \mathrm{~mm} \times 5 \mathrm{~mm}$; (b) malha com elementos de $3 \mathrm{~mm} \times 3 \mathrm{~mm}$. 

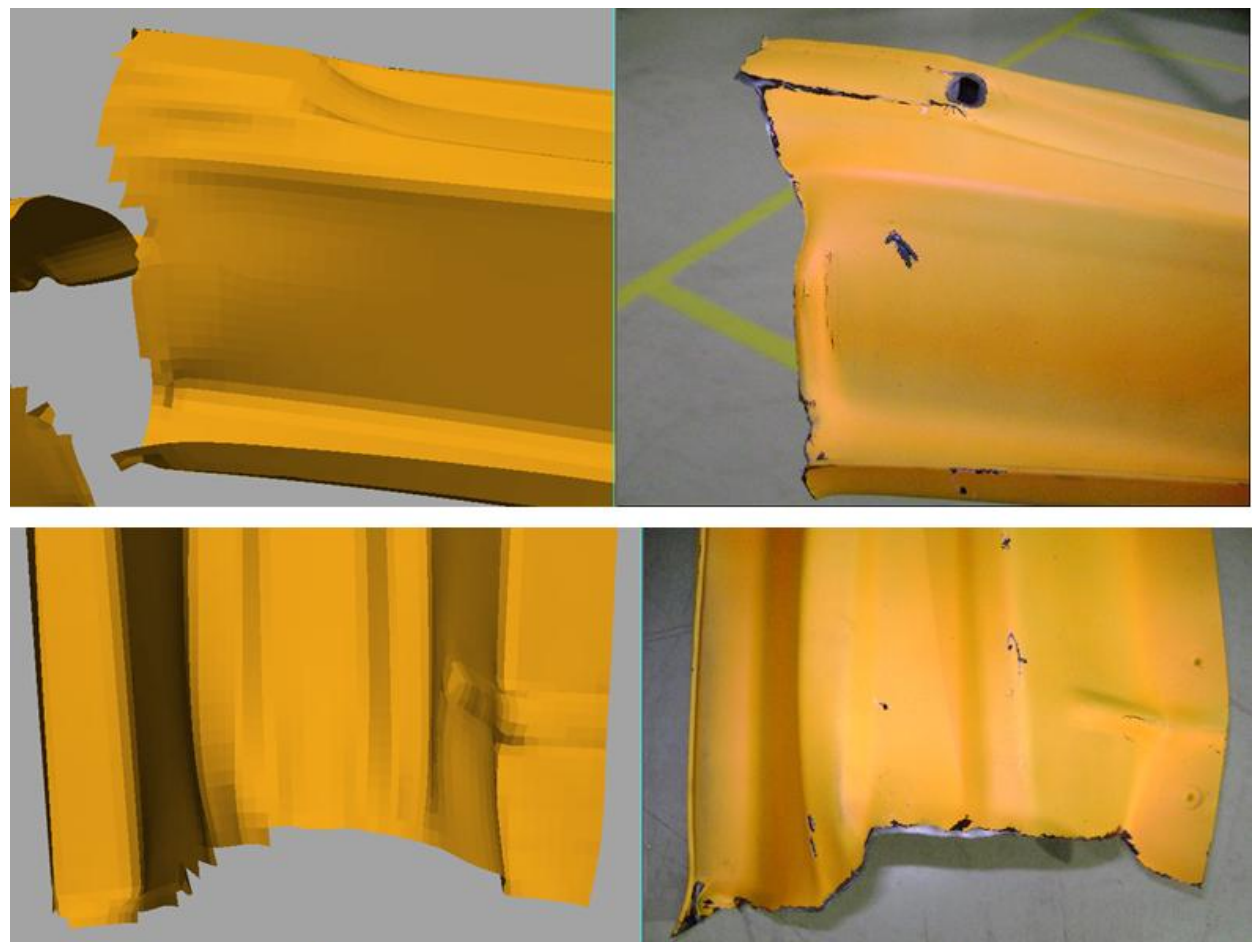

(a)

(b)

Figura 76. Comparativo da ruptura utilizando o critério da máxima deformação plástica equivalente, (a) malha com elementos de $3 \mathrm{~mm} \times 3 \mathrm{~mm}$; (b) resultado do Teste\#6.

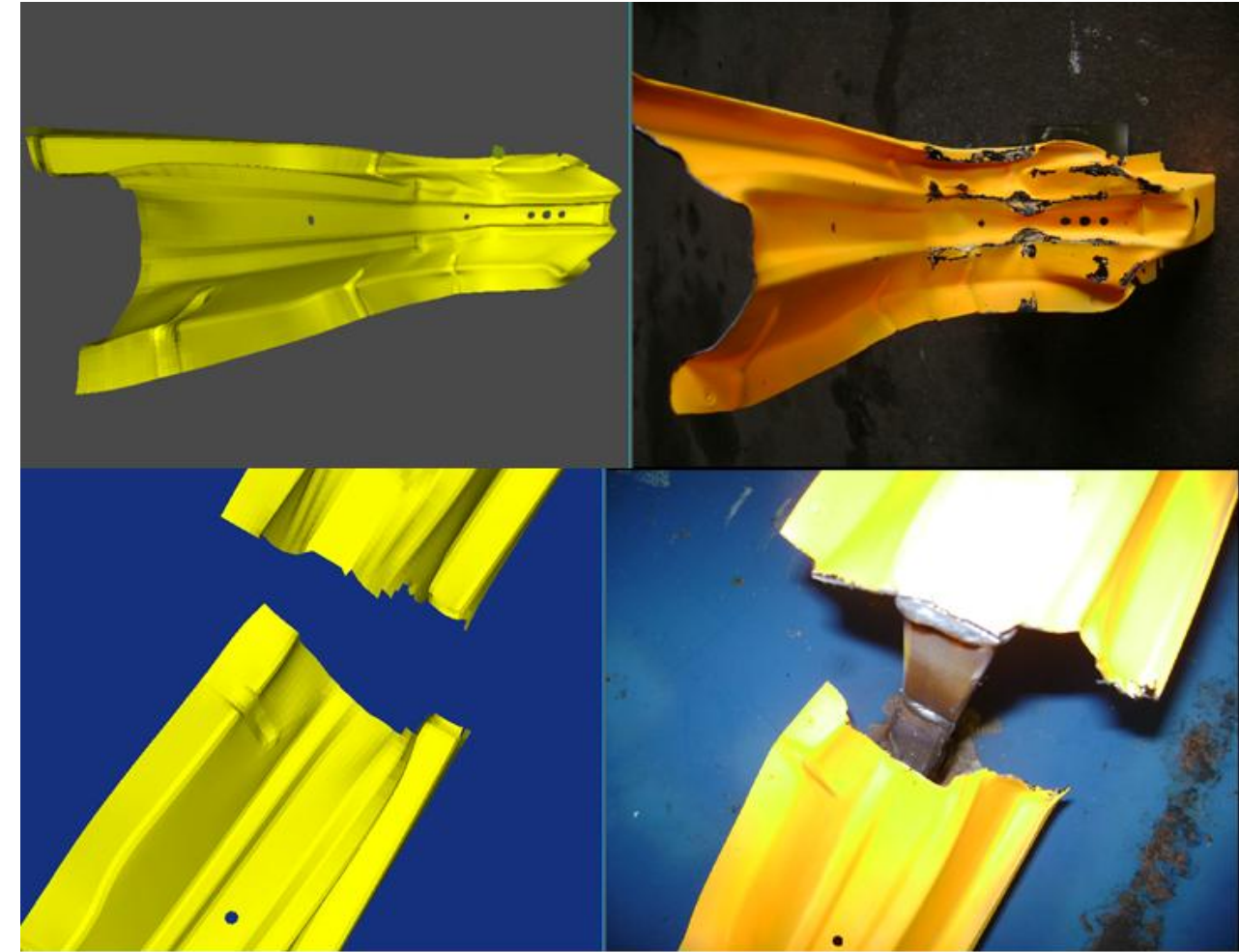

(a) (b)

Figura 77. Comparativo geral do resultado do critério da máxima deformação plástica equivalente, (a) malha com elementos de $3 \mathrm{~mm} \times 3 \mathrm{~mm}$; (b) resultado do Teste\#6. 
Para o critério da máxima tensão cisalhante, o software não dispõe do artifício de eliminar o elemento assim como descrito anteriormente. Sendo assim, a análise desse critério fica restrita apenas a indicar o local de início de ruptura. A Figura 78 ilustra os níveis de tensão cisalhante no pára-choque para as malhas com elementos de $5 \mathrm{~mm}$ e $3 \mathrm{~mm}$. Ambos indicam início de ruptura na região central do pára-choque, em conformidade com o Teste \#6. Porém, ambos também indicam início de ruptura na região inferior, não verificada no Teste \#6. A explicação para tal fato pode ser encontrada ao analisar a evolução da deformação plástica equivalente dessas regiões ao longo do tempo. A Figura 79 ilustra que a deformação plástica equivalente da região inferior do pára-choque (Figura $78 \mathrm{~b}$ ) não cresce tão rapidamente como ocorre na região central (Figura 78c) até o instante de inicio de ruptura a $19 \mathrm{~ms}$. Isso indica que a falha surgiria inicialmente no centro do párachoque, e caso o software dispusesse do artifício de eliminar tais elementos, a distribuição de carga ao longo do componente seria alterado, descarregando a região da Figura 78b, permanecendo, provavelmente íntegra como observado experimentalmente.

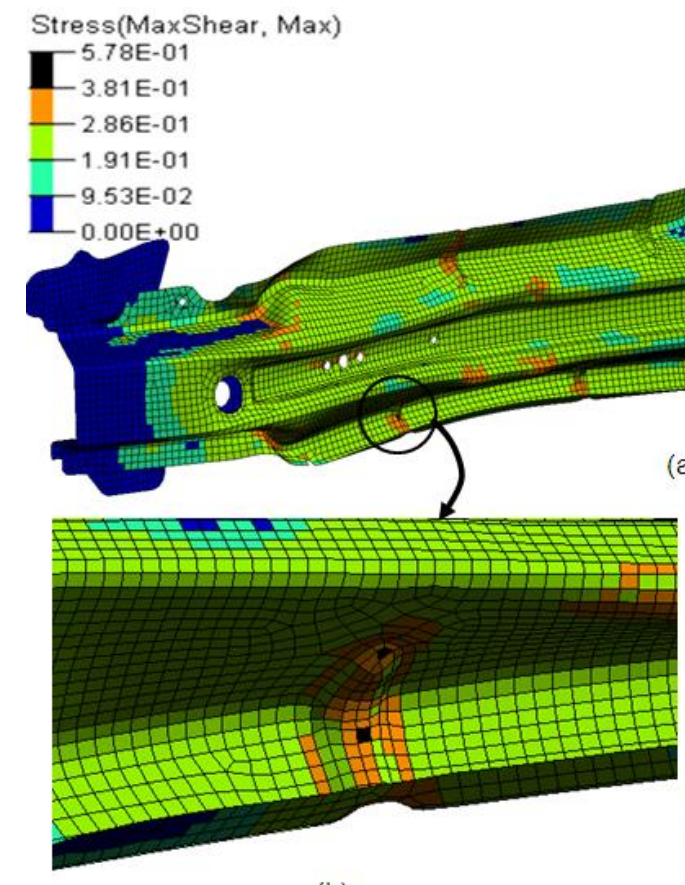

(b)

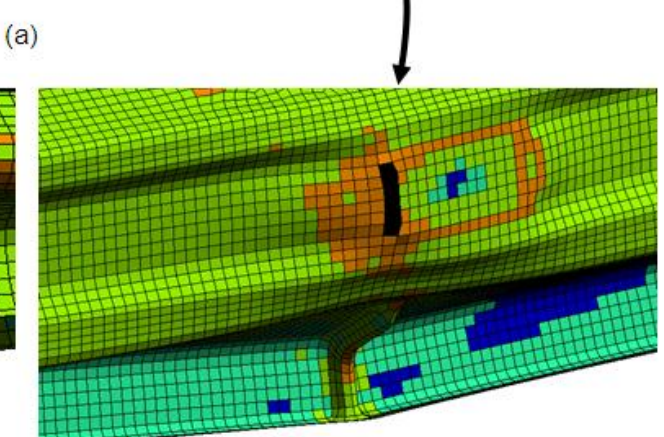

(c)

Figura 78. Critério da máxima tensão cisalhante, elementos negros indicam tensão de cisalhamento acima do limite de $381 \mathrm{MPa}$, (a) vista geral com malha de $5 \mathrm{~mm}$ x $5 \mathrm{~mm}$; (b)-(c) detalhe das regiões com falha na malha de $3 \times 3 \mathrm{~mm}$. 


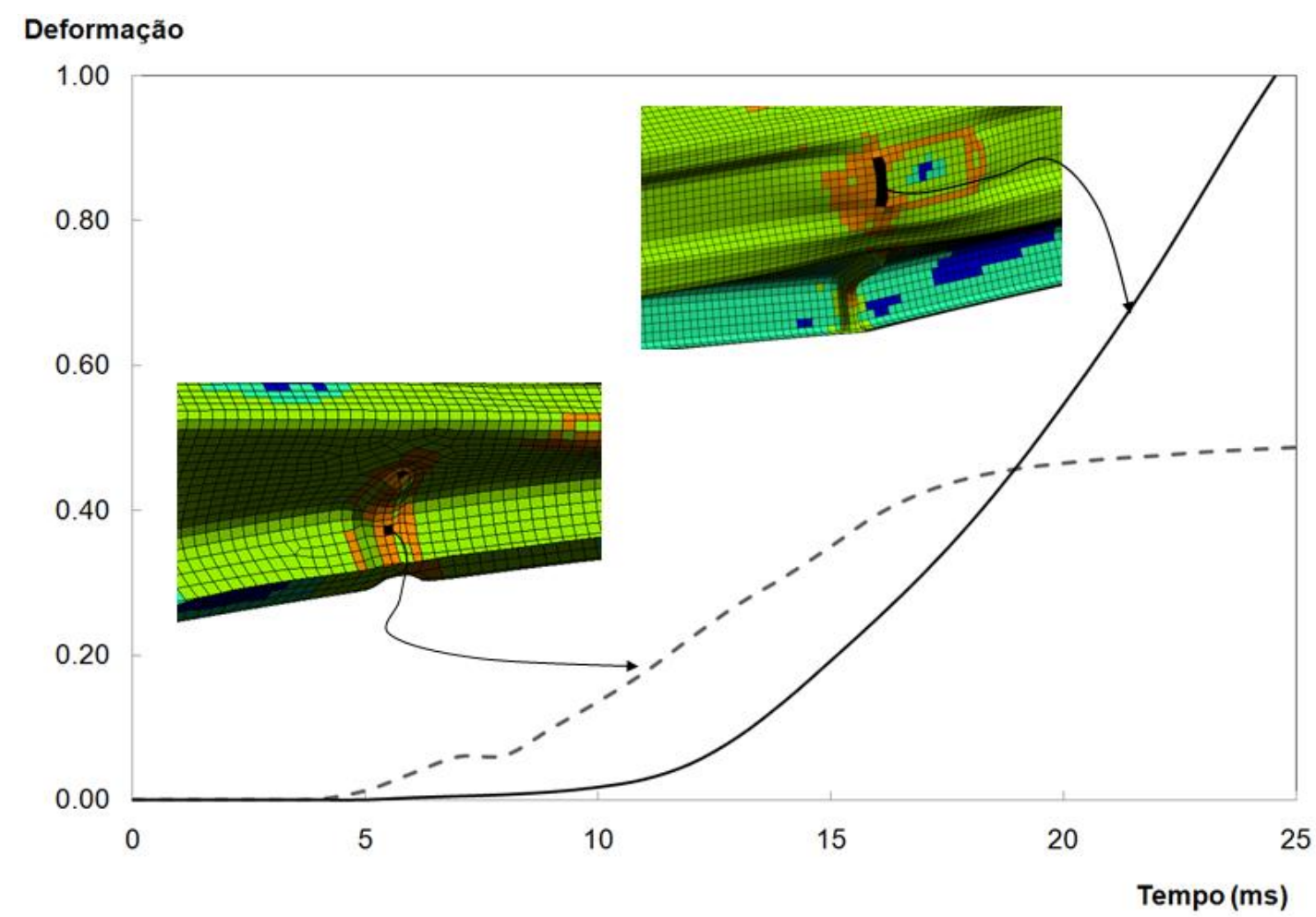

Figura 79. Evolução da deformação plástica com o tempo dos elementos indicados pelas setas (escala da Figura 78a).

O modelo de dano de J-C foi utilizado considerando os dois conjuntos de parâmetros calibrados, J-C Inferior e J-C Superior. Ambos indicaram de maneira consistente a localização do início de ruptura na região central do pára-choque. Porém, os dois conjuntos de parâmetros resultaram em diferentes velocidades de evolução da ruptura. Observa-se na Figura 80 que o modelo J-C Inferior resulta em uma evolução de ruptura ligeiramente mais rápida quando comparado com J-C Superior. Este comportamento seria esperado caso os elementos que sofreram ruptura nesta região estivessem em um estado de tensões cuja triaxialidade fosse entre 0,4 e 0,5, com base na Figura 32. De fato, monitorando a triaxialidade e a deformação plástica equivalente do elemento indicado pela seta amarela na Figura 81, verifica-se que o mesmo evolui no regime plástico nessa faixa de triaxialidade. Isso demonstra que JC Inferior possui uma margem de segurança maior que J-C Superior nessa faixa de triaxialidade. Ou seja, é possível que se tenha uma ruptura detectada utilizando-se J-C Inferior que não seja verificada em ensaio físico. Como exemplo, tem-se o caso da Figura 82, onde não foi verificado ruptura experimentalmente. A falha ocorre apenas no modelo utilizando-se $\mathrm{J}$-C Inferior, tanto com a malha de $5 \mathrm{~mm}$ quanto a 
malha de $3 \mathrm{~mm}$ (Figura 83 e Figura 84). Neste caso, o elemento em questão tem triaxialidade da ordem de 0,3 e, portanto, não sofreria ruptura considerando $\mathrm{J}-\mathrm{C}$ Superior, conforme ilustra a Figura 85. Com relação à velocidade de propagação da ruptura, J-C Superior se mostrou mais próximo do resultado experimental, conforme evidenciado na Figura 86. Além disso, a ruptura central do pára-choque foi consistente com os resultados do Teste \#6, tanto com a malha de $5 \mathrm{~mm}$ quanto a malha de $3 \mathrm{~mm}$, conforme ilustrado na Figura 87. O modelo de material específico de J-C (*MAT_JOHNSON_COOK) disponível no software foi extensivamente testado, porém não trouxe resultados coerentes, sendo então descartado. As análises com modelo de $\mathrm{J}-\mathrm{C}$ aqui descritas foram realizadas com um modelo de material híbrido do $L S-D y n a^{\circledR}$, que considera a formulação de Gurson e JohnsonCook. Com a manipulação de alguns parâmetros é possível reduzir o modelo para que contemple apenas a formulação de J-C.

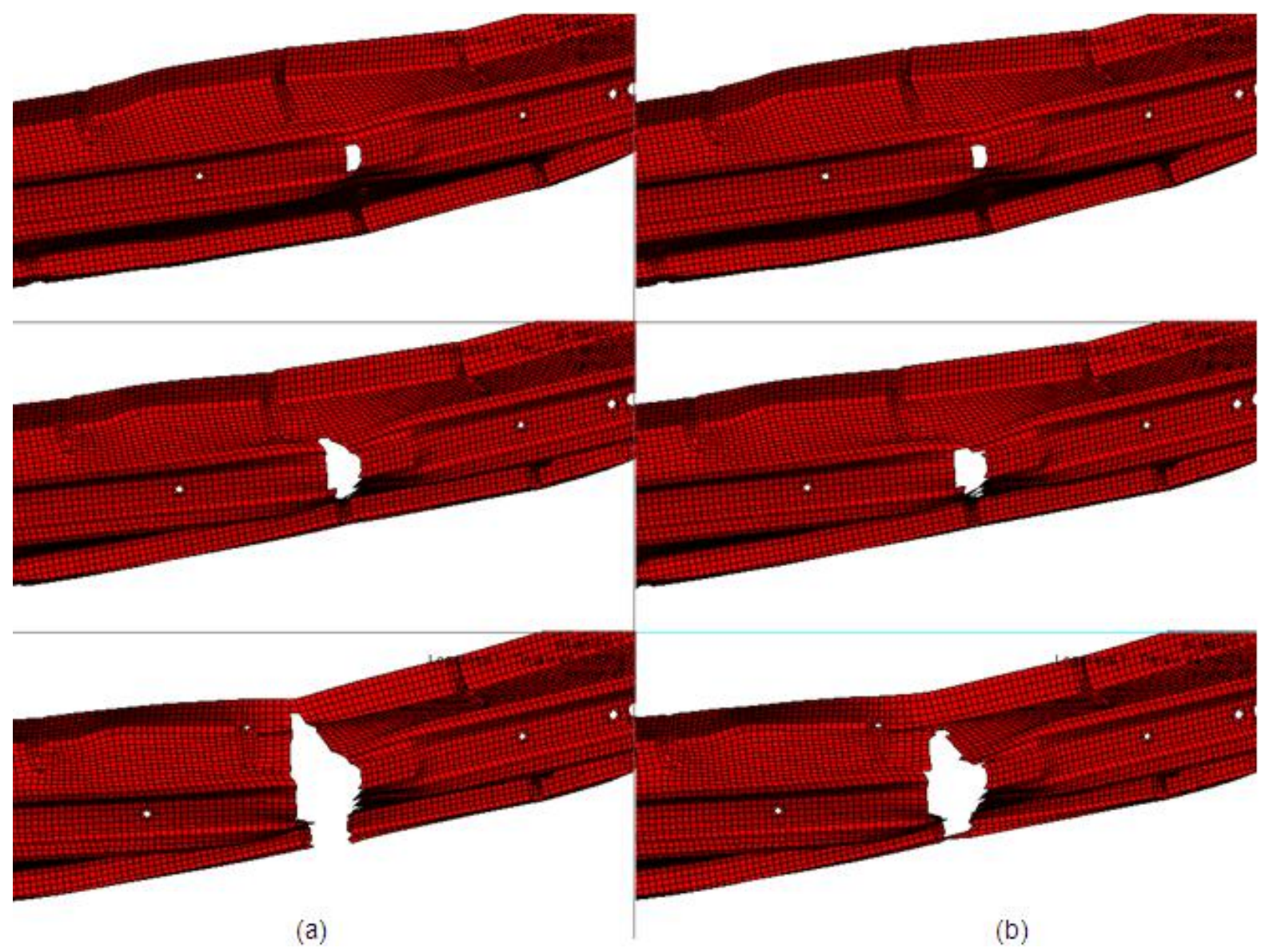

Figura 80. Resultado do modelo de dano de J-C com malha de $5 \mathrm{~mm}$, (a) modelo com parâmetros J-C Inferior; (b) J-C Superior. 


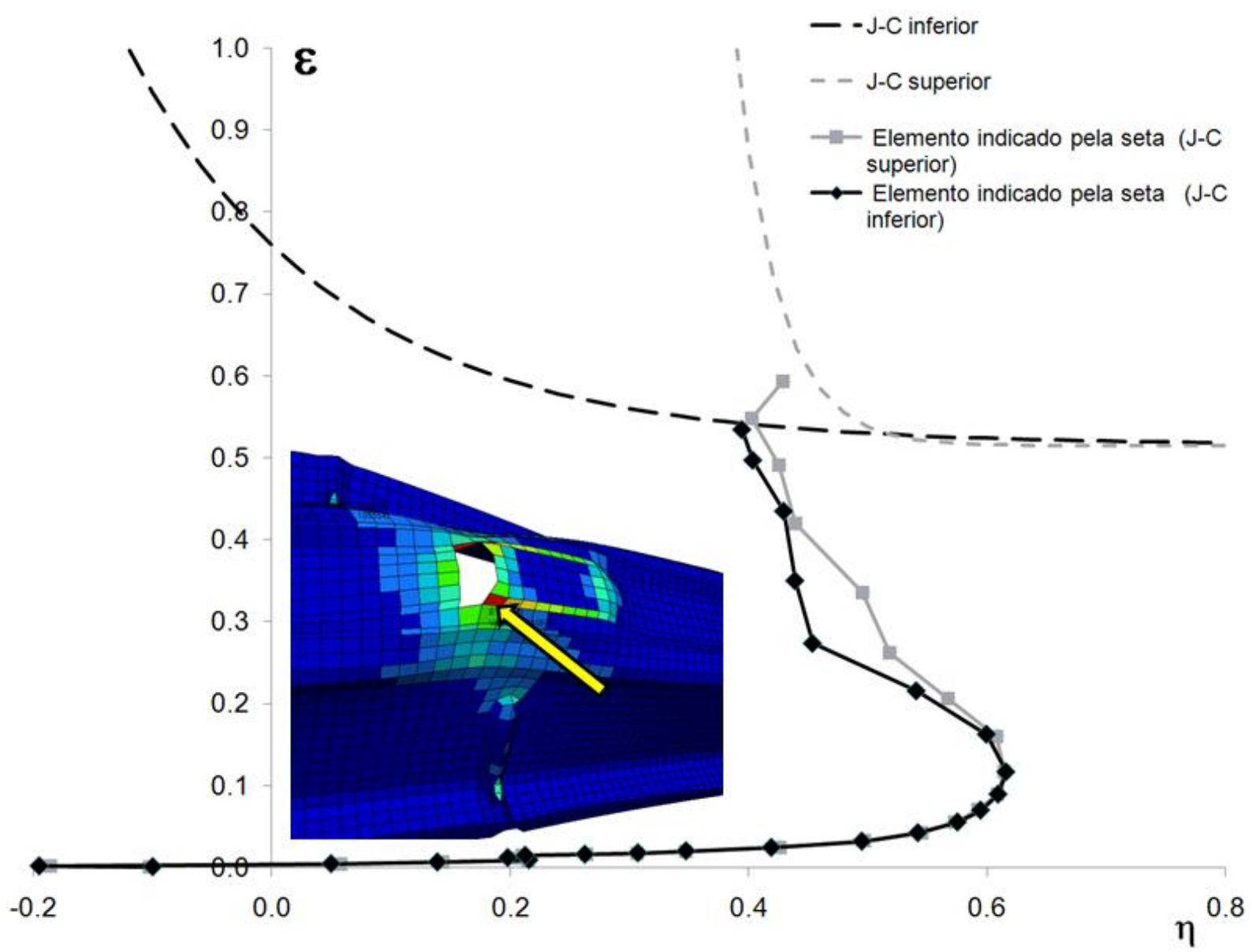

Figura 81. Deformação plástica equivalente e triaxialidade do elemento indicado pela seta durante a simulação utilizando-se o modelo de J-C Superior e Inferior. 


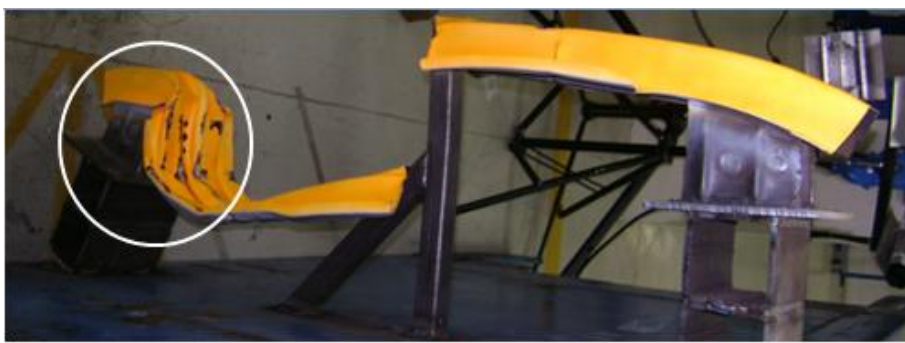

(a)

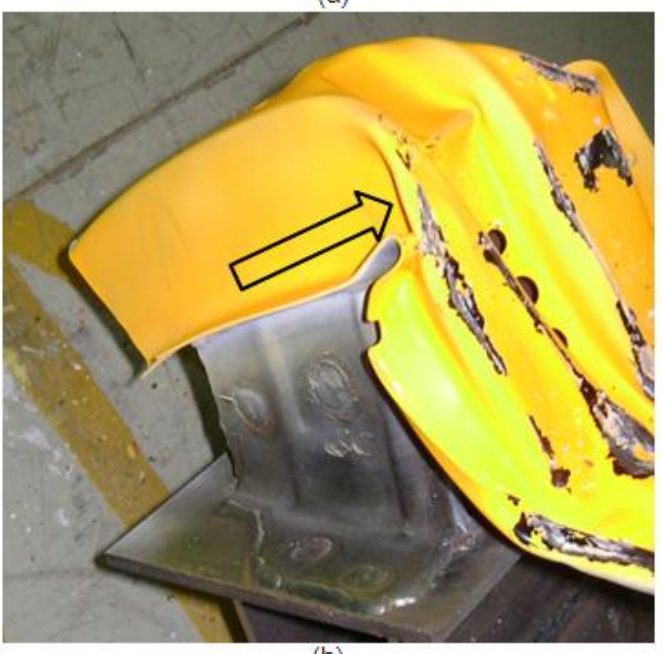

(b)

Figura 82. (a) região onde não houve ocorrência de falha no Teste\#6; (b) vista local.

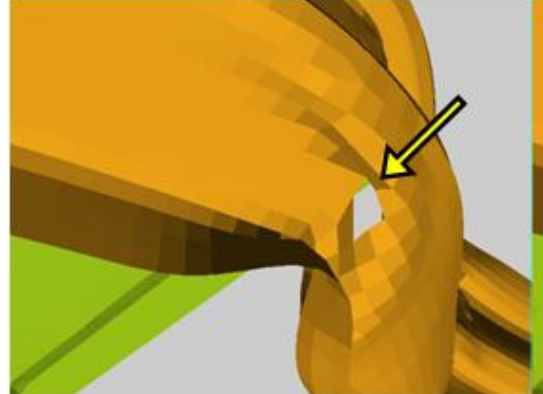

(a)

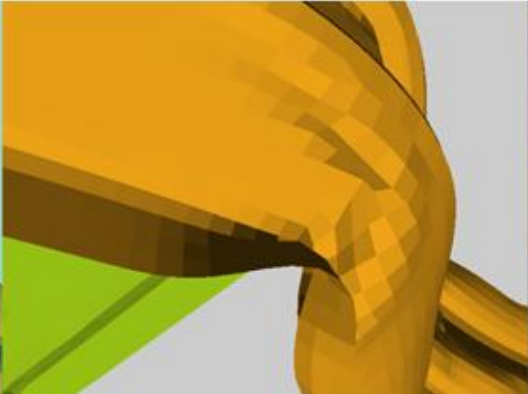

(b)

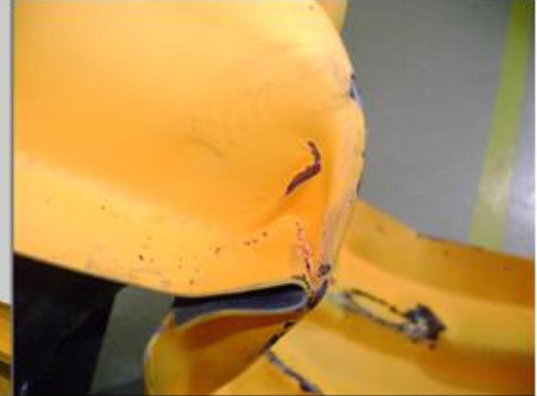

(c)

Figura 83. Comparativo utilizando o modelo de dano de $\mathrm{J}-\mathrm{C}$ com malha de $5 \mathrm{~mm} \times 5 \mathrm{~mm}$ (a) J-C Inferior; (b) J-C Superior; (c) resultado do Teste\#6.

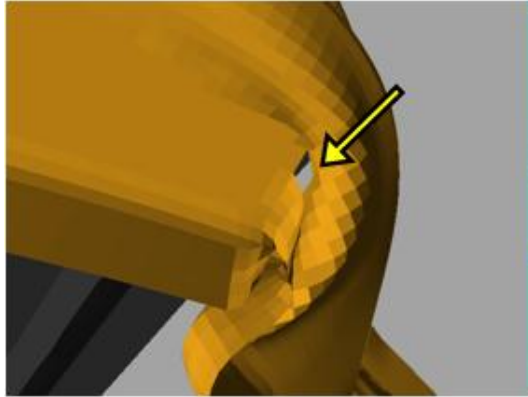

(a)

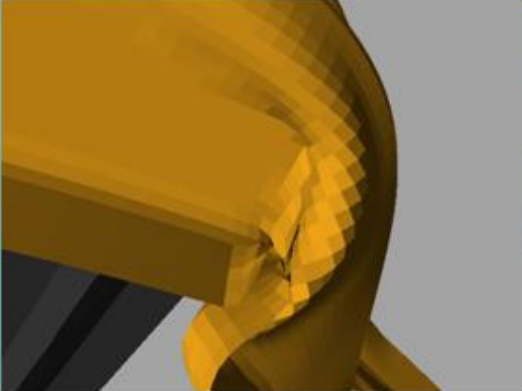

(b)

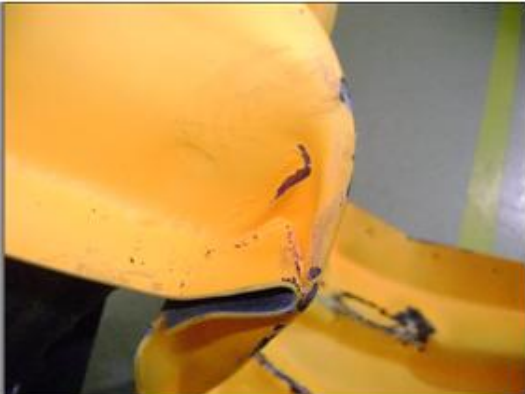

(c)

Figura 84. Comparativo utilizando o modelo de dano de $\mathrm{J}-\mathrm{C}$ com malha de $3 \mathrm{~mm} \times 3 \mathrm{~mm}$ (a) $\mathrm{J}$-C Inferior; (b) J-C Superior; (c) resultado do Teste\#6. 


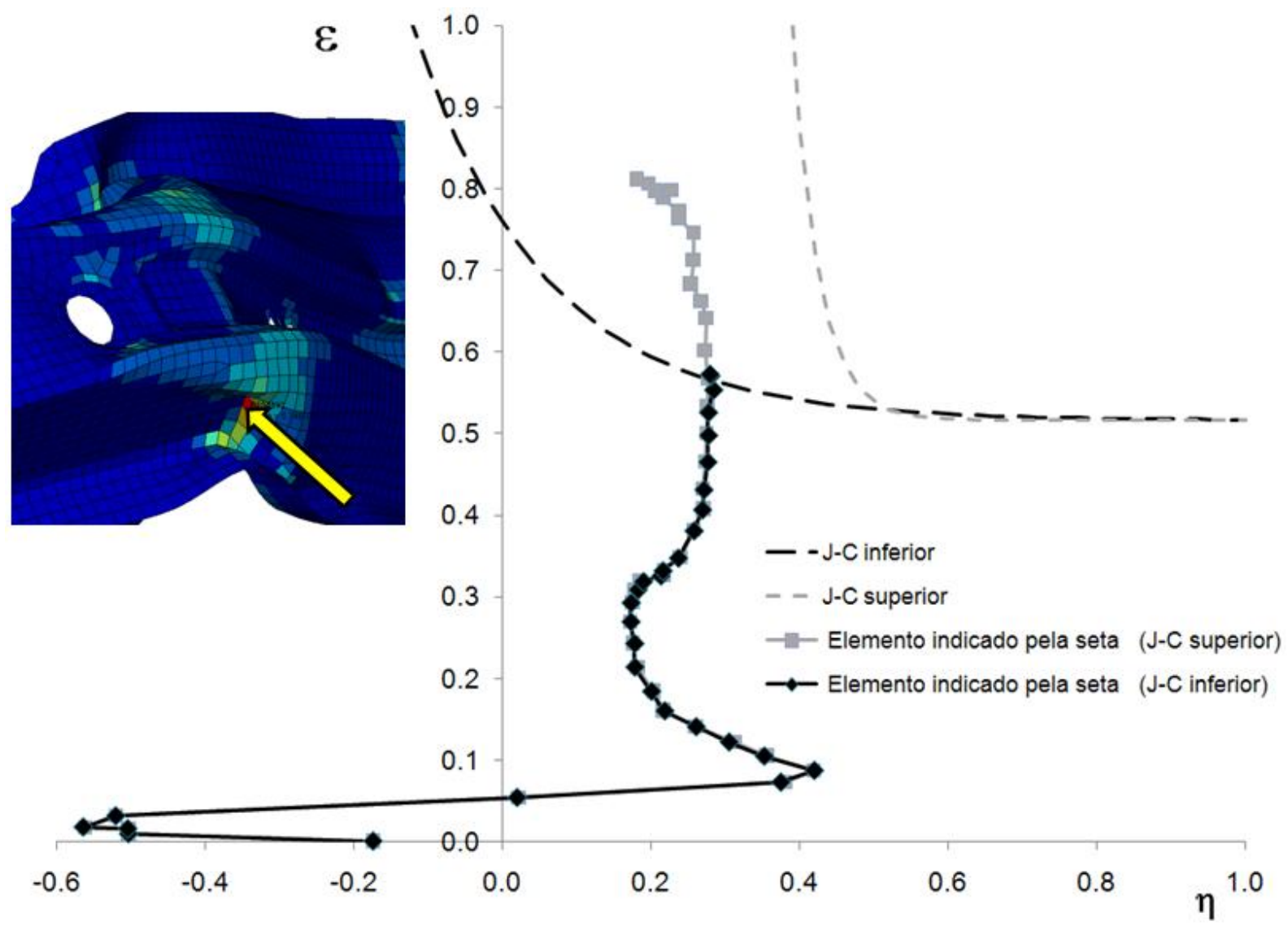

Figura 85. Deformação plástica equivalente e triaxialidade do elemento indicado pela seta durante a simulação utilizando-se o modelo de J-C Superior e Inferior.

(a)

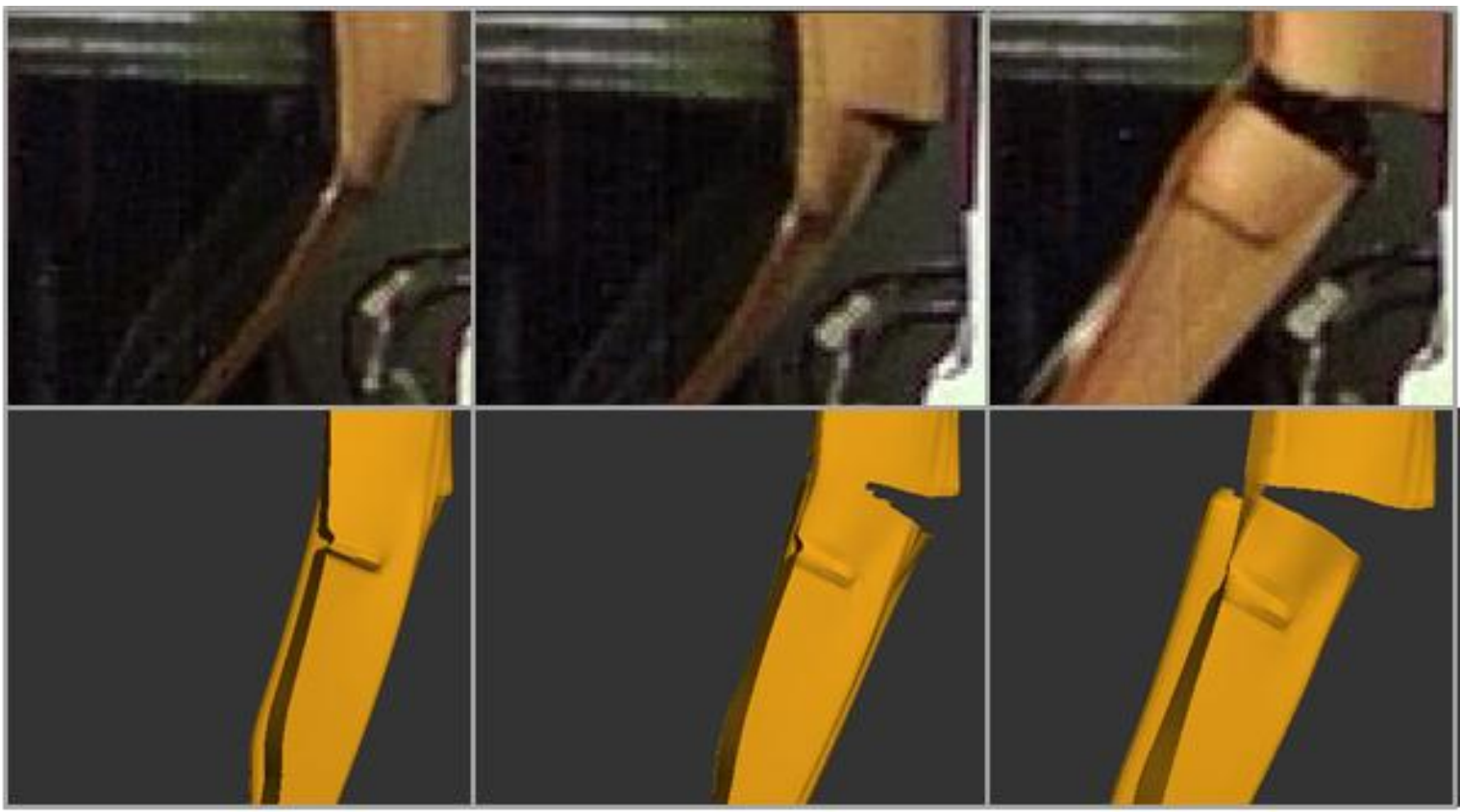

Figura 86. Comparativo da ruptura utilizando o modelo de dano de J-C Superior (a) resultado do Teste\#6; (b) malha com elementos de $3 \mathrm{~mm} \times 3 \mathrm{~mm}$. 


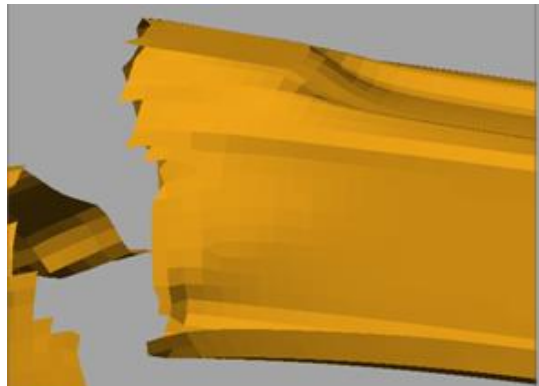

(a)

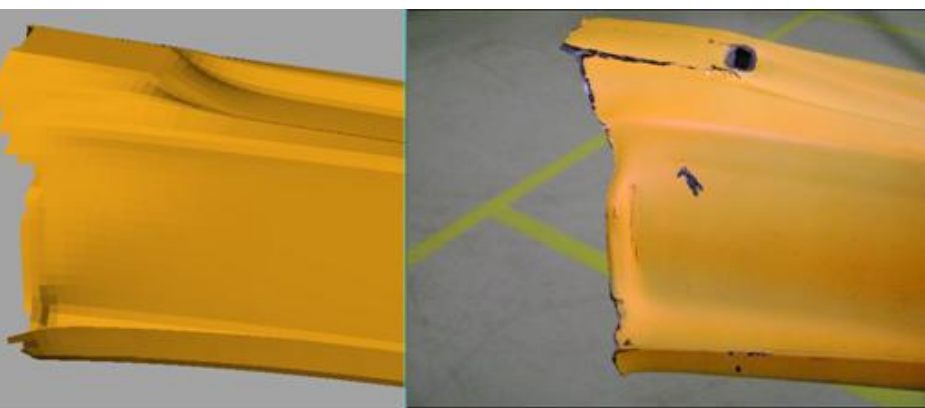

(b) (c)

Figura 87. Comparativo da ruptura utilizando o modelo de dano de J-C Inferior com (a) malha com elementos de $5 \mathrm{~mm} \times 5 \mathrm{~mm}$; (b) malha com elementos de $3 \mathrm{~mm} \times 3 \mathrm{~mm}$; (c) resultado do Teste\#6. 


\section{CONCLUSÕES}

Atualmente no mercado automotivo global busca-se a competitividade desenvolvendo veículos mais leves, de modo a reduzir os custos de material, índices de emissões e consumo de combustível. Para tal, o uso de ferramentas de simulação numérica se faz necessária para reduzir os custos de desenvolvimento com a redução de protótipos. No entanto, a caracterização numérica de falha de material ainda não é aplicada industrialmente, levando os desenvolvedores de veículos a considerar margem de segurança adicional para cobrir a eventual ocorrência de ruptura. Este trabalho visou o estudo de diversos modelos de falha em materiais metálicos, com o objetivo de avaliar sua aplicabilidade na indústria, mais precisamente em desenvolvimento de veículos.

Primeiramente fez-se um extenso estudo bibliográfico dos diversos modelos e critérios de falha existentes na literatura, a partir do qual foram definidos três critérios de falha a serem aplicados em um caso de impacto pendular em pára-choque. Sendo estes o critério da máxima deformação plástica equivalente, modelo de dano de Johnson-Cook e critério da máxima tensão cisalhante.

A caracterização do material foi feita por meio de ensaios de tração de espécimes com e sem entalhe e de cisalhamento para prover dados em uma ampla faixa de triaxialidade. O comportamento dinâmico do material dependente da taxa de deformação foi considerado através das equações de Cowper-Symonds e de Johnson-Cook, utilizando-se de parâmetros retirados de fontes diversas. A calibração dos parâmetros necessários para cada modelo através das componentes de tensões e de deformações na região de ruptura foram obtidas por meio de análises numéricas destes ensaios, que permitiram também a definição de dois conjuntos de parâmetros de J-C, denominados "Inferior" e "Superior".

Diversos ensaios de impactos em pára-choque foram realizados para que os modelos de falha em questão fossem estudados. Uma vez que pára-choque é um componente desenvolvido para absorver energia, obter falha através de um ensaio 
de impacto pendular não se tratou de uma tarefa trivial. O primeiro conjunto de ensaios teve como objetivo gerar informações úteis para a posterior correlação de parâmetros do modelo de elementos finitos. Para tal, manteve-se o carregamento e condições de contorno em níveis baixos de modo que a ruptura do material não ocorresse. Já a segunda bateria de testes objetivou a ocorrência de ruptura. Neste caso, uma estratégia de aumento progressivo da severidade dos ensaios foi adotada, resultando em ruptura satisfatória no Teste \#6.

Por fim, os modelos de falha calibrados foram aplicados em simulações de impacto pendular em pára-choques. Parâmetros iniciais do modelo de pára-choque foram correlacionados com os ensaios de baixa severidade. A aplicação dos modelos de falha foi feita nas simulações de ensaio severo, reproduzindo as condições de contorno e carregamento do Teste \#6. Nestas simulações foram analisados os efeitos dos modelos de falha em duas malhas de pára-choque, a primeira com elementos de $5 \mathrm{~mm} \times 5 \mathrm{~mm}$ e a segunda com elementos de $3 \mathrm{~mm} \times 3 \mathrm{~mm}$.

O critério da máxima deformação plástica equivalente é disponível em softwares comerciais e é de simples caracterização. Apenas um ensaio de tração e respectiva análise numérica são suficientes para se determinar o limite de deformação plástica. Neste trabalho, o resultado do espécime com entalhe de raio de 1,25 $\mathrm{mm}$ foi utilizado. Porém, qualquer um dos espécimes com entalhe poderia ter sido utilizado, uma vez que os limites de deformação plástica ficou na estreita faixa de 0,5157 e 0,5423. Este critério se mostrou eficiente na predição da localização do início de ruptura para ambos os refinos de malha. Porém, a descrição da propagação da ruptura através da eliminação de elementos finitos que atingiram o valor de deformação máxima foi condizente com o resultado experimental apenas para a malha mais refinada. Isso demonstra uma dependência relevante de sua eficiência com o grau de refinamento da malha. Além disso, por ser um critério de deformação constante em função da triaxialidade, o mesmo deve apresentar elevada margem de segurança para casos em que a triaxialidade é baixa ou negativa (caracterizando compressão).

O critério da máxima tensão cisalhante, indicado pela literatura com sendo muito eficaz na predição de falha pra casos de tensão plana, também demonstrou ser de simples caracterização. Basta um ensaio para obter o valor da máxima tensão 
cisalhante e, neste trabalho, um valor médio foi adotado. A dificuldade na utilização deste critério reside no fato de o mesmo não estar disponível em uma ampla gama de softwares comerciais. Sendo assim, sua aplicabilidade foi analisada considerando apenas a indicação do início de ruptura. Comparando-se com o resultado experimental, este critério indicou corretamente o início de ruptura no centro do pára-choque para ambas as malhas. Porém, indicou simultaneamente início de ruptura em uma região onde a falha não foi verificada experimentalmente. A análise dessa região indicou que a evolução da deformação plástica equivalente rege a ruptura no centro do pára-choque antecipadamente. Como resultado, tem-se que a região onde não foi verificada falha seria descarregada e não sofreria ruptura numericamente caso o critério estivesse disponível no software.

O modelo de falha de $\mathrm{J}-\mathrm{C}$, por sua vez, exige uma quantidade maior de ensaios para ser caracterizado. No mínimo três ensaios de tração a diferentes triaxialidades para caracterizar o material estaticamente são necessários. Neste trabalho, o conjunto de ensaios de caracterização permitiu a calibração de dois conjuntos de parâmetros do modelo de falha, J-C Inferior e J-C Superior. O primeiro representa uma condição de maior margem de segurança, uma vez que subestima o limite de deformação do material para triaxialidades inferiores a 0,5. Já o segundo, que considera o valor de deformação do espécime sem entalhe na calibração, não representaria falha para triaxialidades inferiores a 0,4 . Na aplicação específica do caso de impacto do Teste \#6, ambos os modelos descreveram de maneira satisfatória o início e propagação da ruptura no centro do pára-choque para ambas os refinos de malha. Isso demonstra que a dependência da resposta numérica deste modelo para a propagação da ruptura em função do grau de refinamento da malha é menor quando comparado ao critério da máxima deformação plástica equivalente. Foi observado que a propagação da ruptura central com J-C Inferior ocorreu de forma mais rápida que o observado com o J-C Superior, uma vez que o mesmo subestima o limite de deformação do material. Especificamente para este ensaio, pode-se afirmar que J-C Superior apresentou resultados mais próximos ao observado experimentalmente, porém, sabe-se que o uso deste critério para casos em que a triaxialidade é inferior a 0,3 é arriscada. Pois é certo que nesta condição não há limite de deformação plástica e a resposta numérica certamente superestima a capacidade de deformação do material. Além da eficácia observada neste trabalho, o modelo de J-C também 
pode ser aplicado a casos de elevada taxa de deformação e com influência de efeitos térmicos. Justificando assim sua extensa aplicação em casos de balística.

Trabalhos futuros devem focar em casos que resultem em uma faixa mais ampla de triaxialidades, ou então, em delimitar uma faixa de triaxialidade que seja mais importante e usual em casos específicos de impacto veicular. Isso confirmaria algumas das justificativas apresentadas. Além dos critérios e modelos aqui expostos, técnicas avançadas de elementos finitos podem ser exploradas. Como exemplo, pode-se citar o algoritmo que reproduz a propagação de trincas a partir da ruptura inicial através da divisão de elementos "element splitting" de acordo com critérios baseados em energia, em linha com a Mecânica da Fratura. Outro método a ser explorado trata do refinamento automático da malha ("remeshing") na região de possível início de ruptura. Tais técnicas permitem o uso mais racional de recursos computacionais uma vez que malhas muito refinadas em toda sua extensão não necessárias. 


\section{REFERÊNCIAS}

1 SEIFFERT, U.; WECH, L. Automotive Safety Handbook. Warrendale: SAE International, 2003.

2. CESVI Brasil. Disponivel em: <http://www.cesvibrasil.com.br/index.asp>. Acesso em: 31 jan. 2009.

3. EuroNCAP. Disponivel em: <http://www.euroncap.com>. Acesso em: 22 Agosto 2008.

4. Insurance Institut for Highway Safety - IIHS, Michigan. Disponivel em: $<$ http://www.iihs.org/>. Acesso em: 31 Janeiro 2009.

5 DRIEMEIER, L.; ALVES, M. On different tensile tests for failure criteria analysis. Internacional Symposium on Plasticity. Havaí: [s.n.]. 2008.

6 ALVES, M.; J. L.YU; JONES, N. On the elastic modulus degradation in continuum damage mechanics. Computers \& Structures, 2000. v. 76, 703-712-712.

7. Research Council for Automobile Repairs - RCAR. Disponivel em: <http://www.rcar.org/>. Acesso em: 21 Novembro 2008.

8 PICKET, A. K. et al. Failure prediction for advanced crashworthiness of transportation vehicles. International Journal of Impact Engineering, 2004. (30) 853-872.

9 LEMAITRE, J. A course of damage mechanics. Berlin: Springer, 1989.

10 HULT, J. A. H. Creep in Engineering Structures. [S.I.]: [s.n.], Waltham,Blaisdell publishing company, 1966. 
11 DRIEMEIER, L. Considerações sobre a fadiga em metais e o comportamento do concreto sob solicitação cíclica. Dissertação de Mestrado, São Carlos, 1995.

12 RICE, J. R.; TRACEY, D. M. On the ductile enlargement of voids in triaxial stress fields. Journal of the Mechanics and Physics of Solids, 1969. (17) 201-217.

13 ALVES, M.; JONES, N. Influence of hidrostatic stress on failure of axisimmetric notched specimens. Journal of Mechanics and Physics of Solids, 1999. (47) 643667.

14 GRYTTEN, F. et al. Quasi-static perforation of thin aluminium plates. International Journal of Impact Engineering, 2009. (36) 486-497.

15 BORVIK, T. et al. Perforation of AA5083-H116 aluminium plates with conical nose steel projectiles - experimental studies. International Journal of Impact Engineering, 2009. (36) 426-437.

16 BORVIK, T. et al. Perforation of AA5083-H116 aluminium plates with conical nose steel projectiles - Calculations. International Journal of Impact Engineering, 2009. (36) $426-437$.

17 WIERZBICKI, T. et al. Calibration and Evaluation of seven fracture models. International Journal of Mechanical Sciences, 2005. (47) 719-743.

$18 \mathrm{BAO}, \mathrm{Y}$;; WIERZBICKI, T. On the fracture locus in the equivalent strain and stress triaxiality space. International Journal of Mechanical Sciences, 2004. (46) 81-91.

19 OCKEWITZ, A. et al. Damage modelling of automobile components under crash loading. LS-Dyna Anwenderforum, p. 12, 2006.

20 BAO, Y.; WIERZBICKI, T. On the cut-off value of negative triaxiality for fracture. Engineering of Fracture Mechanics, 2005. (72) 1049-1069.

21 TENG, X.; WIERZBICKI, T. Evaluation of six fracture models in high velocity perforation. Engineering Fracture Mechanics, 2006. (73) 1653-1678. 
22 BIGONI, D.; PICCOLROZA, A. A new yield function for geomaterials. In:

Constitutive modelling and analysis of boundary value problems in geotechnical engineering. Napoli: [s.n.], 2003. p. 266-281.

23 JOHNSON, G. R.; COOK, W. H. Fracture characteristics of three metals subjected to various strains, strain rates, temperatures and pressures. Engineering Fracture Mechanics, 1985. 21(1) 31-48.

24 WILKINS, M. L.; STREIT, R. D.; REAUGH, J. E. Cumulative strain damage model of ductile fracture:simulation and prediction of engineering fracture tests. Livermore. 1985. (UCRL-53058).

25 MIRONE, G. Elastoplastic characterization and damage predictions under evolving local triaxiality: axysimmetric and thick plate specimens. Mechanics of Materials, 2008. (40) 685-694.

26 BRUNIG, M. Numerical simulation of the large elastic-plastic deformation behavior of hydrostatic stress-sensitive solids. International Journal of Plasticity, 1999. (15) 1237-1264.

27 BRUNIG, M. An anisotropic ductile damage model based on irreversible thermodynamics. International Journal of Plasticity, 2003. (19) 1679-1713.

28 XUE, L.; WIERZBICKI, T. Ductile fracture initiation and propagation modeling using damage plasticity theory. Engineering Fracture Mechanics, 2008. (75) 32763293.

29 MIRONE, G. . C. D. A local viewpoint for evaluating the influence of stress triaxiality and Lode angle on ductile failure and hardening. International Journal of Plasticity, 2010. (26) 348-371.

30 GURSON, A. L. Continuum theory of ductile rupture by void nucleation and growth: Part I: yield criteria and flow rules for porous ductile media. Eng Mat Technol, 1977. (99) 2-15. 
31 NEEDLEMAN, A.; TVERGAARD, V. Analysis of ductile rupture in notched bars. Journal of Mechanics Physics and Solids, 1984. (32) 461-490.

32 GOLOGANU, M.; LEBLOND, J. B.; DEVAUX, J. Approximate models for ductile metals containing non-spherical voids-case of axysymmetric prolate ellipsoidal cavities. Journal of Mechs Phys Solids, 1993. (41) 1723-54.

33 KESSLER, L. et al. An approach to model sheet failure after onset of localized necking in indusrial high strength steel stamping and crash simulations. SAE Internation, Detroit, p. 12, 2008. ISSN 2008-01-0503.

34 WANG, H.; SIVASAMY, S.; SCHROTER, M. Material failure approaches for ultra high strength steel. LS DYNA Anwerdenforum. [S.I.]: [s.n.]. 2006. p. 8.

35 MARCINIAL, Z.; KUCZINSKI, K. Limit strains in the processes of stretch forming sheet metal. International Journal of Mechanical Sciences, 1967. (9) 609-20.

36 KURTARAN, H.; BUYUK, M.; ESKANDARIAN, A. Ballistic impact simulation of GT model vehicle door using finite element model. Theoretical and Applied Fracture Mechanics, 2003. (40) 113-121.

37 NEUKAMM, F.; FEUCHT, M.; A., H. Forming and crash induced damage evolution and failure prediction Part 2: A comparison of damage models. LS DYNA Anwenderforum. Frankenthal: DYNAmore GmbH. 2007. p. 12.

38 SCHILEOLA, E. et al. Subject-specific finite element models implementing a maximum principal strain criterion are able to estimate failure risk and fracture location on human femurs tested in vitro. Journal of Biomechanics, 2008. (41) 356367.

39 JOHNSON, G. R.; HOLMQUIST, T. J. Test data and computational strength and fracture model constants for $\mathbf{2 3}$ materials subjected to large strain, high strain rates, and high temperature. Los Alamos National Laboratory. [S.I.]. 1989. (Technical Report LA-11463-MS). 
40 ALVES, M. Measurement of ductile material damage. Journal Of Mechanics Of Structures And Machines, v. 29, p. 451-476, 2001.

41 BRUNIG, M. et al. A ductile damage criterion at various stress triaxialities. Internacional Symposium on Plasticity, Havaí, 2008. 1731-1755.

42 HALLQUIST, J. O. LS-Dyna Theory Manual. [S.I.]: Livermore Software, 2005.

43 SANTOS, D. F. G. et al. The sulfur effect on the microstructure and mechanical properties of the ABNT 1045 steel. 20th International Congress of Mechanical Engineering, Gramado, COBEM 2009. 


\section{APÊNDICE A - PROCEDIMENTOS DE TESTE}

Tabela A 1 - ensaios de impacto que são realizados em laboratório seguindo diversos procedimentos internacionais

\begin{tabular}{|c|c|c|c|}
\hline & Descrição & & Objetivos \\
\hline \multirow{5}{*}{ 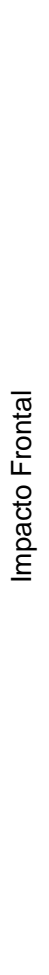 } & & $\begin{array}{l}\text { Velocidade: }(48,3-53,1) \mathrm{km} / \mathrm{h} \\
\text { Barreira rígida com } 100 \% \text { de } \\
\text { sobreposição } \\
\text { Sem dummies }\end{array}$ & $\begin{array}{l}\text { Proteção ao Ocupante: medição do deslocamento da coluna de } \\
\text { direção vertical e horizontal durante o impacto. } \\
\text { Integridade do Sistema de Combustível: não é permitido vazamento } \\
\text { de combustível após o impacto. }\end{array}$ \\
\hline & & $\begin{array}{l}\text { Velocidade: }(48-50) \mathrm{km} / \mathrm{h} \\
\text { Barreira rígida com } 100 \% \text { de } \\
\text { sobreposição } \\
\text { Com dummies (motorista e } \\
\text { passageiro) }\end{array}$ & $\begin{array}{l}\text { Proteção ao Ocupante: medição do deslocamento da coluna de } \\
\text { direção vertical e horizontal residual. } \\
\text { Medição de índices de lesão (cabeça, tórax e fêmur) } \\
\text { Integridade do Sistema de Combustível: não é permitido vazamento } \\
\text { de combustível após o impacto. } \\
\text { Integridade de bancos, cintos de segurança e painel de } \\
\text { instrumentos. }\end{array}$ \\
\hline & & $\begin{array}{l}\text { Velocidade: } 56,3 \mathrm{~km} / \mathrm{h} \\
\text { Barreira rígida com } 100 \% \text { de } \\
\text { sobreposição } \\
\text { Com dummies (motorista e } \\
\text { passageiro) }\end{array}$ & $\begin{array}{l}\text { Proteção ao Ocupante: medição do deslocamento da coluna de } \\
\text { direção vertical e horizontal residual. } \\
\text { Medição de índices de lesão (cabeça, pescoço, tórax, abdômen, } \\
\text { pélvis, joelhos, fêmur e tíbia) } \\
\text { Integridade do Sistema de Combustível: não é permitido vazamento } \\
\text { de combustível após o impacto. } \\
\text { Integridade de bancos, cintos de segurança e painel de } \\
\text { instrumentos. }\end{array}$ \\
\hline & & $\begin{array}{l}\text { Velocidade: }(56-57) \mathrm{km} / \mathrm{h} \\
\text { Barreira deformável com } 40 \% \text { de } \\
\text { sobreposição } \\
\text { Com dummies (motorista e } \\
\text { passageiro) }\end{array}$ & \multirow{2}{*}{$\begin{array}{l}\text { Proteção ao Ocupante: medição do deslocamento da coluna de } \\
\text { direção vertical e horizontal residual; medição do deslocamento dos } \\
\text { pedais. } \\
\text { Medição de índices de lesão (cabeça, pescoço, tórax, joelhos, } \\
\text { fêmur e tíbia) } \\
\text { Integridade do Sistema de Combustível: não é permitido vazamento } \\
\text { de combustível após o impacto. } \\
\text { Integridade de bancos, cintos de segurança e painel de } \\
\text { instrumentos. }\end{array}$} \\
\hline & & $\begin{array}{l}\text { Velocidade: }(63-65) \mathrm{km} / \mathrm{h} \\
\text { Barreira deformável com } 40 \% \text { de } \\
\text { sobreposição } \\
\text { Com dummies (motorista e } \\
\text { passageiro) }\end{array}$ & \\
\hline \multirow{3}{*}{ 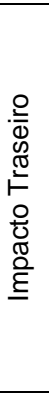 } & & $\begin{array}{l}\text { Barreira rígida móvel }(1100 \mathrm{~kg}) \\
\text { Velocidade: }(35-38) \mathrm{km} / \mathrm{h} \\
100 \% \text { de sobreposição } \\
\text { Sem dummies }\end{array}$ & $\begin{array}{l}\text { Integridade do sistema de combustível } \\
\text { Medição do deslocamento longitudinal do ponto } \mathrm{H} \text { dos assentos } \\
\text { traseiros }\end{array}$ \\
\hline & & $\begin{array}{l}\text { Barreira rígida móvel }(1367 \mathrm{~kg}) \\
\text { Velocidade: }(48-52) \mathrm{km} / \mathrm{h} \\
100 \% \text { de sobreposição } \\
\text { Sem dummies }\end{array}$ & Integridade do sistema de combustível \\
\hline & & $\begin{array}{l}\text { Barreira rígida móvel }(1100 \mathrm{~kg}) \\
\text { Velocidade: }(79-81) \mathrm{km} / \mathrm{h} \\
100 \% \text { de sobreposição } \\
\text { Sem dummies }\end{array}$ & Integridade do sistema de combustível \\
\hline \multirow[t]{2}{*}{ 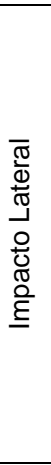 } & & $\begin{array}{l}\text { Barreira deformável móvel (1361 } \\
\mathrm{kg}) \\
\text { Velocidade: } 53 \text { e } 63 \mathrm{~km} / \mathrm{h} \\
\text { Impacto a } 27^{\circ} \\
\text { Com dummies motorista e } \\
\text { passageiro traseiro lado esquerdo } \\
\text { Barreira deformável móvel }(950 \mathrm{~kg}) \\
\text { Velocidade: } 53 \text { e } 63 \mathrm{~km} / \mathrm{h} \\
\text { Impacto a } 90^{\circ} \\
\text { Com dummy motorista }\end{array}$ & \multirow[t]{2}{*}{$\begin{array}{l}\text { Medição de índices de lesão (cabeça, pescoço, tórax,abdômen e } \\
\text { pelvis). } \\
\text { Integridade do Sistema de Combustível: não é permitido vazamento } \\
\text { de combustível após o impacto. } \\
\text { Integridade de bancos, cintos de segurança e painel de } \\
\text { instrumentos. }\end{array}$} \\
\hline & & $\begin{array}{l}\text { Impacto contra poste } \\
\text { Velocidade: } 29 \mathrm{~km} / \mathrm{h} \\
\text { Impacto a } 90^{\circ} \\
\text { Com dummy motorista }\end{array}$ & \\
\hline
\end{tabular}


Ensaios de impacto pendular em pára-choques com o veículo em repouso fazem parte de requisitos legais de diversos países, como Estados Unidos (CFR 49 Parte 581), Coréia (KMVSS 93), Canadá (CMVSS 215) e países da Europa (ECE R42). Este ensaio envolve o impacto frontal e traseiro de um pêndulo como o da Figura $A$ 88a, sendo que as posições de impacto variam entre angular, longitudinal central e deslocado, em alturas variadas conforme.

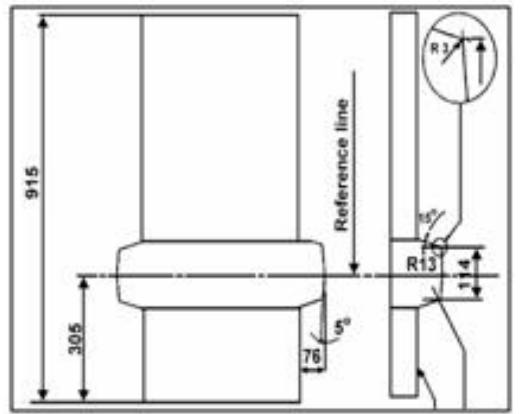

(a)

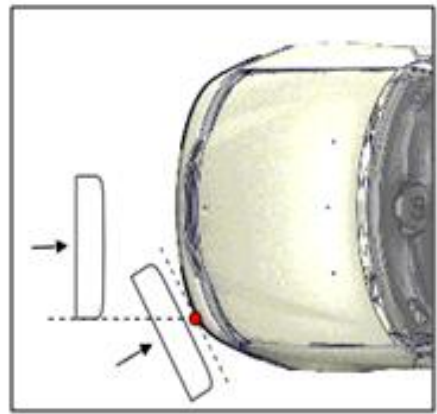

(b)

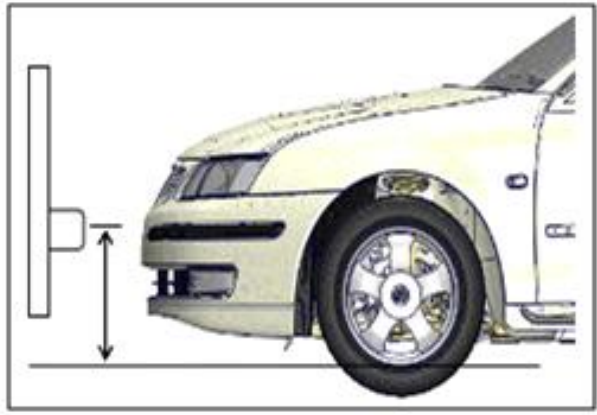

(c)

Figura A 88. Ensaio de impacto pendular, (a) desenho do pêndulo, (b) posições de impacto e (c) altura do pêndulo.

A maioria dos requisitos está ligada a severidade de dano das regiões frontal e traseira do veículo, como por exemplo:

- Capô, portas, porta-malas devem continuar operacionais e funcionais após o teste.

- Os sistemas de combustível e de refrigeração devem permanecer intactos e livres de vazamento.

- O sistema de escapamento não deve ser afetado.

- O motor, suspensão, sistema de direção e freios devem permanecer funcionais e sem alteração em calibragem/ajuste. 
Todas as regulamentações citadas exigem que uma bateria de testes, (resumidos na Tabela A 1, Tabela A2, Tabela A3e Tabela A 4 - para cada legislação), seja realizada com o mesmo veículo, sem a permissão para substituição do sistema de pára-choques. A ECE R42 a única que permite a troca de peças entre ensaios.

Tabela A2 - Bateria de ensaios de impacto pendular frontal e traseiro conforme CMVSS 215

\begin{tabular}{llll}
\hline \# Teste & Posição do impacto & $\begin{array}{l}\text { Velocidade do } \\
\text { pêndulo }(\mathrm{km} / \mathrm{h})\end{array}$ & $\begin{array}{l}\text { Altura do } \\
\text { pêndulo }(\mathrm{mm})\end{array}$ \\
\hline 1 & Angular & 4,8 & 508,0 \\
2 & Longitudinal - Centro & 8,0 & 406,4 \\
3 & Longitudinal - Centro & 8,1 & 508,0 \\
4 & Longitudinal - Deslocado & 8,2 & 406,4 \\
5 & Longitudinal - Deslocado & 8,3 & 508,0 \\
6 & Barreira rígida & 8,4 & - \\
\hline
\end{tabular}

Tabela A3 - Bateria de ensaios de impacto pendular frontal e traseiro conforme CFR 49 Parte 581

\begin{tabular}{llll}
\hline \# Teste & Posição do impacto & $\begin{array}{l}\text { Velocidade do } \\
\text { pêndulo }(\mathrm{km} / \mathrm{h})\end{array}$ & $\begin{array}{l}\text { Altura do } \\
\text { pêndulo }(\mathrm{mm})\end{array}$ \\
\hline 1 & Angular & 2,4 & 406,4 \\
2 & Angular & 2,4 & 508,0 \\
3 & Longitudinal - Centro & 4,0 & 406,4 \\
4 & Longitudinal - Centro & 4,0 & 508,0 \\
5 & Longitudinal - Deslocado & 4,0 & 406,4 \\
6 & Longitudinal - Deslocado & 4,0 & 508,0 \\
7 & Barreira rígida & 4,0 & - \\
\hline
\end{tabular}

Tabela A 4 - Bateria de ensaios de impacto pendular frontal e traseiro conforme ECE R42

\begin{tabular}{llll}
\hline \# Teste & Posição do impacto & $\begin{array}{l}\text { Velocidade do } \\
\text { pêndulo }(\mathrm{km} / \mathrm{h})\end{array}$ & $\begin{array}{l}\text { Altura do } \\
\text { pêndulo }(\mathrm{mm})\end{array}$ \\
\hline 1 & Angular & 2,4 & 445 \\
2 & Longitudinal - Centro & 4,0 & 445 \\
3 & Longitudinal - Deslocado & 4,0 & 445 \\
\hline
\end{tabular}

Além de ensaios de impacto pendular, existem também ensaios de impacto veicular a baixas velocidades, conforme procedimentos de entidades de avaliação de 
mercado como a RCAR (Research Council for Automobile Repairs) e a IIHS (Insurance Institut for Highway Safety).

A avaliação mais comum e difundida considera um impacto frontal e um impacto traseiro a $15^{+1} \mathrm{~km} / \mathrm{h}$ contra uma barreira rígida a $10^{\circ}$ com $40 \%$ de sobreposição, conforme Figura B 89. Este ensaio fornece informações sobre o nível de dano que as pecas sofreram, essas informações são utilizadas para cálculos de custo e tempo de reparo. Ao final da avaliação, o veículo é classificado quanto ao seu nível de reparabilidade em um ranking disponível ao público (consumidores e empresas de seguro).

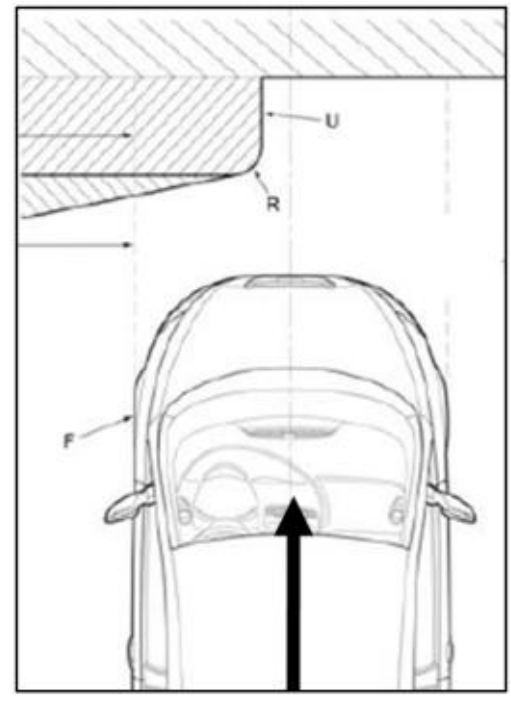

(a)

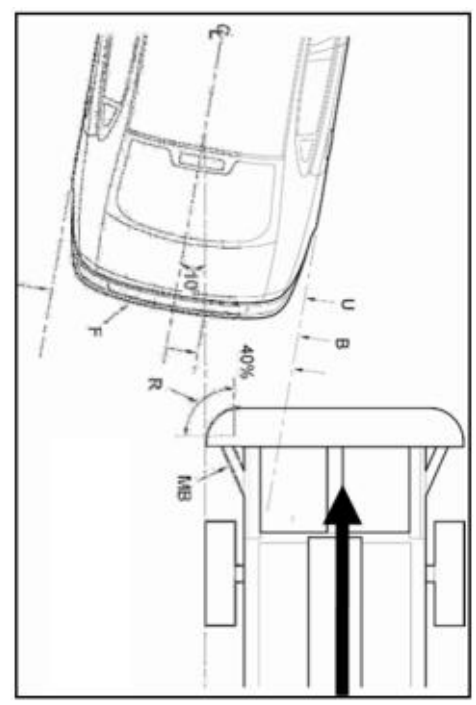

(b)

Figura B 89. Esquema de posicionamento de barreira no teste de reparabilidade $R C A R$

Pesquisas recentes (7) apontam que as ocorrências mais custosas em termos de reparabilidade acontecem quando os pára-choques dos veículos envolvidos se movimentam um sobre o outro, uma vez que não estão alinhados na vertical. Com o objetivo de melhorar o projeto de pára-choques, a RCAR e IIHS desenvolveram procedimentos de avaliação que simulam esta condição. Esses procedimentos visam aspectos geométricos de construção, como altura em relação ao solo e abrangência vertical do pára-choque, e aspectos de desempenho, como 
comportamento estável e progressivo. A Tabela A 5 resume as informações relevantes sobre cada teste de reparabilidade.

Tabela A 5 - Ensaios de impacto e baixa velocidade para análise de reparabilidade

\begin{tabular}{llll}
\hline $\begin{array}{l}\text { Posição do } \\
\text { impacto }\end{array}$ & $\begin{array}{l}\text { Velocidade } \\
(\mathrm{km} / \mathrm{h})\end{array}$ & $\begin{array}{l}\text { Altura da } \\
\text { barreira } \\
(\mathrm{mm})\end{array}$ & Massa do veículo para teste \\
\hline Frontal $100 \%$ & 10,0 & 457,0 & Em ordem de marcha $+88,1 \mathrm{~kg}(I I H S)$ ou $+80 \mathrm{~kg}(R C A R)$ \\
Traseiro $100 \%$ & 10,0 & 457,0 & Em ordem de marcha $+88,1 \mathrm{~kg}(I I H S)$ ou $+80 \mathrm{~kg}(R C A R)$ \\
Frontal $15 \%$ & 5,0 & 406,0 & Em ordem de marcha $+88,1 \mathrm{~kg}(I I H S)$ ou $+80 \mathrm{~kg}(R C A R)$ \\
Traseiro 15\% & 5,0 & 406,0 & Em ordem de marcha $+88,1 \mathrm{~kg}(I I H S)$ ou $+80 \mathrm{~kg}(R C A R)$ \\
\hline
\end{tabular}




\section{APÊNDICE B - INVARIANTES DO TENSOR DAS TENSÕES}

O estado de tensão de um corpo é caracterizado pelas componentes segundo planos coordenados, conforme indicado na Figura B 1:

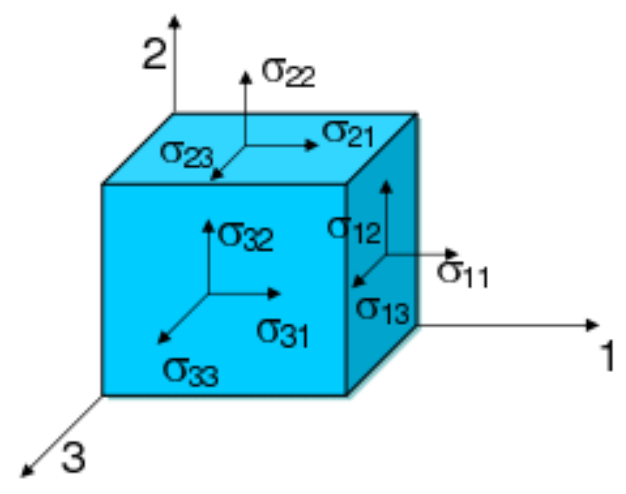

Figura B 1. Representação tridimensional dos componentes do tensor das tensões

Cada componente $\sigma_{\mathrm{ij}}$ representa a tensão normal à superfície $i$ que atua na direção j. O tensor das tensões é descrito em forma matricial como se segue:

$\sigma=\left[\begin{array}{lll}\sigma_{11} & \sigma_{12} & \sigma_{13} \\ \sigma_{21} & \sigma_{22} & \sigma_{23} \\ \sigma_{31} & \sigma_{32} & \sigma_{33}\end{array}\right]$

O tensor das tensões é simétrico devido ao balanço de momentos, de tal modo que $\sigma_{\mathrm{ij}}=\sigma_{\mathrm{ji}}$. As tensões na diagonal são as tensões normais e as demais chamadas de tensões cisalhantes.

O tensor das tensões pode ser decomposto em dois tensores simétricos:

$\sigma_{\mathrm{ij}}=\mathrm{s}_{\mathrm{ij}}+\mathrm{p} \delta_{\mathrm{ij}}$

onde $\mathrm{s}_{\mathrm{ij}}$ se refere ao tensor das tensões da parte desviadora, que distorce o corpo, e o $\delta_{\mathrm{ij}}$ se refere ao tensor da parte hidrostática ou volumétrica, que atua na mudança de volume do corpo (Figura B 2). Na eq.(34), $\delta_{i j}$ é o delta de Kronecker e $p$ é a pressão média, dada por: 
$p=\frac{1}{3}\left(\sigma_{11}+\sigma_{22}+\sigma_{33}\right)$

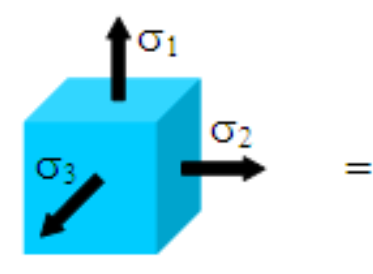

Tensão total

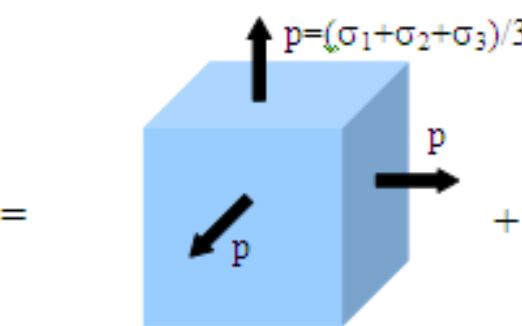

Tensão hidrostática

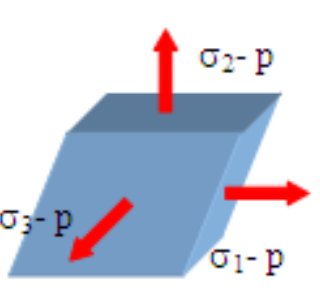

Tensão desviadora

Figura B 2. Representação da decomposição do tensor das tensões

Na notação matricial temos,

$\sigma=\left[\begin{array}{lll}\sigma_{11} & \sigma_{12} & \sigma_{13} \\ \sigma_{21} & \sigma_{22} & \sigma_{23} \\ \sigma_{31} & \sigma_{32} & \sigma_{33}\end{array}\right]=\left[\begin{array}{lll}s_{11} & s_{12} & s_{13} \\ s_{21} & s_{22} & s_{23} \\ s_{31} & s_{32} & s_{33}\end{array}\right]+\left[\begin{array}{lll}p & 0 & 0 \\ 0 & p & 0 \\ 0 & 0 & p\end{array}\right]$

Planos em que as tensões cisalhantes são nulas são chamados de planos principais. Neste caso a matriz $3 \times 3$ é diagonalizada com as três tensões principais e todos os outros componentes iguais a zero. As três tensões principais são conhecidas como $\sigma_{1}, \sigma_{2}$ e $\sigma_{3}$.

É possível demonstrar que cada uma das raízes da equação característica abaixo corresponde a cada uma das tensões principais,

$\lambda^{3}-I_{1}+I_{2} \lambda-I_{3}=0$

Os termos $I_{1}, I_{2}$ e $I_{3}$ são chamados de invariantes do tensor das tensões e são os mesmos para qualquer base adotada. São definidos por:

$I_{1}=\operatorname{tr}[\sigma]=\sigma_{11}+\sigma_{22}+\sigma_{33}$

$I_{2}=\frac{1}{2}\left(\sigma_{i i} \sigma_{i i}-\sigma_{i j} \sigma_{i j}\right)=\sigma_{11} \sigma_{22}+\sigma_{22} \sigma_{33}+\sigma_{11} \sigma_{33}-{\sigma_{12}}^{2}-{\sigma_{23}}^{2}-{\sigma_{13}}^{2}$

$I_{3}=|\sigma|$ 
Os invariantes também podem ser descritos por meio das tensões principais, de modo que:

$I_{1}=\sigma_{1}+\sigma_{2}+\sigma_{3}$

$I_{2}=\sigma_{1} \sigma_{2}+\sigma_{2} \sigma_{3}+\sigma_{1} \sigma_{3}$

$I_{3}=\sigma_{1} \sigma_{2} \sigma_{3}$

Qualquer combinação de invariantes permanece invariante. Se uma equação característica é definida para a parte desviadora, diferentes invariantes são determinados, porém são derivados dos invariantes do tensor das tensões como se segue:

$J_{1}=s_{k k}=\operatorname{tr}[s]=0$

$J_{2}=\frac{1}{2} s_{i j} s_{j i}=\frac{1}{3}\left[I_{1}-3 I_{2}\right]=\frac{1}{6}\left[\left(\sigma_{1}-\sigma_{2}\right)^{2}+\left(\sigma_{3}-\sigma_{1}\right)^{2}+\left(\sigma_{2}-\sigma_{3}\right)^{2}\right]$

$J_{3}=\frac{1}{3} s_{i j} s_{j k} s_{k i}=\frac{1}{27}\left[2 I_{1}^{2}-\frac{1}{3} I_{1} I_{2}+27 I_{3}\right]$

\section{Interpretação geométrica dos invariantes}

O estado de tensão em um ponto $P$ pode ser visualizado em um espaço 3D no qual as coordenadas são as tensões principais $\sigma_{1}, \sigma_{2}$ e $\sigma_{3}$ como mostra a Figura B 3(a). Este espaço é chamado de Haigh-Westergard e o vetor $O P$ resume o estado de $P$.

No mesmo espaço, um vetor eqüidistante dos três eixos, chamado de eixo hidrostático, pode ser definido. Como pode ser visto na Figura B 3(b), o vetor $O P$ pode ser decomposto em duas componentes: $O N$ na direção do eixo hidrostático e $N P$ no plano contendo $P$ e perpendicular ao eixo hidrostático.

Pode-se notar que existem oito planos perpendiculares ao eixo hidrostático, conforme ilustrado na Figura B 4. 


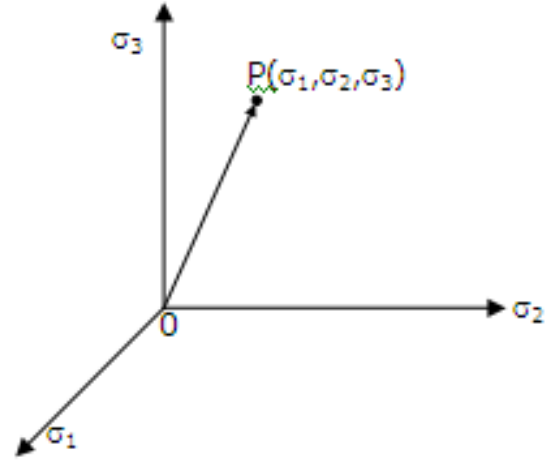

(a)

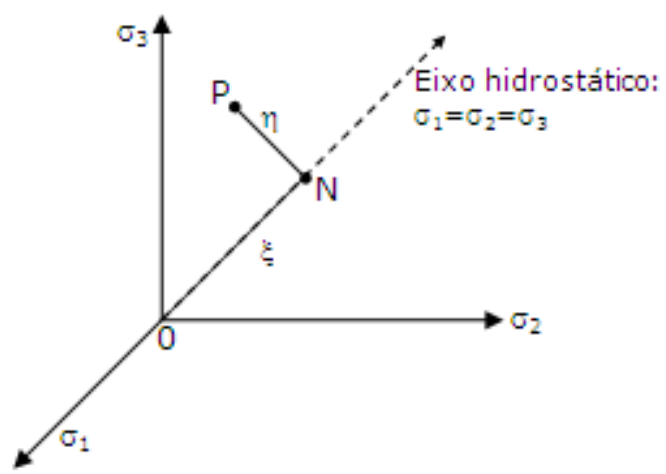

(b)

Figura B 3. (a) espaço das tensões principais e (b) decomposição do Vetor $O P$.

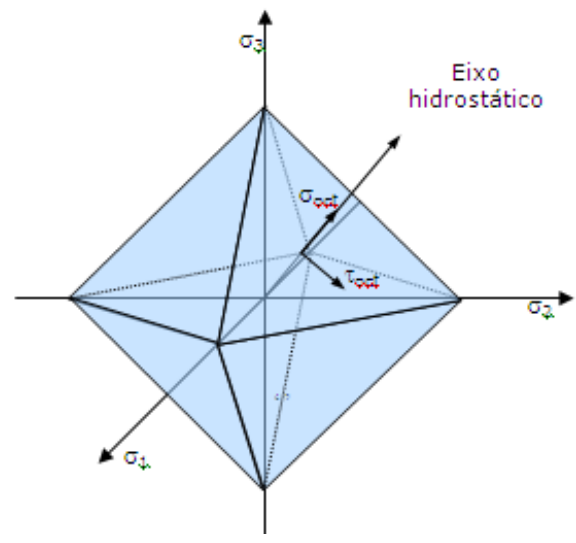

Figura B 4. Oito planos representados no espaço das tensões principais.

As componentes normais e cisalhantes do tensor das tensões nesses planos são chamados de tensões normais octaédricas e tensões cisalhantes octaédricas, expressas, respectivamente, por:

$\xi=\sigma_{o c t}=\frac{1}{3}\left(\sigma_{1}+\sigma_{2}+\sigma_{3}\right)$

$\eta=\tau_{\text {oct }}=\frac{1}{3} \sqrt{\left[\left(\sigma_{1}-\sigma_{2}\right)^{2}+\left(\sigma_{3}-\sigma_{1}\right)^{2}+\left(\sigma_{2}-\sigma_{3}\right)^{2}\right]}=\sqrt{\frac{2}{3} J_{2}}$

A Figura B 5 ilustra os planos octaédricos e o plano $\pi$, na figura do lado dieito 0 plano octaédrico é visto no plano da folha, com as projeções de $\sigma_{1}, \sigma_{2}$ e $\sigma_{3}$ sobre 
este plano. Coordenadas cilíndricas de Lode $\xi, \eta$ e $\theta$ são freqüentemente usadas para decompor tensores em parte desviadora e parte hidrostática.
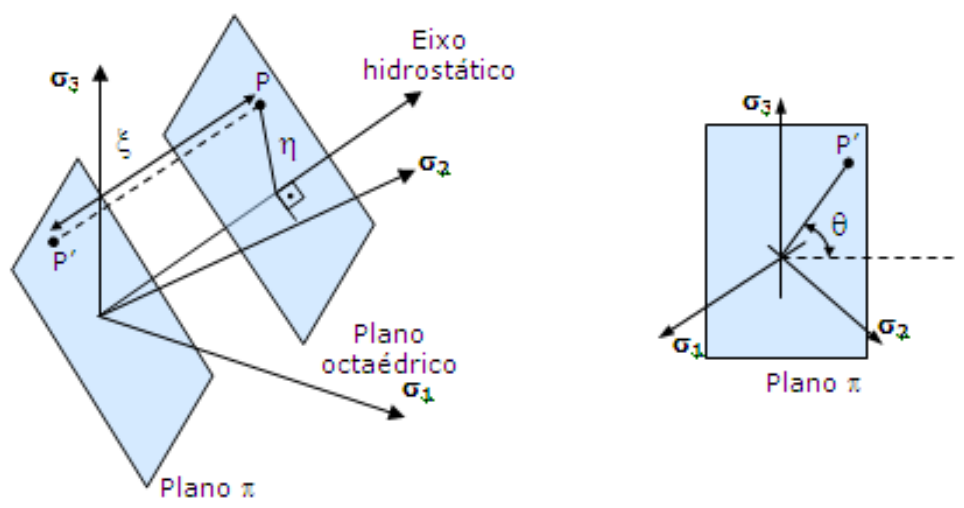

Figura B 5. Plano octaédrico, para $\xi$ nulo o plano é chamado de $\pi$.

O eixo de $\xi$ é paralelo ao eixo hidrostático, que por sua vez é proporcional a tensão média. A coordenada radial $\eta$ equivale à magnitude da parte desviadora. A coordenada angular $\theta$, também conhecido como ângulo de Lode, é a medida da relação proporcional das tensões principais, mostrando especialmente os efeitos de $\sigma_{2}$.

Através de uma transformação de coordenadas, é possível escrever $\theta$ através dos invariantes:

$\operatorname{sen}(3 \theta)=-\frac{J_{3}}{2}\left(\frac{3}{J_{2}}\right)^{3 / 2}$

A partir da eq.(43), é possível verificar que:
$\sigma_{1} \neq 0 ; \sigma_{2}=\sigma_{3}=0$
tensão uniaxial
$\theta=-30^{\circ}$
$\sigma_{1}=-\sigma_{3} ; \sigma_{2}=0$
cisalhamento
$\theta=0^{\circ}$
$\sigma_{1}=\sigma_{2} ; \sigma_{3}<0$
compressão uniaxial
$\theta=30^{\circ}$ 
Isto significa que para $\sigma_{1} \geq \sigma_{2} \geq \sigma_{3}$ temos $-30^{\circ} \leq \theta \leq 30^{\circ}$. Particularmente para $\sigma_{1}=\sigma_{2}=\sigma_{3}$ temos $\mathrm{P}$ no eixo hidrostático com $\eta=0$. O ângulode Lode alterna ciclicamente de $-30^{\circ}$ a $30^{\circ}$ uma vez que o resultado deve ser independente da ordem dos autovalores (ver Figura B 6).

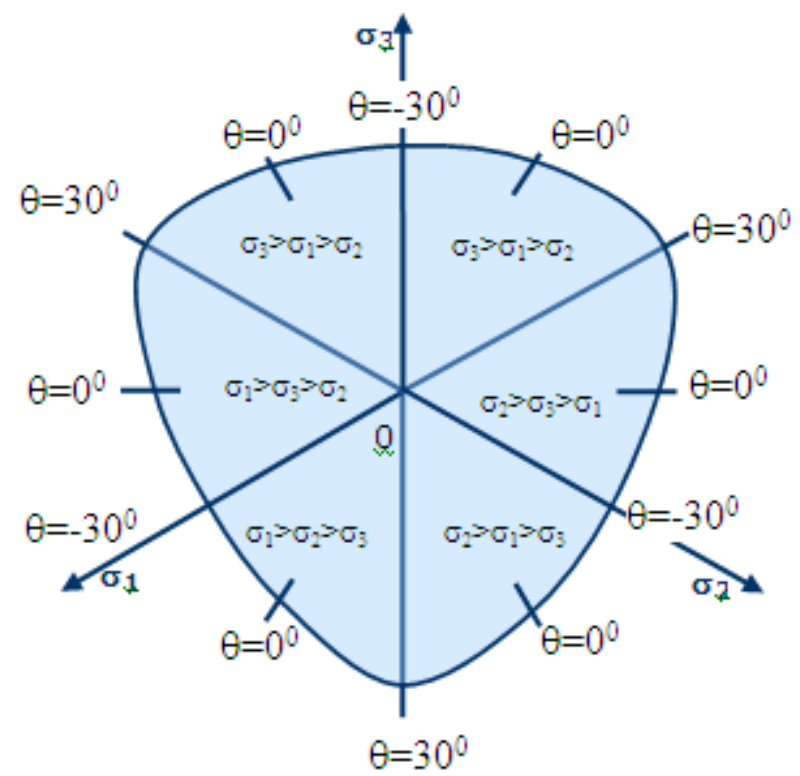

Figura B 6. Ângulo de Lode 